THE INTERNATIONAL

REVIIEW OF RESEARCH IN

OPEN AND DISTANCE LEARNING
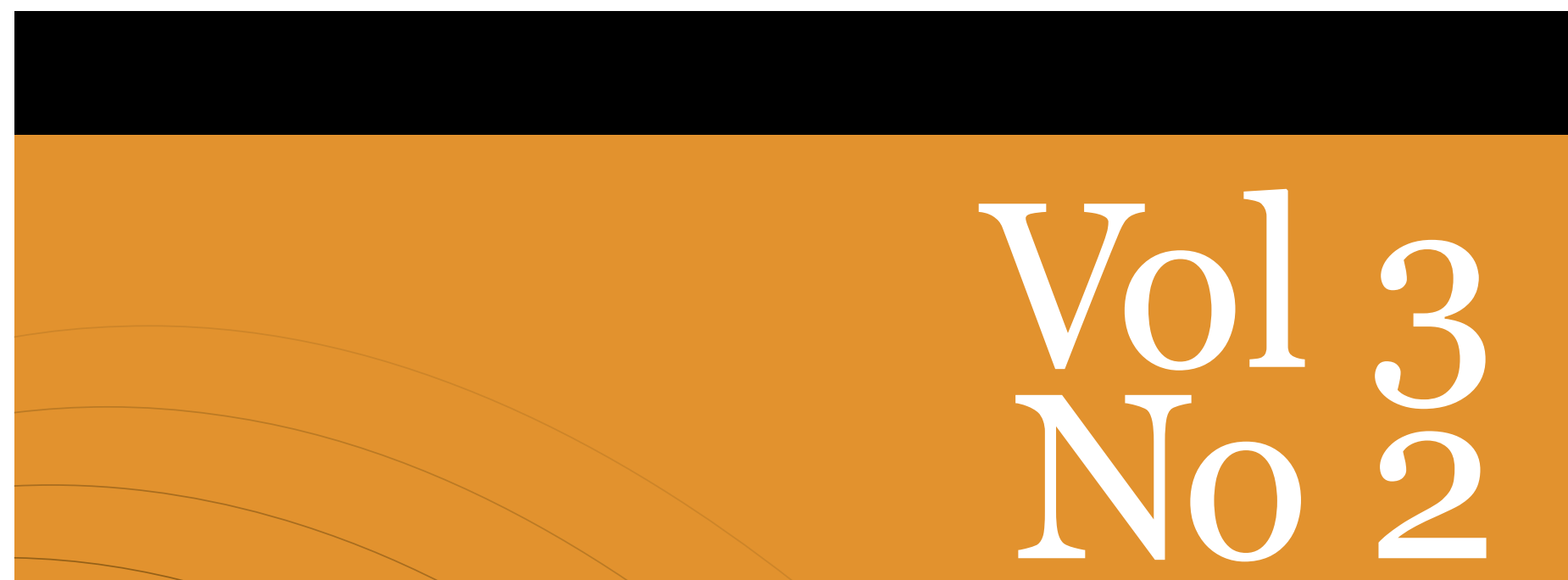
October - 2002

\title{
Online Postgraduate Education: Some reflections
}

\author{
Peter S. Cookson, \\ Editor, IRRODL
}

In early November 2002, I travelled from my present location at the University for Peace in San José, Costa Rica to Mexico City to attend el Primer Encuentro Iberoamericano de Educación Superior en Línea (the First Iberoamerican Meeting of Online Education). It was sponsored by la Facultad de Filosofía y Letras, la División del Sistema Universidad Abierta and la Coordinación de Universidad Abierta y Educación a Distancia of la Universidad Nacional Autónoma de México. The theme of the conference was "Online Education Myths and Challenges." This editorial is an elaboration of a theme presented in one of the panel sessions.

\section{Online Learning - a Manifestation of Distance Learning}

As has been amply recorded in the institutional and national case studies presented in previous issues of IRRODL, one manifestation of the current technological revolution is the rush of higher education institutions around the world to offer courses online (via the Internet). It is fascinating to observe how many university professors and administrators are unaware that such courses and programmes of study are not a completely new phenomenon rather than one of the most recent developments in the vast field of practice of distance education. Oblivious of what their online programs have in common with previous forms of teaching and learning at a distance, many of these newcomers are eager to suggest replacement of the term distance education with such in vogue terms as online education, distributed education, Web-based education, etc. While such terms usefully refer to current technological applications, they also reflect "blind spots" of understanding with respect to distance education that may lead not only to incomplete course and programme design, but also failure to construct the attendant course, student, regulatory, and logistical subsystems (Kaye, 1981) that comprise the infrastructure required for optimal distance education system functioning.

\section{Online Postgraduate Education}

Although distance education programs now serve people of all ages worldwide, the fastest growing form is postgraduate education delivered via the Internet for mature working men and women. The aim of this editorial is to present a conceptual scheme with which to understand more fully this "offspring" of fourth generation distance education technology (Peters, 2002), a conceptual scheme that draws on four factors: higher education, lifelong education, distance education, and technology. Thought of as "ideal types," definitions of each of these factors follow:

- Higher education (HE) is that form of education that occurs in universities and other postsecondary or tertiary education institutions. Reluctant to merge the concept of higher education with every type of training given to adults after secondary school, some people 
in traditional universities distinguish between "postsecondary/ tertiary" education on the one hand and "higher" education on the other hand. Students in higher education earn credits. When they complete their programmes of study, institutions are authorized by the state to award them diplomas or titles. First degree programmes are referred to as "undergraduate" programmes and possession of undergraduate degrees often constitutes a minimal credential for entry to certain occupations. Second or third degree programmes are referred to as "graduate" or "postgraduate programmes." Demographic characteristics of people who enroll in undergraduate and graduate programmes are changing. Although the majority of undergraduate students continue to be older adolescents/ young adults who define their principal (often fulltime) social role as college, institute, or university "student," the majority of participants in many graduate programs, the focus of this editorial, tend to be mature working adults.

- Based on a definition of adult education advanced by Houle (1972), lifelong education (LE) may be defined as a comprehensive process whereby men and women (alone, in groups, in institutions, or community contexts), seek to improve their knowledge, skills, or sensitivities with the objective of improving themselves or others. It is a comprehensive process carried out not only formal education in schools, but also in a myriad of other work, civic, recreational and voluntary organizational settings. Sometimes lifelong education may be viewed as a process coterminous with the entire life cycle. Nevertheless, the term may be more usefully reserved for the process of education experienced by people who, having progressed beyond the status of older adolescent/ young adult, have accepted the status of working men and women.

Given the pace of globalisation with attendant flows of goods, capital, people, and new technologies, as well as the threat of mass violence now emanating from terrorist organizations, the need for people to continue learning throughout the life cycle has never been greater. Abundant opportunities to participate in lifelong education exist in all but the poorest parts of the world. Businesses and agencies provide training to employees during work hours. Schools and universities design education programs for adults in their free hours. Voluntary agencies and nongovernmental organizations provide instruction for staff members as well as for the general public. Lifelong education programmes provide practical emphasis on application on the knowledge learned to work and daily life.

The majority of lifelong education programs are conducted face-to-face, requiring participants to comply with location and schedule conditions set by programme providers. Still, not all learning needs can be delivered by face-to-face education and training. Physical locations of the lifelong education programmes may be inaccessible to many. Too, the number of people who a common interest may be insufficient to justify specific face-to-face programmes in any particular geographical area. Barriers of time and geography may thus limit lifelong education opportunities for large segments of the population. In contrast, lifelong education programs offered via distance education formats can enable men and women to overcome barriers of time and space.

- Distance education (DE) is defined as the process of teaching and learning that occurs through interaction between professors and students between or among whom there is a temporal or spatial separation that is mediated by one or more information communication technologies. 
Cookson, Vol. 3, No. 2 Editorial: Online Postgraduate Education: Some reflections

- In the context of distance education, technology $(\mathrm{T})$ is defined as the combinations of technical knowledge, tools, methods, and procedures instructional agents deploy to facilitate the process of teaching and learning for learners from whom they are separated temporally and/or spatially. Often online distance education technology is thought to comprise only of hardware and software connected to the Internet. However, distance education technology, broadly defined, also involves a more comprehensive array of such instruction-related elements as instructional design procedures, development of teaching materials, methods and techniques for instructional delivery, other learning activities planned by instructional agents to enable interaction with and among students and between students and the content to be learned. Beyond these instruction-related functions, online distance education requires a technological infrastructure that includes the administrative functions of registration, counselling, assignment to courses, distribution of materials, evaluation of learners, as well as record-keeping operations. Without this broader technological infrastructure, online distance education programmes will likely be unsustainable.

A manifestation of an inadequate definition of technology is when higher education institutions assume that establishment of online education programs consists merely of the purchase of the essential hardware and software. They are often influenced by what might be referred to as "mythical virtues" of technology. Such common misperceptions of technology include: "more bells and whistles are better," "more expensive is better," "more technically complicated is better," "newer is better", "more like face-to-face teaching is better," "faster is better," and " to teach online all one has to do is upload face-to-face teaching resources to the Web.

\section{Possible Combinations}

Taking into account these four factors higher education (HE), lifelong education (LE), distance education (DE), and technology (T), we can now refer to the following possible combinations:

1. $D E+T$ : Because $\mathrm{DE}$, by definition, involves mediation of some form of $\mathrm{T}$ to bridge the temporal or spatial distance between the instructional agent and the learners, all DE comprises $\mathrm{DE}+\mathrm{T}$. In this regard, the scheme breaks down because it is impossible to have DE that does not constitute a combination without $\mathrm{T}$.

2. $H E+T$ : Perhaps the most prominent expression of this combination is face-to-face higher education courses that are enhanced or supplemented through the application of various information and communication technologies (e.g., online resources and extension of in-class discussions on the Web). In articles published in recent issues of this journal, such combinations have been referred to a hybrid courses.

3. $L E+H E$ : This combination is evidenced by the long-held practice of higher education institutions to offer non-credit programs that meet the ongoing learning needs of men and women that arise from the performance of their multiple social roles. Such programs are commonly referred to as instances of continuing education or professional continuing education.

4. $D E+L E$ : This combination is manifest when numerous providers, both public and private, sponsor literally thousands of online training and educational programs. Conducted for profit, 
cost-recovery, or free, such programs provide abundant lifelong education opportunities for men and women located anywhere there is a connection to the Internet.

5. $H E+D E$ : This combination is manifest by the ever increasing number of higher education courses being offered for credit via distance education, with the Internet being the most popular vehicle. Although such programmes serve an increasing number of younger adults, older and more mature adults tend to be better suited for participation in online postgraduate education courses that require self initiative, self direction, and high motivation.

6. $L E+T$ : This combination refers to all instances in which technology is being applied to facilitate learning of men and women across the life cycle in both face-to-face and distance education settings.

7. $D E+T+L E+H E$ : This combination of all four concepts corresponds to online postgraduate education that for many mature working adults, has become the most accessible forms of not only higher education, but also lifelong education, and distance education.

\section{Online Postgraduate Education}

As indicated by the seventh option, all four factors (HE, LE, DE, and T) can make significant contributions to online post-graduate higher education for mature working men and women. Realizing that most participants of postgraduate online education are mature adult participants, organizers of online postgraduate education will treat them differently than the young adult/ older adolescent students who study fulltime in undergraduate programs. They will avoid replication of the teaching/ learning processes of higher education that have been developed over time for older adolescent/ young adult students and will modify the traditional rules that govern student admission, participation and residence. They will also devise course assignments and activities that incorporate the rich and varied experience of mature adults. In short, mobilizing and combining elements from all four factors can result in more appropriate, balanced and optimal

online postgraduate education and, as a consequence, more optimal conditions for effective teaching and learning.

\section{Contents of This Issue}

As will be noted by the contents of the main and succeeding sections of this journal "open issue, “ the field of distance education encompasses far more than the online postgraduate education that is the focus of my reflections above. The twelve articles in the main section address such varied topics as analysis of communication patterns in online instruction, analysis of standards of quality in distance learning, the effects of dialogue on learning, the use of case studies in distance education, the nature of learning objects in distance education, comparative description of courseware platforms adopted by Australian and Scandinavian universities, meta analysis of research on Web-based courses, a macro-analysis of how distance education institutions may resolve the crisis faced by tradition-bound Latin American universities, the cultural differences in using educational psychology in the Chinese context, and the role of libraries and how their funding structure may affect DE. The international diversity of our main section is continued in our succeeding “Book Notes” and "Research Notes” sections. 


\section{Acknowledgements}

As has been the case with all previous issues of the journal, this issue represents the culmination of efforts by many people. Even with the addition of new editorial team members, there were so many manuscripts to review that we still had to send multiple manuscripts for our individual Editorial Board members and Consulting Editors to review. Speaking for the editors, I express our heartfelt appreciation for what in some cases amounted to many hours of service in behalf of our now 4,000 readers in more than 80 countries. Thank you also to our many contributors to the different sections. We especially applaud the service rendered by Professor Jonathan Baggaley who, along with several students, has produced a second collection of articles about free and/or inexpensive software options that distance educators will find useful expanding their teaching and learning options via the Internet. Too, we appreciate the efforts of all the authors who submitted their manuscripts for review.

We encourage all of our readers to consider IRRODL as their journal of preference for sharing their scholarly work with distance educators worldwide. IRRODL is now the only "mainstream" journal explicitly designed to serve the entire field of distance education internationally. While the other distance education journals one by one have transformed themselves into for-profit commercial ventures, thanks to the generous sponsorship of Athabasca University, Canada's Open University, subscriptions to IRRODL continue to be available free of charge to anyone anywhere with a connection to the Internet.

\section{Our Next Two Issues}

Our guest editor for the April 2003 "theme issue” will be Professor Alan Tait of the UK Open University. That issue will focus on the topic of support for distance learners. If you are one of our 4,000 subscribers in more than 80 countries, we will notify you as soon as it becomes available.

If you are the author of a manuscript relating to any aspect of distance education theory, research, or best practice, we invite you to consider submitting your manuscript to us for our next "open issue" to be published via the Web in October 2003. Our deadline for that issue will be 30 June 2003.

\section{References}

Houle, C. O. (1972). Design of Education. San Francisco: Jossey-Bass.

Kaye, A. (1981). Origins and structures In A. Kaye and G. Rumble (Eds.) Distance teaching for higher and adult education. London: Croom Helm in association with the Open University Press.

Peters, O. (2002). Distance education in transition: New trends and challenges. Oldenburg, Germany: Bibliotheks und Informationssystem der Carl von Ossietzky Universität Oldenburg. 


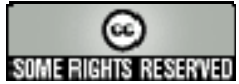




\title{
The eClassroom used as a Teacher's Training Laboratory to Measure the Impact of Group Facilitation on Attending, Participation, Interaction, and Involvement
}

\author{
Mia Lobel \\ Concordia University \\ Canada \\ Michael Neubauer \\ Stanford University \\ USA \\ Randy Swedburg \\ Concordia University \\ Canada
}

\begin{abstract}
This paper describes and quantifies the role of group facilitation in an experiential, realtime, online, university level credit course entitled eAHSC/ 230 Interpersonal Communications and Relations. A new and unique group interaction pattern called parallel communication, as well as classical elements of group interaction are described and quantified. New measures of online group facilitation attributes with analogous faceto-face (F2F) counterparts are presented. Specifically, the impact of effective group facilitation on Attentiveness, on Interaction, on Involvement, and on Participation is explored. The paper also examines the eClassroom's potential effectiveness as a real time teaching and training laboratory which also functions as a process observation tool that collects and feeds back interaction data, providing teachers and trainers immediate and ongoing measures of facilitation effectiveness.
\end{abstract}

\section{Introduction}

Communication not only enables humans to survive, it is the only way we can learn about whom we are. One's sense of identity is derived from the way one interacts with other people. Deprived of communication with others, one would have no sense of identity. This is illustrated by cases like the "Wild Boy of Aveyron." This feral child, who spent his early childhood without any apparent human contact, was discovered digging for food and captured in 1797 in the French countryside. As Shattuk (1980) put it: "The boy had no human sense of being in the world. He had no sense of himself as a person related to other persons (p.37).” It was only under the influence of a skilled connective facilitator that the boy began to behave and to think of himself as human. Communication not only defines human identity, it also provides a vital link with a community of others. Some 
theorists have gone as far as to argue that communication is the primary goal of human existence. Anthropologist Goldschmidt (1990) terms the drive for meeting social needs as the "human career."

The extreme case of the Wild Boy of Aveyron serves well as a metaphor for interpersonal connections in face-to-face (F2F), as well as online interactions. In general, humans, regardless of circumstance, have a 'lost child' inside them. One deals with internal and external consequences when one fails to understand their impact on others, or when one encounters a blind spot that hampers their ability to appropriately decode feedback. No matter if one is male or female, young or old, rich or homeless, each person brings with them a 'bag' of interpersonal skills containing a unique constellation of needs and wants, strengths and limitations. In order to reduce unwanted consequences and maximize perceived successes in their relationships, humans need a skilled and connective facilitator in order to help them process knowledge about themselves and others and thus to learn interpersonal skills.

The Internet is presently the newest and, as of yet, the least understood communication channel available for people to connect and exchange information with others. Online, we are still experimenting with online human contact and interaction. In short, research on online facilitation is still in its infancy. How can one bring lost children into a community that does not yet know itself, and still act as competent connective facilitators of growth? This means that for those wishing to join in and learn in this new environment, online facilitators need to provide them with an accurate map of the online community. To achieve this objective, online facilitators must first observe, describe, and quantify characteristics of online communications and group development.

\section{Conceptual Context}

Communication or interaction is not a uniformly "good thing." In fact, communication is neither good nor bad in itself. It is situation dependant and its value derives from the way or context in which it is used. Communication can be a tool for expressing useful facts and warm feelings, but under different conditions or contexts the exact same words and actions, may be perceived as harmful (Adler and Rodman, 2000). Another serious misconception about communication, is the notion that listening and actually "hearing," is a natural, involuntary activity like breathing; wherein, in fact, "listening" is a is a learned skill, much like speaking, reading and writing. Once again, it is human contact and the inherent interactive exchange among and between humans that facilitates or retards the acquisition of these skills.

Theorists and researchers have identified a range of personal and social needs that are satisfied through interactive communication. Some of these needs such as inclusion, control, and affection are developmental in nature (Schutz, 1988). Other needs such as trust, acceptance, productivity, and interdependence are conceptualized as concurrent and omnipresent human factors (Gibb, 1964). In a qualitative sense, "interpersonal communication occurs when people treat one another as unique individuals, regardless of the context in which the interaction occurs or the number of people involved" (Adler and Rodman, 2000, p. 174).

In the quantitative sense, one may assess the communication process by using concrete group observational measures in the following four areas of group development: 
Lobel, Neubauer \& Swedburg - The eClassroom as a Teacher Training Laboratory

1. Attentiveness (i.e., who is attentive and who is withdrawn)

2. Interaction (i.e., communication lines such as one to one, one to the group, one to the facilitator)

3. Involvement (i.e., Who are the influential members? Who are isolated? Who are absent? Who are late? 'Idle'?)

4. Participation (i.e., Who are the over or under participators?) (Dimock, 1985).

The Internet, as a channel of communication, can provide immediate or delayed feedback containing personal or impersonal data. Computer Mediated Communication (CMC) is the process of one-to-one, one-to-many, and many-to-many communicative discourse, by using a computer-based communication channel, predominantly in a text-based environment.

Strangelove (1994) proposes:

The Internet is not about technology, it is not about information; it is about communication - people talking with each other, exchanging email, people doing the low ASCII dance. The Internet is mass participation in fully bi-directional, uncensored mass communication. Communication is the basis, the foundation... The Internet is a community of chronic communicators (p. 13).

In her article "Developing Personal and Emotional Relationships Via ComputerMediated Communication,” Chenault (1998) further cites Smolowe (1995), who asserts that the vast majority of people surfing the Internet and communicating via CMC are there "in search of social interaction, not just sterile information" and that 80 percent are looking for "contact and commonality, companionship and community" (p. 20).

Chenault further adds: "CMC is a social phenomena. It is all about people communicating with other people, in any way they can (p. 80)," and "CMC has been debated and misunderstood as a negative phenomenon, because of the prominence given to what CMC does not offer, rather than what it does and suggests further exploration of the positive possibilities and outcomes of CMC interactions. The "virtual community" is not a mythic land of milk and honey, but neither is it any more dangerous, hostile, or unwelcoming than "real life” (p. 81)."

Parks and Floyd (1996) showed that personal relationships conducted via CMC are "common," with just over 60 percent of people in their sample reporting that they have formed a "personal relationship" with someone they had initially contacted through a Usenet newsgroup.

Chenault (1998) concludes:

I do not see how the results of research and the personal accounts outlined in this literature review can be pushed aside - how anyone can say that a community is not possible via CMC, that personal relationships are not happening. They most certainly are (p. 77). 
There is ample evidence that the information exchange afforded by CMC makes it possible for participants to become active distant education "learners." Depending on the specific learning environment, at the very least, exchanging information online is as effective as book learning; most likely it is just as effective as face-to-face learning, albeit altered; and, at best, it may turn out to be the more efficient channel for delivering certain guided interactive learning opportunities. Of course, the type of guidance provided is a major determining variable of learning outcomes. Perception of the role of a skilled, connective facilitator in distance education is still varied and opposed. Teacher/ student interactions in the online learning process range from none, to emails, to message boards, to real-time synchronous discussion sessions.

The issues involved in effectively shaping group growth and learning through facilitation has been a continuing concern for both researchers and practitioners. There is little argument that learning in general, and learning interpersonal communication skills in particular, may be defined as the progressive modification of ideas and behaviors through interpersonal interaction and that the facilitator has a vital role in the acceptance, rejection or clarification of the knowledge being constructed.

French, Sherwood, and Bradford (1966) mention findings that indicate: “a person's selfidentity is influenced by the opinions that others have of him which they communicate to him and that the more that is communicated, the more change is in self-identity (p. 218)." This process of self-change predicated on self-awareness and feedback from others, while engaged in skill building interactions, is at the core of the learning-by-doing experiential pedagogy and the course content discussed in this paper. The role of group facilitators is seen as pivotal in assisting the team in the co-creation of an inclusive, open, and collaborative emotional climate in which participants feel free to engage in soliciting feedback and risking new behaviors.

Marks and Davis (1975) discuss the experiential model and its application to learning that serves well as a guideline for effective group facilitation. They include the following seven points:

1. Involvement and responsibility in an experiential model are centered on learner participation and active involvement

2. The experiential facilitator is responsible for assessing the group's process, selecting the structured activity, attending to the group's emotional climate and conducting the experiment

3. The focus of the experiential model is on process and content

4. Experiential learning fosters awareness of self and others and allows for both cognitive and affective behavioral involvement; the preferred leadership styles are collaborative and role sharing

5. Individuals establish their own levels of interaction and it is assumed they will "get out what they put into" the experience

6. The experiential model is predicated on choices and on taking responsibility for one's actions

7. Facilitation occurs on the task level and on the level of social relationships 
Lobel, Neubauer \& Swedburg - The eClassroom as a Teacher Training Laboratory

Interpersonal communication, effective or otherwise, is an acquired skill that necessitates a lifetime of practice. Teachers, for better or worse, abound under countless guises. This paper explores the role of group facilitation in an experiential, real-time, online, university level credit course entitled eAHSC/ 230 Interpersonal Communications and Relations. Specifically, the impact of effective group facilitation on Attentiveness, on Interaction, on Involvement, and on Participation is quantified, using the instantaneous data collected by the eClassroom in which the course was taught. Because the information collected is unique, new descriptions and measures of interactivity are offered in order to make sense of the experience and add knowledge to the village lore. The paper also examines the eClassroom's potential effectiveness as an ongoing process observation tool, as an instantaneous feedback tool, as a concrete, immediate and ongoing measure of facilitation effectiveness, as well as a real-time teaching and training laboratory for facilitators.

\section{Methods}

\section{Description of Test Environment: The Course}

Lobel, Neubauer, and Swedburg (2002), describe the AHSC/ 230 course:

Interpersonal Communications and Relationships' is a multiple-section, introductory, pre-requisite, credit-course in the Applied Human Science Department of Concordia University. The course is designed to provide knowledge and skill in building and maintaining interpersonal relationships characterized by mutual understanding and respect. Students can expect to enhance their understanding of effective communication behavior and improve their abilities to attend to verbal and non-verbal communication from others, exchange constructive feedback, engage in effective problem-solving, address and deal constructively with conflict, and communicate across such differences as gender, class and race. Conceptual perspectives highlight the contextual influences in relationship dynamics and the role of affect in interpersonal communication. The course also examines ethical and value considerations . . . The target audience for the typical AHSC/ 230 course is undergraduate students, ranging in age between 20 and 70; the prototype student is a mature person, in the work force, seeking retraining in the 'human services' field (p. 18).

The course is delivered by using the experiential, learning-by-doing pedagogy. Experiential learning is "defined as learning in which students are doing something - not just thinking about something (Lobel, et al., 2002, 26).”

\section{The eCourse}

The eClassroom design and the course materials presented were delivered online, in realtime, to 20 students in the fall semester of 2001. The course time was distributed into two four-hour weekend sessions, followed by nine consecutive three-hour weekly sessions, taught from 7:00 to 10:00 p.m. EST on Wednesday evenings, between September 8, and November 7, 2001. 
The medium - a synchronous, online eClassroom available over the Internet and designed specifically for the experiential "learning-by-doing" pedagogy of the Department - uses a real-time, interactive HTML formatted text, image, and animation messaging system. The eClassroom, consisting of a main room and four breakout rooms for small eGroup experiential eActivities and eDiscussions, was password protected, monitored, and archived. Most students logged into the eClassroom from their homes. Text and image based lecture materials were posted to the eClassroom in real-time, and the "learning-by-doing" eGroup activities offered, in this medium, facilitated learning through practice and discussions.

One principal instructor and three eGroup co-facilitators staffed the eClassroom. The ratio of students to co-facilitators was seven to one. Students wrote weekly eJournals, an asynchronous component of the eCourse, which were emailed weekly to their eGroup cofacilitator and principal instructor for comments on the learning progress. All eClassroom activities and interactions took place online, in real-time. There were no face-to-face interactions whatsoever between the students and the instructors during the three months of this eCourse.

The mandate of this theory based and practitioner-oriented eCourse was to eTrain students in interpersonal communications competence skills. The content focused on two major components of interpersonal skills training. One objective was to increase students' self-awareness as communicators. To this end, issues in trust, perception, values clarification, diversity, as well as individuals' learning and conflict management styles were explored. The second goal was to identify interpersonal limitations through feedback, and to practice active listening skills and behavioral changes, both in the eClass and in F2F interactions.

The eClassroom and the program design afforded a new paradigm for a successful online synchronous, real-time distance learning experience, conducive to the practice of identified skills and lasting knowledge (Lobel, et al., 2002).

\section{The eClassroom}

The software for the eClassroom creates HTML formatted real-time messages. The input form for these messages is shown in Figure 1. Instructors have the ability to speak privately with the students during eClass time using Private Messages (PM) (Figure 1, Item 2). Students may return the PM to the teaching staff, but cannot PM/ whisper to other students. All the data included in the post is logged and archived for future reference: ISP identification, eClassroom passwords, patterns of messages sent and received, the time of day, post number, all text, and all HTML formatting used to generate the post.

Students and teaching staff poll the server for data by clicking the "Get/ Send" button (Figure 1, Item 1). Each time an individual clicks the "Get/ Send" button when there is no text in the input box, the server receives the signal and refreshes that individual's screen with the latest set of posts received since the last time the individual polled for data. The software also logs the polling for data, and it is not unusual for hundreds of requests to be processed per minute. 
Figure 1. The Input Form: 1) Get/ Send Button. 2) A pull down menu for Private Messages to students and staff. 3) When retrieving posts, a number in this field; i.e., 25 will refresh the screen with 25 of the previous posts. 4) Input Data Field for the author's text and URL's to graphics. 5) The name of the student or staff member. 6) Input field for the URL to a graphic that is posted each time data is posted in the Input Data Field. 7) The font size and color for the name in item 5, and for the text in item 4. (8) Links to the Breakout Rooms.

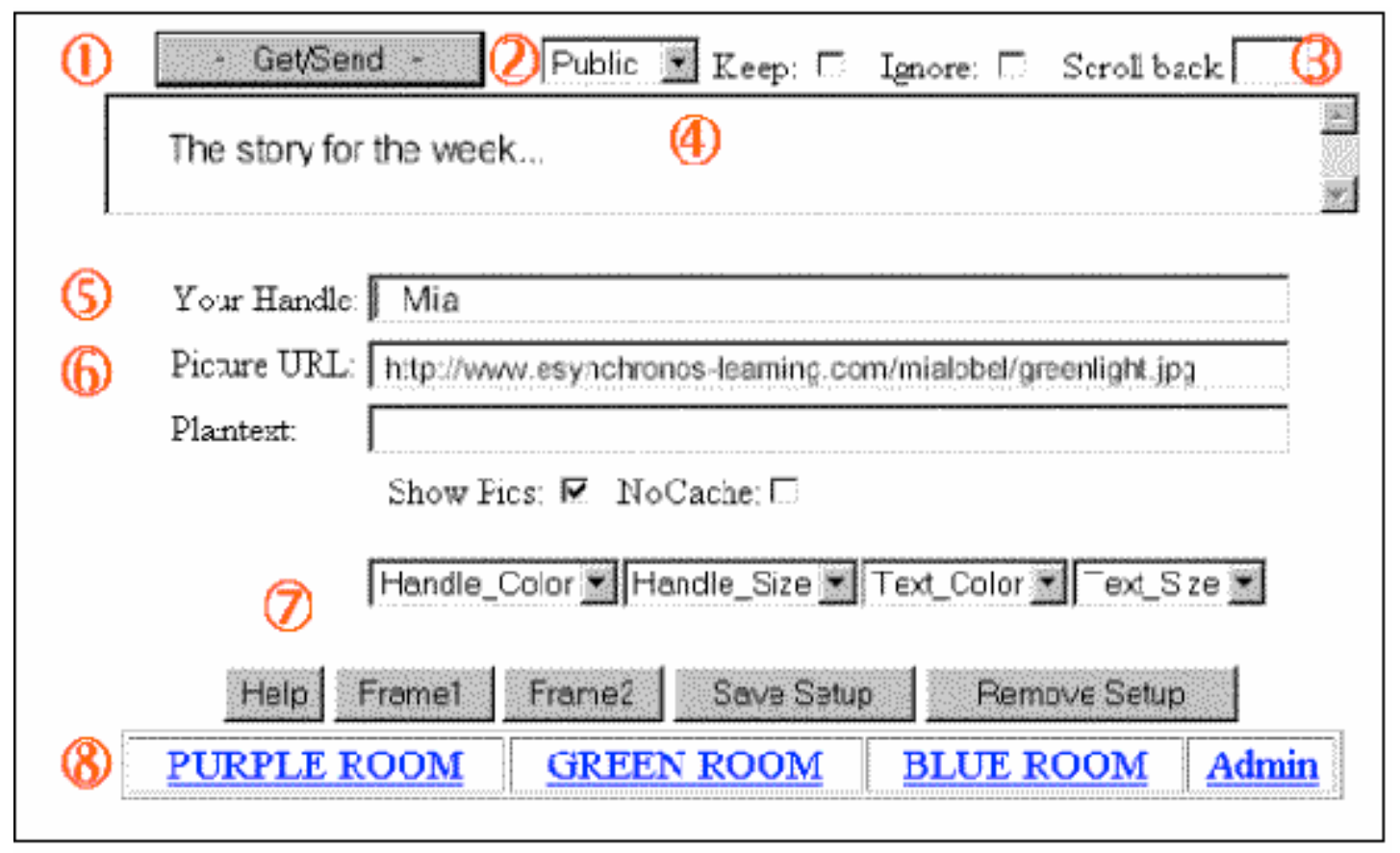

Emoticons can be added to the text to create expressive comments in the posts (Figure 2), and any GIF graphic with a URL can be placed in-line with the text by the author to create energetic, emotional, alive posting comments. The use of this type of graphical emoting has become a new lexicon within the experiential, online, distance learning environment, and the subject of the definition of social presence in the online classroom (Tu, 2000).

Figure 2. Examples of emoticons available in the eClassroom.

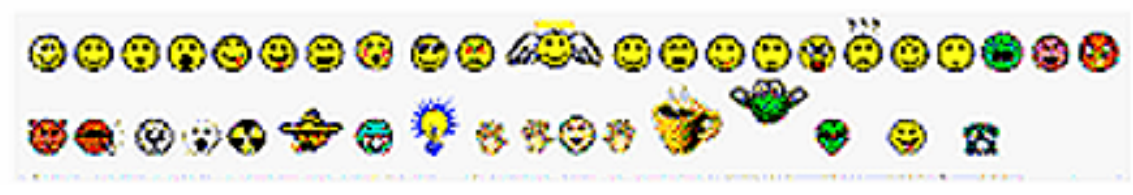

Graphical data are presented by the instructor using URLs to instructional materials uploaded to the classroom website. They can be either text or graphics, animated or not, and can be posted by the teacher in either the data input field or the picture URL field (Figure 1, Items 4 and 6). When posted from the picture, URL field the graphical data is re-posted each time new text is added to the input data field. This allows for re-emphasis of what is being taught, creating an ongoing instructional narrative for the students. Students also post graphics to create their social presence. Since all the posts are archived, a full reading of the three- hour class will include the lecture, the discussion, 
questions and answers, activities, and all comments by the principal instructor and cofacilitators. Archives, which are a unique feature of the eClassroom, are useful for students and teaching staff to review the interactions and reflect on their participation, and are of course, an invaluable adjunct for those who missed a session. A versatile feature of the eClassroom is a whiteboard used in the design of collaborative activities (Lobel, et al., 2002, p. 47).

As the data are examined and the patterns emerge, it becomes clear that the eClassroom is not just a classroom. It is a sophisticated learning and training laboratory, which collects interaction data, provides instantaneous feedback and measures the results of interventions in new and situation appropriate ways.

\section{Data Collection and Analysis}

Three generic types of data were collected in the eClassroom log files for later analysis: 1) Text; (2) time-stamped text; 3) time-stamped data requests. The four following analysis tools were used:

1. ATLAS.ti version 4.2 a computer aided text interpretation and theory building software.

2. Microsoft Excel 2000 for regression analysis, database organization, and graph making.

3. UCINET 5.0 Version 1.00 for network analysis.

4. Pajek, a freeware software program for large network analysis.

\section{Results}

The eClassroom becomes an observation and assessment tool that collects data and quantifies communication lines on learning measures such as: Attending, Participating, Interaction, and Involvement. For a practitioner or for training purposes, the impact of quantified, immediate and ongoing feedback on group facilitation, on group diagnosis and on the assessment of effective interventions, cannot be overemphasized.

\section{Attending and Participating}

Attending is defined both as being there and as paying attention or being attentive. In the F2F classroom it is easy to quantify physical attendance by simple roll calls, but there are no concrete measures available to assess attending as in paying attention. eClassroom software records both the "attending behaviors" as defined above, for each participant. In terms of being there, the eClassroom keeps a log of arrival and departure times, as well as the time participants are "idle" at the keyboard. This feature allows instructors to monitor participants and determine when students are not polling for data and take appropriate action to engage them in the ongoing process. Attentiveness is quantified as the frequency with which participants actively poll the server for the data generated since their last request.

Participation is defined as the state of being related to a larger whole. Participation is quantified as the number of messages containing a communication sent by participants. 
Figure 3 is a scatter plot of Attentiveness and Participation. The data are totals for each participant for the entire semester. On an average, there were 3837 data polls per threehour session with peaks of 80 data polls per minute; while the average number of data polls during the semester is 21 polls per minute. (The principal instructor's data point is 892 messages and instructions, and 1401 data polls.) A regression analysis calculated a .23 correlation $(\mathrm{P}<.05)$. The low correlation is an important finding. It supports the F2F classroom experience, where students who do not speak out in class, may be just as attentive as students who do, while "speaking out" does not necessarily imply paying attention. The data suggest there may be extenuating variables involved, and with this quantifiable measure available in the eClassroom laboratory, it is possible to design further experiments to find the determining factors. For example, it may be that the level of attending as measured in the eClassroom Laboratory is explicated by students and instructors’ Personal Learning Styles (Kolb, 1984).

Figure 3. Attending and participating.

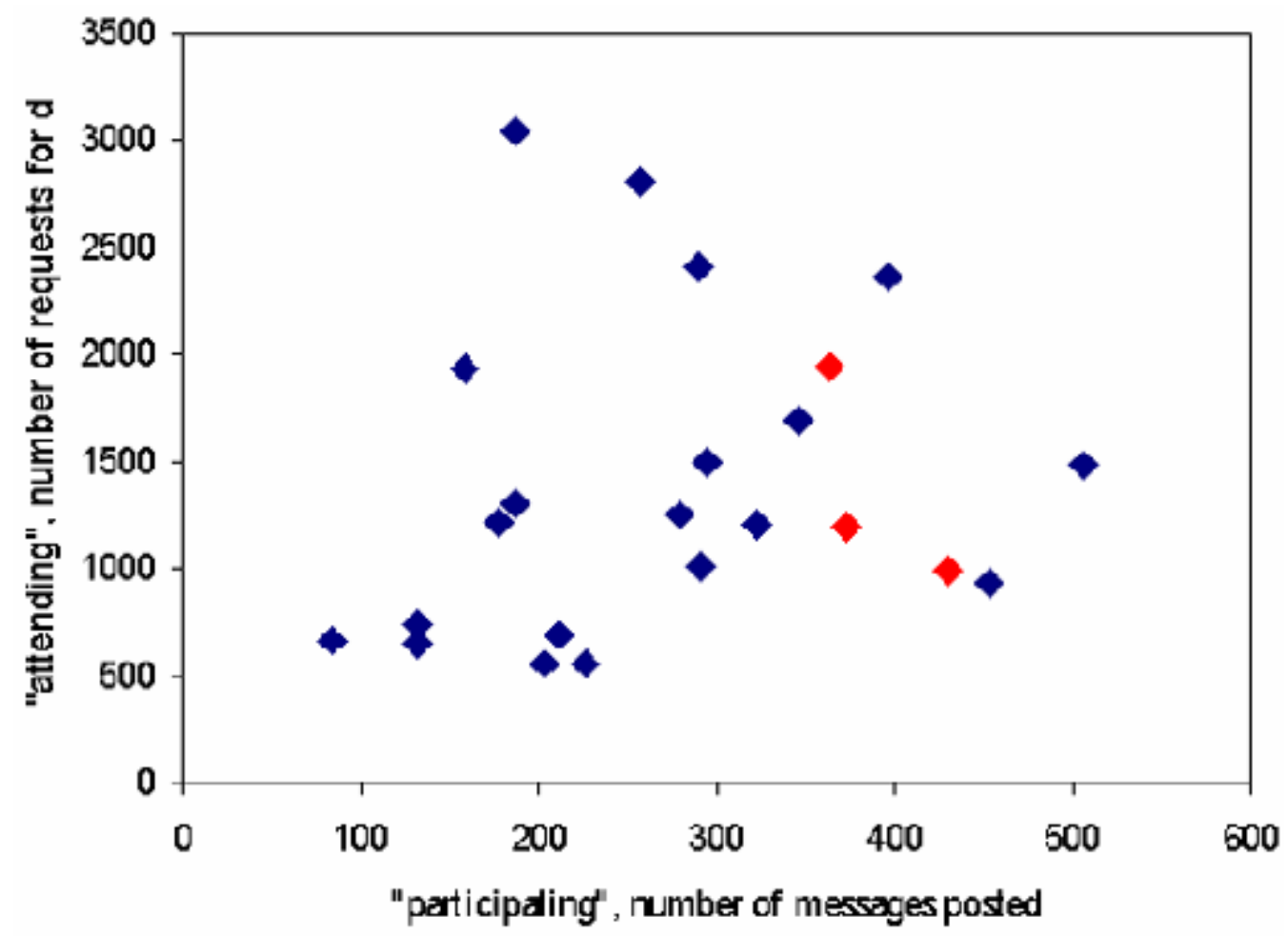

The relationship between attending and participating can be expressed as a ratio. In Figure 4, this ratio is plotted for each student, facilitator, and the principal instructor. It is striking how consistent the range is around a median for each participant, indicating a preference or consistency of style. For the principal instructor, the ratio tends to be less than unity, since her task is to present and explicate the content to the class. From the data, there appears to be three distinguishable types of students:

1. Students with a tendency to attend more than participate $(3,4,7)$

2. Students who are very consistent in this attribute $(5,9,11)$

3. Students with a tendency to participate more than attend $(8,10,14,19)$ 
The measurement of this attribute suggests the eClassroom has sufficient flexibility in its design to allow this behavior to be expressed.

Figure 4. Ratio of Attending to Participating for each participant for each class session. Each data point represents one 3-hour class.

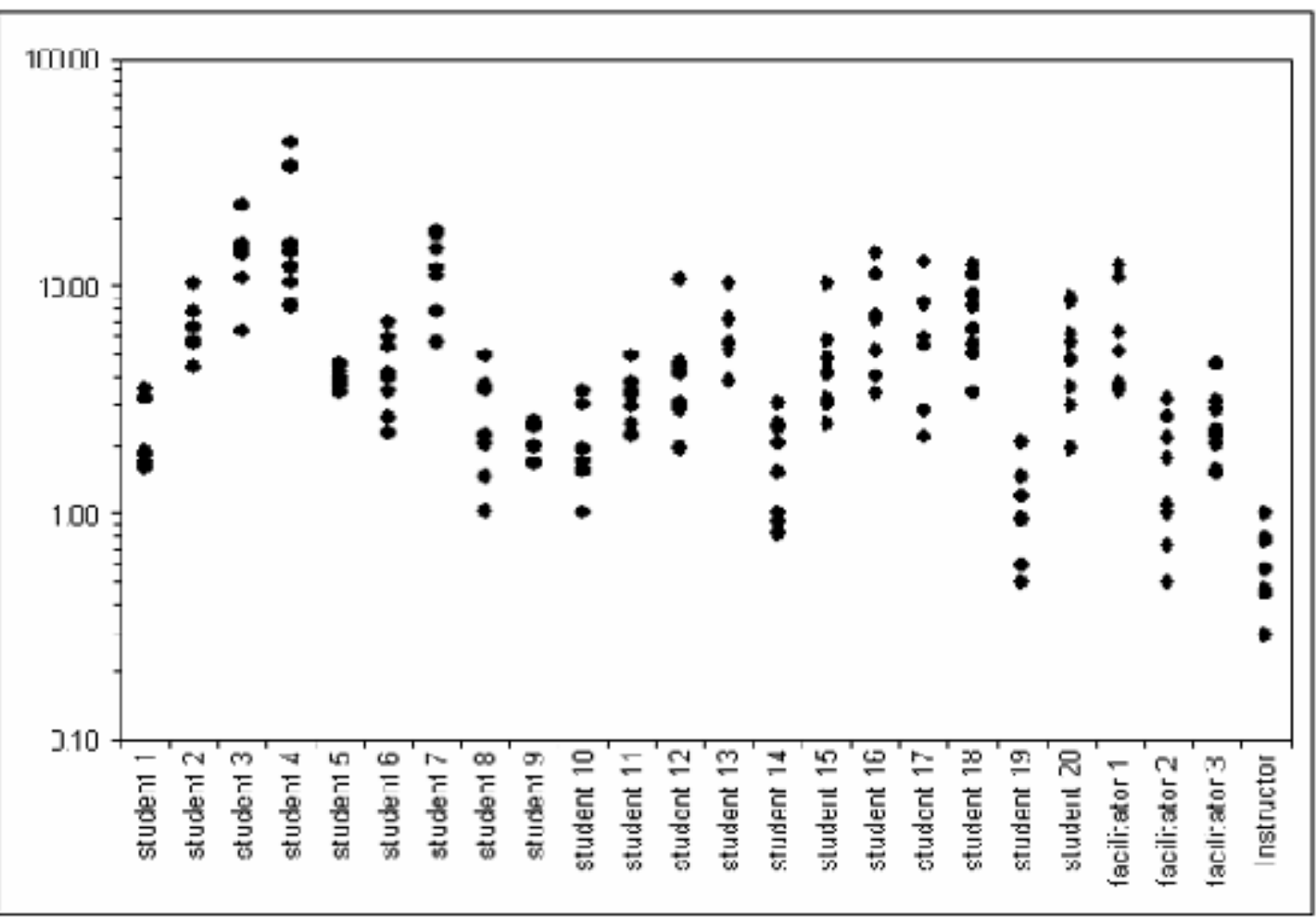

Another way to conceptualize Participation or the individual's relationship to the whole is in terms of patterns of communication lines (Dimock, 1985). Is who speaks to whom worth noting in terms of frequency and diversity? Do members usually talk to one or two people? Such as to the designated leader? To a best friend? To everyone? The interaction diagram (Figure 5) generated by the eClassroom yields a reasonably accurate picture of this type of participation. Each arrow points to the person to whom the remark is directed, or, if it is addressed to the group, the arrow stops in the middle. The total number of directed remarks between the sender and receiver is tabulated and recorded on the diagram.

Over the semester, the median number of posts in the main room is 750 per three-hour class, with an average of 30 posts per student. At peak periods, the posting rate is 20 posts per minute. As mentioned earlier, the extremely high levels of interaction are the result of the "parallel communication" patterns afforded by the eClassroom design. It should be noted that the instructor does not need to interact with the students much more than one post per minute to facilitate the discussion that exhibits high rates of individual participation (Lobel, et al. 2002).

As the one hour Interaction Diagram from the October 10th Learning Module Activity illustrates (Figure 5), the eClassroom design enabled the twenty students present to generate 445 real-time, parallel interactions with an average of 22 words per message. Every student present added some information to the discussion. Such data flow would 
not be useful at all during serial F2F interactions, let alone while the instructor is introducing new material. There was no indication that students found it difficult to receive, assess, and respond to the information generated by the observed parallel communication interactions (Lobel, et al. 2002).

Figure 5. One hour Interaction Diagram of October 10, 2001 eClass, colour coded to the small breakout group identities. The bold numbers are the total messages sent by the participant during this time period.

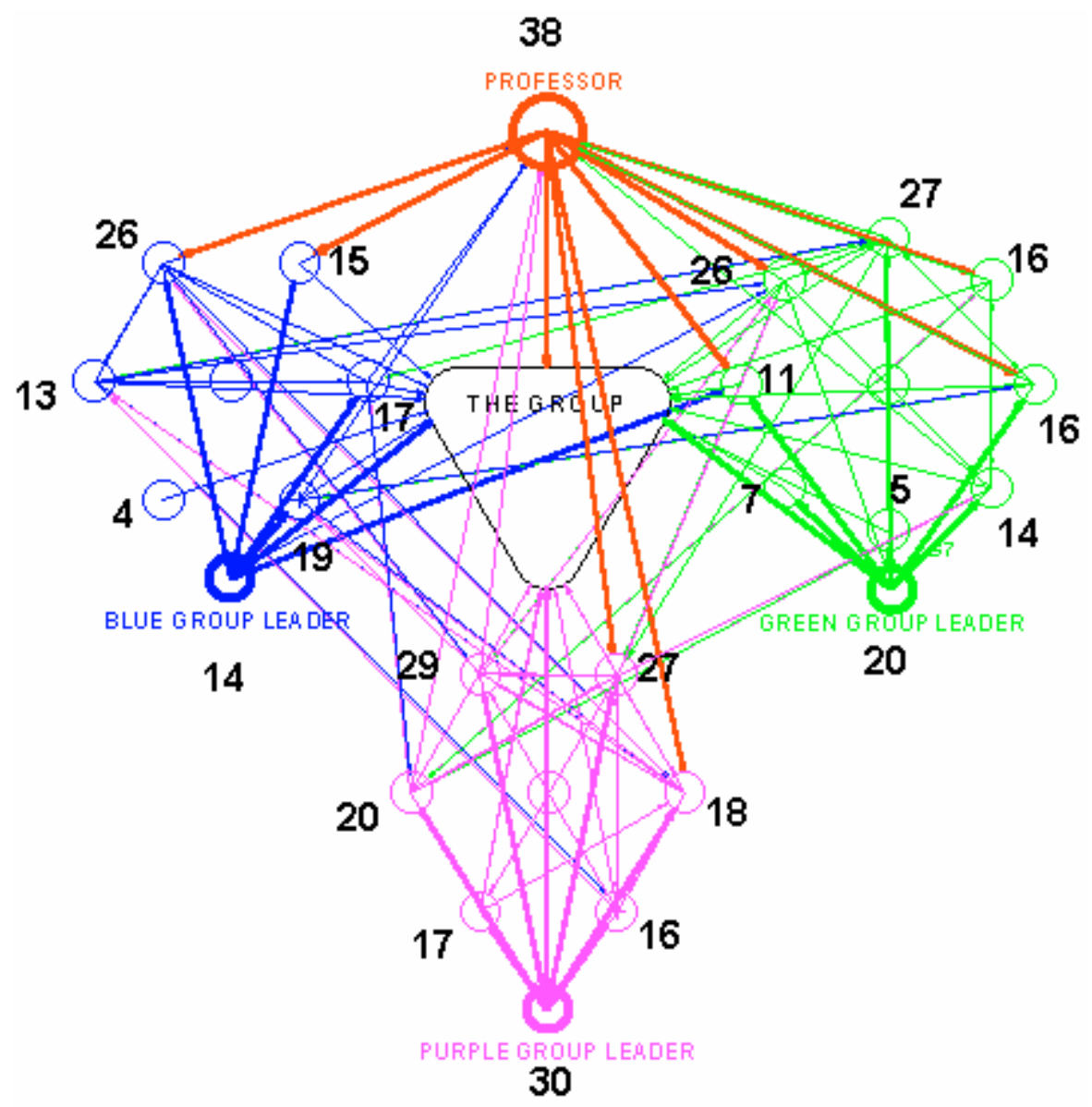

Contrast the interaction illustrated in Figure 5 with the Interaction Diagram in Figure 6, derived from a one-hour videotaped segment of a F2F AHSC/ 230 session Activity section, taught by the same principal instructor in Summer 1999. There were 52 students present in the F2F classroom, but only twelve participated in the class discussion. There were 48 messages exchanged between the F2F class participants during the one hour covered by this measure. One wonders what was going on for the other 40 students as they sat in class? Could they have been lost? Was there space for them to contribute? Is it the nature of serial interaction that dictates a prescribed interactive process in the classroom? For example, the instructor asks a question and a "line of hands" go up and person \#1 is given the floor. Subsequently, that interaction may spark other comments, but person \#2 is waiting in the "line of hands" to offer an opinion. By the time person \#4 gets a chance to speak, most likely the original comment is no longer relevant, and so on. In the eClassroom, however, the "line of hands" is in the hands of the participant. The instructor does not need to choose one individual respondent, and the participants need 
not wait their turn to add knowledge to the class narrative. The "line of hands" is replaced by a complex, parallel, and multi-directional communication pattern.

Figure 6. Interaction Diagram derived from a video of a F2F September, 1999 AHSC230 class.

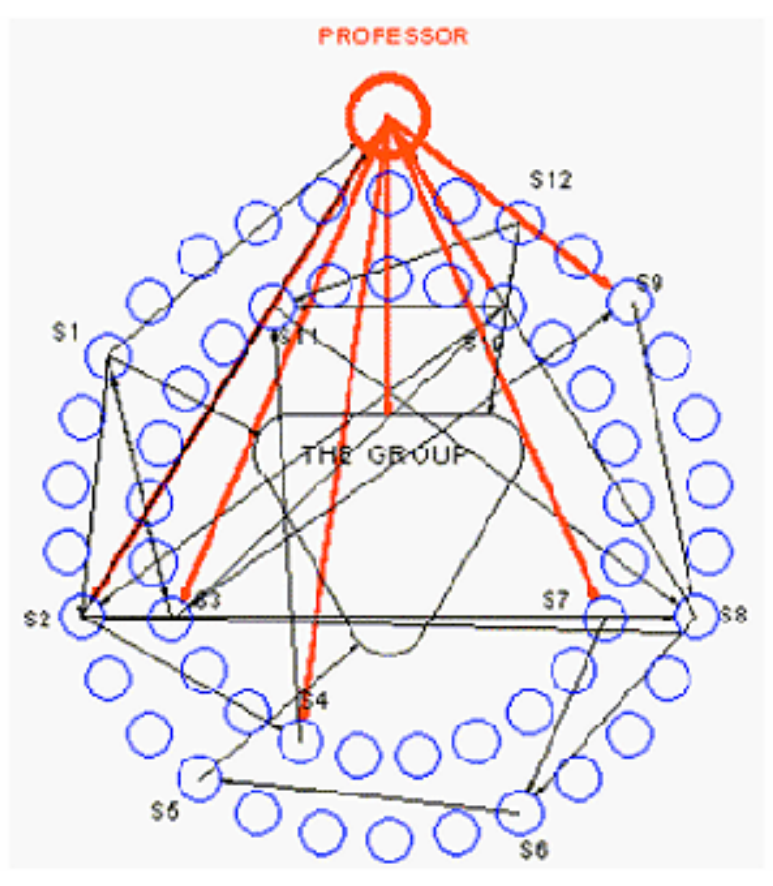

It appears the nature of parallel communication, as witnessed in the eClassroom, allows for everyone to participate and direct comments to any number of people in the same message, or in many messages. In fact, everyone can communicate with everyone at the same time, and at any time.

These observations made it clear that online interactions, in general, and the eClassroom interactions in particular, engender a new type of communication where time to communicate is no longer linear and serial, but holistic and parallel. The Interaction Diagram is an observational tool designed to describe F2F interaction, but it does not adequately describe the unique communication dynamics in the eClassroom. To this end the Interaction Diagrams presented in Figure 5 and Figure 6 are unwrapped along the time axis (Figure 7) that more accurately reflect the rich tapestry of communication lines woven by the participants in the eClassroom. The contrast between the numbers of communication lines generated in the eClassroom and those generated in the F2F session is visually striking. Is it possible that in a F2F classroom, where interaction is predicated on a "line of hands," the participants are more apt to get lost?

The patterns of communication evidenced in Figure 7a, also point to the differences in the small group interaction patterns, to be discussed later in this paper.

Figure 7. Interaction diagram unwrapped along the time axis. Each colored square is a speaker. The red squares represent the instructor. The students in the purple, green, and blue groups are represented by their color. Each column represents a participant. The dark purple, dark green and dark blue columns represent the facilitators. The lines represent directed communications to the prior comments of participants. 1) One-hour 
discussion during Activity I of the October 10 session, showing parallel communication in the main eClassroom. Each row represents one minute of class time. 2) One hour Activity and discussion transcribed from a video of an AHSC/ 230 F2F class taught by the same instructor, illustrating serial communication. Each row is a time-stamped speaker during the F2F activity and discussion.

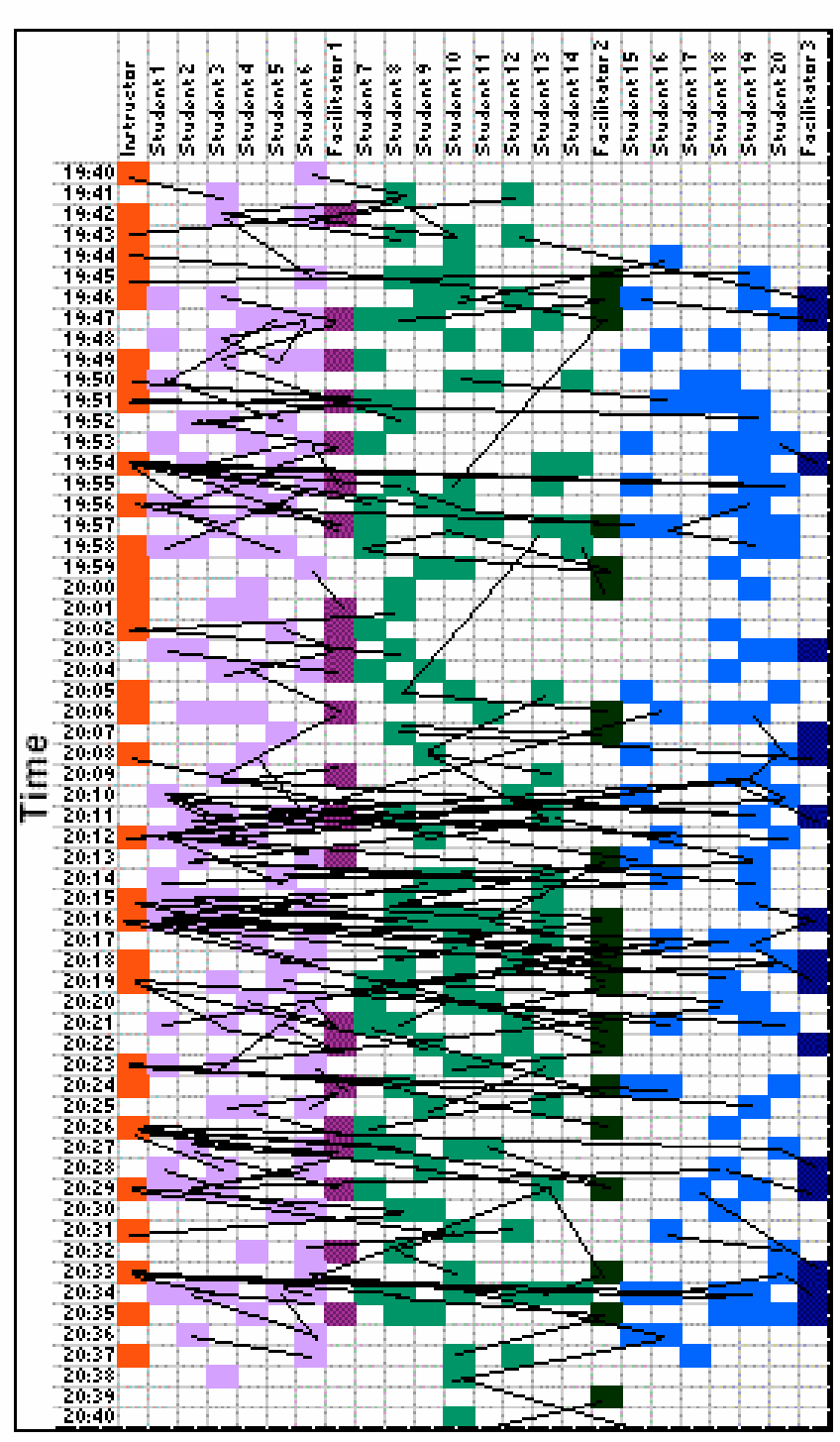

(a)

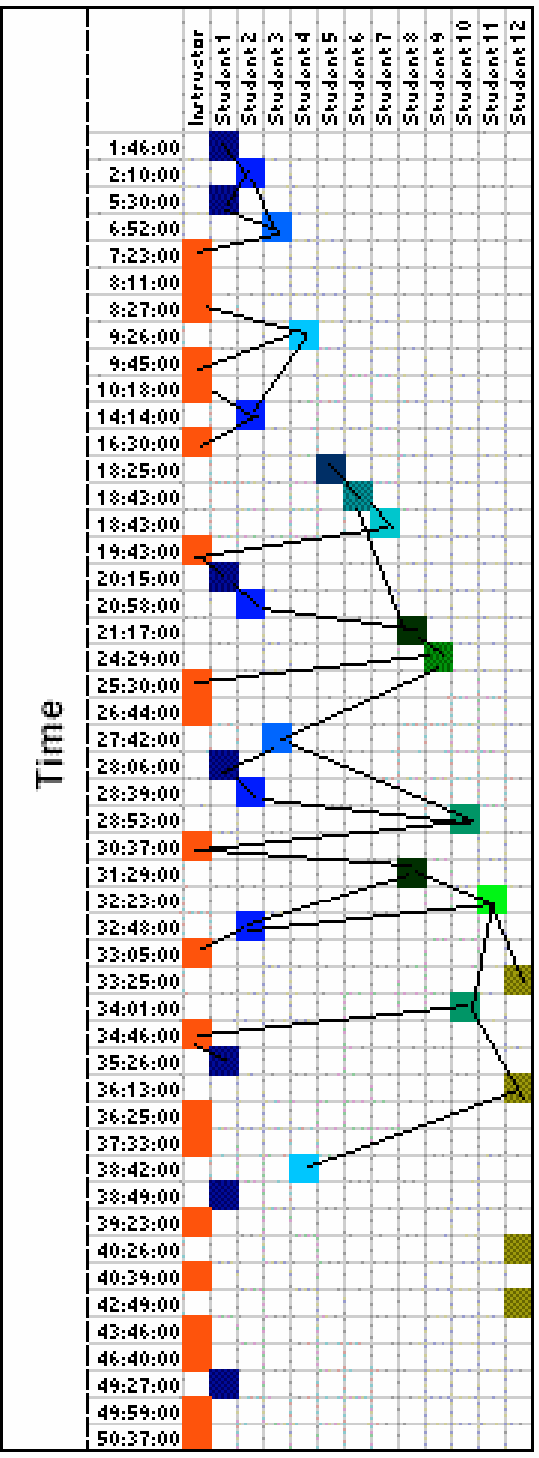

(b)

\section{Group Interaction - Large Group}

Interaction is defined as a mutual and reciprocal action or influence. An often-repeated maxim of facilitation included into the Course Outline states: "You are responsible for your own learning. You will get out what you put into the course." This maxim is strikingly illustrated and dramatically confirmed by the data collected and displayed in the scatter plot of Figure 8 . All the messages posted by each individual into the main 
classroom, over the entire semester, are plotted against all the directed messages received by the same individual. A directed message is defined as one that specifically names the intended receiver of the communication. A regression analysis calculated a .84 correlation between the variables $(\mathrm{P}<.05)$. The response rate, defined as the slope of the straight line curve fit, is 40 percent. Students who posted 100 messages received back an average of 40 responses; students who posted 200 messages received back an average of 80 responses. This appears to be a significant finding. It not only represents a facilitated democratic process at work, but it also suggests a benchmark for further study. What is the response rate in a F2F classroom? How could it be measured? Certainly, this kind of data is relevant for further instructional design modifications that would impact on the training process. What are the limits on interaction for this type of online eClassroom? How would twice as many participants affect this curve?

The Figure 8 scatter plot also indicates that during the large group eClass interactions the co-facilitators are responded to no differently than the group members. This may be a measure of collaborative co-facilitation, and the preferred distributed leadership style of the teaching team (Dimock, 1985). The data also point to the principal instructor's overall prominence in the teaching process. The data for the instructor (not shown on the graph) indicate that 892 messages were posted with 624 directed responses for a 70 percent interactive response rate, representing the highest rate of feedback received by anyone.

Figure 8. Number of messages posted into the main classroom by individuals, and responses to the individuals. The data represents the entire semester.

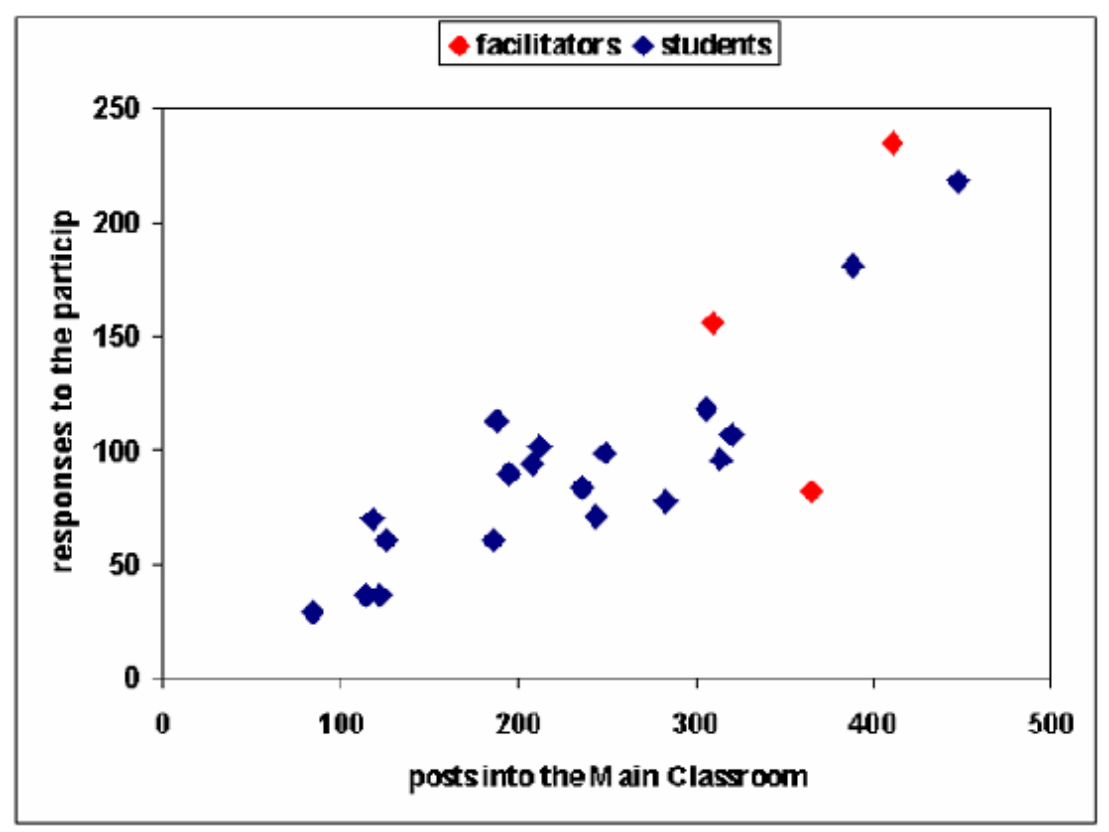

\section{Group Interaction - Small Group}

The small breakout groups are designed to give students an opportunity to interact with a small group, the facilitator, and each other. As expressed as the ratio of attending to participating, it was observed that each small group facilitator has a different interaction and leadership style. In Figure 9, the scatter plot illustrates the rate of interaction between individuals in the small groups during the semester. The 1:1 line represents a participant having the same number of directed messages sent as received. While above the line 
means the student received more directed messages addressed to them, than they themselves addressed to others. As may be noted in the blue group, thirty percent of the students are above the line; in the green group 75 percent of the students are above the line; and in the purple Group fifty percent the students are above the line.

A regression analysis calculated a .46 correlation between the variables $(\mathrm{P}<.05)$ and a mean response rate of 87 percent. As expected, the response rate in the small group is almost twice that of the larger group. This confirms the raison d'etre of small breakout rooms. It is apparent from the breakout groups' data that there is enough "room" within the small groups for students to receive more directed comments than they initiate. This is the space above the diagonal line in Figure 9. Here, 11 of the 20 students are above the line. More than 50 percent of the students received a greater number of directed comments than they sent out. Clearly, such interaction was not achieved in the Main eClassroom, which further validates the pedagogical decision to create small breakout groups. There is a strong experiential indication that the eClassroom Laboratory functions the same as a F2F classroom on this measure. Once again, it appears that the maxim "what you get out is what you put in," as a function of interactive response rates, remains consistent regardless of environment, group size and facilitation styles.

Unlike in the main eClassroom, nearly 75 percent of each small group facilitator's communications were directly addressed. This is a near identical percentage noted for the principal instructor in the Main eClassroom. It appears that in the breakout rooms, facilitators assumed the position the principal instructor held in the Main Room on this particular measure. In the breakout groups, the principal instructor's task is somewhat different than in the Main eClassroom. Since the teaching material has already been delivered in the Main eClassroom, the principal instructor's role is to support the facilitators by clarifying instructions, delivering process questions, and fulfilling any missing leadership functions. The small groups' data indicate that the principal instructor receives 220 percent more direct student responses than is directed to the students. Response rates remained consistent over time, groups, and facilitation styles. The question remains: How could the unusually consistent and direct correlation observed be used to evaluate facilitation and facilitation training effectiveness?

Figure 9. Rate of interaction between individuals in the small groups.

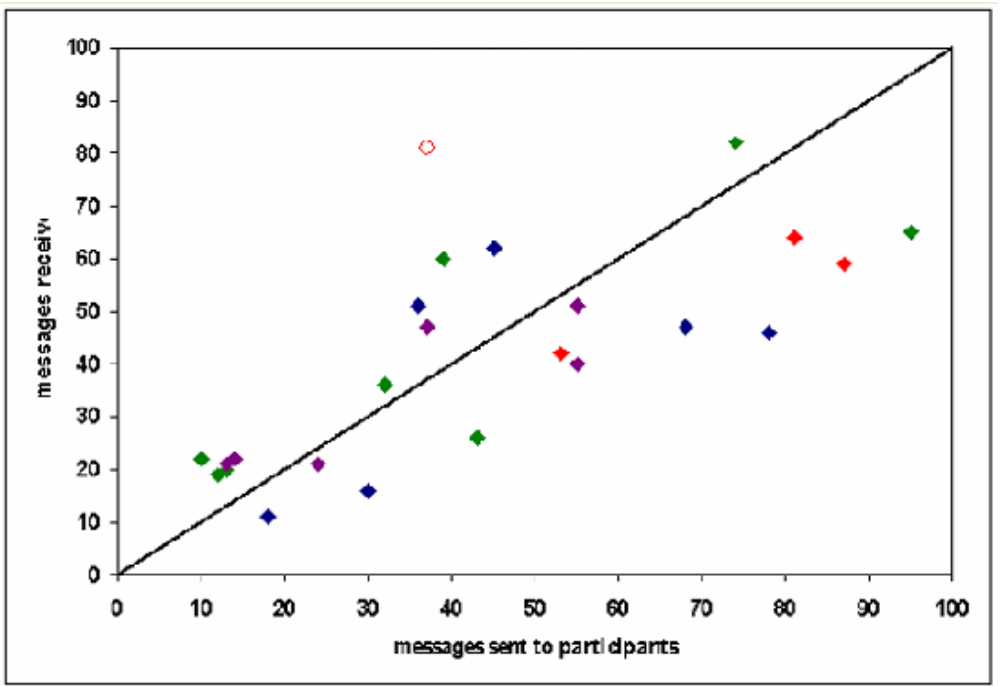




\section{Stages of Interaction}

An overview of the interaction data for the duration of the course reveals a distinct pattern. This pattern seems to remain constant throughout all the nine Learning Management Modules. There are four distinct stages of interaction during each session and they are named: the Greeting stage, the Gathering stage, the Activity stage, and the Conclusion stage. In addition, each Activity stage appears to have four distinct phases of interaction: 1) adding knowledge to the group; 2) facilitation; 3) building on the knowledge of others; and 4) reporting back to the group. It is postulated that each one of these stages of group interactions in the eClassroom has complimentary components to F2F classrooms, but unlike F2F classrooms, interactions in the eClassroom are measurable and quantifiable from the data collected automatically and archived by the synchronous online eClassroom.

\section{The Greeting Stage}

The first stage of group interaction in the eClassroom is the Greeting stage, during which time all participants login and present themselves to the class with greetings to their small group members, to the facilitators, to the larger group, and to individuals within the group. This stage is characterized by socially oriented gobletting behaviors (Schutz, 1988) and the task is simply to make one's presence known to others. The number of interactions measured during this ten-minute stage, throughout all the Learning Management Modules, was typically one hundred and fifty messages per session. As shown in Figure 10, there was surprising consistency in this quantifiable measure.

Figure 10. Cumulative number of messages during the greeting stage for each class session.

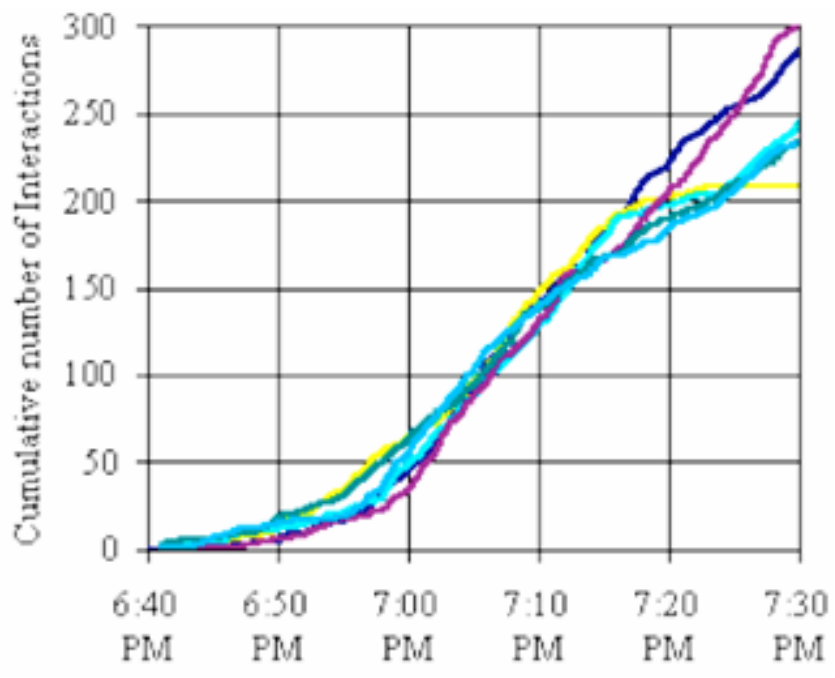

In a F2F group environment, the Greeting stage may be accomplished by a long chat or a simple nod, and is terminated when the "show" begins. Twenty-five participants, sending one hundred and fifty greeting messages in ten minutes, in a F2F situation, would constitute a zesty, noisy crowd. Qualitatively, greeting behaviors in a real-time synchronous environment resemble the F2F situations, albeit adapted to suit the limited bandwidth of social cues. From personal observation, it appears that in terms of group development, unstructured random groups with general goals, like a F2F party or an 
Lobel, Neubauer \& Swedburg - The eClassroom as a Teacher Training Laboratory

online chat-room, will rarely move past the Greeting stage of inclusion. There is no need to do so because members' "stakes" in the group are individually oriented. However, once structure is provided and goals specified so that individuals perceive the group as valuable, (in other words the group process and content is facilitated), the Greeting stage becomes a small part of the inclusion process.

\section{The Gathering Stage}

No matter what environment people meet and greet in, every person comes to the experience from his or her own perspective and present morale (Kass, 2002), having interrupted their lives in some way to be there. The facilitator, as a process observer, at this stage will recognize the need for the stage to be set based on trust and to make it as level as possible. One method to accomplish this is to begin the session with a Transferring In activity. In the F2F environment this may take the form of a relaxation exercise, a guided meditation or a short activity relating to the topic to be covered. From years of feedback, it is clear the effect of this intervention is to bring or gather everyone into the classroom, so that everyone will begin the session from the same "frame."

After approximately ten minutes of greeting interactions, the instructor assesses the appropriate time to formally begin instructions. This judgment is based upon the general level and energy of interactions, and is usually after tending to housekeeping issues such as handing in journals or pictures for identification, and addressing technical issues such as how to use the archives. In F2F classes, the instructor usually begins the session with a short Transfer In event to facilitate students in the transition from "then-and-there/ separate" to "here-and-now/ together." In the online classroom, after the third session, the instructor posted some topic-relevant story, quote, or poem for the students to read and discuss.

This Gathering stage is characterized by socio-emotional interactions designed to resolve issues of membership and prominence, in terms of testing who is listening to whom and searching for personal similarities and differences (Schutz, 1985). Unlike in F2F classroom settings, in the eClassroom, this process of gathering the students into a common starting place is actually measurable by the quantity and frequency of participants' interactions.

The number of times participants polled the server for new data, may provide a valid measure of attentiveness and by extension a measure illustrating individuals' anticipatory interest to find out what information is being generated by the other group members. The data used to identify and describe the gathering process are collected to measure participants' attentiveness, and are quantified as the total number of times the server was polled for data by each participant.

As shown in Figure 11a, this anticipatory interest has two distinct peaks of interaction during the first fifteen minutes of the first three classes. In these first three sessions, these anticipatory interest peaks are well defined, the first occurring five minutes from the start of class and the second occurring fifteen minutes into the class. The content of these gathering discussions centered on commonalities such as names, pictures and technical concerns and served as the Transfer In activity for the first three Learning Management Modules. 
Figure 11a. Sept 12-26 (After 7:15 the curves reflect the beginning of that week's activity. The activity for the week with the blue line was to go to their respective breakout groups and to discuss content there.)

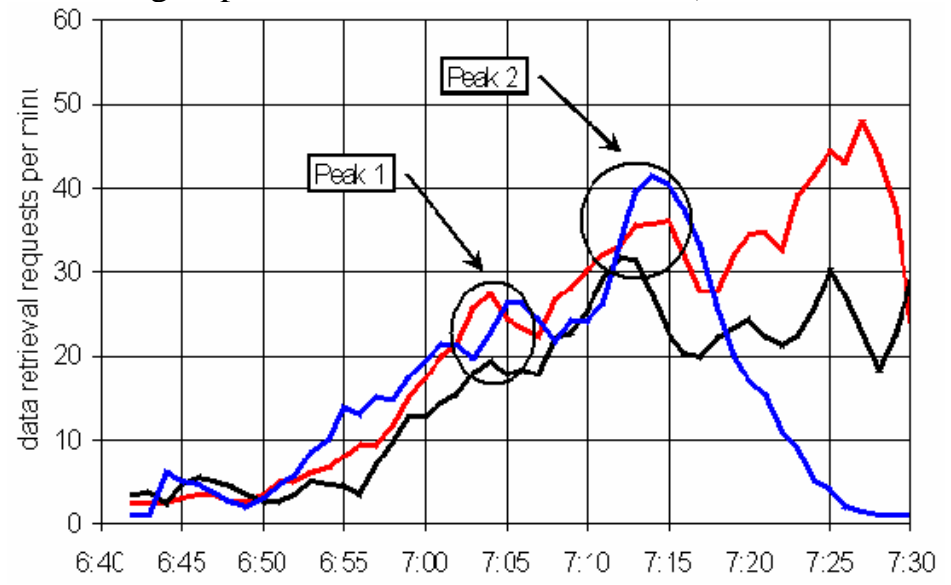

The relatively low points between these peaks were experienced by the principal instructor as a "lull" in the process, and a potential waste of valuable instruction time. Starting each class with a Transfer In story that would then lead into the class content is an intervention directed at eliminating the relatively low points of interaction that occurred during the Greeting stage of the first three sessions. As shown in Figure 11b, the two peaks of interest begin to merge in the three middle Learning Management Modules. Figure 11b shows that the time period between the peaks has changed from ten minutes to five minutes, and the peaks themselves are beginning to disappear. This would indicate that students' anticipatory interest was greater during this fifteen minute time period, compared to the first three sessions, and that the intervention facilitated the important task of creating and maintaining momentum in the gathering process.

Figure 11b. October 3 to 17.

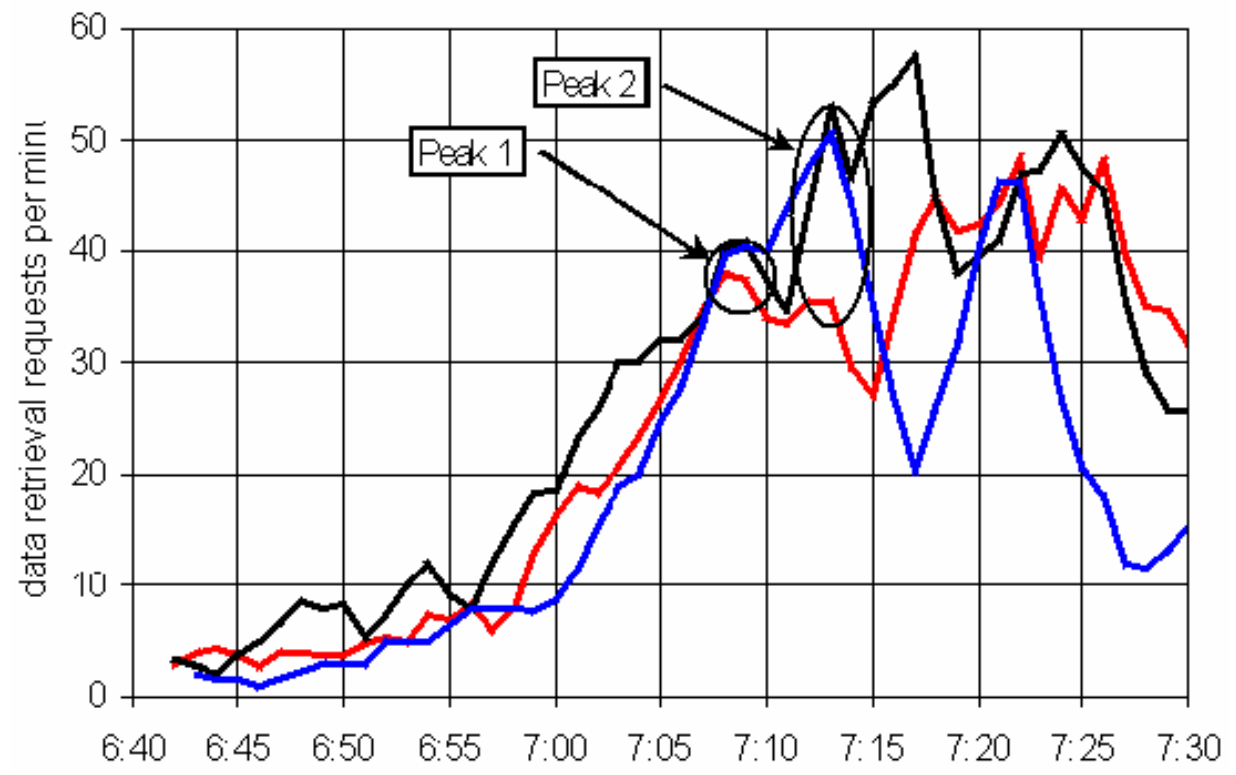


Finally, in the last three Learning Management Modules, as shown in Figure 11c, the merging of interest and momentum in the Gathering stage appears well managed. The periods of reduced attention or waiting are eliminated, as everyone seems primed to know what is to follow. The established gathering process is such: participants arrive and greet one another, housekeeping is addressed, a story is introduced and the ensuing comments form a common base from which to enter into the group and engage in the process, increasing members' preparedness to participate in the learning activity.

Figure 11c. October 24 to -November 7

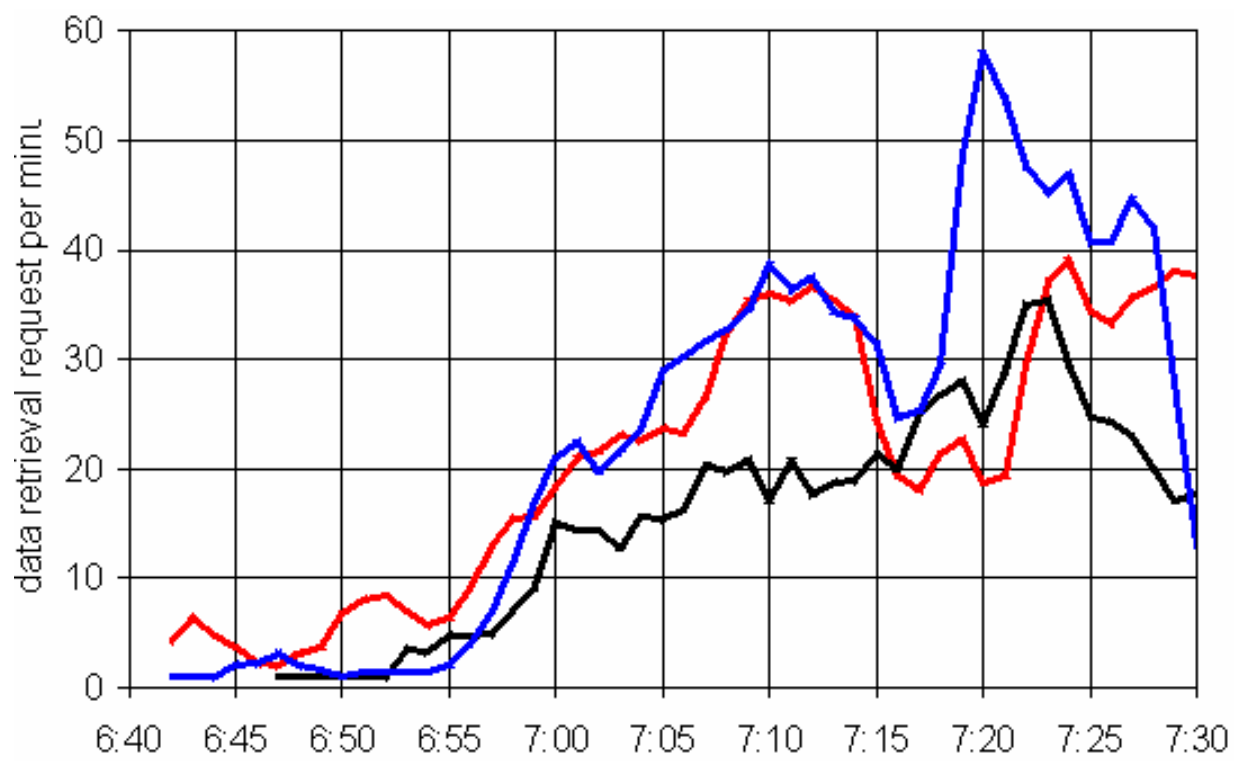

It is important to mention classical conditioning as a major variable involved in the act of polling for data, and its subsequent use as a measure of attentiveness and anticipatory interest. The fact is this button may be akin to a lever one presses to get yet another 'conversational pellet.' In addition, certain personality traits and learning styles may also influence the rate with which any given individual seeks more information in this fashion.

\section{The Activity Stage}

Each Learning Management Module contains at least two associated activities. The learning-by-doing instructional design of these activities follows closely that of the F2F classes, but in the online eClassroom the measures of outcome are quantifiable. The timeline in Figure 12 illustrates a typical class where interactions can peak at 16 to 20 messages per minute and remain consistently at six to ten posts per minute throughout the session. 
Figure 12. Level of Interactions during the Oct 10 Learning Management Module.

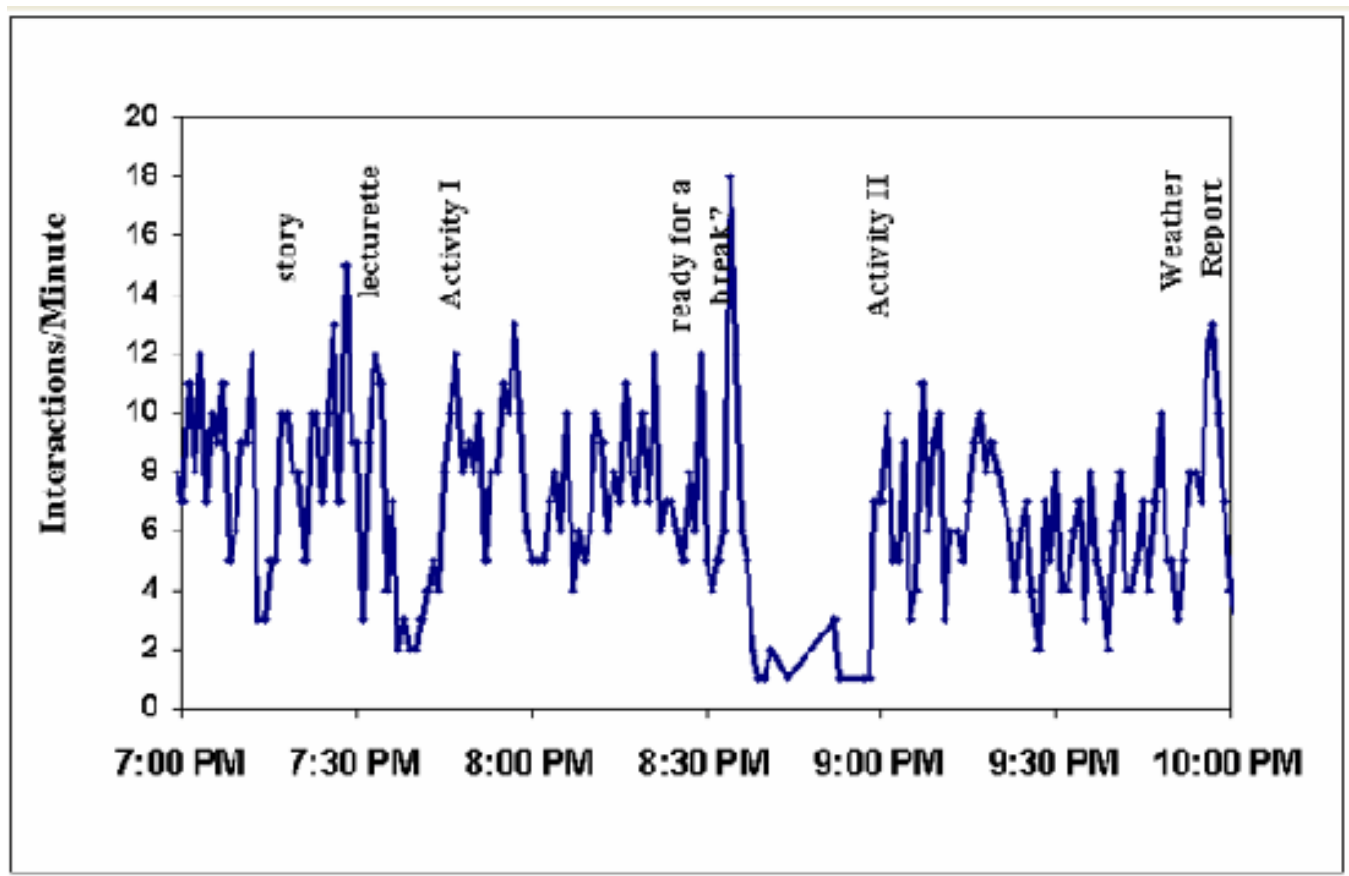

The Activity stage is characterized by task related behaviors. If the Gathering stage was about "being seen" then the Activity stage is about "being heard." The common goal in this stage is to grapple with the instructional material and make decisions about its relevance to the self. As mentioned earlier, each Activity stage includes four distinct phases of interaction: 1) adding knowledge to the group; 2) facilitation; 3) building on the knowledge of others; and 4) reporting back to the group. The Rate of Interaction characteristics during the Activity stage are shown in Table 1. A discussion of the emerging interaction patterns is included below. The flow of interactions as it varies over time is shown in Figure 13. It is clear that throughout all the Learning Management Modules, interaction occurred student-to-student, student to facilitator, and student to group. What appears to have changed over time is the frequency with which the participants were addressed in their respective roles. The fluctuations in the directions of the messages were sent seems to be phase dependent. 
Table 1. Rate of interaction from student to: Student, Facilitator, and Group during the various phases of the Learning Module Activity.

\begin{tabular}{|l|l|l|l}
\hline & $\begin{array}{l}\text { Student to } \\
\text { Student }\end{array}$ & $\begin{array}{l}\text { Student to } \\
\text { Facilitator }\end{array}$ & $\begin{array}{l}\text { Student to } \\
\text { Group }\end{array}$ \\
\hline Plase I & Low & Lowest & Highest \\
\hline Facilitation & Moderate & Highest & High \\
\hline $\begin{array}{l}\text { Phase III } \\
\text { others }\end{array}$ & Highest & Moderate & Lowest \\
\hline $\begin{array}{l}\text { Phase IV } \\
\text { Reporting back to the group }\end{array}$ & Lowest & Moderate & High \\
\hline
\end{tabular}

Figure 13. The four interactive phases of the activity stage: Student-to-Student. Studentto-Group. Student-to-Facilitator.

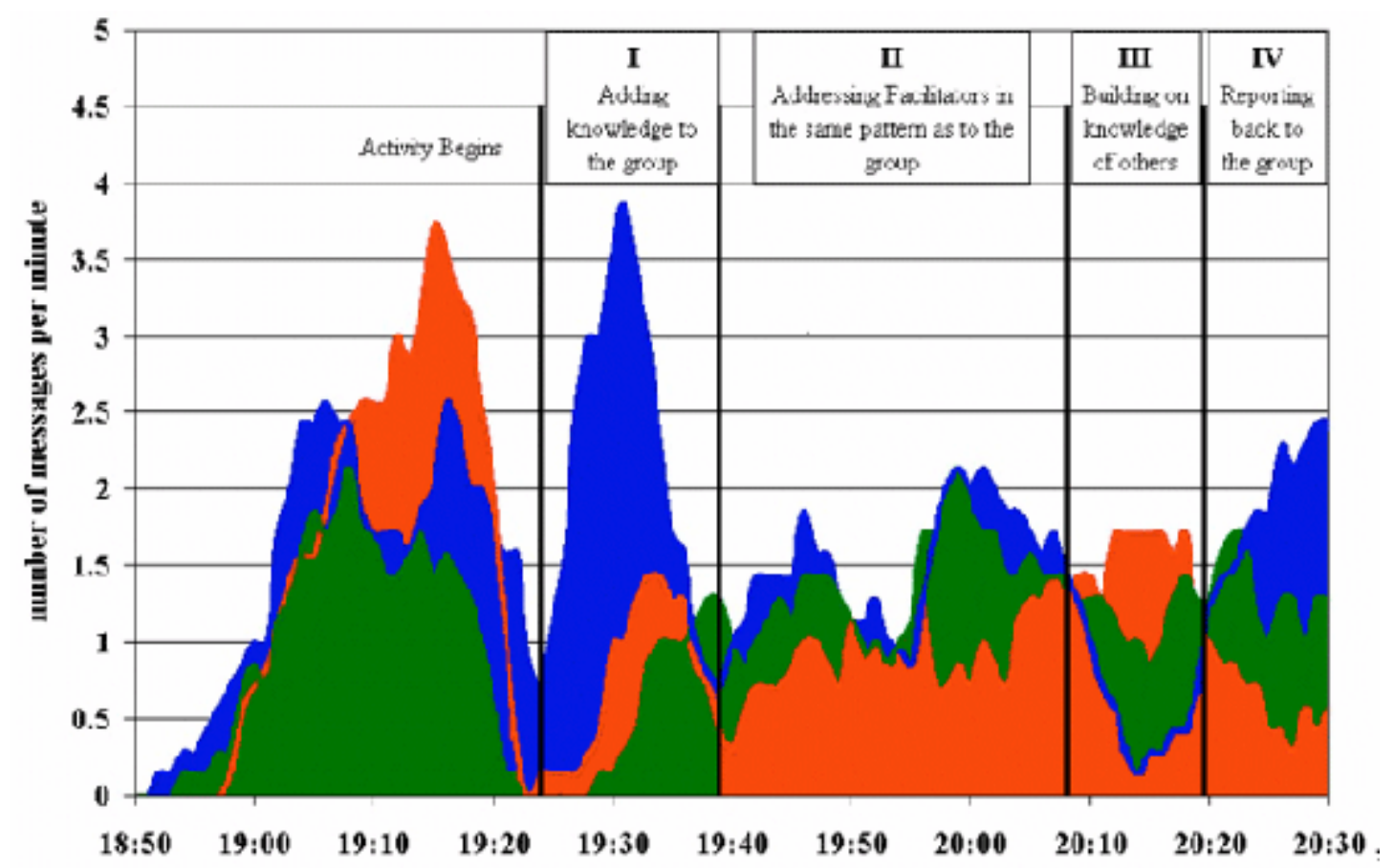




\section{Adding Knowledge to the Group}

During the adding knowledge to the group phase student-to-student and students-tofacilitators interactions are low while the instructional material is being delivered, and students are interacting by directing most of their reactions about the activity to the group in general. Examples of these postings are shown in Figure 14.

Figure 14. Examples of "adding knowledge" to the group in the eClassroom.

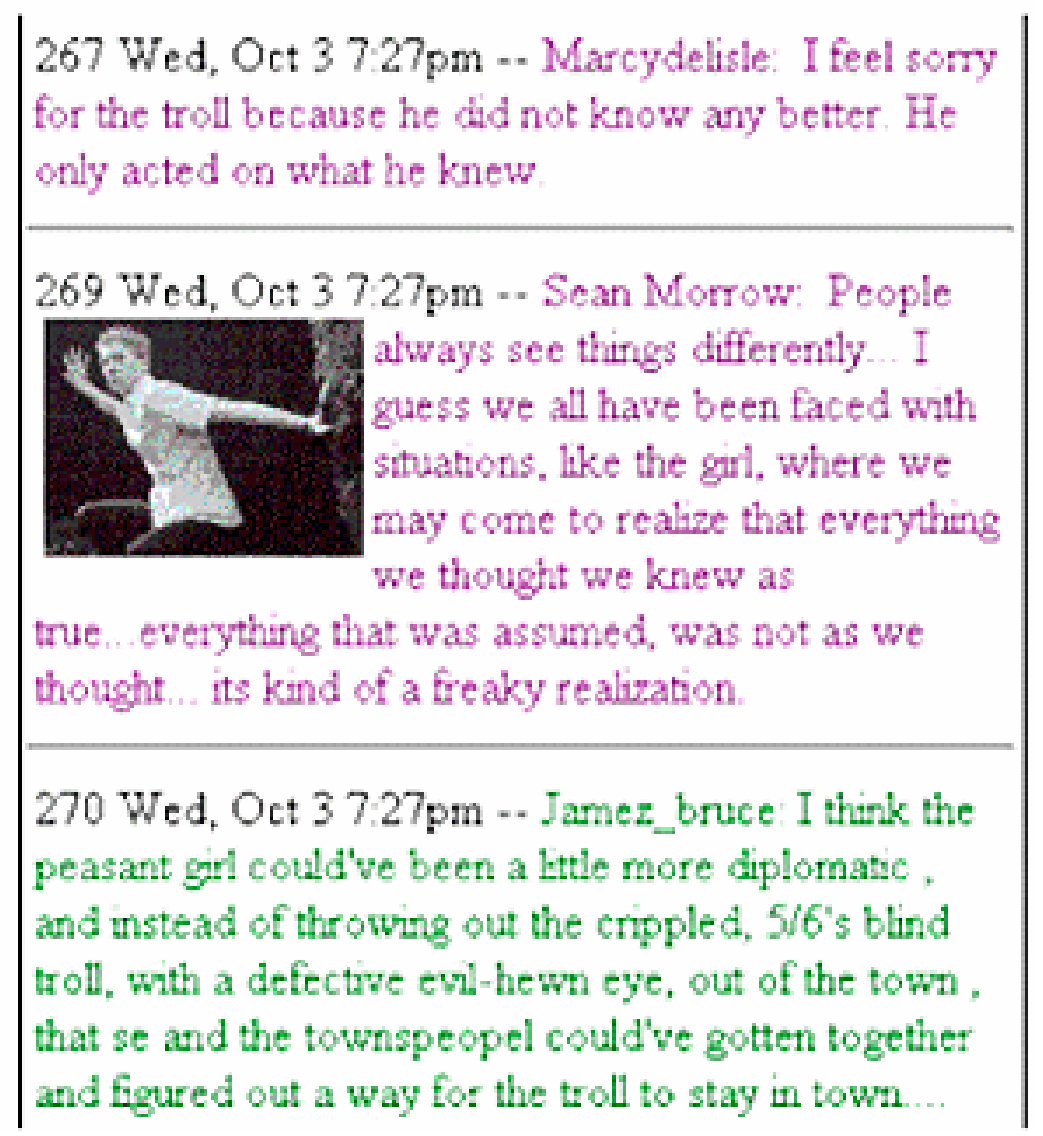

\section{Facilitation}

During the facilitation phase student-to-facilitator interactions are at their highest, as participants define their understanding of the topic and accept the goals of the activity, while student-to-group interactions continue to remain higher than student-to-student ones. Examples of these postings are shown in Figure 15. 
Figure 16. Examples of building on the knowledge of others

\begin{tabular}{|c|}
\hline $\begin{array}{l}519 \text { Wed, Oct } 38: 07 \mathrm{pm} \text {-- Seanmmorrow : Ya } \\
\text { marcy, I think you are right. I don't } \\
\text { beleive that most of us can only live } \\
\text { forselves. I know that } \\
\text { sad friend who needs somebody to }\end{array}$ \\
\hline $\begin{array}{l}535 \text { Wed, Oct } 38: 12 \mathrm{pm} \text {-- Jamez_bruce: Rick, I see } \\
\text { what you're getting at. Not to actually, } \\
\text { CHANGE peoples minds... but the fact } \\
\text { that you think your actions and thoughts } \\
\text { are right for the sheer fact that thier your } \\
\text { own. but, you can always give everyone }\end{array}$ \\
\hline $\begin{array}{l}542 \text { Wed, Oct } 38: 12 \mathrm{pm} \text {-- Marcydelisle: Good point } \\
\text { Ilan. Sometimes we don't realize how much we are } \\
\text { capable of caring until the opportunity presents itself. }\end{array}$ \\
\hline
\end{tabular}

\section{Reporting Back to the Group}

Finally, during the reporting back to the group phase student-to-student interactions are minimal, while student-to-group interactions, moderately facilitated, become relatively high, indicating that students actually have something to report back to the large group. Examples of these postings are shown in Figure 17. 
Figure 17. Examples of reporting back to the group

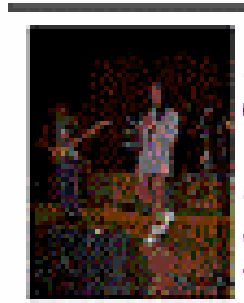

598 Wed, Oct $3823 \mathrm{pm}$-- Alexandra:

This week, I forced myself to go wisit a

distant relatio and I told myself that: I

HAVE to go to aroid my other loud aunt

to make a conment about my absence.

601 Wed, Oct $3823 \mathrm{pm}=-$ Marcydeliste: Irealize

that don't have to do what I don't want to do but

sometimes it's just easier to do it rather than

procrastinate and deal with the consequences. For

example, I didn't have to meet with ny study group

after school today but I did it anyway because it was

easier than risking falling the class.

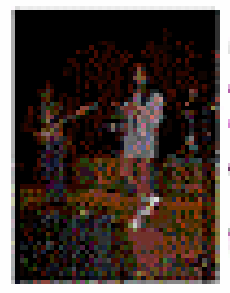

623 Wed, Oct $3826 \mathrm{pm}$-- Alexandra

KIMMLA, Yes, going to wist my relative

was worth it and it served me well. I chose

to 8 .

\section{The Conclusion Stage}

At the end of each session, after processing the experience either in the main eClassroom or in the small breakout rooms, students were asked to fill in a questionnaire called "The Weather Report." The weather became the metaphor used to express and assess students' satisfaction level with themselves and the sessions. As seen in Figure 18, in general, the satisfaction level is "sunny" and topic dependant. 
Figure 18. Weather reports from the students.

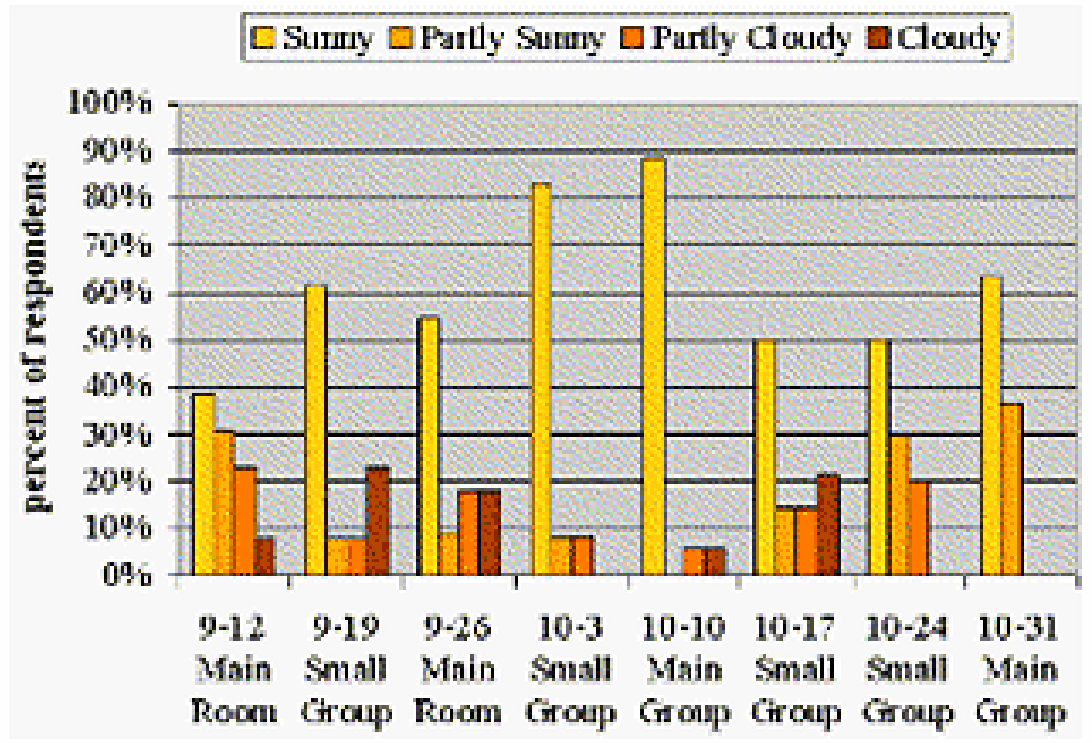

\section{Involvement}

Involvement means to engage as an influential participant, and to commit emotionally to the group. Commitment to the whole increases the value and the influence of the group for the individual. Group members can report on their personal stake in the group and on the importance they each place on the task and on the social relationships. In terms of involvement or willingness to participate, one would need to differentiate between "high" and "low participators." It stands to reason that an "over participator," in general, and in the eClassroom in particular, would send and receive more messages than an "under participator." It also makes sense that "high participators," for better or worse, will become the important hubs, or centers of activity within the group, by drawing interactions to themselves, as illustrated by the direct correlation between sending and receiving directed messages. High participation is a useful tool for information delivery, but does not serve well for processing an experience in a group discussion. In any effective interaction, legitimate, responsible and facilitative authority is necessary to include the lost children. As a result of the willingness and the ability of the teaching team to intervene, if there is inappropriate participation, it is assumed that in the synchronous eClassroom this good authority is well distributed between the students and the teaching team. According to Pajek software (Batagelj and Mrvar, 1996), a hub is good if it points to many good authorities, and it is a good authority, if many good hubs point to it. The following analysis was made with the assumption that all members of the breakout groups were by definition good authorities. This definition will then emphasize the facilitator, whose task it is to direct inquiry and comments to individuals in the group, as needed. The greater the number of directed comments, the larger the circle representing the individual's attribute as a hub within the group. The directed network hubs in Figures 19, 20 and 21 reflect all of the small group interactions over the entire semester. 


\section{Hubs in the Directed Network of Small Groups}

\section{Blue Group}

In the blue group, the facilitator, $\mathrm{BL}$, is the most important hub. It appears the strong leadership in the blue group may result in the principal instructor's (PI) position as the smallest hub, meaning that the PI sent the least amount of directed messages in this group. The number of directed messages for the members of this group from highest to lowest is BL-97, B3-78, B5-68, B1-45, B2-36, B4-30, B6-18, and PI-10. It is only after generating this figure that it became apparent that there is a missing link between students B4 and B6, who have not directly addressed each other once, throughout the semester. This information is the impetus used to modify the eClassroom data collection algorhythm so that in the future such data is made available to instructors and facilitators on an ongoing basis.

Figure 19. Directed network of hubs in the blue group.

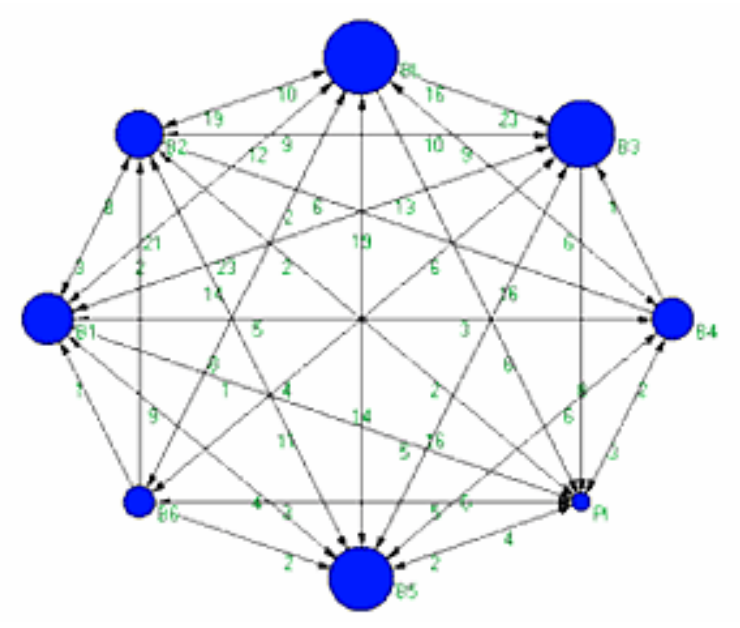

As was seen in the Unwrapped Interaction Diagram in Figure 7a, in the main eClassroom, the blue group members direct more communication lines to the rest of the class than to each other. This measure may also speak to the group's cohesion level. Cohesion is defined as the degree of solidarity or “we'ness" in a group (Dimock, 1985). According to this definition, group cohesion in the group appears low.

\section{Green Group}

In the green group, the most important hub, the one directing most of the comments was student G2. The green group facilitator GL, and student G4 were almost equal in terms of directed comments to members of the group, while some group members directed very few comments in general. In this group, the PI seems to have exerted more influence with directed messages to the students in the group. Without exerting too much influence and without drowning out the comments of the other group members in this group, the PI provides the authority balance and is more influential as a hub than student G1 and G3. The number of directed messages for the members of this group from highest to lowest is G2-95, GL-87, G4-74, G5-43, G6-39, G7-32, PI-19, G8-13, G3-12, and G1-10. The missing links in this small group were between G3-G6, G1-G3, and G7-G8. It remains to 
be seen how the hubs in a directed network, in which the facilitator receives immediate feedback about the existence of these missing links, would be different.

Figure 20. Directed network of hubs in the green group

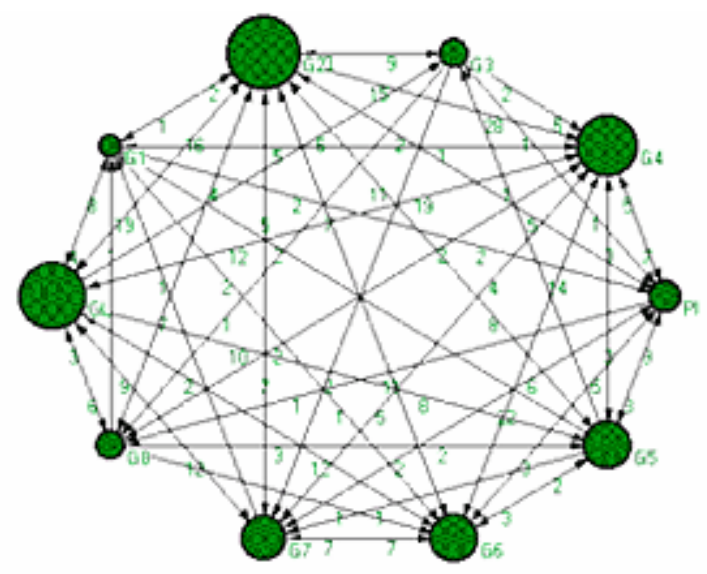

The Unwrapped Interaction Diagram in Figure 7a points to the green group members' preference to associate in a balanced fashion with each other and with the large group as well. This group may represent a group that exhibits a sense of connection with both the large and the small groups.

\section{Purple Group}

In the purple group, the facilitator PL, Student P3 and Student P5 had almost equal importance as hubs, directing comments to other members of the group. In this group, the PI did not exert any influence and remained in the background as the least important hub, directing the fewest comments to members of the group. The number of directed messages for the members of this group from highest to lowest is P3-55, P5-55, PL-53, P6-37, P4-24, P1-14, P2-13, and PI-8. In this small group, the missing links were between P2-P3 and P1-P2.

Figure 21. Directed network of hubs in the purple group

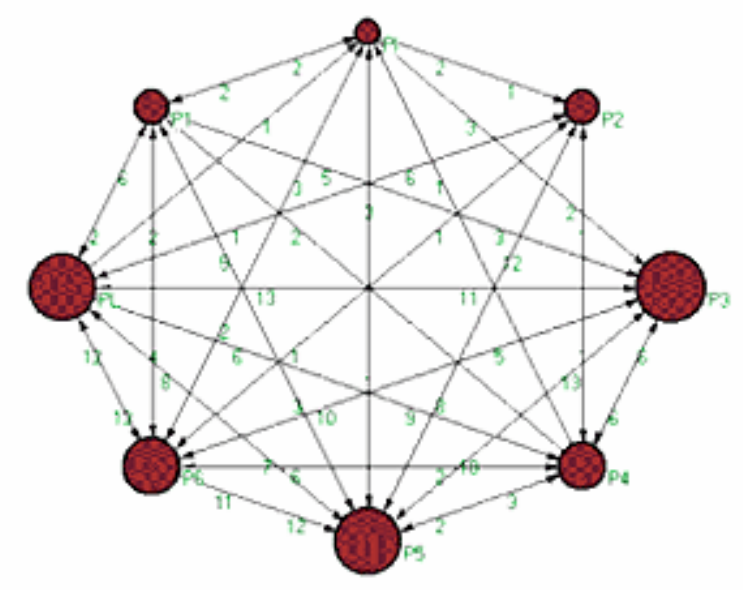


The vigorous and dense small group intra-communication shown in the Unwrapped Interaction Diagram, Figure $7 \mathrm{a}$, at the expense of inter-group communication, exemplifies another pattern of involvement students exhibited during the semester. This group may represent a group with a high degree of "village" solidarity.

In conclusion, the principal instructor's role was least pronounced in the blue and purple groups, and most pronounced in the green group. This can be seen by the size of the hub relative to the size of other hubs in the directed network of the group. It appears that the small group facilitators' participation styles may be reflected in their groups' interactions with each other and with the class as a whole. These measures also illustrate the eClassroom's efficacy as a feedback tool for the facilitators, pointing towards the interventions needed to manage leadership roles and hubs of influence effectively. It is surprising that there were students who did not interact with one another, even in the small group setting. While all students interacted with other students, and in that sense they were not lost, there still remained a few individuals who remained lost to each other.

\section{Conclusion}

The data presented throughout this paper visually demonstrate the social network woven by the participants' interactions during the eClass sessions. The interactions presented clearly illustrate that given the chance, people will reach out to each other to establish connections and to develop relationships any way they can. The lost children, who in this pilot study would include the instructor, the facilitators, and the students, found ways to show up and pay attention, to participate and get involved, and to construct lasting interpersonal knowledge, all within the context of the eCourse and the eClassroom. The measures provided by the eClassroom offer the instructor and facilitators real-time, instantaneous data in order to observe the areas of potential group development and intervene in effective ways to increase appropriate group interaction, to build trust and cohesion and to experience learning in productive and creative ways.

Since this online learning environment is a new one, new terms and definitions have to be applied. For the eClassroom, attendance is defined as both "being there" and as "paying attention." "Paying attention" is quantified as the number of times a participant polled the server for new data generated since their last polling. In the eClassroom, participation is defined as the state of being related to the whole and it is seen as the number of messages posted by each participant. There is no apparent correlation between the measures of "attending" and "participating," which confirms that "vocal participation" may not necessarily mean "paying attention," while "non vocal participation” does not necessarily imply inattention. The relationship between attending and participating is expressed as a ratio that remains surprisingly consistent for each of the participants over time. In the eClassroom, three distinguishable types of ratios are observed: 1) participants with the distinct tendency to attend more than participate; 2) participants who attend and participate equally; 3) participants with a tendency to participate more than attend.

Interaction is defined as mutual or reciprocal action or influence. The eClassroom collects data instantaneously. The data can be used to illustrate the interactions in a way that affords feedback to the instructor and facilitators. Lines of communications indicate high levels of democratic interaction as participants build a solid interpersonal network. Parallel participation patterns are found to be a unique feature of online synchronous realtime communication. A new Unwrapped Interaction Diagram, which quantifies and 
illustrates the unique online parallel communication patterns observed in the eClassroom, is offered.

In the time series data there are four distinct Interaction stages noted during each Learning Management Module: 1) greeting stage; 2) gathering stage; 3) activity stage; and (4) conclusion stage. Within each Activity stage four distinct phases of interactions are described. These are: 1 ) adding knowledge to the group; 2) facilitation; 3) building on the knowledge of others; and 4) reporting back to the group. The data describing the four phases illustrate high levels of participation and phase appropriate interactions. Quantitative and qualitative measures of interactions are presented to illustrate the nature of interaction and learning that took place.

The power of the eClassroom as an observational, diagnostic and feedback tool is clearly demonstrated. The eClassroom not only fosters learning of content, but it also provides the laboratory in which a "problem" can be observed, it offers the tools to diagnose the problem, it points to the map to formulate a prescription, and it supplies the feedback needed to assess the results of an intervention.

A matched study, comparing a F2F class with an eClass on the measures presented in this paper, while keeping content, time frames, facilitators and pedagogy a constant, will be conducted in the Fall 2002. Perhaps much like the "Wild Boy of Aveyron," as people connect online and learn how to learn in this environment, each answer will elicit a flood of new questions, as we grapple with the medium and the process it entails. This process of inquiry will itself hone the skills of the participants to become effective group members, teachers, and facilitators.

\section{References}

Adler, R., and Rodman, G. (2000). Understanding human communication. Orlando, FL.: Harcourt College.

ATLAS.ti (2002). The Knowledge Workbench Visual Qualitative Data Analysis: Management and Theory Building c 1997-2002. Scientific Software Development, Berlin.

Batagelj, V., and Mrvar, A. (1996). Pajek, a freeware software program for large network analysis. University of Ljubljana, Slovenia. Retrieved February 25, 2002 from: http://vlado.fmf.uni-lj.si/pub/networks/pajek/

Borgatti, S. P., M. G. Everett, and Freeman, L.C. (1999). UCINET 5.0 Version 1.00. Natick: Analytic Technologies.

Chenault, B. G. (1998). Developing personal and emotional relationships via computermediated communication. Computer-Mediated Communication Magazine, 5(5) Retrieved April 5, 2002 from: http://www.december.com/cmc/mag/1998/may/chenault.html

Dimock, H. (1985). How to observe your group. Center for Human Resource Development Monograph Series for People working with People. Second Edition, 1 - 46. 
French, D., Sherwood, W., and Bradford, D. (1996). Changes in the self-identity in a management training conference. Journal of Applied Behavioral Science, 2(2), $210-218$.

Gibb, J. R. (1964). Climate for trust formation. In L. P. Bradford, J. R. Gibb, and K. Benne (Eds.) T-group Theory and Laboratory Method. New York: Wiley.

Goldschmidt, W. (1990). The Human Career: The self in the symbolic world. Cambridge, MA.: Basil Blackman.

Kass, R. (2002). Theories of Small Group Development. Montreal: The Center for Human Relations and Community Studies.

Lobel, M., Neubauer, M., and Swedburg, R. (2002). Elements of group interaction in a real-time synchronous online learning-by-doing classroom without F2F participation. USDLA, April. Retrieved May 5, 2002 from: http://www.usdla.org/html/journal/APR02 Issue/article01.html

Marks, S., and Davis, W. (1975). The experiential learning model and its application to large groups. The 1975 annual handbook for group facilitators. San Diego, CA: University Associates Publishers, Inc.

Parks, M., and Floyd, K. (1996). Making friends in cyberspace. Journal of Computer Mediated Communication 1(4). Retrieved February 17, 2002 from: http://jcmc.huji.ac.il/vol1/issue4/parks.html

Schutz, W. (1988). Profound simplicity. (3rd Ed.) Muir Beach, CA.: WSA.

Shattuk, R. (1980). The Forbidden Experiment: The story of the wild boy of Aveyron. New York: Farrar, Straus, and Giroux.

Strangelove, M. (1994). The Internet, electric gala and the rise of the uncensored self: from essays on the anthropology of cyberspace. Computer-Mediated Communication Magazine, 1(5). Retrieved April 5, 2002 from: http://www.ibiblio.org/cmc/mag/1994/sep/self.html

Tu, C.H. (2000). Online Learning Migration: From social learning theory to social presence theory in CMC environment. Journal of Network and Computer Applications, 23(1), $27-37$.

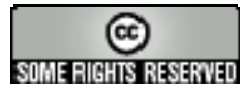


October - 2002

\title{
Global and Critical Visions of Distance Universities and Programs in Latin America
}

\author{
Miguel Casas Armengol \\ Universidad Nacional Abierta (UNA)
}

\begin{abstract}
The future of any region's higher education infrastructure cannot be a matter of guesswork; instead it must be built upon a solid foundation that is both rationally and soundly constructed. This postulate is especially important for regions such as Latin America experiencing problems associated with underdevelopment. Universities, particularly those specializing the area of science and technology, can and do play a constructive role in the advancement and improvement of modern society. However, the current Latin American educational context, which is less than optimal, can be compared with other similarly developing countries around the world, many of which have produced high quality university and scientific systems. Why is Latin America lagging behind? This is a good question that deserves closer examination. This article discusses reasons for the chronic problems for the deteriorated conditions facing Latin American universities. It also suggests ways in which Latin American distance universities can contribute to a transformation of the entire university system throughout the region.
\end{abstract}

\section{Introduction}

Latin America is region characterized by enormous potential coupled with serious economic and political problems. In both cases, Latin America's public state-run oncampus and distance universities can and should give decisive answers and guidelines to allow for the sound utilization of Latin America's abundant national resources. Such actions will help advance social development and progress throughout the Latin American region. However, most countries in this region are currently facing exacerbated social realities stemming from socio-economic conditions that have their roots in past shortcomings. During the 1980s and 1990s, many of Latin America's most important public universities were neither upgraded nor modernized. Moreover, their curricula were not modernized and, as a consequence, failed to recognize and address the new and changing socio-economic realities occurring domestically, throughout Latin America, and globally.

How do we resolve these problems? First, Latin America's nation states must fundamentally recognize the central role higher education can play in advancing human and national development. My contention is that current educational and pedagogical processes in both residential and distance universities, many of which have been adopted in other so-called developing countries and regions throughout world, can point Latin America in the right direction - a pathway that will yield effective interrelationships and linkages between knowledge, higher education, and society as a whole. 
When rethinking and restructuring Latin America's university system, higher education policy makers must keep in mind underlying objectives of innovation, quality, equity, and social and cultural pertinence. To achieve these objectives, superficial rhetoric must be permanently cast aside. Doing so, however, arguably represents a serious challenge for many of Latin America's conservative and relatively static institutions. It follows then, that creative tools and processes will be necessary to facilitate a deep and rapid transformation of Latin American's university system. By doing so, Latin America's university system can move forward to generate positive outcomes for Latin American society as a whole. It is within this context that distance and virtual universities can be seen as an alternative to traditional universities, and become drivers of positive social and economic change.

\section{Regional Potentialities and Problems}

From a geographical perspective, Latin America is blessed with an abundance of natural resources. This region of the world is capable of generating tremendous economic wealth and social potential - but this can only happen if these resources are rationally and soundly exploited. Indeed, Latin America's ecology is one of the most diverse on Earth. Here are some statistics to support this assertion:

- Latin America's diverse geography is comprised of humid tropical rain forests, including the Amazonian region, which alone produces approximately 42 percent of the Earth's vegetal biomass and oxygen, life sustaining elements that regenerate our planet's air, soil, water. This statistic can be compared to only 14 percent generated by temperate forests in other continents.

- Three large basins, the Amazon, Orinoco, and Rio de la Plata, comprise one third of the world's total ground water flow.

- Latin America generates 19 percent of the world hydroelectricity, yet only consumes 21 percent of its total hydroelectric generation capacity. In simple terms, there is tremendous potential for redistribution and export of hydroelectric energy to other regions within Latin America.

- Latin America also has three percent of the world's fossil fuel reserves such as the oil and gas reserves found in Venezuela, Mexico, and Ecuador. Exploitation these non-renewable resources are projected to last 50 years or more.

- Latin America has 90 percent (736 million hectares) of arable land under cultivation, representing 12 percent of the Earth's biomass currently under cultivation.

- Latin America is home to 46 percent of all the tropical rain forests in the world, and 23 percent of the Earth's forests.

- Latin America yields 17 percent of the world's cattle production.

From a sociological perspective, Latin America is comprised of countries that share similar cultures and common languages. Sharing the use of Spanish dialects and languages, should allow easy access and economic exchange with other Latin American and Spanish speaking countries around the world. From a cultural, political, and economic point of view, such conditions could result in the creation of powerful economic trading block similar to the European Economic Union. In light of the 
tremendous potential of its natural resources and cultural similarities, Latin America must develop and advance its supportive infrastructures, of which its system of universities is a central building block.

Indeed, those countries and regions that currently hold the balance of power have created social and economic systems premised on "information and knowledge" power structures. In simple terms, technological advances are fundamentally changing the nature of human production, a condition which was outlined by Salvador Arriola (1999), the former permanent Secretary of the Latin American Economic System (SELA) ( http://sela2.sela.org/WM2/WMIO.ASP ): "Previously, economic and social development depended on vast quantities of energy, natural resources, work, and capital. Today, it depends specifically on overall knowledge capacity and the information available.”

In contrast with its inherent potential, the reality is that most Latin American countries are facing serious economic develop problems that require prompt and concerted attention. As Tunnermann (1997) observes:

1. Latin America is home to the world's most unequal wealth distribution ("the most extreme distributive polarization in the world," according to the World Bank). On average, the gap between the richest and poorest populations is 10 to15 times greater than that of industrialized countries, where the ratio is currently six (seven in the Asian countries).

2. Of Latin America's 200 million people, 46 percent live in poverty and 94 million people (22 percent of Latin America's total population) live in abject poverty. The President of the International Development Bank (IDB), Enrique Iglesias, explained, "Throughout history, there is not been a country able to become internationally competitive with 40 percent of its population living in situations of low productivity and poverty."

3. At a rate of 2.3 percent per year, Latin America's population is growing more rapidly than other regions. In 2000, the region's population reached 540 million, 70 percent of which live in urban areas. And of that 70 percent living in urban areas, 30 percent live in large cities with over one million people.

4. Latin America is home to four urban megalopolises: Mexico City, Mexico (population: 26 million); Sao Paolo, Brazil (24 million); Rio de Janeiro, Brazil (13.3 million); and Buenos Aires, Argentina (13.2 million). According to the estimates of the United Nations, 90 percent of Latin America's urban populations currently live in extreme poverty.

5. According to SELA, 60 percent of working age adults are either unemployed or are underemployed, usually in informal sectors of the economy, which historically yield low productivity.

6. According to the figures of the United Nations Conference on Trade and Development (UNCTAD), in 1959 Latin America exported 11 percent of the world total exports. By 1970, this figure was 4.8 percent, and by 1999, only 3.6 percent.

7. Between 1981 and 1992, Latin America suffered an overall trade deficit of about 28 percent. 
Over the past two decades, Latin America's population has become increasingly poor and thus economically marginalized. This can be compared to a small but rich population, whose wealth is tied to the international market economy and who represent a true island of modernity surrounded by a human ocean of poverty.

\section{The Challenges for Latin American Universities}

According to Casas (1997) eight fundamentals must be addressed to overcome the current crisis facing many Latin American countries: 1) adoption of knowledge and information technologies; 2) acknowledgement of the growing importance of globalization and the concomitant process of integration created by globalization; 3) increased social equity in terms of higher education opportunities that will allow regions to become and remain competitive in today's rapidly globalizing economy; 4) universities must adopt new educational technologies and developments; 5) universities must acquire modern technologies and infrastructures necessary to positively influence work and overall productivity throughout Latin America's regions; 6) universities must develop and adopt a new set of pedagogical innovations (e.g., virtual learning); 7) universities must re-train professors, researchers, directors, and administrators to enable them to become more productive and effective; 8) universities must adopt new financing and organizational schemes to support advances in technological and pedagogical innovation. In sum, the growing strategic importance of higher education coupled with the need to reorganize and radically transform Latin America's university system, is essential to help Latin America catch up to other countries around the world. This clearly requires an intensive period of transition to help Latin American countries and their populations at first to survive, then to participate in today's increasingly globalize economy.

In light of the formidable and steadily mounting challenges facing Latin American universities today, one must ask: Under current conditions, can Latin America's universities successfully accomplish the extraordinary task of reform? And if so, can they make the transition quickly enough? To answer this question, I look to a number of research-based studies that reach the disturbing and disheartening conclusion that it is unlikely that change will happen soon enough. In his critical report, "The Latin American University," Atcon (1963) maintained that future development of the region must rely upon a deep reform of its university system. If steps are not undertaken or if they are unsuccessful, the stage will be set for the slow and destructive play Atcon called "social dissolution" to take place. Unfortunately, because of the dominating political ideologies of the 1960s and 1970s, this report's recommendations were largely opposed or ignored. For the next thirty years, several studies defined the problems facing universities and suggested "agendas" for the future reconstruction of Latin America's university systems and institutions. Among the most significant research contributions are: Scherz (1964); Ribeiro (1973); Mayz (1984); Brunner (1985); Albornoz (1993); Garcia (1996); Cresalc/UNESCO (1997); Tunnermann (1998), and Garcia (1997).

A useful way to assess a university's importance in the past, present, and future, is to examine its performance in terms of concepts such as quality, innovation, and pertinence.

1. Latin American universities have proven to be rigid and resistant to change and modernization, conditions that are inimical in today's world, which is faced by deep and accelerated economic and social changes. On the other hand, there has been a dramatic increase of student enrollment in Latin America's education system, but unfortunately, without the corresponding changes in structure, procedures, and resources to support such increase in demand. 
2. The organizational model of many universities in Latin America remains that of the "French, Napoleonic model", with independent professional faculties that do not conform the "collective" concept of a "university." Indeed, there is such a great emphasis in professionalism, current models usually operate in an information silo structure; as a result faculty become intellectually and politically insular, with little possibility of cross fertilization and intellectual transfer. In this context, science and research are not usually considered.

3. "The Chair" is currently the fundamental teaching unit, a position which is often insular, unimpeachable, and usually assigned as some teachers' "rightful property."

4. Learning is mainly based on rote memorization. In many instances, one professor's "notes" often form the only source of information students receive.

5. There remains little interest in developing future academic talent in any integrated or concerted manner.

6. Recruitment and selection of academic personnel are usually made based on political appointment.

7. There is little or no opportunity for poor students to enroll and to complete university degrees.

8. There is an absence of serious policies for research, its integration with teaching, and its direct extension to ameliorate critical social problems.

9. There is an overall absence of modern and functional administrative and managerial systems.

10. In many cases, a university's "pertinence” for its particular social context is irrelevant due to a misconception of its autonomy and the interference of political ideologies.

These and many other important arguments formed the basis for conclusions drawn by the Regional Conference of UNESCO held in Havana in 1997. Citing the urgent need to engage in a deep restructuring of higher education in Latin America, it was determined that such process could be carried out according to some orientating principles as follows:

1. University actions and influence should extend beyond its campus through teaching and research activities. Educational extension should be restructured around national needs and conditions, to help countries to grapple with powerful changes brought about by economic globalization. Networks and strategic alliances must be struck, to help integrate and incorporate complementary talent and programs from other national and international institutions.

2. The topic of Latin American integration must be a main theme for interdisciplinary research. For many universities this will require new areas and forms of research.

3. New universities must be established that allow more flexible academic structures. For instance, they must use the "departmental model" as the basic unit for teaching and research, rather than the traditional and often isolated "chair model” currently in use in most educational institutions. 
4. The new "Informatic-Telematic Paradigm" must be integrated into the structure and operation of all university activities.

5. Universities must operate as integrated communities dedicated to research, and the creation and transmission of knowledge and progress - particularly in science and technology - to a broader class of students. Research and teaching must also be grounded within a context that is relevant to the specific needs of Latin Americans on a regional basis. Universities should no longer be merely seen as "teaching institutions," whose sole goal is conferring professional degrees and certifications, but instead as an active member of the "research community," one which proactively seeks ways and means of addressing Latin America's complex socio-economic problems.

6. Creative forms of learning, aided by new and computer and information technologies, can facilitate the radical changes in educational processes. For instance, "virtual learning" is one such form. There must also be a move towards the "model of lifelong learning," rather than the current model where the concentration of learning takes place at the beginning of one's active life.

7. The framework for training and grooming of future academic talent must be established.

In summary, if Latin America's system of universities continue to hold resolutely to the past, and remain resistant to the evolution, adaptation and the changes necessary for participation in today's increasingly globalized economic landscape, it will be difficult to bring Latin America into a prosperous future that reflects its inherent wealth. To bring about the social and economic conditions for full participation of Latin America in today's global economy, universities must embrace a deep and fundamental change that address all the above.

\section{Insertion of Distance Education in Latin America}

Conditions, resources and requirements of modern industrial and technological societies, demand a profound change to the typical paradigm typical in Latin America's educational and training processes (Garcia Aretio, 1994). Although the transformation of the classical paradigm is applicable to all educational levels, it may be regarded as more critical at the university level. However, some educators who are opposed to such a transformation argue that a simpler solution to the problems facing higher education is for each state or country to supply additional resources to expand and increase the university sector. In my mind, this simplistic view falls short because the problems are much deeper and more complex. A first step toward creation of new paradigm is to find the source of rigidity of traditional education and to find solutions to overcome this rigidity in relation to time and

space. The several elements that define and differentiate current distance and virtual education are shown in Figure 1 (Duart and Sangrá, 2000). 
Figure 1. Educational Coincidence in Space and Time (Duart and Sangra, 2000, p. 29).

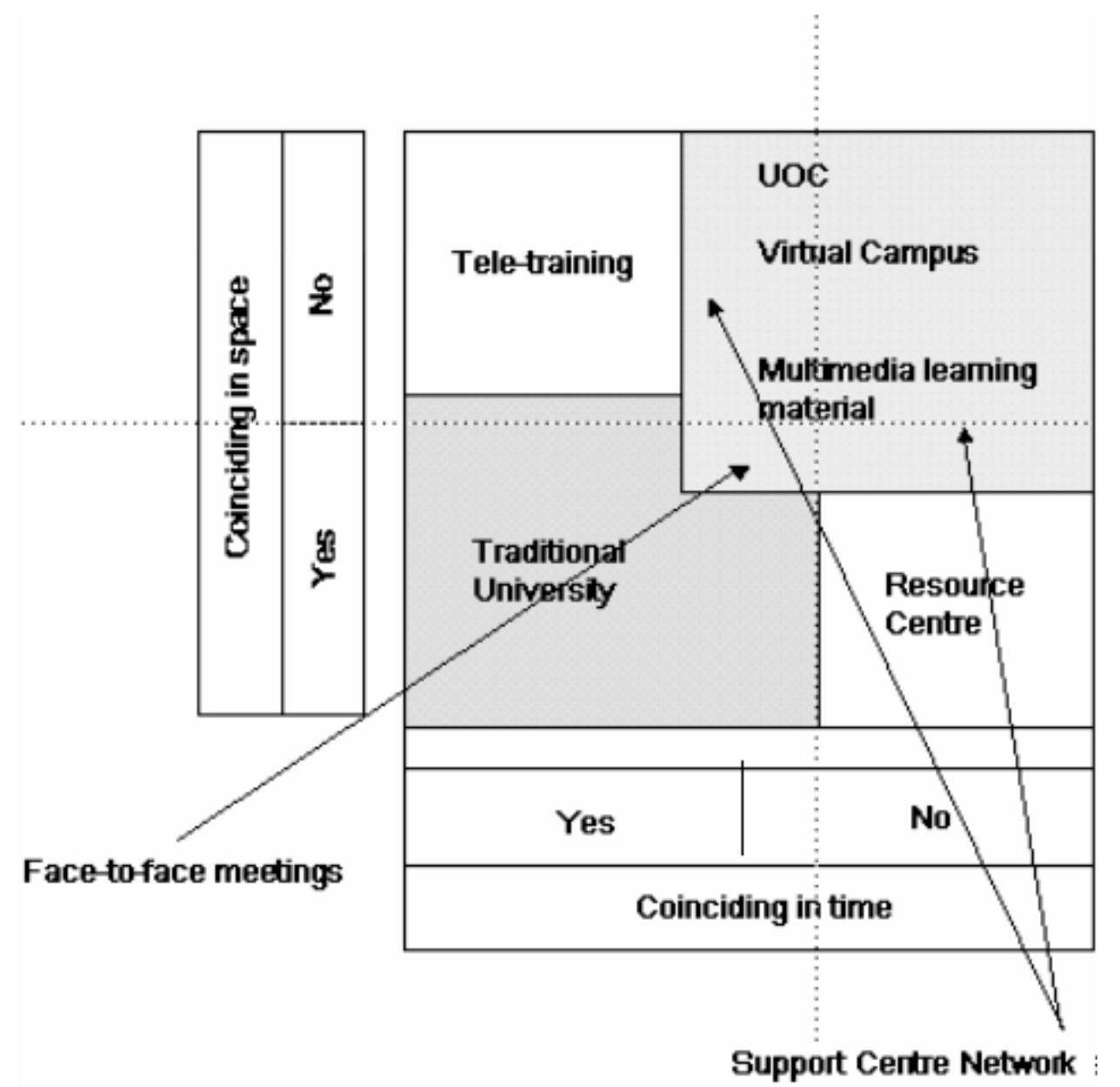

In the search for innovative educational solutions throughout the 1970s, the distance university solution has been progressively building its different structures, procedures, and theoretical frameworks. Although correspondence and radio educational experiences long existed prior to the foundation of the British Open University in 1969, this institution has led to the creation of new distance universities in many countries around the world, including Latin America.

Coupled with the rise of new educational theories and the use of rapidly evolving information and communication technologies, many of Latin America's serious socioeconomic limitations can now be bridged by using open and distance education models. The first two exclusively distance education universities created in Latin America were Costa Rica's Universidad Estatal a Distancia (UNED) and Venezuela's Universidad Nacional Abierta, both established in 1977, and both greatly influenced by the British Open University and Spain's Universidad Nacional Estatal (UNED), which was established in 1972. Prior to this, Mexico had led the way through the development of some important distance learning programs for secondary level education known as "Telesecundaria” in 1971; and at the higher education level, the Autonomous University of Mexico (UNAM) in 1972, both of which were also greatly influenced by the "Open University System,” developed by different professional faculties. In 1996, a private technological institution, Technological Institute for Advanced Studies in Monterrey (ITESM), founded its "Virtual University" based on their experiences, resources, and access to high technology. Their services have now been expanded beyond Mexico to 
other Latin American countries. Following the creation of the universities outlined above, numerous distance education programs have been developed through existing on-campus universities, with heterogeneous characteristics.

\section{Twenty-Five Years of Distance Education in Latin America: A critical view}

During the early years of distance universities and programs, most Latin American politicians and educators viewed the distance education modality as a "remedy" for those who lacked the conditions or economic opportunity to engage in "real" face-to-face studies at a traditional campus-based university. Some felt distance education could reduce costs and provide access to help satisfy increasing demand for higher education throughout Latin American society as a whole. Distance education in this context, however, was usually perceived as a second rate solution to address the training and educational needs of the poorer social classes. Today, these beliefs have changed radically. Distance education is now considered to be the most important educational phenomenon of the 20th and 21st centuries. However, it is also recognized that distance education must be socially relevant and provide the conditions for high quality student achievement. When both conditions of social relevance and high quality student achievement are not duly satisfied, the result is just a massive wave of mediocrity papered with "fake" diplomas - a dangerous condition that holds with it the real potential of hindering positive social progress.

During the initial phase of Latin America's distance universities and programs in the 1970s, the theoretical foundations and purposes were generally well conceived and delineated. However, over time, "content" became the major source of pedagogical concern, unfortunately at the expense of aspects related to distance education design, production, principles, conditions, and evaluation procedures. The net result was a step backwards as the re-establishment of traditional face-to-face courses took preference, albeit with labels borrowed from distance education. This is a clear example of the difficulties inherent during the transition from traditional "present" paradigm, to the new informative-telematic distance learning paradigm.

In some Latin American, cultural traits have become obstacles for experimentation and improvement of distance education. These cultural traits are: a) illusion, b) nominalism, c) postponement, and d) simulation.

a) The distinction between expectations and reality creates an illusion that one is actually being educated.

b) Nominalism assumes that one thing is real only because it has a name. For instance, many programs are labeled "distance education," only because it is considered "fashionable," not because it is actually designed as a distance education course of studies. One such recent instance has been the extended use of the virtual university and virtual learning.

c) Postponement occurs when decisions are slowed down by constant delays.

d) Simulation is the dynamic of concentrating main efforts in one area, giving a misleading appearance of the real thing. 
Planning, research, and evaluation are basic activities required for upholding and preserving the quality and pertinence of any distance university or program. Unfortunately, in the majority of distance Latin American universities, these activities have been neglected mainly because, in practice, they are "teaching universities." Research, on the other hand, requires a team of efficient researchers, something generally difficult to find in a single institution. In fact, if we regard research as the springboard to innovation and construction of solid institutions, this limitation represents one of the most significant obstacles currently facing the advancement of Latin American distance universities.

Many of the problems of Latin American distance universities and programming stem from their incapacity to transform and update their organizational structure, learning processes, recruitment policies, and professional development of their teaching staff. This is a relevant concern, because most are still anchored to the so-called "second generation" of distance education (as defined by Taylor, 1999).

The lack of modern ideas of world globalization and virtualization of universities are still critical issues facing the Latin American context, greatly affecting and undermining the possibilities for substantial change.

At the 2001 meeting of the Ibero-American Association of Distance Higher Education (AIESAD), it was determined that improvement in the quality and advancement of distance education for this region requires correction of such problems as: 1) he lack of norms to regulate proposals, stimulate best practice, and prosecute fraud; 2) tendency to reproduce traditional educational practices in distance education; 3) distrust of some governments regarding their policy on distance education; 4) problems with authors and academics in relation to intellectual property rights; 5) low levels of inter-institutional cooperation; and 6) lack of international agreements that formally recognize programs of learning and govern transfer of academic credits and degrees.

The critical problems requiring answers in Latin American distance universities can be classified as both "general problems" and "specific problems." General Problems comprise tendencies toward improvisation instead of sound planning, development of workable programs without any follow-up, technological / cultural immaturity, resistance to innovation, and political "clientele-ism." Specific Problems comprise high student dropout rates; obsolescence of instructional materials and evaluation methods; low levels of student-to-professor and student-to-student interaction; lack of social pertinence of educational programs; obsolete and inappropriate preparation of professors, researchers, executives, and administrative personnel; dysfunctional organizational structures for distance education unable to meet new academic, social and scientific demands.

\section{Global and Prospective View of Distance Education in Latin America}

Some Latin America countries have distance universities and programs of high quality and concomitant productivity, but they are the exception rather than the rule. However, distance education is still recognized as one of the most important means to generate socio-economic transformation; but to achieve this ideal, present limitations must be overcome and a fundamental restructuring of current organization and procedures needs to be carried out, and without delay. Open and distance learning should not be considered important merely because of the sound of its name or worldwide popularity, but rather because of the quality of its learning, fairness and relevance of its academic 
programming, and its positive effects on other segments of Latin America's educational systems. Moreover, expectations must not be mistaken for reality. The enormous potential of distance education for the Latin America region cannot be achieved overnight. Rather, favorable pre-conditions must be created in order to promote effective learning and knowledge through distance modalities.

Distance education in Latin America, rather than being considered a second rate educational complement for traditional higher education, must be seen as a fundamental engine for restructuring other university systems, especially the public ones. Thus, the entire university sector could foster an effective transformation of their corresponding societies (Casas and Stojanovic, 1999). In this respect, it is important to keep in mind the extraordinary development of computer science and communication technologies that are positively changing the potentialities of Open and Distance Education. Space, time, large scale operation, significant cost reduction, effective support of learning quality - all available through the use of new and emerging information and communication technologies - offer new solutions for advanced planning, production, operation and evaluation techniques. Important changes are being heralded for distance education for Latin America, so long as their systems and institutions have the capacity to implement creative new approaches that recognize and take into consideration their particular worldviews. If the contradiction between diplomas and knowledge is solved in favor of the former, distance education will just be one more "excellent idea," but only for historical record. Here are some ideas are suggested for the restructuring and modernization of Latin American distance education:

- Virtualization, in the form of tapping into the extraordinary educational possibilities offered through the use of new technologies. In this complex process, technologies are used as a means to support the pedagogical principles that underlying effective learning

- Convergence through the use of progressive integration of traditional on-campus and distance universities

- Expansion and consolidation of research at the graduate level as a basic requirement for innovation of distance education modalities that take into consideration the socio-economic condition of the region in which it will be deployed

- Continuous evaluation and accreditation by external boards representing universities, government, and industry at a regional level

- Transformation and consolidation of educational initiatives throughout Latin America. High-caliber inter-institutional and interdisciplinary centers must be created for the training, preparation, and accreditation of academics, directors, and administrative personnel in their use and understanding of distance education modalities

- Establishment of new organizational and functional structures for distance education. Special attention must be given to aspects forming strategic alliances, networks, confederations, etc., and the integration of distance and traditional oncampus universities, public and private, regionally, nationally, and internationally

- Adoption of effective managerial methodologies and procedures - from financial planning to curricula and student evaluation 
As a synthesis of this global and prospective view, one must emphasize that distance universities and programs throughout Latin America have now reached an historical crossroads. To take full advantage of its extraordinary power to generate the fundamental changes required of other educational systems, a prompt and profound restructuring of Latin America's existing distance education system is necessary. If decisive actions continue to be postponed, Latin America's future certainly will be more dismal than it already is.

\section{References}

Albornoz, O. (1993). Education and Society in Latinamerica. Pittsburg PA.University of Pittsburg Press.

Arnove, R. F. (Ed.) (1999). Comparative Education. The Dialectec of the Global and the Local. Oxford: Rowman and Littlefield:

Bates, A. W. (2000). Teaching, Learning, and the Impact of Multimedia Technologies. Boulder CO.: Educause Review. September/October.

Brunner, José Joaquín. (1985). Universidad y Sociedad en América Latina. Un Esquema de Interpretación. Caracas: Cresalc.

Casas Armengol, M., and Stojanovic, L. (1999). Educación a Distancia: Una fuerza decisiva para la reestructuración de la Universidad Latinoamericana. Trabajo presentado a la XIX Conferencia Mundial del ICDE. Vienna.

Casas Armengol, M. (2000a). "Ilusión versus Realidades: Viabilidad de la Universidad Virtual Latinoamericana.” Trabajo presentado a l Conferencia Internacional, Online Educa Madrid 2000: Madrid.

Casas Armengol, Miguel (2000b). Nuevas Fuerzas de Globalización y Virtualización en las Universidades Latinoamericanas. Trabajo presentado en la Conferencia Internacional del Décimo Aniversario del CREAD: Caracas.

Cresalc-Unesco (1997). Hacia una nueva educación superior. Actas dela Conferencia Regional sobre Políticas y Estrategias para la transformación de la Educación Superior en América Latina y el Caribe. Cresalc/ UNESCO: Caracas.

Daniel, J. S. (1996). Universities and Knowledge Media. London: Kogan Page.

Duart, J. M. (2000). Aprender en la Virtualidad. Barcelona: Gedisa.

Garcia Aretio, L. (2001). La Educaciòn a Distancia. De la Teoría a la Práctica. Barcelona: Ariel Educación.

Garcia Guadilla, C. (1996). Conocimiento, Educación Superior y Sociedad en América Latina. Caracas: Cendes-Nueva Sociedad.

Garcia Guadilla, C. (1997). El valor de la pertinencia en las dinámicas de transformación de la educación superior en América Latina. En La educación Superior en el Siglo XXI. Visión de América Latina y el Caribe. Caracas: Cresalc/ UNESCO. 
Armengol - Global and Critical Visions of Distance Universities and Programs in Latin America

Harasim, L. (2000). Redes de Aprendizaje. Barcelona: Gedisa.

Kent, S. R., and Devries, W. (1997). Evaluación y Acreditación de la Educación Superior Latinoamericana: razones, logros, desafíos y propuestas. En La educación superior en el Siglo XXI. Visión de América Latina y el Caribe. Caracas: Cresalc/ UNESCO.

Mayz Vallenilla, E. (1984). El ocaso de las Universidades. Monte Avila ed: Caracas.

McLaren, P. (1999). Critical Education in the Information Age. Oxford: Rowman and Litlefield.

Mason, R. (1998). Globalising Education. Trends and Application. London: Routledge.

Moore, M. G., and Kearsley, G. (1996). Distance Education: A Systems View. Belmont CA.: Wadsworth Publishing Co.

Ribeiro, D. (1973). La universidad nueva. Un proyecto. Buenos Aires: Editorial Ciencia Nueva.

Schank, R. (1997). Virtual Learning. New York: McGraw-Hill.

Sherz Garcia, L. (1964). Una nueva universidad para América Latina. Universidad del Zulia: Maracaibo.

Silvio, J. (2000). La Virtualización de la Universidad. Como podemos transformar la educación superior con la tecnología Caracas: Iesalc/ UNESCO.

Taylor, J. C. (1997). Distance Education: The Fifth Generation. En XIX Conferencia Internacional del ICDE. Vienna, Austria.

Tunnermann Bernheim, C. (1997). La Educación Superior en América Latina y el Caribe, en su contexto económico, político y social. En Hacia una nueva educación superior. Cresalc/ UNESCO: Caracas.

Tunnermann Bernheim, C. (1998). La Educación Superior en el umbral del Siglo XXI. Segunda Edición. Caracas: Cresalc/ UNESCO.

UNESCO/ Cresal (1992). Calidad, Tecnología y Globalización, en la Educación Superior Latinoamericana. Caracas: Cresalc/ UNESCO.

Yarzábal, L. (1999). Consenso para el cambio en la Educación Superior.Ed. Caracas: Iesalc/ UNESCO.
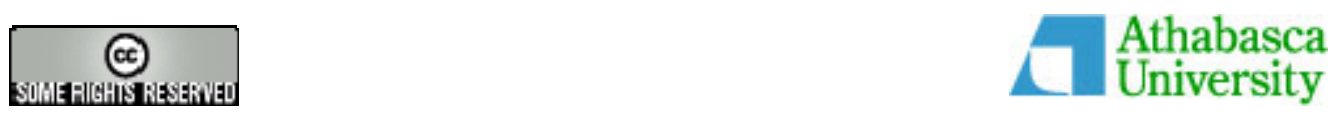


\title{
A Study of the Relationship Between Tutor's Personality and Teaching Effectiveness: Does Culture Make A Difference?
}

\author{
Bobbie Chan \\ Open University of Hong Kong
}

\begin{abstract}
Good tutoring requires appropriate interpersonal and pedagogical skills. Tutor personality is a major factor affecting how tutors communicate and deals with students, and yet it is a largely unexplored context of distance education. Using the Chinese Personality Assessment Inventory (CPAI)* this paper examines how the personality of tutors' affects their teaching effectiveness at a distance learning institution in Hong Kong. The results are compared to those reported by Chan (2001) in a similar study using the Myers-Briggs Type Indicator (MBTI). The results indicate that certain scales on the Chinese Tradition factor of the CPAI are significantly related to tutors' teaching performance, and that the MBTI could not subsume all the CPAI scales. Future research with the CPAI should explore whether this Chinese Tradition factor is unique to the Chinese culture or whether it comprises elements of a universal domain useful in understanding key interpersonal aspects of personality that have been absent from Western personality inventories.
\end{abstract}

Keyword: Chinese Assessment Inventory; tutor effectiveness; Myers-Briggs Type Indicator; personality; Chinese

\section{Introduction}

Special thanks to the developers of the Chinese Personality Assessment Inventory (CPAI): Prof. Fanny Cheung, Prof. Kwok Leung, Prof. Song Weizhen, Dr. Zhang Jianxin, and Zhang Jianping, who granted permission to use the instrument for this study.

Education involves human relationships; human interaction and distance education is no exception. During the past few decades, distance education has become an increasingly popular and widespread mode in response to adult learners' need for individualized and decentralized educational opportunities. Tutors and tutorials are important components within a distance education system. Distance education providers offer structured materials to guide students, enabling them flexibility in choosing where and when they study. Tutors act as a crucial link between the University and its students, and tutorials provide a great opportunity for face-to-face interaction between and amongst students and their tutors.

Tutors are content experts who must cope with heterogeneous student group(s). Distance learners are mostly working adults and tend to be more intrinsically motivated than their younger counterparts (Harper and Kember, 1986). Distance learners also tend to rely 
Chan - A Study of the Relationship Between Tutor's Personality and Teaching Effectiveness

more on a deep learning approach than school-leavers, who mainly rely on rote learning (Watkins and Hattie, 1981; Watkins, 1983). As Beaudoin (1990) states, tutors engaged in distance education must be adept at facilitating students' learning by paying particular attention to process, rather than their work being confined to selecting and sharing content. Building on previous research findings that the environment is, to a large extent, influenced by the teacher (e.g., Deci, Schwartz, Sheinman, and Ryan, 1981a; Deci, Nezlek, and Sheinman, 1981b), this paper defines an effective tutor as the one who uses autonomy-supportive strategies instead of controlling strategies to assist students to become independent learners.

Good tutoring requires a repertoire of appropriate interpersonal and pedagogical skills. Tutor personality is a major factor affecting how they communicate and deal with their students; however, it is a largely unexplored context of distance education. Using the Myers-Briggs Type Indicator (MBTI), Chan (2001) investigates the impact of personality types of tutors on their teaching effectiveness at a distance learning institution in Hong Kong. The results revealed that tutors characterized by a high degree of extraversion were more effective in the classroom environment. Yet no statistically significant difference was found with respect to other personality dimensions. The MBTI is probably the most widely used personality measure in occupational and counseling psychology. However, because it was developed in the West, most studies using this measure have been restricted to North American contexts. Whilst the use of MBTI did not yield particularly significant result in Chan (2001), this paper replicates that study using the Chinese Personality Assessment Inventory (CPAI), which consists of personality constructs of specific interest to people of Chinese culture - personality constructs not covered in most of the translated personality inventories. The aim of this paper is to explore whether a culturally specific instrument will be a more comprehensive measure, one that works to reveal particular distinctive factors in the relevant culture.

\section{Tutor's Roles, Personality, and Classroom Environment}

The concept of self-learning is heavily emphasized in distance education. Tutors are leaders, facilitators, and coaches of their tutorials (Barrows, 1992). Aspects of tutors' role in tutorials encompass answering queries, clarifying points, diagnosing misconceptions, providing alternative explanations, assisting students to relate material to their individual situations, and helping with the application and practice of principles. Another important aspect of tutors' role is that of assisting students to become independent learners. With tutor guidance, students can be encouraged to dig deeper and to explore the unknown to support their ideas, thoughts, comments, and feelings. How tutors teach is critical to learning, and how they create and foster learning environments that promote creative thinking and problem-solving skills in students is of vital importance. For example, tutors' use of diverse methods and strategies in presentation of subject content, in leading discussions and debates, and in encouraging small group interactions, helps to nurture student curiosity. These approaches encourage students to study issues from contrasting views. An innovative tutor can create ways to build mutual successes between themselves and students. Therefore tutors must be able to tolerate new ideas and differences of opinion. They must also be willing to venture fresh avenues of teaching and learning, and consider what triggers, inspires, and motivates students' intellectual and individual interests (Barrows, 1992).

Tonelson (1981) suggests that teacher personality can affect student learning outcomes via the psychological environment of the classroom. Research indicates that a teacher's motivating style is an important educational construct (Deci et al., 1981a; Ryan and Grolnick, 1986) because it affects students' developmental and academic outcomes (Deci 
and Ryan, 1987; Deci, Vallerand, Pelletier, and Ryan, 1991; Reeve, 1996). Yet how do teachers motivate students in their studies? A number of researchers (e.g., Deci et al., 1981a; Reeve, 1998; Ryan and Grolnick, 1986) suggest that teachers motivate students using interpersonal styles that range from highly controlling to highly autonomous and supportive. Highly controlling teachers use rewards, threats, deadlines, etc., to "control" student learning outcomes. The teacher's goal is to control students' goals and behaviours toward a prescribed end. On the other hand, relatively autonomy/ supportive teachers encourage students to pursue self-determined agendas, and foster and support students' initiatives and intrinsic motivation (Deci et al., 1981b). Their goal, in this instance, is to strengthen students' autonomous self-regulation.

In order to become independent and to develop the ability to solve problems and to be able to learn on their own, distance learners must not be put into passive learning situations where tutors determine what should be learned, to what depth, and in what sequence (Barrows, 1992). Instead, students must practice dealing with problems and learn to identify what they need to learn. To facilitate student independence and foster students' critical thinking and self-directed continuous learning, tutors should guide students in their thinking, stimulating them to be reflective, carefully reasoning thinkers not impulsive ones. Students should become independent problem solvers and selfdirected learners. In this regard, effective tutors in a distance education system should adopt autonomy-supportive strategies, which seem to be more appropriate than controlling strategies in teaching distance learners.

Compared to students who have been taught by controlling teachers, students with autonomy/ supportive teachers report greater perceived academic competence (Deci et al., 1981a; Ryan and Grolnick, 1986), higher academic intrinsic motivation (Deci et al., 1981), greater creativity (Amabile, 1979; Koestner, Ryan, Bernieri, and Holt, 1984), more mastery motivation (Ryan and Grolnick, 1986), preference for optimal challenge (Pittman, Emery, and Boggiano, 1982; Shapira, 1976), greater conceptual understanding (Benware and Deci, 1984; Flink, Boggiano, Main, Barrett, and Katz, 1992; Boggiano, Flink, Shields, Seelbach, and Barett, 1993; Grolnick and Ryan, 1987), positive emotionality (Patrick, Skinner, and Connell, 1993; Ryan and Connell, 1989; Williams, Weiner, Markakis, Reeve, and Deci, 1994), lower dropout rates (Vallerand, Fortier, and Guay, 1997), as well as higher academic performance (Boggiano et al., 1993) and achievement (deCharms, 1976; Flink et al., 1992). Indeed, Kagan and Grandgenett (1987) observe that a sizeable body of empirical research reveals consistent relationships between teachers' personality traits and their preferred instructional style. For example, Lorentz and Coker (1977) found significant relationships between teachers' scores on the MBTI and the behaviour of their students, concluding that teacher personality influenced the way in which students reacted in class. Using the MBTI and another instrument, Fisher and Kent (1998) found significant associations between teacher personality type and perceptions of classroom environment. For example, both students and teachers perceived greater student cohesiveness in classes taught by extraverted teachers.

Whilst these studies are related to teaching and learning in high schools, personality characteristics and classroom management behaviours seem to be related in particular patterns. Barrett (1991) shows that certain personality types have a positive relationship to a number of important teaching effectiveness competencies and that certain styles have greater ease or difficulty in achieving high effectiveness scores. Hamza and Nash's (1996) study shows that teachers of particular character traits are better able to foster a learning environment that promotes creative thinking and problem solving skills. 
Chan - A Study of the Relationship Between Tutor's Personality and Teaching Effectiveness

\section{The Cross-Cultural Challenge}

Historically the study of personality, groups, leadership, and other topics of organisational behaviour have largely been a North American endeavour and for years researchers have asked whether or not particular personality traits are found universally. Meanwhile, the use of personality assessments were imported from the West to Asia in the 20th century. However, there has been severe criticism of validity and reliability problems associated with a blind importation of Western instruments into non-Western countries (e.g., Cheung, 1996).

Bond (2000) cites three reasons that the importation of personality theories from the US to other countries should be rejected. First, the measure and the relevant theory will affect the development of a local theory. Second, the receiving culture may not have the necessary support for translating and interpreting such a test and extending its theories into their new cultural territory. Consequently, the imported constructs and measures may not be as appropriate as indigenous instruments or theory in predicting key outcomes. Third, the imported instrument and its theory may not fully encompass the local reality associated with a concept.

A challenge for cross-cultural personality assessment is to construct an inventory suited to the local needs while retaining the standards of validity and reliability expected of established assessment instruments (Cheung, 1996). Often people fail to address the issue of the omission of important culture-specific constructs that are indigenous to a particular culture (Church, 1987). If the purpose of a personality inventory is to provide a reliable and valid assessment instrument within a particular culture rather than to investigate cultural universals, then we need an inventory that includes the major culture-specific personality domains in addition to the culture-comparable personality constructs. Leung and Zhang (1995), after a review of various viewpoints, conclude that indigenous research and theorizing, as well as research that integrates different cultural perspectives, are crucial to the establishment of more useful and universal psychological theories.

\section{Chinese Personality Assessment Inventory (CPAI)}

In the early 1990s, Cheung and her colleagues began developing a Chinese Personality Assessment Inventory using self-referent statements about beliefs, attitudes, values, and behaviours to describe personality for both normal and diagnostic assessment (Cheung, 1996).

The personality constructs included in the CPAI were derived from groups of personality adjectives or descriptions reflecting daily experiences. The sources of these adjectives include a selection of popular contemporary Chinese novels, books on Chinese proverbs, informal surveys to obtain statements of self-descriptions by people in the street, and statements of other-descriptions by professionals, managers, teachers, and health workers, as well as the research literature on personality of the Chinese people (Cheung et al., 1998, p.4).

The CPAI is an extensive personality questionnaire developed by indigenous psychologists in a deliberate attempt to include culture-specific indigenous content. They have taken special care to include "the emic personality characteristics that were deemed to be of specific interest to the Chinese culture, but are not covered in imported personality inventories” (Cheung et al., 1998). The final version of the CPAI consists of 
524 items, comprising 22 personality scales, 12 clinical scales, and three validity scales or indexes. By factor analysis, the 22 personality scales have been reduced to four personality factors, labeled as Dependability, Chinese Tradition, Social Potency, and Individualism (Table 1). Cheung et al. (1998) have studied the degree of overlap between CPAI and the Revised NEO Personality Inventory (Costa and McCrae, 1992) and the results show that the indigenously developed instrument broadens the definition of the personality sphere relative to the imported NEO-PI-R. It has been found that the unique dimension of personality from the CPAI is Chinese Tradition. Cheung et al., regard four of its facets - Ren Qing (Relationship Orientation), Flexibility, Harmony, and Face - as defining unique aspects of personality. These facets of Chinese Tradition have no counterparts in the NEO-PI-R and therefore would have been missed in operationalization of the personality sphere provided by the imported measure (Kwan and Bond, 1997).

The finding of a distinct indigenous factor of personality variation in Chinese populations raises some fascinating points. With respect to the Cheung et al. (1998) research, it is interesting to examine whether the distinctive facets of Chinese Tradition supplement the apparently universal Big Five or MBTI personality factors; and whether local constructs that are shown to be empirically distinct from relevant imported material add predictive power to the imported constructs.

\section{Indigenous Personality Constructs on the CPAI}

In the development of the CPAI, consideration was given to Chinese culture in general and to the specific socio-cultural contexts of the PRC and Hong Kong. The following are six personality constructs that were deemed to be of specific interest to Chinese culture, but that were not covered in most of the translated personality inventories (Cheung, 1996).

\section{Harmony}

Harmony measures one's inner peace of mind, contentment, as well as interpersonal harmony. The avoidance of conflict and maintenance of the equilibrium are considered virtues in Chinese culture. This aspect of social behavior has been discussed extensively by Chinese social psychologists in conjunction with studies in conflict avoidance and conflict resolution (Bond and Hwang, 1986; Bond and Wang, 1983).

\section{Renqing}

This is a more complicated social relationship concept in the Chinese culture. Hwang (1987) describes Renqing as social favors that are exchanged in the form of money, goods, information, status, service, and affection according to an implicit set of rules. However, this set of rules is dependent upon the category of social ties between the individuals involved in the interaction. In this sense, the Renqing scale measures the individual's adherence to cultural norms of interaction based on various standards of social exchange. The forms of interaction involve courteous rituals, exchange of resources, reciprocity, maintaining and utilizing useful ties, and nepotism.

\section{Ah-Q Mentality}

This consists of a pattern of defense mechanisms depicted in the caricature of $A h-Q$, a well-known fictional character in Chinese literature in the early 20th century, upon which 
the personality construct is based. Defense mechanisms include self-protective rationalizations, externalization of blame, self-enhancement, and belittling others' achievements. In the True Story of $A h-Q$ by Lu Hsun (Lu, 1976), the character of $A h-Q$ was meant to satirize the personality shortcomings of traditional Chinese people. To a certain extent, a mild degree of $A h-Q$ mentality is accepted as a protective mechanism against defeat and disappointment.

\section{Graciousness}

Graciousness is a Confucian virtue characterized by patience, forgiveness, acceptance of self and others, and self-sacrifice, as opposed to the mean and calculating characteristics of cynicism, vindictiveness, and negativism. This virtue resembles the values of patience, courtesy, and kindness found in the "human-heartedness" factor of Bond's Chinese Value Survey (Hofstede, 1991)

\section{Veraciousness-Slickness}

This is a personality dimension often used by Chinese people to judge the trustworthiness of a person. Veracious individuals are loyal and honest, keep their feet on the ground, work hard without pretense, uphold their principles, and sacrifice their personal interests for the group. However, people who are overly veracious may be inflexible and not able to adapt. On the other hand, slick people are not to be trusted because they tend to be too smooth and tactful, always try to please others, and would change their principles to fit their objectives.

\section{Face}

Face is a dominant concept in interpreting and regulating social behaviour in Chinese culture. Although the concept of Face has universal applicability (Ho, 1976) and has been defined by the Western sociologist Goffman (1955) as "an image of self delineated in terms of approved social attributes," Bond and Hwang (1986) point out that what constitutes a desirable Face is specific to the culture. In Chinese culture, the concept of Face is more interpersonally connected. The protection and enhancement of Face are "more disciplined by concerns about hierarchical order in Chinese culture" (p.249). In the CPAI, the Face Scale covers the concern for maintaining Face and social behaviours that enhance one's own Face and that avoid losing one's Face. Too much emphasis on Face, as in the case of slickness, will lead to superficiality.

\section{Methodology}

\section{Sample}

Data for the present study were collected from tutors and students on different courses offered by the Open University of Hong Kong. Form B of the Chinese Personality Assessment Inventory (CPAI), consists of 352 items, was sent to the 59 tutors who had completed and returned the MBTI in an earlier study (Chan, 2001), of which 57 were completed correctly, thus constituting a 96.6 per cent response rate. The same set of data obtained from 1,106 students with respect to their evaluation of tutors' teaching performance was also used for this paper. 


\section{Procedure}

As indicated in Chan (2001), 110 tutors were administered a self-rating personality instrument (the MBTI) at the start of a semester, and 59 tutors completed and returned the questionnaire. In addition, a teaching evaluation questionnaire was distributed to their students during a tutorial session by the end of the semester. In order to examine the difference, if any, when a different measure was used, all 59 tutors were administered the CPAI during the same semester. The same set of data on students' evaluation of tutors was also used. All response forms from tutors were returned directly to the researcher for scoring and report generation. The scoring was done with the use of a scoring syntax using SPSS programs.

Before completing the questionnaires, all participants were given formal written information regarding the purpose of the assessment process and the manner in which the feedback and personality results would be used. They were also instructed to be as open and honest in their ratings as possible. Tutors were assured that their preference scores would be reported only in aggregate form, and that their unique scoring would not be released to anyone, not even their course coordinator. The procedure was conducted in this manner to ensure the confidentiality of the assessments and thus to enhance rater motivation and the subsequent validity and utility of the feedback data collected. Although these conditions do not guarantee the absence of biases entering into the rating process, they do provide an acceptable level of confidence in the integrity and accuracy of the data obtained.

\section{Measures}

The CPAI was completed by tutors, and the Teaching Evaluation Questionnaire (TEQ) completed by their students in the earlier study (Chan, 2001), was again used for this study. As noted above, the CPAI is a personality measure developed by Cheung et al. (1996). It was chosen for classifying psychological type in this paper because it is a unique measure with scales that were deemed to be of specific pertinence to Chinese culture, but were not covered in imported personality inventories.

The TEQ was designed exclusively for Chan (2001) and the present study. It was based on a combination of prior behavioural research differentiating between the performance of teachers (Fernandez and Mateo, 1992; Gaski, 1987; Wagenaar, 1995). The opinions of tutors, students, as well as expert colleagues, were also sought in the design of the questions. The instrument contains twenty-seven items pertaining to various aspects of teaching behaviour, including fifteen items designed to evaluate tutors' teaching strategies/ styles that ranges from highly controlling to highly autonomous and supportive. For each item, respondents were asked to rate their tutor using a scale from 1 to 5 (where 1 = almost never and 5 = almost always) on the degree to which that tutor engaged in a given behavioural practice, such as:

- Praises students for good ideas or useful contributions

- Welcomes imagination, creativity and new ideas

- Stimulates students to think independently

- Communicates the purpose of each class session and learning activity

- Presents ideas in an interesting way

- Shows enthusiasm in teaching; treats students with respect

- Manages classroom discussions so that they are a useful part of learning experiences 
Chan - A Study of the Relationship Between Tutor's Personality and Teaching Effectiveness

- Acts as a member of the group rather than an autocratic leader, etc.

\section{Results and Discussion}

The result obtained from a principal components factor analysis on the behavioural ratings student data is shown in Table 2, which summarises result of the factor analysis of the TEQ. It yielded four independent and distinct dimensions of teaching effectiveness (all with eigenvalues greater than 1.0). Based on the item content, these factors were labeled as: motivation, presentation, attitude, and interaction. The fifteen items designed for testing degree of autonomy-supportiveness were found to belong to subscales of 'motivation' and 'interaction' respectively. Overall, this four-factor solution accounted for 58.1 per cent of the total variance in behaviour ratings, with the largest portion (43.3 per cent of the variance) represented by the motivation factor. This finding, in and of itself, highlights the singular importance of autonomy-supportive dimension involved in the evaluation of teaching effectiveness within the context of distance education - the support of students' initiatives and intrinsic motivation is of vital importance.

Subscales were calculated for each of these factors for further analysis. Calculated reliability quotients were all within an acceptable range (.78 to .87). Next, item analysis using the reliability analysis procedure was carried out to decide which items to exclude from each sub-scale. Two items were deleted from subscale of 'motivation' and one from 'presentation.' Reliability quotients increased and fall within the range .78 to .91.

An independent sample t-test was carried out to evaluate the difference between the means of the four subscales and each of the 22 personality dimensions. As teaching effectiveness can be affected by various independent factors other than personality, such as tutor's age, gender and cultural background, a $p$ value less than 0.10 was adopted as a criterion in this study. The result indicated that four personality dimensions are significantly related to tutors' teaching performance: Renqing, Face, Harmony and Leadership (see Table 3). Each personality type, however, contributes to make to the effectiveness of the tutorial process. Obviously, this does not imply that other factors were not important. Each is discussed as follows:

\section{Renqing}

The result shows that tutors with high score on Renqing were evaluated by their students as significantly better than those less concerned about Renqing in terms of motivation, presentation and attitude $(t=1.963, p<.1 ; t=1.869, p<.1$; and $t=2.209, p<.05$ respectively).

Renqing is one of the commonly accepted social norms regulating Chinese interpersonal relationships, and it has three different meanings in Chinese culture (Hwang, 1987). First, it indicates the emotional responses of an individual confronting the various situations of daily life. In this sense, Renqing is closely related to the Confucian concept of behavioral propriety, which stresses the social responsibility of individuals to be aware of and behave according to certain prescribed rules of behaviour. If an individual can understand other people's emotional responses to various life circumstances, then such a person is well versed in Renqing. If a person is accused of "understanding no Renqing," it means that this person is incapable of managing interpersonal relationships. Renqing is a kind of favour with the inclusion of a sentimental element. It can be interpreted as "human feelings" which covers not only sentiment but also its social expressions such as the offering of congratulations or showing of sympathy. Such expressions are likely to be 
associated with perceptions of being supportive and friendly. Accordingly, it is not surprising to find that tutors who rank highly on Renqing, were perceived by students as better than those less concerned with Renqing in terms of motivation and attitude.

Second, Renqing is a resource that an individual can present to another person as a gift during the course of social exchange.

Third, Renqing connotes a set of social norms by which one has to abide in order to get along well with other people in Chinese society. This norm includes two basic social behaviours: 1) one should keep in contact with the acquaintances in one's social network; and 2) when a member of one's network gets into trouble or faces a difficult situation, one should sympathize, offer help, and "do a Renqing” for that person. In this sense, Renqing is closely intertwined with guanxi. Since Renqing involves social exchanges, there is an inherent obligation for people to keep equity in mind. For example, it will be highly possible for this tutor to entertain students' request for extension in submitting assignments, and he or she would tend to be patient in dealing with students'queries, clarifying misconceptions, etc. Having rendered such a Renqing to a student, the tutor may, however, also expect to receive in reciprocity, a positive evaluation from student that can boost his or her reputation. Therefore, Renqing is best translated as 'humanized obligation,' which implies that a continued favor exchange with a sentimental touch is involved.

Cross-cultural research has shown that, in comparison with their American counterparts, Chinese subjects tend to be more collectivist in contrast to the general individualistic orientation of Americans (Hofstede, 1980). Research also indicates that Chinese are bound by the social obligation to help others who need help in the social group to which they belong (Huang and Harris, 1974). Hwang (1987) suggests that in Chinese society, many people like to make the best of the special qualities of the mixed tie by cutting a figure of power in order to impress others. This, they hope, will place them in a favourable position for any future allocation of some others' resources. Thus the person who allocates resources (the tutor in this case) has to take the rule of Renqing into account whenever he or she is asked to distribute a resource in a beneficial way to any other individual sharing the same 'network.'

\section{Face}

Tutors that rated high on Face were evaluated by their students as significantly better than those less concerned about Face in terms of their attitude of teaching $(t=1.988, p<.10)$.

Face is an individual's public image, gained by performing one or more specific social roles that are well organized by others (Tsang, 1998). The concept of Face and its role in social interactions has been extensively studied since Goffman's $(1955,1956)$ pioneering work. Goffman (1955) conceptualized Face as "the positive social value a person effectively claims for himself by the line others assume he has taken during a particular contact.”

Face is another key element in the development and maintenance of guanxi. According to $\mathrm{Hu}$ (1944), there are two dimensions to the Chinese concept of Face: Lien and Mien-tzu. Lien is good moral character, and carries with it the idea of one being a 'decent human being.' It is more ascribed than achieved. Mien-tzu, as well as meaning the Face physiologically, carries with it the idea of reputation based on one's own efforts. Mien$t z u$ is considered useful but not essential to life and is more achieved than ascribed. 
The concept of Face refers to one's ability to deal smoothly with people. Face-to-Face one's generosity and actions are taken to enhance one's personal prestige and/ or that of their family and social associates (Brunner and Wang, 1989). Face can be gradually increased by personal endeavor such as hard work, political status or connections, personal services benefiting society, superior intellectual knowledge, or skillful negotiating. It can also be borrowed from others, and enhanced by the accumulation of wealth, a good reputation, and exemplary behaviour.

The nature of Face interaction is interdependent (Kim and Nam, 1998). Each participant is responsible for saving both their own Face and the other's Face. Chinese children are inculcated with the concept of Face and therefore develop an internalized sense of appropriate behaviour. One's Face is also closely associated with their status in society. The higher one's social or political standing, the more dignity one has to maintain, and those who have more power are expected to adhere to a higher code of ethics than those of lesser standing. Further, one who is well educated is expected to maintain more selfcontrol in social activities then those who are not as well educated. Those who are better educated are expected to control their emotions and not to engage in arguments with those on lower social levels. Tutors at the Open University of Hong Kong have at minimum a Bachelor degree and many, in fact, work at managerial levels within their work organizations. This explains why tutors who rank high on Face scale are perceived as having good attitudes in teaching. As leaders of a group of adult students, they may feel too self-conscious to behave in a friendly and helpful way and also uphold the level of respect from students.

In Chinese culture, many individuals are highly conscious of their responsibility for developing their character according to the demands of their status in society. Moreover, many are acutely aware that any disregard of these standards of behaviour will result in their associates questioning their moral character and doubting their ability to perform their role in society. This 'loss of Face' could conceivably isolate them from those with whom they function and result in such deep feelings of insecurity that they would be unable to function effectively (Brunner and Wang, 1989). Tutors ranking high on Face, tend to be concerned about students' opinion of them, and their attitude towards them. They are not ready to discuss their weaknesses, even with their closest friends. Hence they may feel a loss of Face when they cannot answer students' queries. A tutor high on Face, therefore, may strive to protect himself or herself from losing Face in tutorials. Often tutors may achieve this by working hard, and being well prepared and organized for their tutorial sessions.

Traditional Chinese cherish hierarchical status in social relations (Hwang, 1987). As noted earlier, the Face Scale in the CPAI covers the concern for maintaining Face and social behaviors that enhance one's own Face and that avoid losing one's Face. An individual's social connections are important factors that are frequently taken into consideration by others in judging overall social status. Within a social network, having Face enhances not only relative position, but also bestows many kinds of privileges that further improve the quality of life. This being so, saving Face rather than losing it becomes a primary objective in Chinese society. When one is subjectively suffering loss of Face, one's self-esteem is injured, resulting in emotional uneasiness. Thus, in addition to maintaining Face, one must utilize every sort of Face work to 'earn' Face. Some common strategies of saving Face for another include: avoiding criticizing anyone in public, using circumlocution and equivocation in any criticism of another's performance, and according greater social rewards to those skilled at preserving Face for others. Chinese use all these strategies frequently in managing a modern social organization (Silin, 1976). Tutors may also adopt these strategies when they conduct tutorials in order 
to earn Face and save others' Face. These strategies help bring about harmony, which is discussed in the following section.

\section{Harmony}

Tutors ranking high on Harmony were evaluated by their students as being significantly better than those less concerned about Harmony in terms of motivation, presentation, attitude and interaction $(t=3.848, p<.05 ; t=3.347, p<.05 ; t=3.934, p<.05$; and $t=$ $2.595, p<.05$ respectively).

Harmony is a deeply embedded social value in Chinese culture, emphasized in the dominant religious and philosophical traditions - Confucianism, Taoism and Buddhism. It refers to the balance achieved in relationships (Kwan and Bond, 1997). The major focus of this concept is on the relationship, rather than on the satisfaction of its constituent individuals or support derived by an individual from that relationship. Chinese people pursue harmony in their relationships with nature, self, and other individuals (Lee, 1995). One of the characteristics of a culturally salient 'socialorientation' personality is that Chinese people can sacrifice their own interests and suppress their own desires to achieve and maintain harmonious relations with other people (Leung and $\mathrm{Wu}, 1996)$. The importance of harmony is highly related to cultural values such as Face and reciprocity. Chinese traditions stress harmony between people and their environment, intra-personal harmony and, of most significance here, harmony in social relationships. Harmony is not a central construct in Western ideology where dominant value orientations are based upon notions of equality, egalitarianism, and consensus (Westwood, 1997). Chinese tend to discourage and inhibit aggressive outbursts in order to maintain interpersonal harmony within their group (Bond and Wang, 1983).

Tutors with a high concern for Harmony will tend to conduct tutorials so as to maintain proper harmony, both within the group and between themselves and other members. Tutors are prone to subordinate personal needs to those of the group, to accept the group's norms rather than insisting on their personal norms. Harmony therefore, is more important than, for example, broadcasting one's personal notion of truth. They tend to believe harmony helps foster sentiments of solidarity and that it consolidates beneficial bonds of mutual obligation and reciprocity. An interesting point to note in this study is that all 22 tutors with a high score on Harmony also score highly on Face and Renqing. As noted earlier, a tutor well versed in Renqing is likely to express friendship and sympathy, in the hope that harmony within the group is maintained through gracious reciprocity of help. A tutor scoring high on Face is also concerned about earning face as well as saving student's face - in the latter case, the tutor is obviously adopting conflict avoidance strategies in the hope of bringing harmony in classes.

\section{Leadership}

Tutors ranking high on Leadership were evaluated by their students as significantly better than those less concerned about Leadership in terms of motivation, interaction and presentation ( $t=2.528, p<.05 ; t=2.401, p<.05$; and $t=1.758, p<.1$ respectively).

Whilst Renqing, Face, and Harmony are three dimensions on the Chinese Tradition factor of the CPAI, Leadership is not of specific interest to the Chinese culture. Nonetheless, it can be easily comprehended why Leadership is crucial to teaching, and will not be discussed in detail in this paper. Apart from possessing excellent presentation skills, an effective tutor should be able to lead discussions and debates, as well as encourage small 
group interactions. As leader of a tutorial group, tutors must be able to facilitate student independence and foster students' critical thinking and self-directed learning. In doing so, they have to guide the students in their thinking, thereby stimulating them to be reflective thinkers. Therefore, tutors who are eager to become a leader of a group are likely to be more effective in presentation as well as in motivating and interacting with students.

\section{Conclusions}

This study reveals that Renqing, Face, Harmony and Leadership significantly predict tutors' teaching effectiveness in the classroom environment. Certain facets from the distinctive indigenous factor of Chinese Tradition seem to be a useful complement to MBTI in predicting Chinese teaching attitudes and behavior. In particular, Harmony seems to be significantly related to all four dimensions of teaching.

As the Chinese are relation-orientated people, they are naturally preoccupied with guanxi construction. Whilst the concepts of Face, Renqing and Harmony are very different from each other, they all interrelate. They depict the emphasis on implicit rules of interpersonal dynamics within Chinese culture. A tutor scoring high on Renqing may tend to give Face to students participating in tutorials, with the underlying aim of maintaining a harmonious relationship with each other.

The major aim of Confucianism is to achieve social harmony, which depends not only on the maintenance of correct relationships among individuals, but also on the protection of an individual's Face or one's dignity, self-respect, and prestige. Social interactions should be conducted so that nobody's Face is lost. If one does not have Face, one has limited social resources to use in cultivating and developing one's connection network. Therefore, one has to have Face in order to build one's own network. Normally, a teacher is regarded as one who holds higher social position and has greater Face. In the Chinese art of relationship management, Renqing also plays an important role; it is a crucial vehicle in Chinese social exchanges. In general, Renqing and Face represent some kind of social capital or resource in interpersonal exchanges.

This paper suggests that imported personality instruments may not necessarily be comprehensive enough to reveal particular distinctive factors in specific cultures. As shown in this case, some scales on the Chinese Tradition factor may have important contributions to make in the predictive role of personality measures. The uniqueness of the Chinese Tradition factor has been confirmed in a number of follow-up studies. The Chinese Tradition factor was found to stand apart from the five-factor structure (Goldberg, 1990; McCrae and Costa, 1997) when both the CPAI and the NEO Personality Inventory, which measures the Big Five, were used (Cheung et al., 1998; Sun, 1997; Zhang and Bond, 1998). Such research with the indigenous constructs identified in the CPAI points to the inadequacy of existing personality theories and instruments in covering all the relevant domains of Chinese personality. As it could be shown that the MBTI could not subsume all the CPAI scales, it may be challenged that this model is incomplete.

Certain scales on the Chinese Tradition factor of the CPAI have been shown to be relevant in predicting Chinese tutors' behavior. Yet it remains uncertain as to whether this Chinese Tradition factor is unique to the Chinese culture or whether it is also comprises part of a universal domain useful in understanding key interpersonal aspects of personality that have been inadvertently overlooked by psychologists who rely solely on Western personality inventories. Future research with the CPAI involving cross-cultural samples may provide answers to this. 
Table 1. Categorization of the 22 Personality Dimensions on the CPAI

\begin{tabular}{|c|c|c|c|c|}
\hline & Dependability & Chinese Tradition & Social Potency & Individualism \\
\hline 1. Self v. social orientation & & & & $\sqrt{1}$ \\
\hline 2. Graciousness v. meanness & $\sqrt{ }$ & & & \\
\hline 3. Introversion-Extroversion & & & $\sqrt{1}$ & \\
\hline 4. Harmony & & $\sqrt{ }$ & & \\
\hline 5. Leadership & & & $\sqrt{1}$ & \\
\hline 6. Face & $\sqrt{1}$ & & & \\
\hline $\begin{array}{l}\text { 7. Ren Qing (Relationship) } \\
\text { Orientation }\end{array}$ & & $\sqrt{1}$ & & \\
\hline 8. Family Orientation & $\mathrm{v}$ & & & \\
\hline 9. Optimism-Pessimism & $\sqrt{ }$ & & & \\
\hline 10. Flexibility & & $\sqrt{1}$ & & \\
\hline $\begin{array}{l}\text { 11. Logical vs. Affective } \\
\text { Orientation }\end{array}$ & & & & $\sqrt{1}$ \\
\hline 12. Modernization & & $\mathrm{v}$ & & \\
\hline 13. Emotionality & $\sqrt{ }$ & & & \\
\hline 14. Thrift-Extravagance & & 1 & & \\
\hline 15. Responsibility & $\sqrt{1}$ & & & \\
\hline 16. Adventurousness & & & $\sqrt{1}$ & \\
\hline 17. Meticulousness & $\sqrt{ }$ & & & \\
\hline 18. Defensiveness & & & & 1 \\
\hline 19. Veraciousness-Slickness & $\sqrt{ }$ & & & \\
\hline 20. Practical Mindedness & $\sqrt{ }$ & & & \\
\hline $\begin{array}{l}\text { 21. External vs. Internal } \\
\text { Locus of Control }\end{array}$ & $\sqrt{ }$ & & & \\
\hline $\begin{array}{l}\text { 22. Inferiority vs. Self- } \\
\text { Acceptance }\end{array}$ & $\sqrt{ }$ & & & \\
\hline
\end{tabular}


Table 2. Total variance explained

\begin{tabular}{|c|c|c|c|c|c|c|}
\hline \multirow[b]{2}{*}{ Component } & \multicolumn{3}{|c|}{ Initial Eigenvalues } & \multicolumn{3}{|c|}{ Extraction Sums of Squared Loadings } \\
\hline & Total & $\%$ of Variance & $\begin{array}{c}\text { Cumulative } \\
\%\end{array}$ & Total & $\%$ of Variance & $\underset{\%}{\text { Cumulative }}$ \\
\hline 1 & 11695 & 43.316 & 43.316 & 11.095 & 43.316 & 43.316 \\
\hline 2 & 1.722 & 6377 & 49.608 & 1.722 & 6377 & 49.698 \\
\hline 3 & 1251 & 4634 & 54.327 & 1251 & 4634 & 54.327 \\
\hline 4 & 1.029 & 3810 & 58.137 & 1.029 & 3810 & 58.137 \\
\hline 5 & .920 & 3.407 & 61.544 & & & \\
\hline 6 & .80 & 3261 & 64.805 & & & \\
\hline 7 & .817 & 3.027 & 67.832 & & & \\
\hline 8 & .728 & 2697 & 70.529 & & & \\
\hline 9 & .676 & 2500 & 73.003 & & & \\
\hline 10 & .617 & 2286 & 75.319 & & & \\
\hline 11 & .563 & 2046 & 77.366 & & & \\
\hline 12 & .528 & 1956 & 79.321 & & & \\
\hline 13 & .514 & 1908 & 81.224 & & & \\
\hline 14 & .496 & 1836 & 83.061 & & & \\
\hline 15 & .478 & 1.771 & 84.832 & & & \\
\hline 16 & .464 & 1.681 & 86.513 & & & \\
\hline 17 & .429 & 1590 & 88.103 & & & \\
\hline 18 & .405 & 1501 & 89.604 & & & \\
\hline 19 & .379 & 1.400 & 91.007 & & & \\
\hline 20 & .360 & 1333 & 92.340 & & & \\
\hline 21 & .348 & 1290 & 93.600 & & & \\
\hline 22 & .309 & 1.143 & 94.773 & & & \\
\hline 23 & .302 & 1.118 & 95.891 & & & \\
\hline 24 & .287 & 1.064 & 96.956 & & & \\
\hline 25 & .284 & 1.052 & 98.007 & & & \\
\hline 26 & .274 & 1.016 & 99.023 & & & \\
\hline 27 & .264 & .977 & 100000 & & & \\
\hline
\end{tabular}


Table 3(a). t-test Analysis between High-Face(H) and Low-Face(L) Groups on the Four Teaching Dimensions

\begin{tabular}{|c|c|c|c|c|c|c|}
\hline & FACE & N & Mean & Std. Deviation & $t$ & sigrificance \\
\hline \multirow{2}{*}{ Motivation } & H & 34 & 40000 & .3023 & \multirow{2}{*}{.229} & .820 \\
\hline & L & 23 & 39800 & .2292 & & \\
\hline \multirow{2}{*}{ Presentation } & H & 34 & 35143 & .3340 & \multirow[t]{2}{*}{.807} & .423 \\
\hline & L & 23 & 3.4448 & .2947 & & \\
\hline \multirow{2}{*}{ Attitude } & H & 34 & 3.4392 & .3956 & \multirow[t]{2}{*}{1988} & $.052^{\alpha}$ \\
\hline & L & 23 & 32281 & .3900 & & \\
\hline \multirow{2}{*}{ Intersction } & H & 34 & 3.7210 & .3998 & \multirow{2}{*}{-.014} & .989 \\
\hline & L & 23 & 3.7223 & .3147 & & \\
\hline
\end{tabular}

$* p<0.10$

Table 3(b). t-test Analysis between High-Leadership (H) and Low-Leadership (L) Groups on the Four Teaching Dimensions

\begin{tabular}{|c|c|c|c|c|c|c|}
\hline & FACE & $\mathrm{N}$ & Mean & Std. Deviation & $t$ & sigrificanoe \\
\hline \multirow{2}{*}{ Motivation } & $\mathrm{H}$ & 19 & 4.1167 & .2179 & \multirow{2}{*}{2528} & $.014^{\pi}$ \\
\hline & L & 38 & 39314 & .2798 & & \\
\hline \multirow{2}{*}{ Presentation } & H & 19 & 35891 & .2724 & \multirow[t]{2}{*}{1.758} & .084 \\
\hline & L & 38 & 3.4349 & .3297 & & \\
\hline \multirow{2}{*}{ Attitude } & $\mathrm{H}$ & 19 & 3,3560 & $\$ 816$ & \multirow[t]{2}{*}{.037} & .971 \\
\hline & L & 38 & 3,3526 & .4191 & & \\
\hline \multirow{2}{*}{ Interaction } & H & 19 & 38790 & .2363 & \multirow[t]{2}{*}{2.401} & $.020^{\circ x}$ \\
\hline & L & 38 & 3.6488 & .3939 & & \\
\hline
\end{tabular}

$* p<0.10$

$* * p<0.05$ 
Table 3(c). t-test Analysis between High-Renqing(H) and Low-Renqing(L) Groups on the Four Teaching Dimensions

\begin{tabular}{|c|c|c|c|c|c|c|}
\hline & RENQING & $\mathrm{N}$ & Mean & Std. Deviation & $t$ & sigrificanoe \\
\hline \multirow{2}{*}{ Motivation } & H & 24 & 40743 & .2502 & \multirow[t]{2}{*}{1963} & \multirow[t]{2}{*}{$.055^{\circ}$} \\
\hline & L & 33 & 39341 & .2774 & & \\
\hline \multirow{2}{*}{ Presentation } & H & 24 & 3.5765 & .3376 & \multirow[t]{2}{*}{1869} & \multirow[t]{2}{*}{$.06 \%^{\pi}$} \\
\hline & L & 33 & 3.4206 & .2905 & & \\
\hline \multirow{2}{*}{ Attitude } & H & 24 & 3.4600 & .4638 & \multirow[t]{2}{*}{2209} & \multirow[t]{2}{*}{$.031^{x x}$} \\
\hline & L & 33 & 32567 & .3274 & & \\
\hline \multirow{2}{*}{ Interaction } & H & 24 & 3.7988 & .4174 & \multirow[t]{2}{*}{1374} & .175 \\
\hline & L & 33 & 36653 & .3161 & & \\
\hline \multicolumn{7}{|l|}{$* p<0.10$} \\
\hline
\end{tabular}

Table 3(d). t-test Analysis between High-Harmony(H) and Low-Harmony(L) Groups on the Four Teaching Dimensions

\begin{tabular}{|c|c|c|c|c|c|c|}
\hline & RENQING & N & Mean & Std. Deviation & $t$ & sigrificance \\
\hline \multirow{2}{*}{ Motivation } & H & 22 & 4.1504 & .2801 & \multirow[t]{2}{*}{3848} & \multirow[t]{2}{*}{$.000^{\alpha x}$} \\
\hline & L & 35 & 38943 & .2197 & & \\
\hline \multirow{2}{*}{ Presentation } & H & 22 & 3.6497 & .3454 & \multirow[t]{2}{*}{3347} & \multirow{2}{*}{$.001^{x \pi}$} \\
\hline & L & 35 & 3,3805 & .2542 & & \\
\hline \multirow{2}{*}{ Attitude } & H & 22 & 35905 & .4248 & \multirow[t]{2}{*}{3934} & \multirow[t]{2}{*}{$.000^{x x}$} \\
\hline & L & 35 & 32054 & .3129 & & \\
\hline \multirow{2}{*}{ Intersction } & H & 22 & 3.8722 & .4529 & \multirow[t]{2}{*}{2.595} & \multirow[t]{2}{*}{$.012^{\mathrm{xx}}$} \\
\hline & L & 35 & 3.6208 & .2619 & & \\
\hline
\end{tabular}

$* * p<0.05$ 
Chan - A Study of the Relationship Between Tutor's Personality and Teaching Effectiveness

\section{References}

Amabile, T. M. (1979). Effects of External Evaluations on Artistic Creativity. Journal of Personality and Social Psychology, 37, 221 - 233.

Barrett, L. A. (1991). Relationship of Observable Teaching Effectiveness Behaviours to MBTI Personality Types, Paper Presented at the Ninth International Conference of the Association for Psychological Type, Richmond, Virginia.

Barrows, H. S. (1992). The Tutorial Process. Springfield: Southern Illinois University of Medicine.

Beaudoin, M. (1990). The Instructor's Changing Role in Distance Education. The American Journal of Distance Education 4(2), 21 - 29.

Benware, C., and Deci, E. L. (1984). The Quality of Teaching with an Active Versus Passive Motivational Set. American Educational Research Journal 21, 755 765.

Boggiano, A. K., Flink, C., Shields, A., Seelbach, A., and Barrett, M. (1993). Use of Techniques Promoting Students' Self-Determination: Effects of students' analytic problem-solving skills. Motivation and Emotion 17, 319 - 336.

Bond, M. H. (2000). Localizing the Imperial Outreach. American Behavioral Scientist 44(1), $63-72$.

Bond, M. H. and Hwang, K. K. (1986). The Social Psychology of Chinese People. In M. H. Bond (Ed.) The Psychology of the Chinese People. (p. 213-266). HK: Oxford University Press.

Bond, M. H., and S. H. Wang (1983). Aggressive Behaviour in Chinese Society: The problem of maintaining harmony. In A. P. Goldstein and M. Segall (Eds.) Global Perspectives on Aggression. New York: Pergamon, 58 - 74.

Brunner, J. A., and Wang, Y. (1989). Chinese Negotiating and the Concept of Face. Journal of International Consumer Marketing 1(1), 27 - 43.

Chan, B (2001). An Empirical Study of the Relationship Between Tutor's Personality and Teaching Effectiveness: Implications for Management of Tutors in Distance Education. International Conference on Offshore Education and Training in an e-Learning World, Australia.

Cheung, F. M. (1996). Development of the Chinese Personality Assessment Inventory. Journal of Cross Cultural Psychology 27(2), 181 - 199.

Cheung, F. M., and Leung, K. (1998). Indigenous Personality Measures: Chinese Examples. Journal of Cross-Cultural Psychology 29(1), 233 - 248.

Cheung, F. M., Leung, K., Zhang, J. X., Sun, H. F., Gan, Y. Q., Song, W. Z., and Xie, D. (1998). Indigenous Chinese Personality Constructs: Is the Five Factor Model Complete? Manuscript submitted for publication. Cited in M. H. Bond (2000) Localizing the Imperial Outreach, American Behavioral Scientist 44(1), 63 - 72. 
Church, A. T. (1987). Personality Research in a Non-Western Culture: The Philippines. Psychological Bulletin 102, 272 - 292.

Costa, P. T. Jr., and McCrae, R. R. (1992). Revised NEO Personality Inventory (NEO-PI$R$ ) and NEO Five-Factor Inventory (NEO-FFI) Professional Manual. Odessa, FL.: Psychological Assessment Resources.

deCharms, R. (1976). Enhancing Motivation: Change in the Classroom. New York: Irvington.

Deci, E. L., Schwartz, A., Sheinman, L. and Ryan, R. M. (1981a). An Instrument to Assess Adult's Orientations Toward Control Versus Autonomy in Children: Reflections on Intrinsic Motivation and Perceived Competence. Journal of Educational Psychology 73, 642 - 650.

Deci, E. L., Nezlek, J., and Sheinman, L. (1981b). Characteristics of the Rewarder and Intrinsic Motivation of the Rewardee. Journal of Personality and Social Psychology 40, $1-10$.

Deci, E. L., and Ryan, R. M. (1987). The Support of Autonomy and the Control of Behaviour. Journal of Personality and Social Psychology 53, 1024 - 1037.

Deci, E. L., Vallerand, R. J., Pelletier L. G., and Ryan, R. M. (1991). Motivation and Education: The Self-Determination Perspective. Educational Psychologist 26, $325-346$.

Fernandez, J., and Mateo, M. A. (1992) Student Evaluation of University Teaching Quality: Analysis of a Questionnaire for a Sample of University Students in Spain, Educational and Psychological Measurement 52(3), 675 - 686.

Fisher, D. L., and Kent, H. B. (1998) Associations Between Teacher Personality and Classroom Environment, Journal of Classroom Interaction 33(1), 5 - 13.

Flink, C., Boggiano, A. K., Main, D. S., Barrett, M., and Katz, P. A. (1992). Children’s Achievement-Related Behaviours: The role of extrinsic and intrinsic motivational orientations. In A. K. Boggiano and T. S. Pittman (Eds.) Achievement and Motivation: A Social-Developmental Perspective (p. 189-214). New York: Cambridge University Press.

Gaski, J. (1987). On Construct Validity of Measures of College Teaching Effectiveness, Journal of Educational Psychology 73(3), 326 - 330.

Goffman, E. (1955). On Face-Work: An analysis of ritual elements in social interaction, Psychiatry 18, $213-231$.

Goffman, E. (1956). Embarrassment and Social Organisation. American Journal of Psychology 62, $264-271$.

Goldberg, L. (1990). An Alternative "Description of Personality" The Big Five Factor Structure. Journal of Personality and Social Psychology, 59, 1216 - 1229. 
Grolnick, W. S., and Ryan, R. M. (1987). Autonomy in Children's Learning: An experimental and individual difference investigation. Journal of Personality and Social Psychology, 52, 890 - 898.

Hamza, K., and Nash, W. R. (1996). Creating and Fostering a Learning Environment That Promotes Creative Thinking and Problem Solving Skills. Research Report. ERIC Document ED 406435.

Harper, G., and Kember, D. (1986). Approaches to Study of Distance Education Students. British Journal of Educational Technology 17(3), 212 - 222.

Ho, D.Y. F. (1976). On the Concept of Face. American Journal of Sociology 81, 867 884.

Hofstede, G. (1991). Culture and Organisations: Software of the mind. New York: McGraw-Hill.

Hu, H. C. (1944). The Chinese Concepts of Face. American Anthropologist 46, 45 - 64.

Huang, L. C., and M. B. Harris (1974). Altruism and Imitation in Chinese and Americans: A Cross-Cultural Experiment. Journal of Social Psychology 93, 193 $-195$.

Hwang, K. K. (1987). Face and Favor: The Chinese power game. American Journal of Sociology, 92(4), $944-974$.

Kagan, D. M., and Grandgenett, D. J. (1987). Personality and Interaction Analysis, Studies in Higher Education 14, 13 - 24.

Kim, J. Y., and Nam, S. H. (1998). The Concept and Dynamics of Face: Implications for organizational behaviour in Asia. Organization Science, 9(4), 522 - 535.

Koestner, R., Ryan, R. M., Bernieri, F., and Holt, K. (1984). Setting Limits on Children's Behaviour: The differential effects of controlling versus informational styles on intrinsic motivation and creativity. Journal of Personality 52, 233 - 248.

Kwan, V. S. Y., and Bond, M. H. (1997). Pancultural Explanations for Life Satisfaction: Adding relationship harmony to self-esteem. Journal of Personality and Social Psychology, 73(5), 1038 - 1051.

Lee, Y. Y. (1995). The Chinese Traditional View of the Universe and Modern Business Behavior, In J. Qiao, and Y. G. Pan (Eds.) Chinese Conception and Behavior. TianJin: TianJin People Press.

Leung, K., and Wu, P. G. (1996). The Dual Role of "Harmony” in Management. Paper presented in the Conference of Organization and Management of Chinese Business. Taiwan University: Taipei.

Leung, K., and Zhang, J. X. (1995). Systemic Considerations: Factors facilitating and impeding the development of psychology in developing countries. International Journal of Psychology, 30, 693 - 706. 
Lorentz, J. L., and Coker, H. (1977). Myers-Briggs Types as Predictors of Observed Teacher Behaviour. Paper Presented at Second National Conference on the Use of the MBTI, Michigan State University, East Lansing.

Lu, H. (1976). The True Story of Ah-Q. HK: C\&W.

McCrae, R. R., and Costa, P. T. Jr. (1997). Personality Trait Structure as a Human Universal. American Psychologist 52, 509 - 516.

Patrick, B. C., Skinner, E. A., and Connell, J. P. (1993). What Motivates Children's Behaviour and Emotion? Joint effects of perceived control and autonomy in the academic domain. Journal of Personality 65, 781 - 791.

Pittman, T. S., Emery, J., and Boggiano, A. K. (1982). Intrinsic and Extrinsic Motivational Orientations: Reward induced changes in preferences for complexity. Journal of Personality and Social Psychology 42, 789 - 797.

Reeve, J. (1996). Motivating Others: Nurturing inner motivational resources. Boston, MA: Allyn and Bacon.

Reeve, J. (1998). Autonomy Support As An Interpersonal Motivating Style: Is It Teachable? Contemporary Educational Psychology 23, 312 - 330.

Ryan, R. M., and Connell, J. P. (1989). Perceived Locus of Causality and Internalization: Examining Reasons for Acting in Two Domains. Journal of Personality and Social Psychology 57, 749 - 761.

Ryan, R. M., and Grolnick, W. S. (1986). Origins and Pawns in the Classroom: SelfReport and Projective Assessment of Individual Differences in Children's Perceptions. Journal of Personality and Social Psychology 45, 736 - 750.

Shapira, A. (1976). Expectancy Determinants of Intrinsically Motivated Behaviour. Journal of Personality and Social Psychology 34, 1235 - 1244.

Silin, R. (1976). Leadership and Values: The organisation of large-scale Taiwanese enterprises. Cambridge, MA.: Harvard University Press.

Sun, H. F. (1997). Choice of Influence Tactics in Chinese Organizations: The effect of the interactants' personality and status. Unpublished Doctoral Dissertation. University of Hong Kong (In Chinese).

Tonelson, S. W. (1981). The Importance of Teacher Self-Concept to Create a Healthy Psychological Environment for Learning. Education 102, 96 - 100.

Tsang, E. W. K. (1998). Can Guanxi be a Source of Sustained Competitive Advantage for Doing Business in China? Academy of Management Executive 12(2), 64 - 73.

Vallerand, R. J., Fortier, M. S., and Guay, F. (1997). Self-Determination and Persistence in a Real-Life Setting: Toward a motivational model of high school dropout. Journal of Personality and Social Psychology 72, 1161 - 1176. 
Wagenaar, T. C. (1995) Student Evaluation of Teaching: Some Cautions and Suggestions, Teaching Sociology 23, pp.64-68.

Watkins, D. (1983). Only Rote Learning Needed at ANU, ANU Reporter, 14(16), 3.

Watkins, D., and Hattie, J. (1981). The Learning Processes of Australian University Students: Investigation of contextual and personological factors. British Journal of Educational Psychology 51, 384 - 393.

Westwood, R. (1997). Harmony and Patriarchy: The cultural basis for 'Paternalistic Headship’ among the overseas Chinese. Organization Studies 18(3), 445 - 480.

Williams, G. C., Weiner, M. W., Markakis, K. M., Reeve, J., and Deci, E. L. (1994). Medical Students' Motivation for Internal Medicine. Journal of General Internal Medicine, 9, 327 - 333.

Zhang, J. X., and Bond, M. H. (1998). Personality and Filial Piety Among Colleg Students in Two Chinese Societies. Journal of Cross-Cultural Psychology, 29(3), $402-417$.

\section{Athabasca}


October - 2002

\title{
Quality Standards in e-Learning: A matrix of analysis
}

\author{
Jia Frydenberg \\ Irvine Distance Learning Center \\ University of California
}

\begin{abstract}
Most institutions of postsecondary and higher education are creating or adopting quality statements, standards, and criteria regarding their niche of the "e-Learning enterprise." In doing so, they have a tendency to reinvent the wheel. This article summarizes current published quality standards in the US, and analyzes and organizes them into a nine-cell matrix. It concludes with discussion of emerging issues with respect to the nine standards-areas.
\end{abstract}

Keywords: e-Learning; online learning; Web-based learning; quality standards; development delivery and support of online learning

\section{Introduction}

\section{Who Are The Standard-Setters?}

The defining feature of most forms distance education is that learners and teachers are not within eyesight of each other. They may also be separated in time (asynchronous learning). In electronic learning, or e-Learning, instructors, at times, may be a machine, as in computer-based training or computer-based tutorials (CBT). e-Learning or Webbased learning, a relatively new form of distance education, is only now being integrated into distance learning research literature. It is, however, rapidly becoming the dominant form of distance learning delivery in developed countries.

This article focuses on the e-Learning that institutions of higher education make available to an ever-growing student body. However, this article does not consider e-Learning as created by, and provided for, for-profit non-educational organizations. Nor does it consider e-Learning in the context of the K-12 system. Instead, the purpose here is to present a matrix within which to examine, compare, contrast, and synthesize the standards of e-Learning quality that have been proposed in the literature.

Higher education institutions in the US have a long history of independence from governmental control. The US constitution, unlike the constitutions of many other countries, gives individual states the right to determine how the education of its citizenry should be organized and monitored. All 50 states have chosen to allow tertiary education to be largely self-governing and self-policing, similar to those organizational models used 
by the mediaeval guilds that reserved the right to professional training, certification, and censure of its members.

While providers of higher education, colleges, and universities, are long lasting and frequently appear to be permanent fixtures in the teaching and learning landscape, the seekers of learning tend to be temporary members of these "guilds." As a result, the seekers (students) are not organized into lasting associations or other groupings that can effectively influence the education they seek. Naturally, there are exceptions to this; one need only look back in time to the sit-ins and demonstrations of the 1960s to find a time when student pressure rocked the academic establishment. But, in general, such upheavals have been limited in time and level of influence. It remains that the primary influences in tertiary education in the US are: 1) professional faculty associations; 2) regional accrediting agencies that have the charge of guiding and evaluating education providers; and 3) university faculty and administrators. These three groups are the main players in the arena of presenting and debating standards of quality for electronically mediated teaching and learning in US higher education.

\section{Distance Education and the World Wide Web}

Distance education in the US comes out of the tradition of "independent learning," in which learners who did not have ready geographical access to a physical campus, studied on their own using materials (e.g., texts, assignments, exams) mailed to them by universities. The norm in independent learning has been that learners do not follow the standard university terms (semesters, trimesters, or quarters) nor do they have a known cohort group with whom to interact. A considerable amount of print-based independent learning still occurs across the US. Although e-Learning may be offered in this non-term, non-cohort fashion, the quality standards considered in this article apply primarily to group-based, time-limited activities. In fact, most providers of standards still operate within a paradigm that mimics the "group of learners coming together to study with an expert" tradition. However, other standards of quality will be needed for the emerging eLearning forms of individual tutoring and non instructor-led, on-demand Web-based learning.

Certain attributes of the World Wide Web that have fueled the explosion of learning opportunities include: capacity to enable sharing of rich media files (pictures, complex diagrams, video, audio); and interactivity of electronic communication in user-friendly modalities such as email, bulletin boards, and simultaneous chat rooms, as well as more bandwidth intensive forms of Web-enabled video and audio teleconferencing. A third attribute, the non-linearity of the platform-independent standards of hypertext markup language (HTML) and its successors, has so far been much less employed in designing WWW education. In fact, most of the "best designed" e-Learning still follow the hierarchical, linear, sequential mode of presenting learning material, in that learners are "forced" to proceed through their learning experience in a chronological fashion. Many such examples of e-Learning garner the derogatory epithet "HTML page-turners."

Why has e-Learning gathered such momentum? With the increasing pace of change, most of us need to continue to acquire university-level understanding and knowledge throughout our working lives. This learning, combined with our involvement with family, community, and work, encompasses an ever-larger slice of our 24-hour pie. Secondly, because we continue to locate our places of residence further away from our places of employment and education, we also find ourselves increasingly caught in gridlock as we attempt to move from one location to the other. The question becomes: When can we access the thinking and new ideas we need to be successful in our profession, or the art 
we need to excite our soul? The emerging answer seems that we seek such learning as we commute in the car, train, or ferry, or after the evening news, during lunch hour, or on company time.

The brave new pioneers who choose to experiment in e-Learning are often those who are challenged by constraints of time and space. In addition, various authors have drawn conclusions that those who will be most successful in online learning have certain personality traits or characteristics, such as independence, assertiveness, persistence, and a reflective attitude (Wahlstrom, Williams, and Shea, 2003; Gibson, 1998; and Gilbert, 2001).

However, learners' criteria for quality in their e-Learning experiences are generally not well understood. There are not yet any Consumer Reports from the learner's perspective. e-Learning is most frequently offered by institutions at prices representing "full cost recovery" (which, in the US, means programs that are not supported by state or government tax-based expenditures, are instead required to be fully self financing, including all overhead costs). Nevertheless, learners certainly apply market tests for these expenditures - specifically quality and service value. Although institutions pay attention to the evaluations learners offer of their experiences, we are not always sure we are asking the right questions on the often-lengthy end-of-course evaluations. More research remains to be done to fully explore consumer standards for e-Learning and to integrate those standards with traditional academic institutional concerns. In the face of the lack of consumer information, this article presents and assesses the points of view of the academic institutions, rather than that of the "education consumer."

\section{Standards Domains}

What, then, constitutes the quality of e-Learning from the viewpoint of the educator? The following nine domains are repeatedly described in the literature:

\section{Institutional Commitment}

One frequently mentioned domain is that of institutional or executive commitment to the education and the provision of learning. Yet there is considerable variation in the understanding of what constitutes such a commitment. The Western Interstate Commission for Higher Education (WICHE) presents nine aspects of the domain of "commitment" (WICHE, 2001). These encompass such aspects as financial commitment, the physical plant, articulation and other policies, technical support, legal compliance, etc. The Institute for Higher Education Policy in the report Quality on the Line: Benchmarks for Success in Internet-Based Distance Education emphasizes technological aspects of institutional support in terms of having a technology plan, security, redundancy in the delivery structure, and systems for maintenance of the technological infrastructure (IHE, 2000). Although the American Council on Education (ACE, 1996) adds faculty and staff development and a commitment to research to their list activities relating to "organizational commitment," it does not specify that the research needs to be directly related to distance education.

\section{Technology}

The technological infrastructure necessary for the delivery of a quality e-Learning program is often described separately as a second domain. While none of the assessors 
venture to set absolutes such as: "There must be technological opportunity for synchronous interaction between learners and teachers," they generally include such aspects as security and privacy of data and communication as well as the need for interactivity. None of the reports and position papers this author has reviewed, indicate availability of materials (text, video, audio) as essential as a highly rated component of a quality education program. This is hardly surprising given that the standards-writers arrive at their proposals from the context of traditional educational institutions in which the role of faculty is paramount to their mission. But failure to stipulate standards for instructional materials is curious in light of the recent announcement by the Massachusetts Institute of Technology (MIT), that will make available on the Web a large portion of its instructional materials (such as syllabi, papers, lecture notes) created and used by its professors (http://ocw.mit.edu/index.html). In terms of the standards described here and listed in the references, the MIT project does not qualify as an educational program, nor - obviously - does MIT think it is. In the type of distance education assumed by the standards documents reviewed in this article, the role of technology in permitting access to materials is to foster interactivity among students and between students and teachers. This interactivity is generally left undefined by the documents, and, in many cases, interaction with a computer in a complex branching program that guides the learner in a "step-and-remediation" process will qualify as interactive. On the other hand, most documents mention faculty in one or more of the standards, though generally not under the heading of technology. For example, the American Association for Higher Education says: "Good practice encourages contacts between students and faculty" (AAHE, 2000). The American Federation of Teachers report Distance Education: Guidelines for Good Practice posits: "Close personal interaction should be maintained in distance education courses among students and between students and teachers" (AFT, 2001). The IHE report of March 2000 under "Teaching and Learning" writes: "Student interaction with faculty and other students is an essential characteristic and is facilitated through a variety of technologies including voice mail and / or email” (IHE, 2000). The common underlying assumption of these standards document is that a human guide is available in the form of a faculty member or instructor who leads the student group toward a learning goal. To my knowledge, we have not yet in the US, begun to grapple with quality standards in non instructor-led education. In most cases, the standards under the heading "technology" have yet to identify criteria related to the functions of material access and interactivity, as well as to deeper technical issues such as system maintenance, up-time, redundancy, network access, and so on.

\section{Student Services}

A third aspect of quality standards concerns neither teaching nor learning, but is instead centered on student services. This domain can be subdivided into the services needed before students' entrance to a virtual classroom, support during the learning experience, and the continued connection between learners and the institution after the particular course or program has been completed.

Prospective students need to find out, first and foremost, that the learning opportunity exists and to obtain accurate information about it. For a provider organization, the decision to create an e-Learning program must be based, in part, on an assessment of a learning need in an identifiable and reachable group of potential learners. The first of the seven AFT standards mentions that "distance education students should be given advance information about course requirements, equipment, and techniques for succeeding in a distance learning environment ..." (AFT, 2001), while the IHE study adds that: "students are informed of and have easy access to information about the programs, including 
admission, tuition and fees, books and supplies, and student support services” (IHE, 2000). However, none of the standards documents include benchmarks of quality market research and marketing processes as a domain to be included in an evaluation of the educational program. There is a fine line between marketing efforts and providing accurate and timely information to prospective students, and such documents and processes should be included in the assessment of the pre-program student services.

As the "inquirer" becomes a "prospect" in marketing jargon, more hands-on activities occur. The advising role of student services begins, and both practical and academic counseling and advising are frequently mentioned as necessary to a quality e-Learning program. Systems such as toll-free phone numbers with clearly stated hours of operations, database-driven student management software (contact management), advising chat-rooms, and many other tools are used experimentally across the US. In addition, technical training through required or optional pre-program "how to use our virtual facilities" processes, is offered at many institutions. Thirdly, easily accessible and clearly worded statements of time-to-completion, student evaluation, financial aid, stopout policies, etc., are often cited as examples of quality student services.

An aspect of a quality educational program sometimes subsumed under instructional design, sometimes under teaching and learning, and sometimes under student services, is access to supporting materials. We generally see this as access to an electronically available library, such as the California Digital Library (http://www.cdlib.org/). However, an evaluator might also want to assess the quality of any electronic course packets and reading lists as well as supplementary video and audio recordings under the rubric of supporting materials.

The American image of a "student" relies heavily on campus-centric traditions. Hence, in the US, there is an understandable encouragement of students to become active participants in out-of-class student activities for such potentially self-serving reasons as enhancing degree completion rates, and because researchers (Astin, 1993) report that acculturation into the larger entity of the learning and research body of practice, adds value to the kind and level of learning students' are able to attain. Many universities currently attempt to forge virtual student-government organizations, student health services available online, career services, and even "virtual football." As a learner progresses from novice to certificate or degree recipient, virtual alumni associations are also beginning to be mentioned.

\section{Instructional Design and Course Development}

Many parties are also offering standards for the design and development of e-Learning programs. A report from The Pennsylvania State University titled An Emerging Set of Guidelines for the Design and Development of Distance Education (IDE, 1998) presents the following five aspects of course design with specific principles for each: 1) learning goals and content presentation; 2) interactions; 3) assessment and measurement; 4) instructional media and tools; and 5) learner services and support. While all the standards-proposals describe the need for the design of the virtual classroom to be based on educational outcome objectives, some go as far as to specify that these must be at higher levels of learning such as abstract thinking and critical reasoning (SREB, 2001). For-profit providers of e-Learning content or courseware and the corporations that create and employ e-Learning in their internal workforce, development strategies often include standards of effective and efficient program development processes (project management) in this category (See, for example, Berge, 2001 and Mantyla, 2000-2001). 
Given that this study is based on standards proposed primarily by academic institutions and organizations, we have difficulty separating instructional design from instruction. In academe, it is generally the same person, the faculty member, who does it all: determines what the course objectives are, what the learners are to study, when and how students should study, and when and how to conduct assessment. The same faculty member also provides lectures, seminars, and discussions that form the link between the content, its scope, selection, and sequencing, and students' learning outcomes. However, in eLearning it is crucial to separate the two roles since it is not given that the person who develops materials for a course will be the one, or the only one, to teach from these.

Design and development of e-Learning, then, is comprised of all the activities that go into getting ready to enable learning to take place. Unlike traditional education, however, eLearning is heavily front-loaded. Electronic course design takes considerable time, effort, and money, and the results of instructional design decisions are not easily changed. Benchmarks of quality for instructional design as divorced from the process of utilizing that design to facilitate learning (commonly known as "teaching") tend to state that the design must flow from the objectives - a lofty goal - and that it must enable interactivity. The type and function of this interactivity is not defined and is traditionally left up to the faculty to determine. In addition, we are only beginning to explore how instructional design needs to vary by discipline or by the type of educational outcome objective. Informal discussions occur in many venues of how Web layout and functionality for an electronic course may vary when the objective is to list the steps in performing a multiple regression analysis (considered a lower-level skill); or to evaluate whether the most appropriate statistical techniques have been employed in a research article in a particular field of study (considered a higher-order cognitive practice) (Bloom, 1956 and 1964).

The design imperative of enabling interactivity is based on the assumption that learning occurs through discourse, or at least that the kind of learning opportunities that educational institutions offer occurs through such activity. Interestingly, the development of instructorless CBT does not make this assumption, nor do software-based tutorial programs. However, these tend to have objectives at the Bloom's taxonomy levels of knowledge, comprehension, and application, rather than the university levels of analysis, synthesis, and evaluation. Can instructorless courses (Schank, 2002) be designed that demonstrably develop learners' creativity, innovativeness, and abstract thinking? From such studies we will be better able to assess the quality of instructional design separately from instruction.

\section{Instruction and Instructors}

The fifth domain of quality is that of instruction and instructor services. What is quality instruction at a distance? In addition to the benchmarks of quality instruction in a face-toface setting (such as depth of knowledge of the instructor, presentation and organizational skills, encouraging attitudes toward student dialog, feedback and guidance, etc.), one issue crops up in most of the standards documents: that the distance learner is mostly solitary. The first principle of good practice from the American Association for Higher Education, for example, states: "Good practice encourages contacts between students and faculty" (AAHE, 2000). In the traditional setting, this occurs in a lecture or seminar where during an hour or two the contacts are between one teacher and several learners, with the possible addition of some one-on-one outside-of-class exchange when brave learners venture to seek out faculty members during office hours. However, unless the instructional design of the electronically mediated course overtly emphasizes the students as a group of learners, individual students are most likely to perceive themselves as interacting within a mutually exclusive student / tutorial relationship with the instructor. 
It is obvious that this orientation contrasts with the tradition of lecturing to 100,200 , or 1,000 students at one time. Experiments of an instructional team with defined responsibilities comprising the professor, the teaching assistants, and invited guest moderators (e.g., the course Learning Theories and Classroom Practices at the University of California Irvine at http://www.gse.uci.edu/ed173, or at the Open University in the UK http://www.open.ac.uk/frames.html), which employs tutors supporting small groups of learners), are of great interest to universities in coping with the dilemma of class size in e-Learning.

Instructor services, as is the case with student services, can be divided into pre, during, and post course services. Prior to teaching, an instructor must feel comfortable utilizing the media of the course and hence may need training and guidance. During an e-Learning class, personnel must be available at the institution to assist instructors to resolve issues of a technological nature or to mediate difficulties in student and faculty perceptions of what constitutes good instructional practice, such as, for example, reasonable response time. Just as with on-ground instruction, the faculty member must have access to postcourse assistance related to evaluation (course, instructor, and student) etc. In addition, as the WICHE guidelines spell out: "Issues of workload, compensation, and intellectual property ownership (should) have been discussed with faculty and agreements worked out” (WICHE, 2001).

\section{Delivery}

Some standards document a sixth category, program delivery, as a separate domain. This may or may not include student and instructor services. The WICHE guidelines place delivery under "institutional context," noting such aspects as coordination, oversight, and articulation as parts of this domain. The Southern Regional Education Board (SREB, 2000) provides 15 principles of program management, which include such aspects as monitoring students to ensure academic honesty, content revision and oversight, technical requirements for acceptable access, recourse for appeal if a Web-based course is not delivered as described, and so on. Good program delivery depends on two aspects: 1) defined policies, procedures, responsibilities; and 2) communication, and fair and impartial management. In the best of all possible worlds, program delivery and program administration should be transparent to learners, just as the existence of the power plant on campus generally is.

\section{Finances}

The headlong rush to develop courses and programs for e-Learning, sometimes fails to heed standard business and accounting practices. The bill is coming due. Many assumed, for example, that the intellectual property fixed in HTML was so valuable that it would have years of shelf-life and could be licensed and / or sold over and over with only minor maintenance. Many also had delusions that the cost of one instructor at regular salary levels could be spread over hundreds of full tuition students and enable a rapid economy of scale. Neither of these assumptions has proven true. Hence, the financial health and responsible business planning of e-Learning programs is a necessary and yet-to-be addressed domain of evaluation standards.

As with all educational programs, there are fixed and variable costs of e-Learning. Universities, which have undertaken the production of full in-house programs from scratch, have often discovered to their dismay that expenditures per course are not inversely proportional to volume of courses to be produced. Instead of a factory model of 
production, many institutions treat online course development as a cottage industry where each new course is handcrafted. An interesting benefit of this practice is the discussion and nascent development of "learning objects," the theory being that such molecules of learning can be developed once and then shared and / or licensed to others. Large-scale standards experiments are currently in progress following this line of thought (See http://www.wiadlcolab.org; http://www.adlnet.org, and http://www.imsproject.org). The licensing of content, whether in the form of objects or of complete or partial courses, is generally based on the business model where the content owner receives a per-student royalty in return for the university being able to use that content in a university-approved and offered course. If the intellectual property owner figures it has cost $\$ 40,000$ to produce the IP and accepts a per-student royalty of $\$ 100$, the profits begin to arrive with the 401st student. This is a financial risk, of course, and what is more, it may be in opposition to a university's perceived mission (i.e., most faculty would balk at the idea of using another professor's lecture notes, yet we have no trouble using someone else's textbook). However the hybrid model of combining licensed learning objects with university-developed specialty content has promise. This is so, because it enables the university to focus on its primary strength, innovative thought, while licensing or buying the more mundane necessary objects that lead a learner onward, such as self-tests, "bridge" units that connect one topic with the preceding topics, and standard graphs, charts, and diagrams. Many textbook publishers are looking at such a model with interest and are at work disaggregating their traditional bound textbooks into defined, tagged, retrievable, and sharable learning objects.

Some e-Learning programs work on a full-cost recovery model where student tuition is intended to cover all the programs' costs, while others must work within the funding models (usually average daily attendance) dictated by their respective state. (In the US, it is common for state governments to funnel resources to local schools according to a set formula of funding per capita of the attending student body. Hence, the school only receives funding based on the number of students who show up on any given day.) Either way, the financial management of the distance learning enterprise is an important component of the total assessment of the program's quality and ability to sustain itself. Most standards documents do not set more specific criteria for financial health than: "There must be financial and administrative commitment" (ACE, 1996) and "The institution's budgets and policy statements reflect its commitment to the students for whom its electronically offered programs are designed" (WICHE, 2000).

\section{Regulatory and Legal Compliance}

Regulations governing e-Learning are growing. The two primary sources of regulation in the US are the regional accreditation agencies that have a long history in the US, and the 1990 Federal Americans with Disabilities Act (ADA) requirements (See, for example, detailed specifications of ADA-compliant web design at:

http://www.usdoj.gov/crt/ada/stdspdf.htm).

An accrediting agency, such as WASC (Western Association of Schools and Colleges), or NCASC (North Central Association of Schools and Colleges), has as its charge to set standards of quality practice and to guide institutions toward achieving those standards. In addition to the concerns described above, regional accreditation agencies and schools must follow applicable state and federal laws. The WICHE report states as its first benchmark: 
The institution seeks to understand the legal and regulatory requirements of the jurisdictions in which it operates, e.g. requirements for service to those with disabilities, copyright law, state and national requirements for institutions offering educational programs, international restrictions such as export of sensitive information or technologies, etc. (WICHE, 2000, p. 4).

There is considerable discussion within the e-Learning community about how best to ensure ADA compliance. Many believe that e-Learning holds great promise, especially for learners with physical and mental challenges. Suggestions, such as ensuring that every "talking head" or interview segment also has an accompanying text for those who cannot hear the audio or that audio files describe what happens in a visual simulation for those who cannot see it, are being taken seriously. Legal compliance has also focused on intellectual property law, which is in a state of flux. Intellectual property issues are hotly debated both in our US governing bodies and on campuses. Being so new, the e-Learning field is still trying to find its way through the constantly changing legal landscape.

\section{Evaluation}

Program evaluation is frequently listed as a separate domain in standards documentation. While assessment of student achievement is normally described as part of instructional design and tied to specific course objectives, program evaluation is a meta-activity that incorporates all the aspects of the e-Learning experience. Among its benchmarks, the IHE identified the following three criteria:

1. "The program's educational effectiveness and teaching / learning process is assessed through an evaluation process that uses several methods and applies specific standards.

2. Data on enrollment, costs, and successful / innovative uses of technology are used to evaluate program effectiveness.

3. Intended learning outcomes are reviewed regularly to ensure clarity, utility, and appropriateness.” (IHE, 2000)

The WICHE accreditation document includes these components:

“ 5 d. Overall program effectiveness is determined by such measures as:

1. The extent to which student learning matches intended outcomes, including for degree programs both the goals of general education and the objectives of the major.

2. The extent to which student intent is met.

3. Student retention rates, including variations over time.

4. Student satisfaction, as measured by regular surveys.

5. Faculty satisfaction, as measured by regular surveys and by formal and informal peer review processes.

6. The extent to which access is provided to students not previously served. 
7. Measures of the extent to which library and learning resources are used appropriately by the program's students.

8. Measures of student competence in fundamental skills such as communication, comprehension, and analysis.

9. Cost effectiveness of the program to its students, as compared to campus-based alternatives."

Program evaluation includes the assessment that students make of their learning experience (point 4 above). At the University of California Irvine, we are experimenting with a Web-based evaluation form comprised of the following seven areas of questions: 1) course content; 2) course design; 3) course materials; 4) instructor and instruction; 5) online student services; 6) overall comments; and 7) a few items asking about demographic information ${ }^{1}$.

As always with program evaluation measures and processes, it is critical to build these into the program design from the beginning. That, of course, is in no way unique to eLearning.

\section{Conclusion and Current Issues}

The final section of this article will explore some of the current issues and research needs within the nine sets of standards identified above. To recap, the domains are:

1. Executive commitment

2. Technological infrastructure

3. Student services

4. Design and development

5. Instruction and instructor services

6. Program delivery

7. Financial health

8. Legal and regulatory requirements

9. Program evaluation

What are the issues associated with development of e-Learning programs, as they become an ever-larger segment of the higher education enterprise? Each arena has its own concerns and research agendas.

\section{Executive Commitment}

Consumers of higher education rightfully expect universities to be around for a long time. They expect that if an institution offers a program on-ground or online, it will demonstrate the organizational commitment to see the admitted students through. For the e-Learning center to gain such institutional commitment is a human process of relationship management, willingness to meet skepticism and probing questions, and taking the risk of being wrong. Stakeholders and gatekeepers must all be invited to the table along with the converted advocates. It will be advantageous to the higher learning providers to encourage research on the processes of developing e-Learning capabilities in both separate centers of service and fully integrated models. Such studies may reasonably come out of our graduate schools of management. 


\section{Technological Infrastructure}

The central issue in courseware development at the moment is the potential for developing reusable learning objects, tagging them in a systematic way, storing them in well-designed databases, and retrieving and recombining them with other objects to create customized learning experiences for specific needs. In the learning management arena, technical solutions are required to track student-learning performance. With respect to student services, we are grappling with questions of how to engage learners who have never set foot on campus, how to make them feel part of the university community, and how to advise and guide them through technical interfaces. For content experts and instructors, we are looking for more user-friendly tools to enable them to create excellent learning materials and intellectual meeting spaces easily and quickly. We also see an explosion in the number of people wirelessly attached to their personal digital assistants and who want their learning programs compressed to a screen the size of a palm. And, of course, we need all these technical innovations to interface seamlessly with all legacy systems. All of these issues point to interdisciplinary studies that merge pedagogy with technical tools.

\section{Student Services}

Student service departments worry about financial aid regulations and about advising. Since the number of students served continues to be a benchmark of both academic and financial success, the issue of compromise between marketing, which has a tendency toward hyperbole, and accurate information and high program admissions standards is a constant. Another desire of student services is to be able to offer prompt and high quality tutorial assistance to those students who need it.

What are the most effective ways of advising students who never set foot on campus? How do we build a virtual community that they can feel a part of? In general, we are still at a stage where each institution may present "this is how we did it" at local and national conferences, but we do not yet have published qualitative or quantitative studies leading to replicable results. There is a considerable research gap in the arena of student services.

\section{Design and Development}

Instructional design for the World Wide Web is based on the temporal, chronological models of speech, where one has to speak one word at a time. Few examples of eLearning courses are truly non-linear. Yet those programs, which are intended for students under age 30, are enrolling learners who are fully at ease in an avatar-and-bot world. While we are used to controlling learning by requiring that module 1 be completed before the learner has access to module 2, many younger learners have no such predispositions. How do we design non-sequential instruction?

In development, we need faster "time to market.” Rather than sequentially developing courses, we need to outsource components and develop them simultaneously. This requires much higher skills in project specifications and project management than we are used to in universities. We also need multi-skilled staff who can take on intellectual property law one minute and come up with solutions to "make or buy" valid student assessment instruments the next.

The research questions that emerge include those of linearity and non-linearity in enabling learning. What is the optimum level of control and for whom? We hope that 
graduate schools of education will take up such questions as they study the learning practices that are developing among the younger generations. Secondly, the skills of the new breed of educational manager deserve elucidation as the creation of educational opportunities at a distance increasingly involves multi-disciplinary teams rather than traditional individual faculty members.

\section{Instruction and Instructor Services}

The issue of greatest concern, and perhaps the one about which less is known, centers on the question: How we can specify what quality online instruction is beyond what we already know as quality instruction in a face-to-face mode? In general, all the components that the various standards documents describe are those that are commonly accepted as quality instruction. An example can be seen in the seven principles of the American Federation of Teachers. In this quote, I have made a strike-through of the word "distance" to show this equivalence of the first six principles to valid principles for any kind of educational endeavor (the seventh principle is unique to this AFT document):

1. Distance students should be given advance information about course requirements, equipment, and techniques for succeeding in a distance learning environment, as well as technical training and support throughout the course.

2. Close person interaction should be maintained in distance education courses among students and between students and teachers.

3. Equivalent library materials and research opportunities should be made available to distance education students.

4. Assessment of student knowledge, skills, and knowledge should be as rigorous as assessments in classroom-based courses.

5. Academic counseling and advising should be available to distance learning students at the same level it is for students in more traditional campus environments.

6. Academic faculty should shape, approve, and evaluate distance education courses.

7. Full undergraduate degree programs should include classroom-based coursework, with exceptions for students truly unable to participate in classroom education.

How does quality distance instruction differ from quality face-to-face instruction? Anecdotal evidence abounds, but we could use a meta-study approach that can analyze what has been published and draw conclusions from these, albeit scant, documents.

\section{Program Delivery}

Program delivery is a process of making the complexity transparent to the learners. One issue often being informally debated is how to manage learners' expectations. If institutions set, intentionally or unintentionally, the expectation of learners that they will have their questions answered within 20 minutes of emailing their instructors, dissatisfaction is bound to result. Clear communication around expectations and relevant policies is central. 
While we do need to protect our students' right to privacy in an online classroom, it would behoove us to allow researcher "lurkers" to conduct studies in a supervised manner. We need to discover how the student-instructor interactions occur, how such interactions are perceived by both parties, and how to support those that best enable learning. We welcome this research direction.

\section{Financial Health}

Financial management of e-Learning is now often one of making a ".com” within a “.edu.” Transitioning from an allowance-model of financial management wherein a department is given a certain dollar amount to spend, to a revenue-generation model, is a major jolt to many university centers. In addition, current practices of development and then delivery of online education have incurred enormous start-up costs and are showing only sporadic return on investment. Attempts in project-based budgeting and accounting, licensing learning objects, sharing risk and reward, and putting chokeholds on development costs, are all part of a steep learning curve for universities.

It is clear that studies of budgetary and financing models of e-Learning are following a moving target. It has been the author's experience that, while the "going price" of per capita licensing of full-course electronic content was about US\$200 only a year ago, it is rapidly descending to the US\$50 range. In addition, the pricing of course components, such as learning objects, is quite new to content-providers. Comparative studies are needed of pricing models between the educational "industry" and other componentbuying industries, such as clothing manufacturing or high technology equipment assembly.

\section{Legal and Regulatory Requirements}

The rapidly changing environment surrounding copyright and intellectual property law means we must be more vigilant than ever. We must balance our hungry need to put our innovative program "out there" against the equal need for the university to be reasonably protected against risk of unintentional errors. An increasing number of institutions of higher learning are adopting well-crafted generic contracts for the licensing of courseware and content and putting into place revised copyright policies. Studies and interpretations of intellectual property rights are extremely valuable to the e-Learning community.

\section{Program Evaluation}

The literature on e-Learning program evaluation is naturally skimpy, since few fully developed programs have arrived at a stage where summative evaluation is possible. However, we should soon be seeing articles describing solid attempts and preliminary

findings based on in-progress or formative evaluation processes that go beyond the anecdotal. The research body of knowledge of formal program evaluation should be brought to bear on these endeavors.

In conclusion, I believe the distinction between face-to-face and online will soon merge in both quality standard setting and practice. As pedagogy and learning needs drive educational design, every possible mutation of physical and virtual meetings of minds will be created and be grounded in pedagogical purpose. It is a grand time to be an educator. 


\section{References}

American Association for Higher Education. (2000). Implementing the Seven Principles: Technology as a Lever. Washington, DC: AAHE

American Federation of Teachers. (2000). Distance Education: Guidelines for good practice. Washington, DC.: AFT (AFL-CIO)

American Federation of Teachers. (2001). Is Online Education off Course? New AFT Report Proposes Standards for Online Colleges. Press Release. Washington, DC.: AFT (AFL-CIO).

Astin, A. W. (1993). What matters in college? The four critical years revisited. San Francisco: Jossey-Bass.

Bates, A. (2000). Managing Technological Change. San Francisco: Jossey-Bass Higher and Adult education Series.

Berge, Z. (2001). Sustaining Distance Training: Integrating Learning Technologies into the Fabric of the Enterprise. San Francisco: Jossey-Bass.

Bindé, J. (1998). Communication and Intelligence: Distance education and culture.” Futures 30(8), $843-851$.

Bloom, B. (1964). Taxonomy of Educational Objectives: The classification of educational goals. New York: Longman.

Eaton, J. (2000). Core Academic Values, Quality, and Regional Accreditation: The challenge of distance learning. Washington, DC.: Council for Higher Education Accreditation.

Gibson, C. C. (1998). Distance Learners in Higher Education. Madison, WI.: Atwood

Gilbert, S. D. (2001). How to be a Successful Online Student. New York: McGraw-Hill

Innovations in Distance Education. (1998). An Emerging Set of Guiding Principles and Practices for the Design and Development of Distance Education. University Park, PA.: Pennsylvania State University.

Institute for Higher Education Policy. (2000). Quality on the Line: Benchmarks for success in Internet-based distance education. Washington, DC.: IHEP.

Institute for Higher Education Policy. (1999). What's the Difference? A Review of Contemporary Research on the Effectiveness of Distance Learning in Higher Education. Washington, DC.: IHEP.

Keegan, Desmond. (2000). Distance Training: Taking stock at a time of change. London: Routledge-Falmer.

National Education Association. (2001). Focus on Distance Education. Update 7(2). 
Schank, R. (2002). Designing World Class e-Learning. New York: McGraw-Hill.

Smith, S. (1999). An Overview of Internet-Based Education: Challenges facing online education providers. Berkeley, CA.: E-Curriculum Corporation.

Southern Regional Education Board (2000-2001). Essential Principles of Quality: Guidelines for Web-based courses for middle grade and high school students. Atlanta, GA.: SREB Educational Technology Cooperative.

Toffler, A. (1970). Future Shock. New York: Random House

University of Illinois. (1999). Teaching at an Internet Distance: The pedagogy of online teaching and learning. Chicago, IL.:Faculty Seminar.

Wahlstrom, C., Williams, B., and Shea, P. (in press). The Successful Distance Learning Student. Belmont, CA.: Wadsworth.

Western Interstate Commission for Higher Education. (2001). Best Practices for Electronically Offered Degree and Certificate Programs. Boulder, CO.: WICHE.

\section{Endnotes}

1. Please contact the author for access to a sample student course evaluation tool.

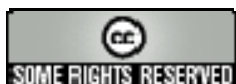


October - 2002

\title{
Measuring MBA Student Learning: Does distance make a difference?
}

\author{
Mark Kretovics \\ Kent State University \\ USA
Jim McCambridge
Colorado State University
USA

\begin{abstract}
This article reports on an exploratory research effort in which the extent of MBA student learning on twelve specific competencies relevant to effective business performance was assessed. The article focuses on the extent to which differences in student learning outcomes may be influenced by one of three different types of instructional delivery: oncampus, distance, and executive MBA. It affirms the high quality of learning that can occur via distance education and proposes a strategy to conduct summative, programlevel assessment. Specific findings include participants in all three groups self-reporting significantly higher scores on seven of twelve outcomes (e.g., goal setting, help, information gathering, leadership, quantitative, theory, and technology skills). It also notes that distance MBA students self reported significantly higher scores than oncampus students on the learning outcomes related to technology, quantitative, and theory skills, and higher scores on technology skills than the executive MBA group. Implications for further research are discussed.
\end{abstract}

Keywords: distance learning; outcomes assessment; management education; MBA program evaluation

\section{Introduction}

During the 1990s, there was serious discussion about the need to fundamentally reform higher education more than at any time in the previous100 years (Angelo, 1996). There was growing concern that the escalating cost of higher education was not linked to an increase in educational quality (Bragg, 1995). This sentiment continues and is reflected by the continuing pressure on universities, colleges, and academic departments to demonstrate the effectiveness of their efforts through some sort of performance measurement or "outcomes assessment" (Angelo and Cross, 1993; Banta, 1993; Ewell, 1997, 2000; Palomba and Banta, 1999; Palomba and Palomba, 1999).

The Association to Advance Collegiate Schools of Business - International (AACSB) adopted a position that requires business schools to measure the outcomes of their curriculum (Edwards and Brannen, 1990; AACSB, 1996). Previously, accreditation 
efforts focused on input measures such as teacher-student ratios, numbers of terminallydegreed faculty, number of volumes in the library, and the breadth and depth of curricular offerings (AACSB, 1980, 1984, 1987). In many of the specialized accrediting bodies, such as AACSB International, the focus has now shifted to value-added measures that assess what students have actually learned as a result of their participation in specific courses or in an entire academic program (Davenport, 2001).

As a result, in the late 1980s, colleges of business throughout the United States began to conduct frequent outcome assessments at both the undergraduate and graduate levels (Edwards and Brannen, 1990). Although there are no generally accepted or preferred ways to measure student learning and educational outcomes (AACSB, 1980, 1989; Beale, 1993; Kretovics, 1999), at the Master of Business Administration (MBA) level, historically the most common assessment techniques included student evaluations, employer perceptions/opinions, objective tests, and student exit interviews (Edwards and Brannen, 1990; Palomba and Palomba, 1999).

Each of these assessments typically occurs after a course is completed, as students are graduating, or in some cases, after they are in the workplace. However, the question remains as to whether students would demonstrate similar scores on an outcome measure before they enrolled in a course or program of study. Is it possible that students who already possess much of the knowledge and skills the program wishes to impart are already being admitted to MBA programs? We do not mean to suggest that students do not learn specific content in each of their classes; rather, we are concerned about the nature and extent of changes that may (or may not) occur on more global learning outcome measures.

This article reports on an exploratory research effort in which the extent of student learning outcomes on twelve specific competencies relevant to effective business performance was assessed. In addition, it discusses the extent to which student learning was influenced by one of three distinct types of instructional delivery: traditional oncampus, face-to-face (f2f) instruction; distance education (in this case, distribution of video recordings of on-campus classes combined with online faculty/student and student/student interaction), and executive education (f2f, cohort).

This research effort was undertaken as part of the college of business preparations for its re-accreditation review. Because our MBA program is presented using three forms of delivery, we were interested in identifying if the learning outcomes, as determined by an established assessment instrument, in each of the three programs were equivalent. The curriculum is approximately the same, meaning the course syllabus for each course across the three forms of delivery was the same, and in two of the three learning contexts, the instructors were typically the same. There are no elective courses in the MBA program. Although students graduating from the program receive the same AACSBaccredited degree, an important question remains unanswered: "Do students receive the same education? This article summarizes the authors' efforts to explore how to answer that question, within the context of the larger issue of outcomes assessment.

\section{Background and Purpose}

Clearly, one systematic way to measure student learning would be to compare measures of student competencies at the beginning and end of their educational experience. Another way to achieve similar results would be to identify two groups of essentially equivalent (demographically-speaking) students — one at the beginning of their learning experience and one at the end and analyze skill/ competency differences. Interestingly, 
according to Albanese (as cited in Boyatzis, Baker, Leonard, Rhee, and Thompson, 1995), few schools of business have conducted outcome studies that compare their graduates to their newly admitted students.

Using an established assessment instrument, this research examined the extent to which students in three contexts developed twelve learning skills/ competencies during the time they were enrolled in an MBA program at a large western US based university.

These three modes of delivery comprised: 1) a traditional on-campus face-to-face program, conducted synchronously in real time; 2) an executive program (EMBA) conducted in real time and face-to-face; and 3) a distance education program (SURGE) offered online through a dedicated software package called Embanet, and supplemented by video recordings of each on-campus class sessions.

Students enrolled in the distance program are never on-campus. All interaction with professors and fellow students is via the Embanet communications software that facilitates online chats, virtual team membership, and the sending and receiving of instructional materials. This distance education program is conducted asynchronously; that is, students receive videotapes of on-campus lectures/ discussions approximately five days after the on-campus class is recorded. Students are not members of a cohort group but work on project assignments either individually or in virtual project teams. Students may take up to eight years to complete their MBA degree.

For the more traditional on-campus delivery format, students attend on-campus evening classes twice a week. Like SURGE students, they may also move in and out of the program, may or may not take all courses in sequence, and often take more than two years to complete the MBA degree.

The executive education MBA group (EMBA) is a close-knit, cohort group that spends approximately two years together in a lock-step program. This group clearly develops significantly more cohesiveness during their time together than do students in either of the other two formats. They work on multiple projects in and out of class together, eat dinner together at each class meeting, and attend classes at an off-campus location in the heart of a major metropolitan area.

\section{Literature Review}

The industrial economies of the world have been transformed into information-based economies creating a greater need for higher education (Levine, 2001). This increase in demand, combined with technological advances, has had a significant influence on the way higher education is delivered. Correspondence courses, audio taped lectures, video taped classes, online, Web-based courses - all of these technologies have made it possible for education to be delivered in multiple ways to learners throughout the world.

The nature of distance education has changed dramatically over the years as technological advances have led to innovations in distance education delivery (Carter, 1996). The explosive growth of personal computer usage and the Internet have fueled the rise in distance learning available via the World Wide Web. Instruction using such technology is typically asynchronous, allowing students access to course materials whenever time permits and from wherever they may have access to the Internet (Barber and Dickson, 1996). Today, it is possible for students to enroll in and graduate from degree-granting programs at accredited institutions without ever having to be physically 
present on the campus (Fornaciari, Forte and Mathews, 1999; Kretovics, 1998). We recognize there are many interpretations of what constitutes distance education. In the specific case reported on in this article, we are referring to the use of mailed videotapes of classroom instruction to students' homes or places of work, and subsequent, online interaction to accomplish program objectives.

There have been numerous articles and papers written about the effectiveness of distance education for student learning. This research has consistently shown that regardless of discipline (e.g., library science, social work, physical therapy, management education, etc.), there are no significant differences in the learning outcomes of students enrolled in distance courses as compared to traditional face-to-face classroom settings (Haga and Heitkamp, 2000; Levine, 2001; Mulligan and Geary, 1999; O’Hanlon, 2001; Ponzurick, France, and Logar, 2000; Weigel, 2000; Worley, 2000). Several other authors have found no significant differences in student satisfaction (Arbaugh 2000c; Phillips and Peters, 1999; Baldwin, Bedell and Johnson, 1997) or participation rates (Arbaugh, 2000a; 2000b), for distance courses compared to face-to-face courses.

Distance education, once viewed as an anomaly on the traditional campus, has now become an accepted and, in some instances, an expected alternative delivery system (Murphy, 1996; Moore, 1997; Cook, 2000). Institutions with distance education programs have demonstrated that these programs are an effective method to deliver classes to a diverse population.

Regarding its use in colleges of business, Boyatzis, Cowen, and Kolb (1995) suggest that distance education may become accepted as a core activity within graduate management education. "The traditional view of executive education is under exploration at many schools and is being expanded to include distance learning” (Boyatzis, Cowen, and Kolb 1995, p. 48). Kedia and Harveston (1998) also notes that for universities "[t]hrough advances in distance learning, the ability to deliver management education at their own locations rather than having them come to campus is not only a possibility, but a growing trend” (p. 214). Additionally, Moore (1997), Fornaciari, Forte and Mathews (1999), and Arbaugh (2000a; 2000b) indicate that distance education is gaining acceptance as an alternative delivery option to the traditional on-campus experience.

It is important to note that the studies reviewed up to this point have all focused on individual courses rather than entire degree programs. The evidence supports the notion that within individual courses, distant learners learn as well and are just as satisfied with their education as are resident students. However, the literature falls short regarding the assessment of learning outcomes within accredited degree programs offered via different distance education modes (Ponzurick, France, and Logar, 2000; Weigel, 2000). This study focuses on the summative assessment of learning outcomes at the end of a program, as distinct from an individual course focus.

In addition, most studies have focused on synchronous (real-time/interactive) rather than asynchronous (delayed or recorded instruction) media. We compare student learning in two synchronous, face-to-face environments with learning in an asynchronous (distance education) environment.

What Moore (1989) said over a decade ago still appears to hold true today:

... the weight of evidence that can be gathered from the literature points overwhelmingly to the conclusion that teaching and studying at a distance, especially that which uses interactive electronic 
communications media, is effective, when effectiveness is measured by the achievement of learning, by the attitudes of students and teachers and by cost effectiveness (p. 30).

It is also important to note that in the late 1980s, criticisms of traditional management education were increasing at the same time MBA programs were moving toward distance education (AACSB, 1989). Those concerns were met within the academy by calls for increased measurement of student learning outcomes. Within graduate schools of business, the measures that appear to be most utilized are testing procedures, students' perceptions, and employer observations (Edwards and Brannen, 1990; Palomba and Palomba, 1999). Hilgert (1995) discussed life-changing developmental outcomes related to an executive MBA program experience, and Baruch and Leeming (1996) discussed graduates' perceptions of their MBA experience. However, these studies did not measure the learning outcomes at the end of an academic program.

\section{Method}

The two primary research questions investigated for this study were:

1. Does MBA students' self-reported performance on a learning outcomes assessment instrument change between the time students begin their MBA program and when they finish it? If so, were those changes uniform ones, or were there significant differences on key outcome measures?

2. Does MBA students' performance on the learning outcomes assessment differ as a function of the form of instructional delivery methodology (on-campus, SURGE, and EMBA)? If so, what is the nature of those differences?

\section{Sample}

The sample of participants in this study included those students enrolled in one of the three MBA programs (on-campus, SURGE, and EMBA) offered by the participating institution. Students who enrolled in a specific program were self-selected. SURGE students could complete their MBA without ever needing to be physically present on campus. While the admission requirements differ slightly for the three formats, there were no statistically significant differences between the groups based on pre-admission characteristics such as test scores, years of work experience, age, or gender. The students enrolling fall term $(n=222)$ were used as the entering pool and those who graduated at the end of the prior spring term $(n=115)$ comprised the exiting pool.

\section{Entering Students}

Of the total of 222 students admitted as new students for the fall semester, 83 students (37 percent) returned usable results and are defined as the entry participants in this study. Of this group, 27 students were female (35 percent), 50 (45 percent) were male, and six did not identify their gender. There were 17 SURGE students (20 percent), 12 EMBA students (15 percent), and 54 on-campus students (65 percent).

\section{Exiting Students}

Of the 115 students graduating the previous May, 39 students (34 percent) returned usable results. Of the 39 usable results, 16 were traditional on-campus students, 11 were 
SURGE students, and 12 were EMBAs. Gender data for the responding group indicates that 14 participants were female (36 percent) and 25 were male (64 percent).

The entering students' mean GMAT total score of 539.38 was not significantly different from the GMAT of the exiting students (535.40). Nor was there a difference in undergraduate GPAs: entering students' mean GPA was 3.10 verses a 3.13 of the exiting students (Table 1.). The gender breakdown in both groups was also similar (36 percent of entering students were female; 35 percent of exiting students were female). Finally, the work experiences of the two entry and exit groups were not significantly different. While these two groups are not exactly the same, on dimensions relevant to performance in this MBA program, the two populations may be treated as equivalent.

\section{Design Challenges}

There were several design challenges associated with this research. For example, without waiting for two or more years for students to complete an MBA program, how does one obtain meaningful performance data on student learning outcomes? In addition, what assessment strategy and/or instrument(s) will provide program-level insights, as distinct from course-level reactions?

Following the modified pretest-posttest or cross-sectional design used by that Boyatzis, Baker, Leonard, Rhee, and Thompson (1995) and Kretovics (1999) in similar research efforts, the authors compared scores of different entering and exiting student groups. The differences in the mean scores of each group were treated as group gain scores as if they were from the same groups. Pascarella and Terenzini (1990), and Terenzini (1989), noted that this cross-sectional methodology is common when measuring change in outcomes studies (see Table 1).

Table 1. Analysis of variance of GMAT and undergraduate GPA by time

ENTERING MBA EXITING MBA

\begin{tabular}{lllllr}
\hline Demographic Variable & $\mathrm{M}$ & $\mathrm{SD}$ & $\mathrm{M}$ & $\mathrm{SD}$ & $\mathrm{F}$ \\
\hline Undergraduate GPA & 3.10 & .43 & 3.13 & .42 & .330 \\
GMAT Total & 539.38 & 71.20 & 535.40 & 65.66 & .200 \\
$\quad$ Quantitative & 33.49 & 7.55 & 33.28 & 6.73 & .055 \\
$\quad$ Verbal & 30.57 & 6.58 & 30.61 & 7.63 & .002 \\
\hline No Significant Differences Found & & & & &
\end{tabular}

\section{Instrumentation}

The Learning Skills Profile (LSP) is a modified Q-sort that utilizes experiential learning skill typology in its analysis. This assessment is a typology of skills based on a foundation of learning styles and experiential learning theory. It is not designed to measure job performance nor specific academic competencies, but rather to measure one's learning skills. Learning skills are defined as "generic heuristic[s] that enable mastery of a specific domain having two components: a domain of application and a knowledge transformation process” (Boyatzis and Kolb, 1995, p. 5).

The LSP requires respondents to sort 72 learning skill cards twice, once into seven personal skill envelopes (the focus of this study) and a second time into seven job skill envelopes. It measures twelve learning skills considered important in business and management education (Boyatzis and Kolb 1995). The twelve learning skills are grouped 
into four major skill areas: 1) interpersonal skills; 2) information gathering skills; 3) analytical skills; and 4) behavioral skills, corresponding to the four phases of experiential learning as seen in Figure 1.

The groupings and definitions of each of the learning skills is as follows:

1. Interpersonal Skills. a) Help skills: the ability to be sensitive to others in gaining opportunities to grow, to be self-aware. b) Leadership skills: the ability to inspire and motivate others, to sell ideas to others, to negotiate, and build team spirit. c) Relationship skills: the ability to establish trusting relationships with others, to facilitate communication and cooperation.

2. Information Gathering Skills. a) Sense-making skills: the ability to adapt, to change, to deal with new situations, and to define new strategies and solutions. b) Information gathering skills: the ability to be sensitive to and aware of organizational events, to listen with an open mind, and to develop and use various sources for receiving and sharing information. c) Information analysis skills: the ability to assimilate information from various sources, to derive meaning and to translate specialized information for general communication and use.

3. Behavioral Skills. a) Goal setting skills: the ability to establish work standards, to monitor and evaluate progress toward goals, and to make decisions based on costbenefits. b) Action skills: the ability to commit to objectives, to meet deadlines, to be persistent, and to be efficient. c) Initiative skills: the ability to seek out and take advantage of opportunities, to take risks, and to make things happen.

4. Analytical Skills. a) Theory skills: the ability to adopt a larger perspective, to conceptualize, to integrate ideas into systems or theories, and to use models or theories to forecast trends. b) Quantitative skills: the ability to use quantitative tools to analyze and solve problems, and to derive meaning from quantitative reports. c) Technology skills: the ability to use computers and computer networks to analyze data and organize information, and to build computer models or simulations.

\section{Reliability and Validity of the LSP}

Using reliability information from Boyatzis, Baker, Leonard, Rhee, and Thompson (1995), Boyatzis and Kolb (1991) and Squires (1993) as a comparative base, a reliability analysis (using Cronbach's alpha) was conducted for this sample. The alphas found in this sample are consistent with those found by Boyatzis, Baker, Leonard, Rhee, and Thompson (1995), Boyatzis and Kolb (1991) and Squires (1993). According to Boyatzis and Kolb (1991), the LSP had internal scale reliabilities, as measured by Cronbach's alpha, ranging from 0.618 to 0.917 , with an average of 0.778. Squires (1993) also found the LSP to be internally consistent with alphas ranging from a low of .800 to a high of .935. The alphas in this study (see Table 2.) ranged from a low of .651 (Information Gathering) to a high of .911 (Technology), which are consistent with the previous studies. 
Kretovics and McCambridge - Measuring MBA Student Learning: Does distance make a difference?

Table 2. Reliability coefficients of the LSP learning skills

\begin{tabular}{lccc} 
Learning Skill & M & SD & Alpha \\
\hline Action & 32.13 & 5.39 & \\
Goal Setting & 28.69 & 5.74 & .876 \\
Help & 29.39 & 4.75 & .724 \\
Initiative & 30.68 & 5.49 & .868 \\
Information Analysis & 28.83 & 5.29 & .818 \\
Information Gathering & 27.81 & 4.47 & .651 \\
Leadership & 26.79 & 6.28 & .857 \\
Quantitative & 24.10 & 7.73 & .907 \\
Relationship & 30.77 & 4.73 & .810 \\
Sense Making & 28.83 & 5.35 & .826 \\
Theory & 26.68 & 6.38 & .870 \\
Technology & 25.35 & $\mathbf{8 . 0 6}$ & .911
\end{tabular}

The LSP is a self-report instrument, and as such, its use is supported in the literature by Kelso, Holland and Gottfredson (1977), Harrington and O'Shea (1993), Harrington and Schafer, (1996), and Kempen et al. (1996). These authors concluded that self-estimates of ability and/or aptitude are valid and self-reported data are as reliable as data gathered by more objective means. Additionally, Boyatzis and Kolb (1991), Boyatzis, Baker, Leonard, Rhee, and Thompson (1995) and Squires (1993) found the use of the LSP to be accurate measures of the twelve dimensions.

\section{Results and Discussion}

The initial analysis was conducted using a set of 12 independent two-way ANOVAs with time (entry and exit) and delivery methodology (on-campus, SURGE, and EMBA) as independent variables, and each of the twelve LSP learning skills as dependent variables. This analysis allowed simultaneous exploration of both research questions: Does participation in an MBA program have an impact on student learning? Does delivery methodology have an impact on student learning?

\section{Program Participation Findings}

One would hypothesize that students exiting the program would rate themselves higher on relevant outcome measures than students entering a program. Our findings support this expectation. With time as the independent variable, the analysis indicates that exiting students report an absolute increase on each of the twelve LSP learning outcome measures. Statistically significant $(\mathrm{p}<.05)$ results were obtained on seven of the twelve measures: goal setting, helping, information gathering, leadership, quantitative, theory, and technology (see Table 3.). These results compare favorably with those found in two studies reported by Boyatzis, Baker, et al. (1995). 
Kretovics and McCambridge - Measuring MBA Student Learning: Does distance make a difference?

Table 3. Results from Two-Way ANOVA - Learning skill by method and time

Method Time Interaction

\begin{tabular}{llll}
\hline Learning Skill & $\mathrm{F}$ & $\mathrm{F}$ & $\mathrm{F}$ \\
\hline Action & 1.844 & 0.384 & 0.050 \\
Goal Setting & 1.380 & $5.931^{\star}$ & 0.953 \\
Help & 0.931 & $4.493^{\star}$ & 0.021 \\
Information Analysis & 0.323 & $2.502^{\star}$ & 0.141 \\
Information Gathering & 0.721 & $4.380^{\star}$ & 0.026 \\
Initiative & 1.595 & 2.753 & 0.384 \\
Leadership & 0.105 & $4.038^{\star}$ & 0.046 \\
Quantitative & $5.182^{\star \star}$ & $4.333^{\star}$ & 0.349 \\
Relationship & 0.317 & 0.861 & 0.020 \\
Sense Making & 0.775 & 1.605 & 0.430 \\
Technology & $10.191^{\star \star}$ & $6.694^{\star}$ & 0.377 \\
Theory & $4.850^{\star \star}$ & $6.849^{\star \star}$ & 2.918 \\
\hline
\end{tabular}

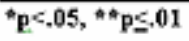

All skill areas within the analytical skills group were found to be significantly higher at exit than they were at entry. Only one each of the skill areas in the interpersonal group (i.e., helping) and in the information gathering group (i.e., leadership) were found to be significantly higher. Significant increases over time were not found on five of the outcome measures: action and initiative (behavioral group), sense making and information analysis (information gathering group), and relationship (interpersonal group).

It is not immediately evident why students did not show significant gains on these five skill areas, but did show significant gains on all components of the analytical group. Most of the students studied are also full-time employees and may have experienced significant training in specific areas prior to enrollment. Perhaps the incremental improvement contributed by program participation was marginal in the NS groups and more substantial in the analytical group. Perhaps these particular learning outcome measures were not sensitive enough to detect improvements in the identified outcome categories, or perhaps the small number of respondents was insufficient to reflect accurately the population's true variance.

The interaction between the variables of time and delivery methodology (see Table 3.) were not significant. Students' scores on the LSP increased from entry to exit regardless of the delivery methodology used. The post hoc analysis (Tukey) for the time variable determined that in each of the seven cases where a significant difference was found, the mean scores increased from entry to exit. By enrolling in and completing any one of these three MBA programs, scores will significantly improve on the learning outcomes of goal setting, helping, information gathering, leadership, quantitative, technology, and theory skill areas.

\section{Delivery Methodology Findings}

The second research question explored differences in student learning outcomes among the three MBA delivery methodologies. The results of this analysis concluded that only the analytical skill group (e.g., quantitative, theory, and technology) was significant across delivery methodologies (see Table 3.). The post-hoc analysis determined that the SURGE students rated themselves higher than did students participating in the other two delivery methodologies. Specifically, SURGE students reported significantly higher scores than the on-campus students on quantitative, theory and technology outcome 
measures, and significantly higher scores than did the EMBA participants on the technology outcome measure.

As expected, all three groups of exiting students rated themselves higher than did the three groups of entering students. Were these differences the result of pre-existing differences among the participating students? To answer this question, additional analyses were conducted to determine if the significant differences found for exiting students in the three programs could be attributed to differences that existed prior to program entry.

Data were divided into two independent sets: one containing entering student data and one containing the exiting student data. Using the independent variable and each of the twelve learning skills as the dependent variables, one-way ANOVAs enabled detection of any significant differences among entering students within each methodology. A similar analysis was completed for students exiting the program.

Significant differences were identified on two of the twelve learning outcome measures: technology and theory, with both findings favoring the distance students. Students entering the SURGE program rated themselves significantly higher on technology (see Table 6. and 7.) than did the on-campus students. The mean difference at entry was 6.15 $(\mathrm{p}<.05)$, while the mean difference at exit was $9.16(\mathrm{p}<.01)$, indicating that a portion of the difference found in exiting students may be attributed to a difference at entry.

The exiting group of students (see Table 4. and 5.) account for much of the variance in the main effect differences found on the learning outcome measures of technology and theory. It is not surprising that distance students would rate themselves higher on the technology skill, since they know going into the program that their primary means of communication with faculty and classmates will be via the Internet. Such students may have greater familiarity with technology applications, leading them to feel more comfortable using such tools to obtain their MBA degree. This potentiality was not explored here, and is recommended as an area for future research.

Table 4. Analysis of variance of LSP learning skills by method (Exiting Students)

\begin{tabular}{|c|c|c|c|c|c|c|c|}
\hline \multirow{2}{*}{$\frac{\text { Number: }}{\text { Learning Skill }}$} & \multicolumn{2}{|c|}{$\begin{array}{c}\text { ON-CAMPUS } \\
16 \\
\end{array}$} & \multicolumn{2}{|c|}{$\begin{array}{c}\text { SURGE } \\
11 \\
\end{array}$} & \multicolumn{2}{|c|}{ 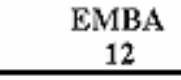 } & \multirow[b]{2}{*}{$\mathbf{F}$} \\
\hline & M & SD & $\mathrm{M}$ & SD & $\mathrm{M}$ & $\mathrm{SD}$ & \\
\hline Action & 32.62 & 5.09 & 34.82 & 4.83 & 32.00 & 6.10 & 0.880 \\
\hline Goal Setting & 29.50 & 4.75 & 31.73 & 5.36 & 32.00 & 4.71 & 1.136 \\
\hline Help & 30.12 & 4.62 & 31.55 & 3.48 & 31.50 & 4.73 & 0.484 \\
\hline Information Analysis & 29.75 & 3.61 & 30.91 & 6.39 & 29.92 & 6.03 & 0.171 \\
\hline Information Gathering & 29.19 & 5.18 & 29.91 & 3.78 & 28.75 & 5.22 & 0.167 \\
\hline Initiative & 30.56 & 5.91 & 33.91 & 5.05 & 32.67 & 6.03 & 1.184 \\
\hline Leadership & 28.50 & 6.95 & 28.73 & 6.40 & 28.83 & 5.59 & 0.010 \\
\hline Quantitative & 24.62 & 6.70 & 30.73 & 7.18 & 26.42 & 5.45 & 2.928 \\
\hline Relationship & 31.31 & 4.78 & 30.91 & 4.64 & 31.75 & 4.20 & 0.097 \\
\hline Sense Making & 28.69 & 6.07 & 30.73 & 6.56 & 30.50 & 4.64 & 0.518 \\
\hline Technology & 25.75 & 7.17 & 34.91 & 4.25 & 27.42 & 7.04 & $7.002^{\text {k }}$ \\
\hline Theory & 26.00 & 5.85 & 33.64 & 4.90 & 28.75 & 4.94 & $6.709^{k \star}$ \\
\hline
\end{tabular}


Kretovics and McCambridge - Measuring MBA Student Learning: Does distance make a difference?

Table 5. Multiple comparisons (Tukey HSD)

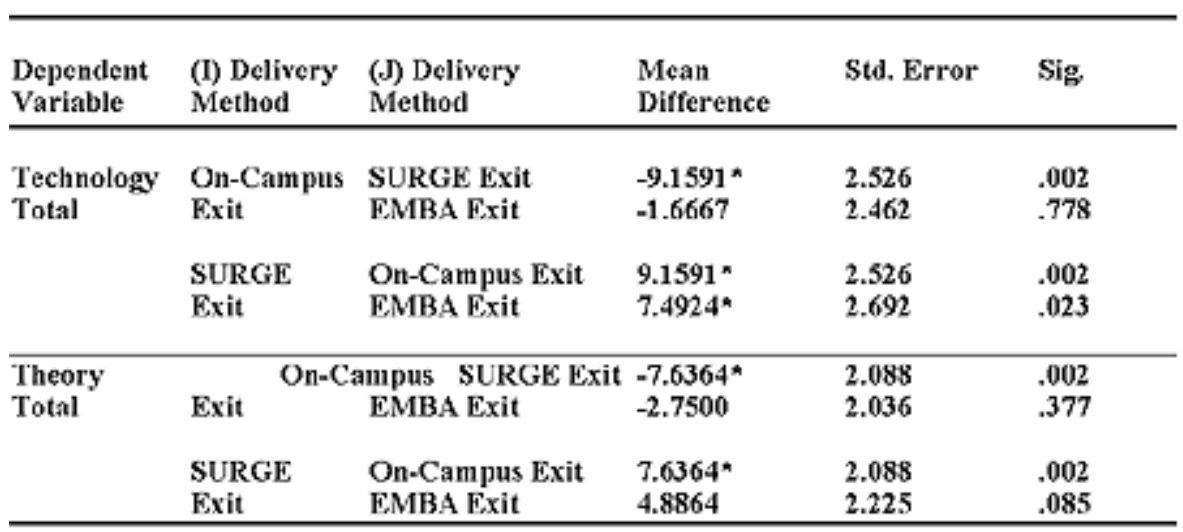

Table 6. Analysis of variance of LSP learning skills by method (Entering Students)

\begin{tabular}{|c|c|c|c|c|c|c|c|}
\hline \multirow{2}{*}{$\frac{\text { Number: }}{\text { Learning Skill }}$} & \multicolumn{2}{|c|}{$\begin{array}{c}\text { ON-CAMPUS } \\
54 \\
\end{array}$} & \multicolumn{2}{|c|}{$\begin{array}{c}\text { SURGE } \\
17 \\
\end{array}$} & \multicolumn{2}{|c|}{$\begin{array}{c}\text { EMBA } \\
12\end{array}$} & \multirow[b]{2}{*}{$\mathbf{F}$} \\
\hline & $\mathrm{M}$ & $\mathrm{SD}$ & M & SD & $\mathbf{M}$ & SD & \\
\hline Action & 31.67 & 5.47 & 33.88 & 4.09 & 31.83 & 5.56 & 1.182 \\
\hline Goal Setting & 27.91 & 5.81 & 30.06 & 6.67 & 26.83 & 3.64 & 1.295 \\
\hline Help & 28.33 & 4.63 & 29.53 & 5.29 & 29.25 & 3.25 & 0.532 \\
\hline Information Analysis & 28.78 & 4.66 & 29.00 & 5.33 & 27.75 & 5.72 & 0.257 \\
\hline Information Gathering & 27.26 & 3.87 & 28.29 & 5.06 & 26.58 & 3.37 & 0.681 \\
\hline Initiative & 29.83 & 5.37 & 30.94 & 5.80 & 30.67 & 4.16 & 0.339 \\
\hline Leadership & 25.44 & 6.39 & 26.59 & 7.44 & 25.92 & 4.50 & 0.211 \\
\hline Quantitative & 22.96 & 7.93 & 27.53 & 4.95 & 21.83 & 8.41 & 2.854 \\
\hline Relationship & 30.44 & 4.92 & 29.65 & 6.20 & 31.00 & 3.84 & 0.271 \\
\hline Sense Making & 28.39 & 4.84 & 29.53 & 5.28 & 27.75 & 5.80 & 0.493 \\
\hline Technology & 23.20 & 8.02 & 29.35 & 4.43 & 23.75 & 8.60 & $4.382^{\star}$ \\
\hline Theory & 26.13 & 6.04 & 27.12 & 5.33 & 25.58 & 6.59 & 0.264 \\
\hline
\end{tabular}

${ }^{*} \mathrm{p}<.0 \mathrm{~s},{ }^{* *} \mathrm{p}<.01$

Table 7. Multiple comparisons (Tukey HSD)

\begin{tabular}{llllll}
\hline $\begin{array}{l}\text { Dependent } \\
\text { Variable }\end{array}$ & $\begin{array}{l}\text { (I) Delivery } \\
\text { Method }\end{array}$ & $\begin{array}{l}\text { (J) Delivery } \\
\text { Method }\end{array}$ & $\begin{array}{l}\text { Mean } \\
\text { Difference }\end{array}$ & Std. Error & Sig. \\
\hline Technology & On-Campus & $\begin{array}{l}\text { SURGE Exit } \\
\text { Total }\end{array}$ & $-6.1492^{\star}$ & 2.096 & .012 \\
& Enter & EMBA Exit & -.5463 & 2.405 & .972 \\
& SURGE & On-Campus Exit & $6.1492^{*}$ & 2.096 & .012 \\
& Enter & EMBA Exit & 5.6029 & 2.692 & .023 \\
\hline
\end{tabular}

The increase in theory skills, defined as "the ability to adopt a larger perspective; to conceptualize, to integrate ideas into systems or theories, and to use models/ theories to forecast trends," is not as easily explained. Perhaps distance students, by virtue of their willingness to participate in such a program, may be manifesting the strength of their theory skill set, which includes quantitative skills, technology skills, and theory skills.

Alternatively, distance students' and on-campus/EMBA students may see different paths to achieve their MBA objectives. On the one hand, on-campus and EMBA students meet face-to-face with instructors regularly, and often develop a personal rapport with those individuals. The more intimate interaction that such settings provide is not available to 
distance students. The necessity for on-campus and EMBA students to apply their analytical skill set (i.e., theory-oriented skills) may be somewhat diminished by the opportunity to develop stronger interpersonal relationships with their instructors. Such relationships may provide avenues for increased class discussion interactions that shift the nature of instruction to a more collaborative one not possible in the distance context. Distance students may compensate for that lack by increasing the use of their analytical skills, relative to their on-campus counterparts. Their challenge becomes one of demonstrating their competence in less interpersonal and more abstract ways. In most instances, individual performance is the distance student's only avenue for establishing rapport with a faculty member. We believe this is an area for further study.

\section{Limitations to the Study}

The findings and implications of this exploratory study need to be considered in light of its limitations. The low participation rate and small sample size must be taken into account when interpreting these results. A larger sample would possibly have provided more informative insights into these complex relationships.

We believe the low participation was in part due to the nature of the assessment instrument. The card-sort methodology requires participants to physically sort the learning skills ratings (either by hand or online) rather than simply checking or circling a number. The process was time consuming. The students enrolled in these MBA programs have numerous interests competing for their time. With no incentives (e.g., extra credit points, financial incentives) provided to encourage participation, many students likely placed this project low on their priority list. A more aggressive follow-up protocol may have increased the response rate.

In addition to the variables on which we focused, confounding or extraneous variables may have influenced these findings. Among those variables are: students' work experience, the length of time taken to complete a degree, curriculum modifications during program participation, and class size variations. Many of the SURGE students and many on-campus students take courses on a part-time basis, often requiring more than three years to complete their MBA degree. In contrast, the EMBAs are engaged in a "lock-step" program that requires less than three years. These students spend considerably more time together than do students in the other two delivery methodologies. The group dynamics that undoubtedly influence the cohort group's learning experience are likely quite different and subject to different factors than are those for the non-distance ones. Finally, faculty may turnover, change their course focus, or their evaluation methods, and thereby alter student experiences in unintended and unknown ways.

Certainly, too, the particular methodology used in this exploratory effort to conduct program level assessment may be questioned. While the methodology provides a particularly parsimonious approach to examining what students learn during their program, legitimate questions may be asked about generalizing across populations that appear equivalent on certain dimensions, but may be quite dissimilar on others. More exploration in this area is encouraged.

\section{Conclusion}

If learning is the ultimate goal of the educational experience, it is up to members of the academy to ensure that this goal is met. "Outcome assessment is perhaps the best vehicle 
available at this time with great potential for affecting positive change and addressing the issues of accountability within higher education" (Kretovics 1999, p 133). That this research represents an attempt at "program-level," as distinct from "course" or "certificate" level assessment is an important additional step toward achieving the larger outcome assessment goal.

Summative evaluations are common at the course level. Most faculty conduct some form of end-of-course assessment to determine student satisfaction, areas for course improvements, and to assign a final grade. In many cases, formative evaluations occur during the progress of courses to determine if they are progressing in the intended direction. Professors conduct mid-course reviews of their courses and may adjust how and what they are teaching as a result. Examinations, peer evaluations, and other forms of assessment are also used to improve student learning and the overall course experience.

Such assessments (both summative and formative) are not as common at the program level. Our effort was to explore how one might do an empirically based, summative evaluation of an entire program and incorporate the critical component of assessing learning outcomes of distance students as well as those experiencing a more traditional learning context. We used an objective learning assessment instrument designed specifically to explore the extent of student learning in twelve key business skill areas identified as critical for our students' ultimate success. We focused not on individual course evaluations, but on student gain scores at the beginning and at the end of this defined learning experience. Such assessments are necessary in order to identify what students are learning in our MBA program and to identify in what areas additional attention may be required in order to achieve our overall program objectives.

Because of the unique nature of our program, we were also able to investigate differences across instructional delivery formats, adding a level of complexity to the design, but also providing additional insights to consider as we continue to refine our learning outcome assessment strategies in increasingly sophisticated learning environments.

Outcome assessments not only benefit program participants and external stakeholders, it can also provide significant benefit to the institution (Kretovics and McCambridge, 1998). The use of outcome studies can provide systematic measures that are necessary for continuous program improvement. Data gathered in outcome studies can be used to stimulate curriculum revision, program development, and improve instructional methodologies. Kirkwood (1981) states: "outcome measurement, examined dispassionately, becomes not a threat but an opportunity” (p. 67). When used properly, outcome measures can effectively bolster an institution's accountability to its various stakeholders (AACSB 1989).

As pressure mounts for academic institutions to document learning outcomes, and as the use of distance education methodologies as a pedagogical strategy increases, these insights regarding the assessment of distance program learning outcomes relative to those in more traditional formats become increasingly relevant. These findings challenge the assumption that face-to-face interaction between the student and the instructor is essential to the instructional process. They suggest that a virtual community, if developed properly, can serve student needs as adequately as more traditional notions of classroom community and "seat-time." Additionally, the results not only support the notion that distance learning is effective, but they also challenge the "no significant difference" research findings by indicating that distance students may, in fact, learn more that the traditional classroom based students. 
This study adds to the body of literature that attests to the quality of learning that takes place via distance education programs. Distance education is no longer a trend, nor is it a mode of education to be implemented in the future. It has arrived as a viable pedagogical strategy that expands educational opportunity for untold numbers of individuals seeking to expand their skill levels in meaningful and convenient ways. It is our hope that educators will continue to embrace distance education as an important, additional avenue for student learning to occur beyond the physical boundaries of the university community.

\section{Future Research Directions}

There are at least four areas in which additional research is encouraged: 1) designing and implementing program-level, summative evaluation methodologies; 2) developing valid and reliable, discipline-specific program-level assessment instruments; 3) developing assessment strategies that are uniquely tailored to the emerging Web-based technologydriven programs, and 4) exploring the relationship of the multitude of demographic and other factors to distance learning outcomes. Future researchers may wish to explore the effects of demographic characteristics such as gender, age, national origin, or prior work experience on distance learning outcomes. There are no limits to the challenges that lie ahead for all of us concerned with maximizing the student learning in the exciting world of distance education.

\section{References}

American Assembly of Collegiate Schools of Business (1980). Accreditation research project: Report of Phase I. AACSB Bulletin 15(2), 1 - 31.

American Assembly of Collegiate Schools of Business (1984). Outcome measurement project of the accreditation research committee: Phase II report. St. Louis, MO.: Author

American Assembly of Collegiate Schools of Business (1987). Outcome Measurement project: Phase III report. St. Louis, MO.: Author

American Assembly of Collegiate Schools of Business. (1989). Report of the AACSB task force on outcome measurement project. St. Louis, MO.: Author

American Assembly of Collegiate Schools of Business. (1996). Achieving quality and continuous improvement through self-evaluation and peer review. Accreditation handbook of the American Assembly of Collegiate Schools of Business. St. Louis, MO.: Author

Angelo, T. A. (1996). Transforming Assessment: High standards for higher learning. AAHE Bulletin April, 3 - 4.

Angelo, T. A., and Cross K. P. (1993). Classroom Assessment Techniques: A handbook for college teachers (2nd ed.) San Francisco: Jossey-Bass.

Arbaugh, J. B. (2000b). Virtual classroom versus physical classroom: An exploratory study of class discussion patterns and student learning in an asynchronous Internet-based MBA course. Journal of Management Education 24, 213 - 233. 
Arbaugh, J. B. (2000c). An exploratory study of the effects of gender on student learning and class participation in an Internet-based MBA course. Management Learning $31,503-519$.

Baldwin, T. T, Bedell, M. D., and Johnson, J. L. (1997). The social fabric of a team based M.B.A. program: Network effects on student satisfaction and performance. Academy of Management Journal 40, 1369 - 1397.

Banta, T. (1993). Summary and Conclusions: Are we making a difference? In T. Banta, (Ed.) Making a difference: Outcomes of a decade of assessment in higher education. San Francisco: Jossey-Bass.

Banta, T., Lund J., Black K., and Olander F. (1996). Assessment in Practice: Putting principles to work on college campuses. San Francisco: Jossey-Bass.

Baruch, Y., and Leeming A. (1996). Programming the MBA Programme: The quest for curriculum. Journal of Management Development 15, 27 - 37.

Beale, A. V. (1993). Are your students learning what you think you're teaching? Adult Learning 4, $18-26$.

Boyatzis, R. E., Baker A., Leonard L., Rhee K., and Thompson L. (1995). Will it make a difference? Assessing a value-added, outcome-oriented, competency-based professional program. In R. E. Boyatzis, S. S. Cowen, and D. A. Kolb, (Eds.) Innovation in Professional Education: Steps on a journey from teaching to learning. San Francisco: Jossey-Bass.

Boyatzis, R. E., and Kolb, D. A. (1991). Assessing Individuality in Learning: The learning skills profile. Educational Psychology 11, 279 - 295.

Boyatzis, R. E., Cowen, S. S., and Kolb, D. A. (1995). A learning perspective on executive education. Selections 11, $47-55$.

Boyatzis, R. E., and Kolb, D. A. (1995). From Learning Styles to Learning Skills: The executive skills profile. Journal of Managerial Psychology 10, 3 - 17.

Bragg, D. 1995. Assessing Postsecondary Vocational-Technical Outcomes: What are the alternatives? Journal of Vocational Education Research 20, 15 - 39.

Cook, K. C. (2000). Online professional communication: Pedagogy, instructional design, and student preference in Internet-based distance education. Business Communication Quarterly 63(2), 106 - 110.

Davenport, C. (2001). How frequently should accreditation standards change. In J. Ratcliff, E. Lubinescu, and M. Gaffney (Eds.) How Accreditation Influences Assessment: New directions for higher education. San Francisco: Jossey-Bass.

Edwards, D. E., and D. E. Brannen. (1990). Current status of outcomes assessment at the MBA level. Journal of Education for Business 65, 206 - 212. 
Ewell, P. (1997). Strengthening assessment for academic quality improvement. In M. W. Peterson, D. D. Dill, and A. Mets (Eds.) Planning and Management for a Changing Environment. (p. 360-381). San Francisco: Jossey-Bass.

Ewell, P. (2000). Accountability with a Vengeance: New mandates in Colorado. Assessment Update 12(5), 14 - 16.

Fornaciari, C. J., Forte, M., and Mathews, C. S. (1999). Distance Education as Strategy: How can your school compete? Journal of Management Education 23, 703 718.

Haga, M., and Heitkamp, T. (2000). Bringing social work education to the prairie. Journal of Social Work Education 36, 309 - 324.

Harrington, T., and O'Shea A. (1993). The Harrington-O'Shea Career Decision-Making System Revised Manual. Circle Pines, MN: Career Planning Associates, Inc. American Guidance Service.

Harrington, T., and Schafer W.D. (1996). A comparison of self-reported abilities and occupational ability patterns across occupations. Measurement and Evaluation in Counseling and Development 28(4), 180 - 90.

Hilgert, A. D. (1995). Developmental outcomes of an executive MBA programme. Journal of Management Development 14, 64 - 76.

Kedia, B. L., and Harveston, P. D. (1998). Transformation of MBA programs: Meeting the challenge of international competition. Journal of World Business 33, 203 217.

Kelso, G., J., Holland, J, and Gottfredson, G. (1977). The relation of self-reported competencies to aptitude test scores, Journal of Vocational Behavior 10, 99 103.

Kempen, G. I. J. .M., van Heuvelen, M. J. G., van den Brink, R. H. S., Kooijman, A. C., Klein, M., Houx, P. J., and Ormel, J. (1996). Factors affecting contrasting results between self-reported and performance-based levels of physical limitations. Age and Aging 25, 458 - 65.

Kirkwood, R. (1981). Process or outcomes: A false dichotomy. In T. Stauffer (Ed.) Quality: Higher education's principal challenge (pp. 63-68). Washington D.C.: American Council on Education.

Kolb, D. A. (1984). Experiential learning: Experience as the source of learning and development. Englewood Cliffs, NJ.: Prentice Hall.

Kretovics, M. (1999). Assessing the MBA: What do our students learn? Journal of Management Development 18(2), 125 -- 136.

Kretovics, M., and McCambridge, J. (1998). Determining what Employers Really Want: Conducting regional focus groups, Journal of Career Planning and Employment 58(2), $25-30$. 
Kretovics and McCambridge - Measuring MBA Student Learning: Does distance make a difference?

Levine, A. (2001). The remaking of the American university. Innovative Higher Education 25, 253 - 267.

Moore, M. (1989). Distant Education: A learner’s system. Lifelong Learning,2, pp. 8 11.

Moore, T. E. (1997). The Corporate University: Transforming management education. Accounting Horizons 11, 77 - 85.

Mulligan, R., and Geary, S. (1999). Requiring writing, ensuring distance-learning outcomes. International Journal of Instructional Media 26, 387 - 396.

Murphy, T. H. (1996). Agricultural Education and Distance Education: The time is now. The Agricultural Education Magazine 68, 3 - 11.

O’Hanlon, N. (2001). Development, delivery, and outcomes assessment of a distance course for new college studies. Library Trends 59, 8 - 27.

Pascarella, E. T., and Terenzini, P. T. (1990). How College Affects Students. San Francisco: Jossey-Bass.

Phillips, M. R., and Peters, M. J. (1999). Targeting rural students with distance learning courses: A comparative study of determinant attributes and satisfaction levels. Journal of Education for Business 74, 351 - 356.

Polomba, C. A., and Banta, T. W. (1999). Assessment Essentials; Planning, Implementing and Improving Assessment in Higher Education. San Francisco: Jossey-Bass.

Palomba N. A. and Palomba C. A. (1999). AACSB accreditation and assessment in Ball State University's College of Business. Assessment Update 11, 3 - 15.

Ponzurick, T., France, K. R., and Logar, C. (2000). Delivering Graduate Marketing Education: An analysis of face-to-face versus distance education. Journal of Marketing Education 22(3), 180 - 187.

Squires, P. (1993). An application of the Learning Skills Model and the Boyatzis Managerial Competency Model: Competencies that distinguish between superior and average performing managers within public libraries. (Doctoral dissertation, Texas Woman’s University 1993/1994) Dissertation Abstracts International, 55, AAC 9417360.

Switzer, J. S. (1994). Attitudes and Perceptions in a Television-Mediated Environment: A Comparison of on- and off-campus MBA students. Unpublished Master's thesis. Colorado State University.

Terenzini, P. T. (1989). Assessment with Open Eyes: Pitfalls in studying student outcomes. Journal of Higher Education 60, 644 - 664.

Weigel, V. (2000). E-learning and the tradeoff between richness and reach in higher education. Change 32(5) $10-15$. 
Kretovics and McCambridge - Measuring MBA Student Learning: Does distance make a difference?

Worley, R. B. (2000). The medium is not the message. Business Communication Quarterly 63(3), 93 - 106. 
October - 2002

\title{
Using Web-Based, Group Communication Systems to Support Case Study Learning at a Distance
}

\author{
Liam Rourke \\ University of Alberta \\ Canada \\ Terry Anderson \\ Athabasca University \\ Canada
}

\begin{abstract}
This study explored the capacity of Web-based, group communication systems to support case-based teaching and learning. Eleven graduate students studying at a distance were divided into three groups to collaborate on a case study using either a synchronous voice, an asynchronous voice, or a synchronous text communication system. Participants kept a detailed log of the time they spent on various activities, wrote a 1,500-word reflection on their experience, and participated in a group interview. Analysis of these data reveals that each group supplemented the system that had been assigned to them with additional communication systems in order to complete the project. Each of these systems were used strategically: email was used to share files and arrange meetings, and synchronous voice systems were used to brainstorm and make decisions. Learning achievement was high across groups and students enjoyed collaborating with others on a concrete task. Keywords: Distance Education, Case-based Learning, Collaboration Software, Online Learning.

The evidence in favour of case-based teaching and learning continues to mount (cf. Lundeberg, Levin, and Harrington, 1999). One interesting facet of this research suggests that group discussions are the active ingredient of case study learning. For on-campus students this is simple to arrange, but where does it leave students who are studying at a distance? Case studies are often used in distance education, but traditionally they have been implemented in an independent mode, with students reading a problem-centred or exemplary narrative in order to contemplate its central issues. This type of case-based teaching omits what may be the most important part of case-based pedagogy.

Fortunately, a wide array of Web-based communication software exists that supports various types of communication at a distance, including text or voice, person-to-person or multi-person, and synchronous or asynchronous interaction. The relative effectiveness of these systems to support collaboration among students is an important issue to distance educators.
\end{abstract}


Rourke \& Anderson - Using Web-Based, Group Communication Systems to Support Case Study Learning at a Distance

\section{Literature Review}

\section{Case-based Teaching and Learning}

The Educational Resources Information Centre (ERIC) (2002) describes case-based teaching as "the practice of using real or imagined scenarios, critical incident analyses, case studies, vignettes, or anecdotal accounts as pedagogical tools in fields such as law, business, medicine, and education.” Carter (1999) distinguishes between two types of cases. An exemplar is a brief episode that clearly epitomizes a concept or issue. These episodes illustrate a general category or exemplify a practice. Their purpose is to increase clarity, make information more interesting, and concretize and contextualize information. Problem-situations are problem-centered stories of practice that are used to examine and clarify the complexities of practice. The purpose of problem situations is to provide students with opportunities for interpretation, analysis, inquiry, and problem solving.

Research on case-based teaching and learning indicates that it may be used to achieve several goals. Lundeberg (1999) identifies four outcomes, the first of which is the development of connections between theoretical and practical knowledge. By comparing students' solutions to a case at the beginning and at the end of a semester, and by analyzing students' explanations of the transformations, Lundeberg and Fawver (1993) found significant changes in their ability to connect theoretical principles to situated problems.

Lundeberg (1999) identified reasoning and reflective decision-making as the second outcome. Problem-based cases, especially those that admit several equally valid solutions, help students to understand the tentativeness in knowing, in turn providing them with opportunities to marshal and evaluate evidence for judging alternative interpretations and actions. Harrington (1995) found that although many students were able to identify the problem in a case, most benefited from practice in using facts and issues from the case, allowing them to ground their identification of the problem or to justify their solution.

Lundeberg identifies meta-cognition — being aware and evaluative of how one thinks as the third outcome. Bartlett and Sather (1992) demonstrated that when students analyze cases, especially if they do so multiple times, they become aware of the assumptions, strategies, and cognitive processes that characterize their interpretations of events.

Lundeberg (1999) identified epistemological growth as a final outcome. Epistemology is the discussion of what counts as knowledge, as truth, and how these claims are justified. Barnet and Tyson (1999) found that the discussions by students focused on case studies "affect their views regarding the sources of knowledge. They shift from thinking that knowledge stems from external sources to thinking that knowledge can be gained from internal sources and peers” (p. 17).

\section{Learning through Discussion}

Several researchers argue that the key element in achieving each of these outcomes is the discussions that the cases stimulate. Shulman (1999), for instance, notes: "Discussion during case method sessions is an essential part of the meaning making process. The focus is not simply on the cases themselves, but also on group deliberation about cases to stimulate analysis, decision-making, and reflection” (p. 16). 
Research on learning through discussion shows that it can be effective in facilitating higher order learning; however, what actually happens as students interact in small groups seems to vary widely in terms of quality and quantity of discourse. Some researchers who have analyzed transcripts of educational small group interactions have characterized the process as "series of superficially-related monologues" (Rourke, Anderson, Garrison, and Archer, 1999) or "mindless and unreflective bull sessions" (Roby, 1988). Others have found evidence of increasing amounts of deep learning as discussion continues on a case (Arnitt, Slack, Green, and Beer, 2002). In best examples of educational discussion, students offer their interpretations which are supported by evidence, and challenge the opinions of others; in short, they engage in the types of processes that actually make discussion a valuable learning activity.

\section{Case-based Learning in Distance Education}

Recently, distance education instructors have become interested in whether case studies can be used in their courses. Borsa, Klotz, and Uzat (1998), for instance, connected graduate students from two universities via a listserv, and had them work collaboratively on a problem-situation type of case study. Aside from the customary educational objectives of their respective courses, namely synthesis and evaluation, these instructors wanted to give their students an opportunity to develop collaborative problem-solving skills. The authors concluded that the achievement of these objectives is dependent upon the instructors' and the students' facility with the technology, and with an appropriate implementation of case-based teaching principles. Cheney (2000) added a set of four cases to her distance learning course on special education and encouraged students to discuss the problem-situations with each other via a computer-based bulletin board. A survey distributed to each of the 56 students shows that they enjoyed reading other students' interpretations of the cases and comparing them with their own. Students also valued the input from professionals whom Cheney invited to participate periodically in the discussions. Comparing her face-to-face and distance teaching experiences, Cheney noted that the case method worked equally well in both situations; in fact, she reported that the lack of restrictions of time and place on the bulletin board prompted more diversity in the discussions.

The literature on the case method of teaching and learning in distance education contexts is meager. Perhaps this is because it has been complicated, expensive, and demanding to support case-based teaching and learning among students who are studying at a distance. However, the increasing availability of several types of Web-based, group communication software may overcome these problems. From the early and simple asynchronous, point-to-point, text systems such as email, to the latest synchronous, multipoint, multimedia systems, distance educators have a variety of communications tools from which to choose.

\section{Media Comparison}

What criteria should inform these choices? According to Clark (1994), media should never influence learning; therefore, any available, inexpensive, functional communication system should do. Yet, it seems unlikely that email would be as effective as, say, videoconferencing in supporting students' case study deliberations.

Media theorists argue that there are important differences. Communication researchers, such as Short, Williams, and Christie (1976) studying these phenomena in the 1970s, noted that interpersonal communication is a complex process, which, to be effective, 
relies on a host of signals, both verbal and nonverbal. They concluded that the ultimate communicative experience occurs face-to-face, and is devalued as one loses signals or channels: a face-to-face meeting is better than a telephone conversation, which in turn is more effective than a faxed memo. In the subsequent decade, Daft and Lengel (1984) presented an articulated version of this argument and suggested that media are differentially suited to specific tasks. For instance, face-to-face communication is beneficial for rhetorical and persuasive tasks, but is too rich and therefore distracting and inefficient for simple information transmission tasks. Sometimes when we call a person, we are hoping to get their answering machine.

\section{Purpose}

The purpose of this study is to explore the capacity of three Web-based, group collaboration systems to support case-based teaching and learning with students who are studying at a distance. The intent is to investigate whether unique features of the systems have any influence on the time that groups spend on the activity, the activities they engage in, and the satisfaction and learning achievement that ensue.

\section{Method}

This study can broadly be described as an action research project in that the primary researcher was investigating learning activity in his own class. Kemmis and McTaggart (1988) define action research as "a form of collective self-reflective inquiry undertaken by participants in a social situation in order to improve the rationality and justice of their own social practices, as well as their understanding of these practices and the situations in which these practices are carried out” (p. 5).

Students were recruited from an optional, advanced instructional technology course that was delivered to Masters of Distance Education students at a major open learning university. This program contained no face-to-face components; although none of the students engaged in our project had met each other face-to-face, many had participated in earlier courses. Of the 30 students enrolled in the course, 11 volunteered to participate in this research project, and the activity counted as a major component of their assessment in the course.

The 11 students were randomly assigned to three separate groups, each of which used one of three Web-based, group communication technologies to complete the case study: Wimba, an asynchronous voice system; MSN Messenger, a synchronous text system; and Tutor'sEdge, a synchronous voice system.

\section{The Case}

The instructor authored the case that the students analyzed. It was brief (134-words), and fits Carter's (1999) description of a problem situation. The case read:

The Board of SaveMore College has just developed a strategic plan calling for an increase of 50 per cent in enrolment using distance education technologies. The Faculty Association has threatened to strike if this new policy has any adverse effect on faculty workloads. The Vice President has asked your team to prepare a 3,000-word report for both the Board and the Association that alleviates the Faculty concerns and provides a set of Action Recommendations that allows implementation of the new strategic plan. The report should recommend a technology platform and an implementation plan, and it 
should also discuss the effect of your recommendations on the college budget. You may model SaveMore College on TechBC (http://www.techbc.ca) in terms of student numbers, budget etc., but feel free to devise fictional, but plausible plans in line with the fictional nature of SaveMore College.

The groups were directed to prepare a 3,000-word report to the 'Board' in 15-days, and to present and defend their recommendations to the 'Board' during a 30-minute audioteleconference presentation. The 'Board' consisted of the course instructor, one of his colleagues, and the first author.

\section{Data Collection}

In addition to the written and verbal reports, three sources of data were used in this study. Students were asked to maintain an activity-time log, write a reflection on the project, and participate in a group interview. Each of these sources of data is described in detail below.

In order to keep track of how much time each of the groups spent on the case study and what types of activities they were engaged in, they were asked to keep a log. Each participant received a table which, for each of the days of the case study, included a cell for activity, time, and number of emails exchanged with group members. Students were also provided with a closed set of numbered activities from which to choose. The set was adapted from Hunter's (1997) list of processes for case study group work. It included seven activities:

1. Learning/experimenting with the technology

2. Planning group work

3. Identifying and evaluating the problem

4. Working towards a solution individually

5. Working toward a solution collaboratively

6. Preparing the final product individually

7. Preparing the final product collaboratively

An additional purpose of the list was to provide students with guidelines for successful collaboration. Therefore, they were sent Hunter's unabridged version of the list. Activity two, for example, "planning group work," included the following description:

"Discussing what the case requires of the group, identifying any individual strengths of group members that apply to the case, deciding on the steps that will be taken and the amount of time that will be allotted to each one, and assigning group roles."

We also asked students to reflect on their experience by writing a 1,500-word essay. We encouraged them to consider issues such as how the communication technology influenced group communication, scheduling, efficiency of completing the assignment, individual learning, group problem solving processes, and critical thinking.

Once the students had completed the assignment and we had reviewed their logs and reflections, we arranged a group interview. The purpose of this interview was to explore the themes students had introduced in the reflections and logs and to test some of the conclusions we were drawing. The interview, which lasted one hour, was conducted via audio-conference. 


\title{
Results
}

The most powerful piece of evidence, and one of the most important for interpreting the data, is that none of the groups maintained the fidelity of their treatment. Each of the groups actively sought and used communication technologies other than the one they had been issued in order to complete the assignment. The synchronous voice and synchronous text groups relied heavily on asynchronous technologies such as email to complete the project, and the asynchronous voice group abandoned their technology altogether after the first week.

The students' reflections indicate that each of the assigned and contraband communication technologies was used strategically. Across groups, email was used for exchanging files and scheduling meetings. Synchronous voice tools were used for brainstorming, discussing, and decision-making. Learning management systems (LMS) were used for document management. One student described the process for us:

"[The synchronous text tool] was used to work collaboratively in real time on items that needed group consensus, to offer opinions, and to make suggestions for further elaboration. Email was used to exchange work, verify minor details between [synchronous text] sessions, and to help set up meeting times" (synchronous text group member).

Similar explanations were offered by members of the other two groups, including this one in which a student describes the optimal use of email, an LMS, and a synchronous voice tool:

\begin{abstract}
"Asynchronous communication is great for planning synchronous meeting times, passing along URLs and content ideas, and sharing files. Having [an LMS] - a visual site to post work-in-progress that everyone can access - allows people to see who is doing what, and how things are organized. When we found [the synchronous voice tool], that's when we became most passionate about the project. We were finally were able to discuss, plan and debate issues in real time. Issues that would take 2-3 days to discuss asynchronously could be resolved in a few minutes" (synchronous voice group member).
\end{abstract}

Each of the groups concluded that asynchronous tools had their purpose, but were too slow and inefficient for spirited discussion, especially in the context of an assignment with a two-week deadline. Similarly, the synchronous tools had their strengths, but introduced scheduling problems and did not allow time for reflection and deliberation during discussion.

An important issue in distance education, and in collaborative work in particular, is social presence - the ability of learners to project themselves into a community of inquiry as real people (Rourke, Anderson, Garrison, and Archer, 1999). Looking at the reflections of this group of students, it is apparent that the learning activity - collaborative case study - was an important factor that transcended modes of communication. As social presence theorists would predict, the synchronous voice group with their instantaneous and multimodal communication tool emphasized the strength and immediacy of their group's rapport. But, so did the asynchronous voice and synchronous text groups. The following evaluations, the first from a synchronous voice student and the second from a synchronous text student, provide an interesting comparison: 
"[The group members] and I built an immediate bond. It was amazing. The sessions provided an opportunity to put a voice to the names. It added a lot to my enjoyment of the project. The voice encouragement for each other was invigorating. Another person's voice saying, 'that budget information you sent was great' really makes you feel like an important part of the group" (synchronous voice group member).

"It is interesting how individual personalities come through in this type of communication even at a distance. We typically began each session with light banter, i.e., how's the weather, how's your day going, etc. In this way, I developed a visual image of the person, became familiar with them to an extent, and also learned some basic social parameters as to what to expect from particular individuals and even boundaries. Some were more serious than others, and some you could joke with. But, having arrived at those parameters, I was then able to tailor my communication in order to work effectively with the group, and with individuals" (synchronous text group member).

Although the instructional activity seemed to have more of an effect than the communication mode, the asynchronous voice group, who switched to synchronous voice mode after the first week, did report a difference:

"We got to know each other better, faster. The [synchronous voice tool] enabled us to joke around with each other and gave us opportunity to chat about things unrelated to the task at hand. This built a community out of our team" (asynchronous voice group member).

Table 1 presents a summary of the quantitative information gathered from the students' activity-time logs. Due to the small number of participants and the interpretive nature of the study only descriptive information is provided.

Table 1. Summary of the Groups'Activity-Time Logs

\begin{tabular}{|c|c|c|c|}
\hline & Asynchronous voice & Synchronous text & Synchronous voice \\
\hline \multicolumn{4}{|l|}{ Time (hours) } \\
\hline Total & 79 & 35 & 33 \\
\hline Daily Average $^{1}$ & 5 & 2 & 2 \\
\hline \multicolumn{4}{|l|}{ Email (no,) } \\
\hline Total & 118 & 39 & 23 \\
\hline Daily Average & 7 & 3 & 1 \\
\hline \multicolumn{4}{|l|}{ Activity $^{2}$} \\
\hline Mode & 5,6 & 5,7 & 5,6 \\
\hline
\end{tabular}




\section{Notes}

${ }^{1}$ Averages represent the sum of each of the individual group member's totals, divided by the number of group members, divided by the number of days in the activity (15 days).

${ }^{2}$ Activity 5 was working towards a solution (individually), which includes consulting with experts, reading pertinent documents, conducting a literature review, and testing solution ideas (against the literature, personal experience, experts, etc.,). Activity 6 was preparing the final product (collectively), which includes developing the framework for the final product, developing a clear statement of the problem, developing a statement of the alternatives considered, developing a detailed action plan with clear documentation of the support or this plan. Activity 7 was preparing the final product (individually), which includes fulfilling individual tasks that have been assigned by the group.

The group that was assigned the asynchronous voice technology spent the most time on the project and exchanged the highest number of emails with each other. Students that were assigned the synchronous voice technology spent the least amount of time on the project and exchanged the fewest number of emails. There is little evidence, however, to suggest that the differences are attributable to the technology or that the technology was more influential than the individual personalities. Moreover, each of the groups sought and used technologies other than the one that they had been assigned. This was most dramatic in the asynchronous voice group who abandoned their technology altogether after a few days.

The logs show that the groups spent the bulk of their time engaged in two of the seven possible activities: 1) working toward a solution; and 2) preparing the final product. The former, which included activities such as reading pertinent documents, consulting with experts, conducting a literature review, and testing solution ideas, was carried out independently. The latter, which involved developing the framework for the final product, a clear statement of the problem, a statement of the alternatives considered, and a detailed action plan, was carried out both individually and collectively.

Based on the information in the students' logs, it seems more work was done independently than collaboratively. Group interviews where we asked the students how they divided their time between working individually toward the group goals and working collaboratively as a group, provided an opportunity to investigate this issue. Contrary to what the logs had shown, students felt that collaboration accounted for the bulk of their time. They confirmed that they had done much of the work individually, but noted that each decision about what to do and the evaluation of what had been done was conducted collectively.

A similar version of events emerges from the students' reflections. One student's description of her group's process recurred in many reflections:

"In the beginning, we brainstormed all our thoughts, questions, and concerns. The next phase involved working on our topics individually. Then we would get together again and ask questions to clarify assumptions or to gain further understanding of the pertinent issues. Then we went back to work, and when we were done, we all showed each other our work, looked to see where changes should be made and discussed how topics could be integrated" (synchronous text group member). 
Only one of the eleven students offered a different opinion. This member, also from the synchronous text group, seemed proud of his group's ability to spend as little time as possible meeting with each other and as much time as possible working independently:

"The group was able to distribute responsibility and assign parts of the report to members of the group and to complete the project within the deadline. I thought that in our group it was probably 70 per cent independent and 30 per cent collaborative. I think that this is a reflection of the short amount of time allowed to complete the assignment (synchronous text group member).

Though much of the work needed to be done individually, almost all of the students were anxious to work collectively with the others.

Scheduling issues were a prominent feature in many of the reflections. All of the students in the Masters of Distance Education were adults and most were working fulltime. Members of each group mentioned prior commitments, family obligations, and job responsibilities when they talked about meeting synchronously with their group. Additionally, students in this program offered by an open university were living in regions across North America. One student touched on all three scheduling issues in her reflection:

"By far, the most difficult challenge of the whole exercise was finding a mutually convenient time to meet online. The group members were from three different time zones and we all had family and work obligations. [One group member] was from Alberta and [the other two group members] were from Ontario and Florida. It took us five days before we could find a suitable meeting time. Eventually, the group settled into meeting online around 6 p.m. my time, which was an extremely inconvenient time for me as I have a two and five year old. I was unavailable during the most important times for my family - mealtime, evening time, and bedtime. I don't think we can underestimate the demands that synchronous communication can place upon working adults with family and other obligations" (synchronous text group member).

Of course, scheduling issues are not unique to distance students. However, an additional problem introduced by the Web-based communication technologies was Internet traffic. Once the groups had agreed upon a schedule that worked around all of their prior commitments and time zones, they still had to determine whether their technology would work well during that time.

The scheduling problems inherent in synchronous communication technologies were expected to be one advantage for the asynchronous technologies. However, members of the asynchronous group made comments such as:

"We found that meeting at approximately 5 p.m. MST was the most viable option because of the three-hour time zone difference amongst our group." And "It was very time consuming to refresh the browser, expand each of the message threads, record a new message, and then repeat the process" (asynchronous voice group members). 
The reason users of the asynchronous system were concerned about finding a good meeting time and refreshing their browsers is because their strategy was to be online simultaneously and attempt to communicate with each other synchronously. One member explained: "Our group tried to use the asynchronous voice technology as a synchronous communications tool when we needed to brainstorm solutions, have discussions, and distribute the tasks” (asynchronous group member). Thus, the scheduling problems were not restricted to synchronous technologies.

When students mentioned learning in their reflections, they referred to things such as learning how to use the software and learning how to work in groups, but the comments that were most interesting were their references to learning the course content.

Three issues were prominent in their descriptions of learning the course content. First, students said that they gained the most knowledge about the particular section of the case that they were working on. This may not seem surprising; however, put another way, one could say that some of students were able to come away with surprisingly little knowledge about other parts of the case. One of the synchronous voice students, for instance, reported:

"My own learning was greatest in the areas in which I was 'person most responsible' and involved consulting the course textbook, study guide readings, and researching online."

A synchronous text group member recounted a similar experience, and distinguishes it from learning about the other group members' foci:

"Conducting the readings and doing the research on my topic was a good opportunity to learn a lot about [that topic]. I expected to learn a lot about [the others' topics], but there was only enough time for me to get a superficial understanding of their issues and how they affected my part of the report."

Students attribute a large part of their learning, particularly the higher order learning, to collaboration with their group members. Some of the higher order processes students described included self-reflection, knowledge application, decision-making, and criticism and revision of concepts and solutions. A student in the synchronous voice group described the process:

"At the outset it seemed that there was some disagreement on some of the key issues. As the issues were discussed and personal experiences were shared, the group seemed to integrate each other's thinking and move toward a consensus. Brainstorming was used to help our group solve the problem as a number of suggestions were narrowed down to the most appropriate choice. The sharing of ideas seemed to make all of the members more aware of the complexities of the issue."

These types of processes were found across groups and communication systems.

An important element in learning for these students was the motivation prompted by the group work. For some, this came as a surprise because of negative experiences they had in the past. For example, one student in the asynchronous voice group asked: 
"I went into the project expecting the usual. That is, I'd work myself to the bone while my partners talked about philosophical or personal issues that had little to do with completing the task at hand. Why would I put myself in such a position?”

Nonetheless, by the time the students wrote their reflections, this attitude had changed. The same student, fifteen days later wrote:

"If all my future collaborative projects are like this one, I cannot wait for my next group project! Connecting with my group-mates energized and invigorated me."

Aside from the general enthusiasm and satisfaction attributable to the group work, it also prompted some of the students to work harder. "To know that there would be questions to answer, and not wanting to be guilty of non-performance, drove me to have my work in ready-plus mode” said one student. Another student from a different group expanded on the idea:

"As I wanted to contribute to the group discussion in a meaningful way, I believe I was more motivated to read and digest the course materials in anticipation of the group work. I had previewed all of the course materials and had read extensively about [the topic] before the commencement of the project (synchronous text group member).

\section{Discussion}

The purpose of this investigation was to explore the relative capacity of various Webbased, group communication systems to support case-based teaching at a distance. Learning achievement and satisfaction levels among this group of students indicate that the systems were effective in supporting this method of learning. But the question remained: Which communication system was most effective at supporting this learning activity? Participants showed us that case-based learning involves several activities, and they judiciously selected appropriate media for each activity. Asynchronous technologies, such as email, were useful for arranging meetings and sharing provisional documents, while synchronous technologies were more useful for brainstorming and decisionmaking. Daft and Lengel's (1984) media richness theory, which argues that media are differentially suited to different tasks, is most consonant with these findings.

Unfortunately, the design of our study did not enable us to attribute many of the interesting outcomes to a particular communication system. Students' activity-time logs, for instance, indicate that the asynchronous group took twice as long as the synchronous groups to complete the assignment. However, it is not clear whether this is a function of the communication mode, the group personalities, or some other factor. Subsequent researchers may design studies that will allow them to probe questions such as these more decisively.

Nonetheless, this exploratory study does yield some implications for instructional designers who wish to exploit the power of the case study method in a distance education context. Based on the results of this study and the work of communication theorists (cf. Daft and Lengel, 1984; Short et al., 1976), it seems convincing that media are differentially suited to various tasks. Therefore, the more modes of communication to which the students have access, the more likely they are to have successful and satisfying 
interactions with their group members. Our attempt to limit the groups to one communication technology prompted them to first, attempt to use asynchronous technologies in the synchronous mode and, second, to abandon their assigned technology in favour of others they thought would be more useful.

Instructors should also note that some of the students commented that they learned the most about the section of the case study on which they worked. In this case study, for example, it was common for groups to divide the case into three sections - budgeting, learning management systems, and change issues - and then assign one section to each member. Students then developed a thorough understanding of their section, but could remain disappointingly uninformed about the other topics. Any other assumptions about students' learning may be inaccurate.

\section{References}

Armitt, G., Slack, F., Green, S., and Beer, M. (2002). The development of deep learning during a synchronous collaborative online course. Paper presented at Computer Supported Collaborative Learning '02. Boulder. Co.: University of Colorado. Retrieved Aug. 1, 2002 from: http://www.newmedia.colorado.edu/cscl/70.pdf

Clark, R. E. (1994). Media will never influence learning. Educational Technology Research and Development, 42(2), 21 - 29.

Borsa, J., Klotz, J., and Uzat, R. (1998). Utilizing distance learning and the case study method to enhance instruction between two universities. ERIC: ED 429270.

Cheney, C. (2000). Combining distance education and Web applications for a course on collaboration in special education. ERIC: ED 439889.

Clark, R. E. (1994). Media will never influence learning. Educational Technology Research and Development 42(2), pp. 21 - 29.

Educational Resources Information Center (2002). “Case method,” Scope note for.

Hunter, W. (1997). Case-based teaching workshop. Retrieved, May 3, 2002 from: http://www.fp.ucalgary.ca/hunter/

Kemmis, S., and McTaggart, R. (1988). The action research reader (3rd ed.). Victoria: Deakin University Press.

Lundeberg, M., Levin, B., and Harrington, H. (1999). Who learns what from cases and how? The research base for teaching and learning with cases. Mahwah, NJ.: Lawrence Erlbaum Associates.

Lundeberg, M. (1999). Discovering teaching and learning through cases. In M. Lundeberg, B. Levin, and H. Harrington (Eds.) Who learns what from cases and how? The research base for teaching and learning with cases (p. 3-23). New Jersey: Lawrence Erlbaum Associates.

Roby, T. W. (1988). Models of discussion. In J. Dillon (Ed.) Questioning and Discussion: A multidisciplinary study (p.163-191). Norwood, NJ.: Ablex. 
Rourke, L., Anderson, T. Garrison, D. R., and Archer, W. (1999). Assessing social presence in asynchronous, text-based computer conferencing. Journal of Distance Education, 14(3), 51 - 70.

\section{Acknowledgements}

The authors wish to thank the developers of TutorsEdge (www.eluminate.com), Wimba (www.wimba.com) and MSN Messenger *www.messenger.msn.com) for the free use of their software products for this project.

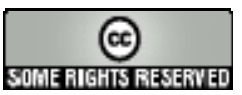


October - 2002

\title{
When is a Learning Object not an Object: A first step towards a theory of learning objects
}

\author{
Mike Sosteric and Susan Hesemeier \\ Athabasca University, Canada - Canada's Open University
}

\begin{abstract}
For some, "learning objects" “ are the "next big thing” in distance education promising smart learning environments, fantastic economies of scale, and the power to tap into expanding educational markets. While learning objects may be revolutionary in the long term, in the short term, definitional problems and conceptual confusion undermine our ability to understand and critically evaluate the emerging field. This article is an attempt to provide an adequate definition of learning objects by: a) jettisoning useless theoretical links hitherto invoked to theorize learning objects; and b) reducing the definition of learning objects to the bare essentials. The article closes with suggestions for further research and further refinement of the definition of learning objects.
\end{abstract}

\section{Introduction}

Fill your bowl to the brim and it will spill. Keep sharpening your knife and it will blunt. Chase after money and security and your heart will never unclench. Care about people's approval and you will be their prisoner.

The advent of the Internet and the expansion of the World Wide Web have created new communication options for our society. New options for leisure activities (surfing the Web, playing games), commerce (Web shopping), and social development (Web activism), to name only a few, have all emerged within the last few years. It is not hyperbole to say we now live in a connected society where access to information has become the defining life characteristic for many of those fortunate enough to enjoy easy access to information technologies. It is not surprising that this enhanced access to information has influenced the way we live our lives. Authors will disagree about the quality and quantity of this influence (Webster, 1997), but few would care to argue that changes have been significant in one aspect or another.

Our concern in this article is with information technology as it is applied to the educational process. But our concern is not with information technology and education in general, but with a specific example of information technology that is being created to bolster the educational system (K-12 and post secondary), known as a learning object.

What is a learning object? Good definitions are difficult to find, and it is really the task of this article to begin the process of developing an adequate definition by: a) jettisoning inappropriate theoretical formations; and b) simplifying our definition of learning object. 
For the purposes of introduction, however, we can say that a learning object is a digital file used in educational settings to support instruction (from K-12, and all levels of postsecondary instruction). Later in this article, we will discuss how learning objects have special characteristics that distinguish them from more mundane learning resources of the type most educators would be familiar with.

Learning objects have been on the educational agenda for several years now (IEEE, 1998). Even so, the corpus of research on learning objects is less than satisfying. This does not mean that research has not been conducted. Organizations such as the IMS Global Learning Consortium (IMS) ${ }^{2}$ and the IEEE $^{3}$ have contributed significantly by helping to define indexing (metadata) standards for object search and retrieval. There has also been some commercial (Baron, 2000) and educational work accomplished (Careo, 2000). But there is a vacuum in descriptive, analytical, and critical examinations of learning object technologies.

This article is our entry into what will hopefully be a dynamic and energetic fray. In an attempt to capture their true nature, we provide an overview of learning objects. In order to evaluate the usefulness of thinking about learning objects in terms of Computing Science (CS) programming techniques, we start by looking at past attempts to define learning objects, and then continue by looking at the ostensible link between learning objects and Object Oriented Programming theory (OOP for short). We end our examination of OOP theory by concluding that CS OOP theory has little to offer in our attempt to define and understand learning objects. Finally, we conclude the article with a short working definition and suggestions as to where future work is needed in the fleshing out of our understanding of learning objects.

\section{What is a Learning Object?}

More than a few words have been produced while trying to give a clear picture of what learning objects are all about. Yet confusion is apparent in the literature, as no consistent definition of learning objects seems to exist. A recent article in Learning Circuits highlights this difficulty.

It may surprise you that no single learning object definition exists within the e-learning industry. Learning objects are different things to different $e$-learning professionals. In fact, there seems to be as many definitions as there are people to ask (ASTD, 2002: 3).

Several problems have made defining learning objects difficult. One bothersome difficulty is that existing definitions are far too general to be of any use in identifying, developing, or criticizing learning objects. As an example, consider the ASTD (2002: 3) article cited above. It begins with the following definition of a learning object: "At its most basic level, a learning object is a piece of content that's smaller than a course." Friesen (2001) also illustrates this particular problem when he quotes from an IEEE definition of learning objects:

The Learning Technology Standards Committee (LTSC) defines an object as "any entity, digital or non-digital, which can be used, re-used or referenced during technology supported learning." The LTSC provides examples of these objects, including "multimedia content, instructional content, learning objectives, instructional software and software tools, and persons, organizations, or events referenced during technology supported learning." 
To paraphrase the above definition, a learning object is "anything that can be used during technology supported learning." The definition lumps all digital and non-digital "things" into the learning object category. Obviously, a definition that includes "everything" is not a definition at all. There is nothing in such a definition to suggest how we might distinguish a learning object from more mundane technological support or any other learning resource such as a computer or a keyboard, for example, and there is certainly nothing to assist us if we want to develop a learning object. All that we know from this definition is that learning objects are "something" used in some sort of learning environment.

We realize, of course, that one might say that anything digital could be used as a learning object. For example, a picture of a rose (or the actual rose itself) could be used in various scientific disciplines to illustrate biological, chemical, or psychological processes. However, this loose definition is problematic for two reasons. On the one hand, most authors seem to assume that objects are more than mere digital files. As we will see below, most authors like to attribute several special features to learning objects such as reusability, searchability, etc. At the least, our definition needs to include these special features. Of course, including these special features will have the net result of excluding those digital files that do not have the required features.

On the other hand, "things" (and this includes more mundane things used as traditional learning resources) do not become useful in learning environments until they are attached a context to them. Consider this picture http://aloha.netera.ca/uploads/crdc/unt5049b.jpg, which exists inside a Canadian learning repository as a learning object. This image is a piece of multimedia content that can be used during technology-supported learning. However, just looking at the picture linked above teaches us nothing. Are we to learn something about religious devotion, or respect for elders, or multiculturalism, or foreign languages, or the creation of posters? We simply do not know this from casual observation. What would make the above image a "learning object," would be additional information that would allow an instructor or instructional designer (or perhaps even an automated program) to know how to use the object in an educational setting.

In the low-tech world, the instructor normally provides this contextual information, by harvesting objects and putting them onto projection screens, or passing them around to students while engaging in lengthy discourse about them. In fact, instructors provide much more than just contextual information; they interpret objects and creatively reorganize their context, and this requires a vast amount of background information. This is a critical function of instructors and its importance is recognized in the learning object literature. By developing learning object metadata standards that provide the necessary context for the educational resource, the IMS (2000) and the IEEE have helped to provide the necessary infrastructure for contextualized learning objects that has, in the past, been provided almost solely by instructors.

In the literature on learning objects, the importance of context is not in question. The point we are asserting here is that because "context" is so important, it should be made part of the definition. A learning object is not just any digital file or any object under the sun. At the least, anything that could be considered a learning object would need associated instructional information. This occurs even with mundane "objects.” Images are often placed in textbooks, but the images themselves are always captioned and explanatory material is provided in the text. Of course, in technological settings where the goal is to use these objects in semi-automated instructional systems, the provision of this type of instructional context is critical. 
Although authors tend to want to include digital and non-digital content as learning objects, we do not feel this is useful. As they are applied in the real world, learning objects are clearly digital objects. Repositories and standards, and all the work being done on learning objects, refer to digital objects. It makes little sense to include a universe of learning resources when there does not seem to be any real intention to include them in practical work.

A look at the pedagogical intention behind the production of objects is also necessary. Clearly, although many digital objects could be construed as learning objects, not all digital files are learning objects. Pornography is one obvious example. Other objects may or may not become learning objects, as pedagogical intent is required for that to happen. For example, a Unix utility program for listing files may be a learning object. But it would only become a learning object if someone decided to use it as one. Intent is necessary, and this brings us to the last component of the learning object definition: associated metadata. We have already seen that files are not useful as learning objects without the provision of context. A rose might be a rose by any other name, but it is not an object unless there is some discourse associated with it.

Armed with this initially simplistic perspective on learning objects, let us now take a first stab at providing a definition:

A learning object is a digital file (image, movie, etc.,) intended to be used for pedagogical purposes, which includes, either internally or via association, suggestions on the appropriate context within which to utilize the object.

There is reasonable clarity in this definition. It usefully limits the universe of learning objects, and it flows from current literature and practice.

If writers in this area stopped at this definition, things would be acceptable. However, writers in this area seem to want to make learning objects "sexier" than they really are. As a result, several attempts have been made to dress up the definition of learning objects. One of the most counterproductive approaches has been for theorists to draw on the discipline of computing science and, in particular, object-oriented programming (OOP) for additional theoretical grist. ${ }^{4}$ We can see this in the following definition by Quinn (2000):

The learning object ( $L O)$ model is characterized by the belief that we can create independent chunks of educational content that provide an educational experience for some pedagogical purpose. Drawing on the object-oriented programming (OOP) model, this approach asserts that these chunks are self contained, though they may contain references to other objects; and they may be combined or sequenced to form longer educational interactions. These chunks of educational content may be of any type - interactive, passive - and they may be of any format or media type. A learning object is not necessarily a digital object . . .

(Quinn, 2000).

Note again the tendency to make anything under the sun a learning object. But putting this aside, our real concern is to assess whether or not we can usefully extract a sensible understanding of what a learning object might be from CS definitions of objects. According to Quinn's definition above, learning objects are: a) self contained; b) modular (i.e., they can be sequenced, combined, etc.); and c) interactive or passive. 
The definitional extensions provided by Quinn are less than satisfactory. The problem is that even though Quinn makes a connection to OOP theory, the definition of a learning object is reduced to a thin description of features (i.e., objects can be combined, sequenced, and contain "references") that do not contribute to our ability to understand or visualize learning objects. It almost seems as if Quinn does not really understand what a CS object is all about and can only provide a terminological gloss.

We could ignore the inadequate definition of learning objects above if it were the only one. But other authors also provide similarly thin definitions linked to OOP theory. Robson (1999), for example, begins his definition by stating that learning objects are learning resources in an "object-oriented model” and then goes on, like Quinn, to provide terse feature sets for learning objects:

Learning resources are objects in an object-oriented model. They have methods and properties. Typically methods include rendering and assessment methods. Typical properties include content and relationships to other resources (Robson, 1999).

As with Quinn's definition, the problem with Robson's definition is one of depth. His definition may only be useful to someone who has experience with object oriented programming methodology. But without significant background knowledge, we have no way to know what exactly a method is, what the properties are, and what these technical features of learning objects provide in the way of functionality for learning objects. In short, without knowing more about CS's application of object oriented programming, how can we assess the appropriateness of CS theory to our understanding of learning objects?

The answer to that question is that we cannot. And this is a significant problem. Authors toss around theoretical connections to object oriented theory with insufficient theoretical rigor. Although there is nothing wrong with borrowing concepts from object theory to develop our ideas about learning objects, we must do so carefully. We cannot just adopt the concept of "objects," and its related terminology such as "references," "methods," etc., without carefully specifying whether or not a method for a learning object is the same as a method for a code object.

The bottom line here is: whether or not code objects really provide suitable guidance for us in theorizing and creating learning objects? We believe the answer to this question is a resounding "no." We believe most authors will admit this when pressed. As Friesen (2001) notes, not only is there conceptual confusion in the literature and no general agreement on how to map the features of OOP programming objects to learning objects, the fit between the two also seems to be counterintuitive.

What senses of the word "object" are [sic] can be profitably applied to the notion of "educational objects"? The separation [sic] educational object and metadata seems to run counter to the combination of code and data that is said to define software objects (Friesen, 2001).

What to make of this then? We believe we need to jettison object oriented theory altogether and proceed to define learning objects on their own terms. However, recognizing that there may be some resistance to this strategy, in the next section we take a more detailed look at the core concepts of OOP theory to see how well they apply to learning objects. The next section is moderately technical and can be skipped by those 
readers so inclined. The conclusion, at the end of the article, simply suggests that we reject the connection to OOP theory when defining learning objects.

\title{
The Etiology of Learning Objects
}

\begin{abstract}
"Object-orientation is a new technology based on objects and classes. It presently represents the best methodological framework for software engineering and its pragmatics provides the foundation for a systematic engineering discipline. By providing first class support for the objects and classes of objects of an application domain, the object oriented paradigm precepts better modeling and implementation of systems. Objects provide a canonical focus throughout analysis, design, and implementation by emphasizing the state, behavior, and interaction of objects in its models, providing the desirable property of seamlessness between activities."

\section{Robert John Hathaway}

"Object-oriented languages and systems are a developing technology. There can be no agreement on the set of features and mechanisms that belong in an object oriented language since the paradigm is far too general to be tied down. We can expect to see new ideas in objectoriented systems for many years to come."
\end{abstract}

\section{Oscar Nierstrasz $z^{5}$}

As noted above, the concept of an "object" is taken from CS theory where it has a precise, if evolving, meaning. One of the most succinct definitions of computing objects we have found to date is provided by Conway (2000, p2), who notes: "An object is an access mechanism for data. In most object-oriented languages that means that objects act as containers for data or, at least, containers for pointers to data. But in the more general sense, anything that provides access to data - a variable, a subroutine, a file handle - may be thought of as an object."

This is a useful starting point. Objects are containers of data. This does not contradict our definition of learning objects - i.e., pedagogical intent, associated metadata, digital file - nor does it enhance the definition we have set up so far for the learning object. Our definition that learning objects are digital files implies, without needing comment, that these objects would contain data. With this in mind, we will need to delve deeper into OOP theory to see sharper contradictions.

A container of data, digital or otherwise, is somewhat useless unless there is a way to access and manipulate data. And in fact, OOP theory extends the definition of objects to include access methods. In computing science, objects will always be written to provide encapsulated access to the attributes (data) of an object.

The notion of encapsulated access to data basically means that in an OOP program, the only way to read or write an object's data is "through certain subroutines associated with the object” (Conway, 2000: 2). In OOP, subroutines are renamed as methods to distinguish them from the more mundane notions of subroutines and functions in unstructured programming. In OOP terminology, we say we access and manipulate object data (attributes) with methods. Let us explore these terms in more detail.

Most people with basic programming experience will be familiar with a program subroutine or function. Typically, a subroutine or function will provide some sort of 
service to the programmer. The code that provides this service, perhaps like printing a block of information, is moved out of the main program code into a subroutine. This is done for several reasons: it makes code easier to follow, hides program complexity, facilitates code re-use (by encouraging programmers to code general routines), and increases the modularity of programs ${ }^{\underline{6}}$. In OOP theory, this is called encapsulation, and "methods" (the OOP version of "functions") do pretty much the same thing. Interestingly, many of the features that authors on learning objects attribute to OOP theory really belong to general programmer guidelines.

A typical subroutine to print a user's name would look something like this:

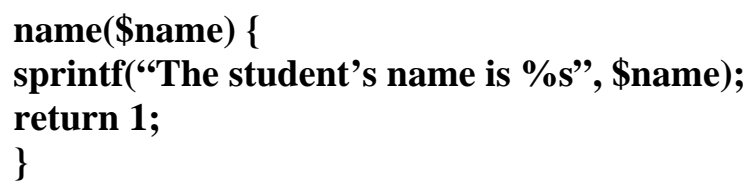

The above example is simple, but it illustrates the functionality of subroutines. It takes a variable (in this case the student's name), and then prints it to some output device in a formatted string. More generally, subroutines take in data (we say we "pass" data to a subroutine), manipulate it, and then output or store it.

OOP methods share all the features of regular subroutines. Methods are designed to allow programmers to re-use code; they also provide encapsulation. However, when individuals program using OOP methodology, they go farther that the encapsulation associated with subroutines because, in addition to wrapping code, they also encapsulate data. This difference is not immediately transparent to the non-programmer.

The same print name function, as a method, might look something like this:

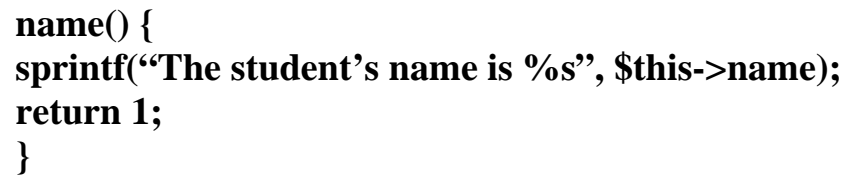

Notice any difference? Really the only difference is that, unlike the function or subroutine in traditional programming, variables (e.g., the student's name) are not "passed" to the subroutine. To rephrase this point, the programmer does not pass data to the method. Understanding this difference is the key to unlocking the mysteries of OOP programming.

In an OOP program, the program knows which name to print because the method is part of an object and the object itself contains (or encapsulates) the data, as we stated in the definition of the "object" above. The method can access data at will without ever having to be told directly by the programmer what the data are. This "magic," as it may seem, occurs with a lot of up front grunt work. In OOP programming, objects are designed to encapsulate meaningful blocks of data, and then incorporate extra code that allows your object to carry around the relevant data.

Once the object is designed, it can then be used in higher-level code. To do that, however, the object must first be "created" — in other words, data must be gathered and spaces must be created in memory to store that data, and methods for accessing that data. In OOP parlance we say we construct the object. 
In a program, constructing an object begins with a call to an object constructor. A constructor might look something like this:

\section{\$myUser = new User('userid'=>239480);}

The above object constructor (signified by the "User" keyword) is simply another "method." The key difference is that the constructor has a specific role or function to play. When programmers write the code for the object, they put all the code they need to create the user object or "data container" inside the User "method" or constructor. Calling the constructor creates the object by gathering data, associating methods, and clearing memory for storage.

In this case the object takes a student ID, finds the associated student, creates data structures to store student data, and returns a user object, which is then stored in the variable myUser for future access. Code in the User constructor might look something like this:

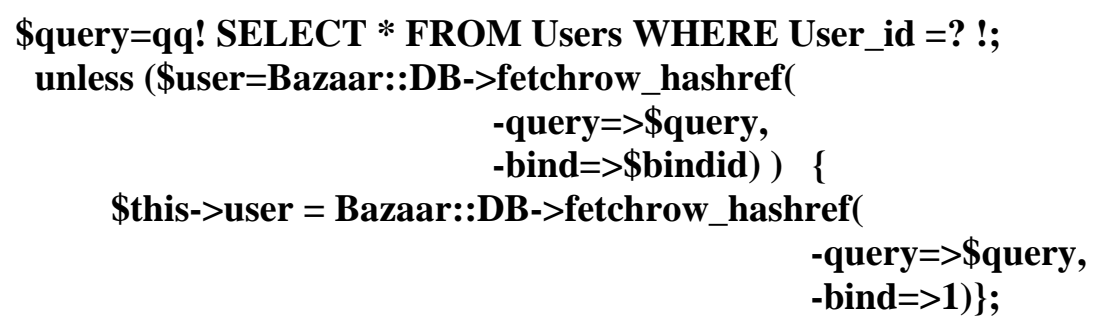

The code above is a real world example - though stripped down by several hundred lines in order to isolate a single key function and to better illustrate the purpose of a constructor. In the above example, we basically execute a Structured Query Language (SQL) command that connects to a database, and then grabs all the information available for the user whose "User_id" is equal to 239480, and stores this information in a special variable (a reference encapsulated in the object) called "\$this->user." By storing information in a variable like this, the data then becomes available to the programmer as part of the object.

Once the user is created, it is possible to manipulate that user object in the code much easier than with traditional functions and subroutines, because it is not necessary to worry about the data associated with the user or the code used to access and manipulate that data. The programmer does not need to pass the user's name in and out, or worry about how to change said name. All data and methods for accessing data are encapsulated inside the well-designed object.

For example, it is possible to:

output the user's name

print \$user->Username()

email the user a message

\$user->email(\$message)

or delete the user. 


\section{Suser->delete()}

It is possible to even change the properties of the object. In the example below, we change the user's first name from whatever it was before, to "Mike."

\section{\$user->username('firstname=>“Mike”)}

All this is done with incredible ease. Of course, behind these simple one-liners of code there is also considerable program code. But the code examples are used here to show that the OOP method hides that complexity and encapsulates the object properties so that we can easily program with the object. OOP is really a way to reduce the amount of complexity involved in creating large-scale applications. ${ }^{7}$

There is one primary disadvantage of OOP programming - the requirement of a large amount of overhead. To do anything with an object requires more initial planning and coding that with traditional methods. With OOP, one must:

1) Do up-front conceptualization of the object (i.e., determine in advance a reasonable set of properties and methods)

2) Write object constructors

3) Write code to encapsulate and deliver properties

4) Write object methods

All of these tasks begin before one even starts to code the main program routines. All of this extra code requires extra time for the programmer and extra resources from the computer. However, disadvantages associated with OOP programs are far out weighed by their advantages, especially when working on larger projects.

One important advantage is that OOP methodology provides clean code that is easy to understand and sift through for programmers. This is important for larger projects that may see several new programmers enter the project over its lifespan. OOP makes it easier for new programmers to navigate the code logic because the logic is separated from the implementation. For example, if you were a new programmer trying to understand what a particular block of code does, you would see the following:

\section{\$user = new User('user_id'=23423); \$user->archive() \$user->delete()}

They would instantly be able to tell what is happening in the code. As new programmers on the project, they do not need to know (or even care) about the several hundred lines of code that are needed to construct the user and then copy the user's data to an archive and delete the user. They can begin modifying program logic immediately. Of course, there may come a time when they may need to debug the archiving function of the program. If that day comes, they will then need to peer into the black box of the archive function and learn the internals of the method. But that is also facilitated by OOP methods. They will know exactly where to start because the program logic is clearly exposed for them. They will not have to deal with the spaghetti-type mess that is common for non-OOP programs.

A second important advantage of using OOP methodology is that the objects and the code are highly extensible and extendable. It is easy and quick to add functionality to an OOP 
program without adding additional bugs. The way that the objects are constructed gives programmers a convenient "container" in which they may put any additional properties or methods that might become useful to the program at a latter date. For example, if it is necessary to add a user's honorific (e.g., 'Dr.'), the required code and routines can easily be added into the user object. In fact, chances are that there is already a code template in the program that may be used for just that purpose. Typically, functionality can be added to OOP programs in a fraction of the time required for a regularly coded project. And, the bigger the project, the bigger this advantage becomes.

A third benefit of OOP programming is that the code is reusable. In programming, reusability means a number of things. First of all, reusability in OOP methodology means that the object code itself can be reused inside the same program (this is called cloning). We have already seen this, and it simply means that more than one copy of an object may be used at the same time. In our code example above, we created multiple user objects, such as we see here:

\section{\$user_one = new User('userid'=>239480) \$user_two = new User('userid'=>480);}

Object reusability also refers to the fact that objects can inherit properties and methods from other objects. Downes (2001) has a solid explication of what this means when he describes the process of moving from simple objects to more complex objects through the inheritance process. Inheriting the methods and properties of other objects in large scale projects $^{\underline{8}}$ saves coding and conceptualization time. ${ }^{\underline{9}}$

There is one other instance in which OOP code can be seen as reusable. This is in the simple ability to cut and paste large blocks of OOP code and insert it into other programs where it may be modified for other purposes. This "feature" of OOP code comes from the highly modular nature of an OOP program, in which all data is encapsulated and all methods have easily definable purposes. It is thus easy to chop and hack out sections of code for reuse in other areas.

To summarize, then, OOP methodology is preferred for larger programming projects because it provides a methodology that makes it easier to understand code logic, easier to debug code when necessary, easier to extend and modify code as project needs evolve, and easier to reuse objects and the code behind these objects.

It does this by providing programmers with a set of conceptual tools that help them organize code and think of their programs in terms of meaningful units. Programmers create objects that provide meaningful containers whereby they can encapsulate data and hide functionality in methods. It is this encapsulation and the methods whereby object data are accessed and manipulated that provide the infrastructure that makes possible the benefits of OOP summarized above.

\section{Learning Objects}

Let us recall our Careo example: http://aloha.netera.ca/uploads/crdc/unit60022b.jpg. Some readers might be wondering what OOP methodology has to do with a picture as a "learning object." As was noted above, there is conceptual confusion in the literature and an inability to map the features of OOP programming objects to learning objects

dominates the literature (Friesen, 2001). 
Friesen (2001) summarizes the thinking in the literature on how computing science objects map to learning objects, when he notes that authors"... most often identify 'modularity', 'interoperability', [and] 'discoverability' as important attributes of educational objects.” However, examining these features only emphasizes the theoretical morass. Not only are interoperability and discoverability decidedly not features of OOP programming (as we have seen), there is no general agreement on how each of these items should be conceived or mapped when it comes to learning objects themselves.

To complicate matters further, Friesen points to three more-or-less distinct definitions of the term modularity in the literature. Ironically, none of these definitions seem to be at all helpful in theorizing learning objects:

Educational objects, as Longmire describes them, must be modular, "free standing, non-sequential, coherent and unitary." Others describe the same idea using slightly different terms. Roschelle, et. al. (1998) states that the object must be adaptable "without the help of the original developers to meet unforeseen needs." According to Ip, et. al., the object must be constructed in such a way that its users "need not worry about the component's inner complexity." The educational object, in other words, should be a "black box" in the sense described in the theory of object-oriented design.

The above definitions are not helpful. Some parts of the conceptual paradigm, such as the requirement that learning objects be freestanding, non-sequential, coherent, or adaptable, do not map to OOP theory at all. A programming object may be some or all of these things, depending upon what the original authors might mean by these definitions. But a programming object also may not be freestanding and non-sequential. Some objects may, for example, be useful only in the restricted context of the program or sub-program for which they were designed. As may be recalled, the real nature of CS objects comes from they way in which they encapsulate code and data. As for the modifiability of an object by other than the original developer, that is a desideratum of all program code and is not the exclusive domain of OOP theory.

To be fair, there is a correspondence between the notion of modularity in the concept of a black box and learning object. But here the link to computing science objects actually reduces our understanding by introducing concepts that confuse they layman and require considerable explanation and modification before they can become useful. Friesen points to Berard's explication of objects: "Specifically, the underlying implementations of objects are hidden from those that use the object. In object-oriented systems, it is only the producer (creator, designer, or builder) of an object that knows the details about the internal construction of that object. The consumers (users) of an object are denied knowledge of the inner workings of the object” (Berard quoted in Friesen, 2001).

In terms of the understanding of a CS object, this is exactly right. Here the consumers are other programmers, and it is not necessary for them to understand the inner workings of code. They simply call the black box within the appropriate parameters.

\section{\$user->email(\$message)}

However, in the case of the CS object, the notion of the consumer is strictly associated with the programmer. The consumer of the above method could be the original programmer using her own code object or a third-party programmer who is part of a 
development team working on a larger project. The consumer could even be an unknown programmer making use of some more generic library of code. This is easy enough.

Confusion enters the world of the learning object when we search for a consumer of said object (as required by CS theory). Here, in looking for an appropriate mirror concept, we end up trying to incorporate even more unnecessary concepts from OOP theory, thus clouding our understanding even further. In the quote from Friesen (2001) an attempt is made to show how applet users as consumers are faced with the black box of code design and how these consumers use an applet's interface to interact with it:

Initially, this principle would seem most appropriate for educational objects, especially for software components. It certainly would seem like a good way to characterize the operation of "executable" educational objects like Java Applets or Flash components. For example, the Java applets collected by the Educational Object Economy (or the EOE, one of the first repositories of educational objects), for example, would seem to conform to this characteristic. Users of an object are denied knowledge of the most detailed, inner workings of the objects. Instead, they must deal with the object via one of two "interfaces" identified by Berard as standard for software objects in general: "The 'public' interface that is open (visible) to everybody", and "the 'parameter' interface" providing the instructor with a limited ability to customize the operation of the object (Friesen, 2001).

Sadly, the concept of interface does not map outside of the internal workings of the Java applet or OOP theory either. To be sure, programs can have interfaces. But they are not the same types of interfaces spoken of in OOP theory when we speak of an object having an interface and there is little meaning in trying to connect the two. In OOP theory, or OOP practice, an object's "interface" means, simply, the methods that are available for manipulating the object's data. For example, a user object might have the following interface:

\section{Public \$user->rename() Public \$user->delete() Public \$user->archive() Public \$user- $>$ copy Public \$user->move() Public \$user->email() Private \$user->frobnicate() Private \$user->dbConnect() Private \$user- $>$ dbDisconnect}

The object interface here is all the methods that the programmer created for manipulating data. The interface itself can be divided into public and private components. The public side of the interface (easily recognized above by the modifier keyword "public") involves those methods to which the application programmer has access. This means that if I am creating a grade book, for example, and want to use an already available user object, I can only use the public methods of that object. The private methods are those that cannot be called outside of the object itself, and to which I cannot have access. Private methods are internal to the object.

Typically, private methods are used by the object itself. For example, the user object might contain a public method to rename a user. The method rename might have the following code:

\section{Public Rename() \{ \$this->dbConnect(); \$newuser $=$ \$user- $->$ copy () ;}




\section{\$user->delete(); \$this->dbDisconnect();\}}

The private methods of dbConnect and dbDisconnect are, basically, internal utility functions of the object itself. They are used by the routine to manage a database connection. This is a benefit for the programmer who is using the object and part of the object's encapsulation. A consumer of the user object, though, would not have to manage the db connections. The object handles that. In fact, some OOP languages, such as Java, make it impossible to use private methods.

There are good reasons for hiding some methods from the user. However, we will not go into detail in this article. Suffice it to say, that hiding unnecessary functions from programmers reduces bugs and enhances the object's long-term utility to the programmer. By exposing only certain methods, and by guaranteeing that the prototype of these methods never changes, programmers can rest assured that future modifications to the way an object is implemented will not affect the programs into which they have incorporated the object.

\section{Conclusion: To object or not to object}

If the above paragraph sounds like so much techno-speak to you, then perhaps we can use that to segue into the main conclusion of this article. Although OOP theory has many interesting concepts wrapped up in a lot of fancy words, the applicability of OOP theory and/or methods to our understanding of learning objects is marginal, at best, and absolutely counterproductive at worst. This can be clearly seen when we consider that: a) few concepts of OOP theory have anything at all to do with learning objects; and b) those that do have marginal applicability actually end up muddying the waters. In simple terms, we end up wasting considerable time and energy trying for force learning objects into an object oriented model.

This is not exactly an original insight. Other authors recognize these difficulties and have even suggested the need to jettison most of the borrowing from OOP theory. Friesen (2001), for example, ultimately reduces the contribution of OOP to only providing the notion of reusability of objects. But even this is not satisfactory, because we really connote something different when we talk about the reusability of learning objects. As well, we do not need OOP theory to define our objects as reusable or modular or platform independent or anything else. In fact, we would probably advance much faster in our understanding of learning objects if we did not use OOP at all. We spend so much time negotiating with the ghosts of OOP theory, that we cut ourselves off from exploring more appropriate theoretical foundations for learning objects. There is a rich literature in developmental psychology, sociology, and even computation that deals directly with issues relevant to our understanding of learning objects, and it is in these resources that

we should be looking if we wish to develop our definitions and refine our understanding of learning objects.

So if we jettison OOP theory, where does this leave us in terms of a definition of learning objects? The definition we introduced at the outset is still useful:

A learning object is a digital file (image, movie, etc.) intended to be used for pedagogical purposes, which includes, either internally or via association, suggestions on the appropriate context within which to utilize the object. 
This definition is a useful starting point, though it is far from complete. As we have seen, learning object users have considerable expectations about how they will perform. They are viewed as more than mere learning resources or as providers of a host of fancy features that will make them useful pedagogically, economically, and politically. Accordingly, in our wildest dreams and fancies, an object is not an object is not an object. It is much more.

Just how much more is a useful question that we need to explore in more detail. The map for that exploration can be easily laid. We need to ask several questions, including:

1. What is the point/purpose of learning objects? Are they here to solve problems in the education system? Are they here to enhance current instruction? Do they form part of a revolutionary front that will transform the provision of face-to-face or distance education?

2. What features of learning objects will help us realize our objectives (as noted above)? Can simple image files function as objects or must these image files be enhanced in several ways to meet our objectives?

3. If files need to be enhanced, what technologies will we draw upon to achieve our objectives? Obviously, our choice of technology will need to be guided by a clear set of objectives and an outline of which objects are intended to be met.

4. What role will standards play? A lot of work has been done to develop standards for meta-data. Given the purposes and features of learning objects, will this work be relevant? Or can we get by with simpler notions of meta-data?

5. How will we evaluate objects from a practical and/or theoretical standpoint? Although we have not broached the topic at all, as a collective, we have high expectations about how learning objects will perform in the new economy. However, we have no way to evaluate our claims. Nor, does it seem, that we are ashamed to reduce ourselves to polemical justifications (Downes, 2001). Yet, if we are to be taken seriously, we will need to develop evaluative mechanisms. And this brings us to the following question.

6. What theories can we draw upon to understand learning objects? We need theories, because it is in the development of theories of learning objects that we will find the means to criticize, evaluate and evolve our understanding and use of learning objects. Our theories can be imported from, for example, instructional design, or modified and distilled from eclectic sources. However, we need appropriate theoretical underpinnings.

This last question could also just as easily be captured in the first question above. The process of answering these questions will be iterative. We will have to constantly move back and forth between theory and standards, and actual implementations as we evolve our understanding of learning objects and their applications. We will need to ground our theory in implementation details and research on the pedagogical effectiveness of learning objects. That is, we need to make sure we can implement our notions of objects in code and we need to be sure our implementations actually contribute something to the realm of educational theory and practice. 


\section{References}

ASTD \& SmartForce (2002, July). A Field Guide to Learning Objects. Learning Circuits. Retrieved October 1, 2002 from: http://www.learningcircuits.org/field_guides

Baron, T. (2000). Learning Object Pioneers. Learning Circuits CAREO (2002). Campus Alberta repository of educational objects Retrieved October 19, 2002 from: http://www.careo.org/

Conway, Damian. (20000. Object Oriented Perl. Greenwich, CG: Manning

Downes, Stephen (2001). Learning Objects: Resources For Distance Education Worldwide. International Review of Research in Open and Distance Education Vol.2(1). Retrieved October 19, 2002 from: www.irrodl.org

Friesen, Norm (2001). What are Educational Objects. Interactive Learning Environments. 9(3). Retrieved October 19, 2002 from: http://www.careo.org/documents/objects.html

IEEE Learning Technology Standards Committee (1998). Learning Object Metadata (LOM): Draft Document v 2.1.

IMS Global Learning Consortium (2000). IMS Learning Resource Meta-data Best Practices and Implementation Guide v1.1

Ip, A., Fritze, P., and Ji, G. (1997). Enabling Re-usability of courseware components with Web-based "virtual apparatus." unpublished document.

Quinn, C. N. (1999). Learning Objects and Instruction Components. International Forum of Educational Technology \& Society. In R. Robson, Object-oriented Instructional Design and Web-based Authoring. Retrieved October 19, 2002 from: http://www.eduworks.com/robby/papers/objectoriented.pdf

Webster, F. (1995). Theories of the Information society. New York: Routledge

\section{Endnotes}

1. In the literature, the terms "learning object" and "educational object" are used interchangeably. In writing this article, we adopt the term "learning object." However other authors use educational object to refer to the same construct.

2. http://www.imsglobal.org/

3. http://ltsc.ieee.org/

4. The reason for the attempt to connect learning objects to code objects is simple. There is a grammatical affinity between the term 'object' used in 'learning object' and objectoriented programming theory. However, as we will see, grammatical affinity is not sufficient justification for drawing from object-oriented programming theory.

5. http://www.cetus-links.org/oo_infos.html 
6. With subroutines, it is possible to create a 1000 line program to, for example, connect to websites, and then reuse that subroutine in multiple parts in the same program, or indeed in different programs altogether. It is even possible to make code more generic and move subroutines into code libraries where they can then be called upon to serve the programmer's whims again and again.

7. OOP hides the complexity of real life applications in other ways as well. For example, with OOP, you can easily manage more than one complex data structure can be managed easily in an intuitive and fluid fashion. It is also possible to have more than one user in your program at the same time. \$user_one = new User('userid'=>239480); \$user_two = new User('userid'=>480); Because the complexity of these objects is hidden, it becomes easy to juggle multiple data objects without getting variables and references confused. The variables and references are in the object and, once the object is created and debugged, one normally does not have to worry about that complexity again.

8. In practice this feature of OOP is seldom used because in all but the largest projects, it adds unnecessary complexity to programs. If programmers want a student object, they simply code a student object from the start, and do not worry about the added complexity of an object hierarchy.

9. In practice this feature of OOP is seldom used because in all but the largest projects, it adds unnecessary complexity to programs. If programmers want a student object, they simply code a student object from the start, and do not worry about the added complexity of an object hierarchy. 


\title{
Gagne and Laurillard's Models of Instruction Applied to Distance Education: A theoretically driven evaluation of an online curriculum in public health
}

\author{
Peggy A. Hannon \\ University of Washington \\ Karl E. Umble, Lorraine Alexander, Don Francisco \\ Allan Steckler, Gail Tudor, and Vaughn Upshaw \\ University of North Carolina - Chapel Hill
}

\begin{abstract}
This article presents an overview of the instructional models of Gagne, Briggs, and Wager (1992) and Laurillard (1993; 2002), followed by student evaluations from the first year of an online public health core curriculum. Both online courses and their evaluations were developed in accordance with the two models of instruction. The evaluations by students indicated that they perceived they had achieved the course objectives and were generally satisfied with the experience of taking the courses online. However, some students were dissatisfied with the feedback and learning guidance they received; these students' comments supported Laurillard's model of instruction. Discussion captured in this paper focuses on successes of the first year of the online curriculum, suggestions for solving problem areas, and the importance of the perceived relationship between teacher and student in the distance education environment.

One of the most widely used sets of guidelines for instructional designers stems from the instructional theory of Robert Gagne. His cognitive theory delineates nine sequential instructional events that provide the necessary conditions for learning (Gagne, Briggs, and Wager, 1992; Figure 1). In this model, the emphasis is on enhancing learner performance. As the events of learning are clearly defined, this model of instruction is compatible with Web-based courses - especially those that make extensive use of group or individual communication capabilities of the Internet. Many Web-based courses are designed according to Gagne's instructional events, or similar models (Beetham, 2002).

Laurillard (1993, 2002) offers a somewhat different perspective on instructional design in technologically mediated instruction. In her book, Laurillard (1993) outlines five steps for the design of instruction that are necessary for "deep" learning to occur. In her Conversational Framework, she (2002) emphasizes the importance of dialogue between student and teacher rather than the transmission of information from teacher to student. In contrast with Gagne, Laurillard's model of instruction was designed with interactive technology in mind.
\end{abstract}


Hannon, Umble, Alexander, et al. - Gagne and Laurillard's Models of Instruction Applied to Distance Education: A theoretically driven evaluation of an online curriculum in public health

Many studies have compared some form of computer-based learning with traditional classroom settings, and findings have generally supported that computer formats can be as effective, or in some cases more effective, than traditional classroom presentations (Kulik and Kulik, 1986; Russell, 1999). Some of the research focuses on online supplements to traditional classes, rather than entire online courses (e.g., Schulz and Dahale, 1999). One study comparing computer based and traditional lecture versions of the same material revealed that students performed equally well after both types of instruction, but preferred traditional presentations (Dewhurst and Williams, 1998). Although these studies have clearly demonstrated the effectiveness of online learning as defined by student performance, it is less clear how students experience the learning process online, and how this experience shapes their overall impressions of a course. Twigg (2001) recommends using strong assessments, a variety of interactive materials and activities, individualized study plans, built-in continuous assessment, and varied human interaction to improve the quality of online courses.

In this paper, we will present the methods and findings for an evaluation of five public health core courses offered online during the 1999-2000 academic year. The instructional design template used to create online versions of these courses was influenced and supported by the work of both Gagne and Laurillard. As the creation and evaluation of these courses was informed by the research of both Gagne and Laurillard, we begin by comparing their perspectives. To simplify this presentation, we compare Laurillard's model with five of the nine steps of instruction proposed by Gagne - those that are similar to the components of Laurillard's model. Findings reported will emphasize items and comments relevant to one or more of the five instructional events reviewed in the introduction.

Our evaluation was designed to answer the following questions:

1. To what degree did students believe they had attained the course objectives?

2. How did the teaching methods used in our online courses provide for five of the major instructional events described by Gagne, and supplemented by Laurillard's Conversational Framework? In what ways, if any, did our methods fall short of these theorists' recommendations?

3. How satisfied were students with the instructional features corresponding with each event of instruction in the online courses?

4. In what ways do our findings about student satisfaction with learning online support the theories of Gagne and Laurillard? Do our findings add new insights to their theories?

\section{Instructional Event 1: Presenting the stimulus material}

Gagne et al., and Laurillard present somewhat different perspectives on how best to design the learning environment, content, and context. Gagne argues that learning stimuli should be driven by what students will be asked to do with the material. In other words, there must be congruence between the learning material and the assessment of student learning. Students also need to be able to generalize concepts and rules to all applicable contexts, so instructors should present a variety of examples. Laurillard emphasizes the importance of students perceiving the structure of ideas being taught, if they are to understand those ideas at a "deep" level. While she does not discourage the use of 
Hannon, Umble, Alexander, et al. - Gagne and Laurillard's Models of Instruction Applied to Distance Education: A theoretically driven evaluation of an online curriculum in public health

examples, she does point out that many students become engrossed in the example and miss the underlying principle(s).

Although Gagne's and Laurillard's recommendations for presenting stimulus materials are not opposed to one another, they do reflect different conceptions of learning. Gagne's suggestions are in keeping with the notion that students have learned the material if they perform well on an assessment; if students are able to do what the teacher asks of them, they have learned successfully. On the other hand, Laurillard appears to be more concerned that students comprehend the concepts being taught on a structural level. She stresses the importance of students understanding how important concepts within a course are related to one another, given that students often learn individual concepts well enough to define them for an examination but fail to see how they are interdependent. Thus, although assessment methods may influence the presentation of stimulus materials, they would not necessarily determine that presentation.

\section{Instructional Event 2: Providing learning guidance}

Simply being exposed to stimulus materials is not generally sufficient for learning to take place. Students are aided in the learning process by questions or prompts that take the students' thoughts in the proper direction (Gagne et al., 1992). How direct these questions or prompts are, and how many are used, should depend on both the nature of the material being taught and the abilities of the students. Laurillard (1993) adds that teachers should be aware of students' "likely misconceptions" about a given subject, based on available literature about teaching that subject, and prior experience. Teachers' efforts to provide learning guidance should include questions to elicit these errors and give opportunities for clarification. However, rather than simply asking students questions and correcting their mistakes, Laurillard's approach emphasizes the importance of establishing interactive dialogue between teacher and student to aid the learning process.

\section{Instructional Events 3 and 4: Eliciting the performance and providing feedback}

Before undergoing a formal assessment, such as an examination or term paper, it is helpful for students to have an opportunity to demonstrate what they have learned via homework assignments, student discussions, or other media. This performance allows students to gain confidence that they are learning the material, and enables the teacher to evaluate student learning and provide feedback (Gagne et al., 1992). This performance also provides further opportunities for the teacher to identify and correct common mistakes and misconceptions.

There is some difference of opinion between Gagne et al. (1992) and Laurillard (1993) about the most important aspects of feedback on student performance. Gagne et al., emphasize the necessity of students receiving information about the correctness of their performance. Laurillard, on the other hand, seems more concerned that students not just receive feedback about whether or not the performance was correct, but that the feedback aids the learning process. She differentiates between intrinsic feedback, which is a natural consequence of student action, and extrinsic feedback, which is simple approval or disapproval. In order for deep learning to occur, students need to be able to integrate the feedback they receive with the larger learning goals of the course. In other words, students need to be able to perceive their performance and feedback as the 
Hannon, Umble, Alexander, et al. - Gagne and Laurillard's Models of Instruction Applied to Distance Education: A theoretically driven evaluation of an online curriculum in public health

implementation of newly acquired knowledge, rather than as simply meeting an instructor's requirements.

\section{Instructional Event 5: Assessing student performance}

For the purposes of this paper, “assessment” will refer to formal examinations and papers rather than course activities and assignments. According to Gagne et al. (1992), teachers need to establish whether a student's correct performance is reliable and valid. In order to determine reliability, students need to be able to repeat the correct performance using a variety of examples. The validity of the correct performance is determined more by the assessment itself, in that a valid performance genuinely reveals the desired learning capability. Thus, a student could perform correctly on an inappropriate assessment in the absence of proper learning.

Laurillard (1993) offers a slightly different view of the nature of assessment, in part because she specifically addresses new teaching technologies. "Part of the point of new teaching methods is that they change the nature of learning, and of what students are able to do. It follows that teachers then have the task of rethinking the assessment of what they do" (p. 218). Laurillard refers to assessment not as a concrete endpoint of learning, but rather as a step in the cycle of learning wherein students have the opportunity to describe their own conceptions of the material and concepts they have learned. Laurillard's Conversational Framework represents more give and take between students and teachers, and less passivity on the part of students. However, given the circular nature of the framework, the role of end of course assessment receives less emphasis in Laurillard's model than in Gagne's.

\section{Methods}

The School of Public Health of the University of North Carolina at Chapel Hill (UNC$\mathrm{CH}$ ), requires all students to complete a core curriculum consisting of five courses. Whereas, the Council on Education for Public Health (CEPH) requires all public health students in the United States take these courses (or close equivalents) in order to receive a Master's degree in the field of public health. Each course provides an introduction to the key concepts of one department within the school (Biostatistics, Environmental Science and Engineering, Epidemiology, Health Behavior and Health Education, and Health Policy and Administration). Due to the CEPH's requirements, UNC-CH elected to offer the entire core curriculum on the World Wide Web in addition to traditional, "live" classroom settings. Four of the five courses were taught online for the first time during the 1999-2000 academic year. The data presented in this paper largely reflect students' evaluations of those new online courses.

Typical students enrolled in the Web-based core classes include: a) residential students who prefer (or in some cases are required) to take core classes outside their major online; and b) students involved in distance learning programs. Most students completing the core curriculum online are enrolled in one of the distance education degree programs offered by the School of the Public Health. Students are professionals with full-time jobs (and often families as well); their motivations for enrolling in distance degree programs often include improving their current practice as public health professionals. Therefore, the online courses must be perceived as relevant to students' current professions in order to benefit and motivate the students. 
Hannon, Umble, Alexander, et al. - Gagne and Laurillard's Models of Instruction Applied to Distance Education: A theoretically driven evaluation of an online curriculum in public health

\section{Teaching Methods}

Although the courses vary in terms of faculty and material being presented, all core classes follow the same basic format of instruction. For the purposes of this article, we will focus on methods that are employed for the entire curriculum. Each course is subdivided into several units. In most courses, units are further subdivided into several lessons. Each lesson follows a common model presented below, in keeping with the steps in Gagne et al.'s (1992) instructional model. This common model allows students to know exactly what to expect after one or two lessons.

\section{Presenting the Stimulus Material and Providing Learning Guidance}

Students first read introductory material, which acquaints them with the faculty and teaching assistants, course objectives, lesson plan and schedule, and information about evaluation and grading. Each course is broken into several units; in most courses, these units are further divided into lessons. Lessons begin with stated learning objectives, which are followed with audio tutorials with slide presentations and (usually) reading assignments. All courses provide students with an email address for questions about the material; questions sent to this address are answered by the professors and teaching assistants. Students are also encouraged to turn to each other with questions and insights about the learning material via the course discussion forums.

\section{Eliciting Performance and Providing Feedback}

There is some variation across courses in the methods employed to elicit student performance. In general, the courses use a case study approach; after learning the lesson concepts, students are exposed to a direct application of those concepts. Students then have to answer specific questions about the case to demonstrate that they can successfully apply the new concepts in a given situation. Most of the courses include a weekly discussion forum in which students are required to post their comments and insights about the current lesson or a related topic. Some courses also provide post-tests at the end of each lesson or unit. Every course uses at least one of these methods of eliciting student performance.

Feedback about student performance depends on the type of performance. Case study answers are generally evaluated by teaching assistants; students receive a quantitative grade and/or qualitative comments. Students receive feedback from each other for the discussion forums, as they often respond to and build on each other's contributions. In some courses, teaching assistants also contribute to the discussion forums and comment on students' remarks. Lesson post-tests are automatically graded on the Web, unless they include open-ended questions.

\section{Assessment of Student Learning}

In addition to the lesson activities described above, all of the courses include formal examinations and some also include final projects or papers. Students either post their exams and papers to the course webpage or email their completed exams and projects directly to the professor. Students' final grades are determined based on performance in discussion forums, completion of case studies and other activities, and scores on examinations (and final papers when applicable). 
Hannon, Umble, Alexander, et al. - Gagne and Laurillard's Models of Instruction Applied to Distance Education: A theoretically driven evaluation of an online curriculum in public health

\section{Evaluation Methods}

During the 1999-2000 academic year, students in all five courses were asked to complete an online evaluation at the end of the semester which consisted of 30 questions that assessed their satisfaction with the course and effectiveness of the teaching methods. These questions were constant across courses (all items used a four point scale, $1=$ Strongly Disagree, 4 = Strongly Agree). Each course evaluation also included a unique set of questions to assess students' achievement of the course objectives; these questions were based on input from discussions and interviews with the teaching faculty. Finally, every course evaluation provided space for open-ended comments. Over the course of one year (two semesters and two summer sessions), 273 students were enrolled in the online core courses. Of these students, 214 (78 percent) completed evaluations, and 171 (63 percent) wrote additional comments.

\section{Results}

\section{Students' Achievement of Learning Objectives}

Each course's online evaluation included a list of learning objectives for the course; students were asked the extent to which they agree that they achieved each learning objective. Students' responses to these items were assessed in two ways (Table 1). First, we determined the proportion of students in each course who agreed that they had achieved every learning objective (i.e., selected the response "Strongly Agree" or "Agree" for every learning objective item). This proportion varied widely between courses, with as many as 94 percent of the students in one course agreeing that they had achieved every learning objective, and as few as 56 percent of the students in another course reporting that they had accomplished all learning objectives.

Second, we calculated the average score of all learning objective items within each course. This analysis yielded a much more unified picture across courses, indicating that students in all courses were likely to agree that they had achieved any individual learning objective (overall $\mathrm{M}=3.28$; 1 indicates "Strongly Disagree" and 4 indicates "Strongly Agree"). Together, these analyses suggest that students felt moderately to very successful in learning the desired material in a distance learning format. Student grades were consistent with student evaluations of achievement of learning objectives; virtually all of the students received a passing grade.

\section{Presenting the Stimulus Material}

The online evaluation form included nine questions assessing students' satisfaction with how course materials were presented (Table 2). The majority of students in our sample were pleased with the delivery of learning materials, particularly the professors' overall presentation of material $(\mathrm{M}=3.31)$, and the orchestration of activities, readings, and assignments $(\mathrm{Ms}=3.31)$. Students were least satisfied with guest lecturers $(\mathrm{M}=2.88)$ and with article readings $(M=2.98)$. However, the qualitative comments indicate that students' dissatisfaction in these areas may have been at least partially due to technical difficulties, some of which are included as examples:

The reading material does not print well and is hard to read on the screen. Maybe next year just supply a CD with all of the readings on it.

The guest speakers need to speak more fluently and more slower. 
Hannon, Umble, Alexander, et al. - Gagne and Laurillard's Models of Instruction Applied to Distance Education:

A theoretically driven evaluation of an online curriculum in public health

Students' qualitative comments about course materials generally pertained to the readings and online tutorials, but occasionally included information about other resources provided with the course materials (Web-links, etc.). A few students complained that lectures were dry or hard to follow. In most courses, students were pleased with the level of the material, but some felt that the material was too simplistic. These students' comments indicated that they were not aware that the courses included undergraduate and graduate students in addition to professional students.

\section{Eliciting Student Performance}

The online evaluation form included five questions concerning the helpfulness of course assignments and activities (Table 3). In general, students agreed that performing the various exercises aided their learning. Specifically, students agreed that the number of course assignments was reasonable $(\mathrm{M}=3.09)$, that the activities and case studies helped their learning $(M=3.23)$, that practice problems helped their learning $(M=3.19)$, and that quizzes helped their learning $(\mathrm{M}=3.25)$. The one activity that students generally found less helpful was the discussion forum (item $M=2.86$ ). In all four courses that included a discussion forum, students offered suggestions for how the forum could be improved. Several students made statements to the effect that the forum did not add to the course and should be dropped. Only a few students were unequivocally positive about the forum experience:

The discussion forums were frustrating to me. Other group members often did not post in a timely fashion. . . . Besides the frustration factor, I didn't learn a lot from the group forum - I would rather learn from an expert (the professor) than other students.

I would recommend changing the format of the discussion forum to more of an INTERACTIVE forum. This was not the case with the current format. We essentially posted individual responses and did not respond to the other students' postings. This interaction can be a significant learning experience.

There were many suggestions for how to change the forums, but no consensus emerged. This is one issue that is difficult to resolve because it is so dependent on student input.

\section{Providing Feedback and Learning Guidance}

Students answered six questions about the helpfulness of feedback given on their work and quality of interaction with professors and teaching assistants (Table 4). Students' answers to these items reflected less satisfaction in this area than with presentation of course materials or eliciting student performance. Item means indicated that several students disagreed with statements that they were satisfied with the amount of interaction they had with the professor $(M=2.80)$ and that they were satisfied with the quality of the professor's feedback on their work $(\mathrm{M}=2.89)$. Items concerning amount of interaction with the teaching assistants $(\mathrm{M}=2.84)$ and the quality of the teaching assistant's feedback on work $(M=2.83)$ received similar ratings. Examination of students' written comments reveals that direct feedback from the faculty and teaching assistants, consisting of comments and corrections on submitted work (rather than scores alone), played a large role in students' experience of the course. In courses where there were problems with returning assignments, many students felt that their learning had been compromised. 
Hannon, Umble, Alexander, et al. - Gagne and Laurillard's Models of Instruction Applied to Distance Education: A theoretically driven evaluation of an online curriculum in public health

When students received grades without comments or corrections of their work, they specifically requested either individualized feedback or examples of ideal responses:

I also would have loved some feedback on my case study work. I think the last time I received any was on lesson three. We were being given exams before we knew if our work was correct or not being provided information at all.

I received very little feedback from my TA about my work. When we did have a response to our case study assignments, they were too late to help in taking the exam. Eventually all case study reviews stopped and it was difficult to know if you were doing anything right.

The issue of feedback was raised by students in every course. It may be that the lack of opportunities for "live" interactions (for questions and discussions about the material) leaves students feeling less sure of themselves when completing assignments and exams, thus heightening the importance of qualitative feedback.

In addition to highlighting the importance of feedback on assignments, many students expressed strong feelings about their attempts to interact with their professors or teaching assistants individually via email. Students who received prompt replies to their questions were pleased, while students whose emails were not answered promptly (or at all) were negative.

Overall, I would rank this class number one among the three Web-based classes I took. The professor was very organized and responded to questions and inquiries promptly.

There were several times beginning with the mid-ter, that we asked for help and never received answers or guidance from the professor or TA. This was very frustrating.

In their comments about responses to emails, some students mentioned the importance of this method of communication in the absence of a traditional classroom.

\section{Assessment of Student Learning}

Students answered three questions about the extent to which examinations and grading aided their learning of the material (Table 5). Overall, students in our sample seemed moderately satisfied with examinations, although there was considerable variation both within and across courses. In several of the courses, a few students complained that the material covered in the readings and tutorials did not match the material in the exams, or that test questions were poorly worded. However, these types of comments were limited in number. Furthermore, these types of comments frequently occur in traditional learning environments as well. Most of the students' test-related comments concerned how feedback was delivered. As with case studies and assignments, students were upset when they did not receive feedback (beyond a simple score), or when feedback was not delivered quickly.

I really wish we had gotten our exams back. I learn the most through my mistakes. 
Hannon, Umble, Alexander, et al. - Gagne and Laurillard's Models of Instruction Applied to Distance Education: A theoretically driven evaluation of an online curriculum in public health

I would also recommend faster grading of submissions. I have the final exam this week and still do not know about my Exam II results.

A few students suggested posting “ideal” responses to qualitative test questions, and/or explanations of why the correct responses were the best answers for forced-choice items. This may be an attractive solution to the problem of grading examinations, because the professor would only have to write the information once, but most students' questions about how individual items were graded would be answered.

\section{Students’ General Satisfaction with Online Courses}

Five questions assessed students' overall satisfaction with the course. Two questions concerning the technical assistance they received (Table 6). Despite some of the problem areas noted above, most students agreed that they were satisfied with the courses (all item Ms > 3.00). In each of the five courses, several students wrote general comments reflecting positive experiences.

This class was great. I can't say enough great things about how clear [the professor] has been in the tutorials, how helpful the quizzes were in promoting my learning, and how logically organized everything was.

This was a very well designed course. It is obvious that a lot of time, effort, and thought went into developing this Web-based course. As a distance learner, I really appreciate this! I learned a lot about our environment and I feel my tuition money was well spent on this course.

I enjoyed the class, learned a lot, and was very impressed with the overall organization of the material, website, etc. Thanks for a great semester.

The online format of the course was great. I learned just as much via this format as I would have learned if it had been an "on campus" course.

I enjoyed taking this course. I learned a great deal and have a much better understanding of the US health care system. This was the first time I had taken a Web-based course and

I was a little apprehensive at first, but in the end I found that I really liked the online course.

It is interesting to note that most students' positive comments were broad or general in nature. Sweeping negative statements were relatively rare; students who reported being dissatisfied with an entire course were more likely to have a list of specific complaints. Most of these problem areas were addressed above, and included issues such as slow feedback. Only a few students felt that the distance learning format of the courses was inherent to their dissatisfaction.

\section{Discussion}

Students' perceptions of their achievement of course objectives, combined with the high percentage of students passing the courses, indicate that students were able to learn effectively online. Overall, both the quantitative and qualitative evaluations given by 
Hannon, Umble, Alexander, et al. - Gagne and Laurillard's Models of Instruction Applied to Distance Education:

A theoretically driven evaluation of an online curriculum in public health

students indicated satisfaction with the online core courses. Students were more pleased with some learning events than others (for example, evaluation items and comments relevant to presenting the stimulus material were generally more positive than the items and comments referring to providing feedback). However, almost all item means indicated that most students agreed with positively worded statements about the courses. Examination of students' qualitative comments revealed that many students felt that they had learned a lot and enjoyed the distance learning format.

The learning event that generated the lowest item ratings and the highest proportion of negative comments was providing feedback. Students' concerns in this area tended to focus on: a) speed with which feedback was given; and b) whether qualitative feedback was given. Few students had any complaints about whether the grading was fair; instead they were concerned that meaningful (e.g., qualitative) feedback be given quickly enough to guide their future performance. This finding supports Laurillard's (1993) assertion that “. . . it is not just getting feedback that is important, but also being able to use it” (p. 61). In current versions of these courses, there has been extended training of teaching assistants to ensure rapid grading of assignments and responses to students' email questions. Faculty members are also increasing their use of class listservs to provide uniform responses to common questions and clarification of difficult concepts. For example, one course now includes a special page in every unit that students may use to ask the professor any remaining questions about the material. The professor then sends the question and the answer to the entire class via the class listserv (cf. Angelo and Cross, 1993). Student evaluations of these online courses in the past two years indicate that these changes have enhanced student satisfaction with learning guidance and performance feedback.

In general, students were less pleased with the discussion forum than with other activities and assignments. A few students reported favorable discussion forum experiences, but the majority of the students' comments reflected a lack of enthusiasm for this activity. Students complained about the lack of involvement on the part of faculty and teaching assistants, the lack of interactivity in the forum, and the problem of other group members not posting responses in a timely fashion. Several students made statements to the effect that the discussion forum did not add significantly to their learning experience and were in favor of removing it from the course activities. In response to these issues, one course changed the format of the discussion forum so that it is now always student led. Students are taught how to lead the discussion forum early in the session. For each unit, the student discussion forum leader sends the professor a list of the insights and questions generated by the forum; the professor posts a response to all students in the forum. This procedure allows the forum to be student led while enabling the professor to give qualitative feedback to students without undue added burden of time. Student satisfaction with the discussion forum has improved in this course.

Students' comments revealed an aspect of the learning experience that both Gagne et al. (1992) and Laurillard (1993) did not address: the students' perception of their relationship with their teachers. Although students were primarily concerned with learning the course material, their comments indicated that they also formed judgments about whether the professors and teaching assistants "cared" about them as students. Generally, students who felt that they could contact their professor (or teaching assistant) and receive a timely, thorough, and kindly worded response to concerns or questions, perceived that their instructors wanted them to learn. These students tended to be positive in their general comments about the course. In contrast, students who reported that their questions were not answered, or not answered quickly enough, or who perceived sarcasm or condescension in responses from faculty or teaching assistants, were much more likely 
to report negative feelings about the course as a whole. Thus, although students rated stimulus materials, learning guidance, and feedback as important to the learning experience, these were not necessarily sufficient. Students were also attuned to their instructors' manner (even in the absence of live interaction), and it significantly shaped their overall impressions of the course. In light of these findings, one course now includes training for teaching assistants on expectations and proper online responses, as well as offer students the opportunity to evaluate their teaching assistants one-third of the way through the semester. This innovation has improved the consistency of teaching assistants' performance and aided the faculty in discovering any problems early enough to be corrected.

\section{Conclusions}

Our findings indicate that online courses can be an effective method of teaching the core concepts of public health to graduate and professional students. Gagne et al.’s (1992) instructional model can be applied to distance learning, permitting students to achieve course learning objectives and have a positive learning experience. However, there are some pitfalls unique to the learning distance environment. Students want (and expect) quick and detailed responses to their questions and concerns, as well as timely, qualitative feedback on their work. These findings support Laurillard's Conversational Framework as well; students in distance learning courses apparently expect active interaction with their teachers. Students who felt that these expectations were met tended to be positive about the course, and about distance learning in general. These expectations can be time consuming for professors and teaching assistants to meet, but there are possible compromises that will satisfy both teachers and students, such as posting ideal responses to exam questions and using a course listserv to answer common questions. Student and faculty evaluations of more recent versions of the online courses reveal that these measures have improved satisfaction with distance learning for both parties.

There are several strengths and limitations to the present work. Strengths include the fact that both the course design and evaluation were influenced by the same theories of learning, the breadth of material presented online and evaluated by students, the diversity of students completing the courses, and the high response rate for students completing course evaluations. Unfortunately, due to different methods of evaluation, comparison of students' evaluations of the online curriculum with those of students in the traditional classroom was not possible. Other research has found little difference between online and traditional presentations of university courses in student satisfaction (Allen, Bourhis, Burrell, and Mabry, 2002). Also reflecting technological difficulties and other problems inherent in new courses, four of the five courses that were being offered online for the first time may have yielded negative evaluations. Future evaluation research of distance learning programs could compare student evaluations of new courses with more established courses, as well as with traditional learning formats of the same material. Continuing to draw on learning theory to develop courses and evaluations will provide distance educators with helpful models to aid in developing new courses. 
Hannon, Umble, Alexander, et al. - Gagne and Laurillard's Models of Instruction Applied to Distance Education: A theoretically driven evaluation of an online curriculum in public health

Table 1. Achievement of All Course Objectives

\begin{tabular}{|c|c|c|c|c|}
\hline Course & $\begin{array}{c}\text { Evaluations } \\
\text { Completed }\end{array}$ & \multicolumn{2}{|c|}{$\begin{array}{c}\text { N Strongly Agree or Agree } \\
\text { (Agreement Rate) }\end{array}$} & $\begin{array}{c}\text { Average Score/ } \\
\text { Objective }^{\text {c }}\end{array}$ \\
\hline BIOS & 28 & 16 & $(57 \%)$ & 3.33 \\
\hline ENVR & 47 & 44 & $(94 \%)$ & 3.64 \\
\hline EPID & 65 & 49 & $(75 \%)$ & 3.16 \\
\hline HBHE & 49 & 38 & $(78 \%)$ & 3.17 \\
\hline HPAA & 25 & 14 & $(56 \%)$ & 3.11 \\
\hline Total & 214 & 155 & $(72 \%)$ & 3.28 \\
\hline
\end{tabular}

${ }^{\circ}$ Course abbreviations for all tables are as follows: BIOS = Biostatistics, ENVR = Environmental Science and Engineering, EPID = Epidemiology, HBHE $=$ Health Behavior and Health Education, and HPAA = Health Policy and $\mathrm{Administration.}$

${ }^{b}$ Number of students that strongly agreed or agreed that they had achieved all course objectives.

'The average score was derived by summing all objective ratings for a course, and dividing that sum by the product of the number of student evaluations completed for that course and the number of course objectives assessed. The total number of missing responses was subtracted from the denominator.

Table 2. Presenting the Stimulus Material

\begin{tabular}{|c|c|c|c|c|c|c|}
\hline & $\underset{(n=28)}{\operatorname{BIOS}}$ & $\begin{array}{l}\text { ENVR } \\
(n=47)\end{array}$ & $\underset{(n=65)}{\text { EPID }}$ & $\begin{array}{c}\text { HBHE } \\
(\mathrm{n}=49)\end{array}$ & $\begin{array}{r}\text { HPAA } \\
(n=25)\end{array}$ & $\begin{array}{l}\text { Average } \\
\text { Item } \\
\text { Score }\end{array}$ \\
\hline & $\underline{M} \underline{S D}$ & $\underline{\underline{M}} \underline{\underline{S D}}$ & $\underline{\underline{M}} \underline{\underline{S D}}$ & $\underline{M} \underline{\underline{S D}}$ & $\underline{M} \underline{\mathrm{SD}}$ & \\
\hline $\begin{array}{l}\text { The professor presented material in a } \\
\text { clear and organized manner. }\end{array}$ & 3.360 .68 & $\begin{array}{lll}3.83 & 0.38\end{array}$ & 3.250 .69 & $3.04 \quad 0.61$ & $\begin{array}{lll}3.09 & 0.78\end{array}$ & 3.31 \\
\hline $\begin{array}{l}\text { The course material was intellectually } \\
\text { stimulating }\end{array}$ & 3.140 .79 & $3.74 \quad 0.49$ & $3.33 \quad 0.52$ & $2.90 \quad 0.68$ & $2.72 \quad 1.02$ & 3.28 \\
\hline $\begin{array}{l}\text { The activities, readings, and assignments } \\
\text { fit to gether well.* }\end{array}$ & $3.24 \quad 0.70$ & $3.70 \quad 0.46$ & $3.27 \quad 0.49$ & $3.04 \quad 0.58$ & & 3.31 \\
\hline $\begin{array}{l}\text { The pace at which we worked was } \\
\text { appropriate.* }\end{array}$ & 3.330 .66 & $3.28 \quad 0.62$ & $2.80 \quad 0.64$ & $3.02 \quad 0.53$ & & 3.11 \\
\hline $\begin{array}{l}\text { The way this course was taught overall } \\
\text { helped my learning. }\end{array}$ & $3.24 \quad 0.94$ & 3.550 .50 & $2.90 \quad 0.87$ & 2.810 .61 & & 3.13 \\
\hline $\begin{array}{l}\text { The Web-based lectures helped my } \\
\text { learning. }\end{array}$ & $3.40 \quad 0.88$ & $\begin{array}{lll}3.67 & 0.88\end{array}$ & 2.340 .75 & $2.86 \quad 0.79$ & & 3.22 \\
\hline The guest lecturers helped my learning* & NA & $3.00 \quad 0.61$ & $2.73 \quad 0.96$ & $2.92 \quad 0.64$ & & 2.88 \\
\hline \multirow[t]{2}{*}{ The article reading helped my learning * } & $3.10 \quad 1.02$ & $3.00 \quad 0.44$ & 3.350 .66 & 2.620 .65 & & 3.02 \\
\hline & $2.29 \quad 1.06$ & $3.51 \quad 0.55$ & $3.18 \quad 0.44$ & $2.94 \quad 0.57$ & & 2.98 \\
\hline
\end{tabular}

"Excludes missing data or "Does not apply" responses

Strongly Disagree $=1$, Disszee $=2$, Agree $=3$, Strongly Azree $=4$

"ttem included only in Spring and Summer evalustions, total $\mathbb{N}$ - 166 
Hannon, Umble, Alexander, et al. - Gagne and Laurillard's Models of Instruction Applied to Distance Education: A theoretically driven evaluation of an online curriculum in public health

Table 3. Eliciting Student Performance

\begin{tabular}{|c|c|c|c|c|c|}
\hline & $\begin{array}{c}\text { BIOS } \\
(\mathrm{n}=21)\end{array}$ & $\begin{array}{l}\text { ENVR } \\
(\underline{\underline{n}}=47)\end{array}$ & $\begin{array}{c}\text { EPW } \\
(n=49)\end{array}$ & $\begin{array}{l}\text { HBHE } \\
(n=49)\end{array}$ & $\begin{array}{l}\text { Average } \\
\text { Item Score } \\
a, b\end{array}$ \\
\hline & $\underline{\mathrm{M}} \underline{\mathrm{SD}}$ & $\underline{\mathrm{M}} \underline{\mathrm{SD}}$ & $\underline{\mathrm{M}} \underline{\mathrm{SD}}$ & $\underline{M} \underline{\mathrm{SD}}$ & \\
\hline $\begin{array}{l}\text { The number of course assignments } \\
\text { (e.g., papers, case studies, } \\
\text { discussions) was reasonable* }\end{array}$ & $3.24 \quad 0.54$ & 3.170 .60 & $2.76 \quad 0.69$ & 3.220 .59 & 3.09 \\
\hline $\begin{array}{l}\text { The activities and case studies helped } \\
\text { my leaming* }\end{array}$ & $3.10 \quad 0.77$ & $3.50 \quad 0.74$ & $3.27 \quad 0.57$ & $3.04 \quad 0.64$ & 3.23 \\
\hline $\begin{array}{l}\text { The discussion forums helped my } \\
\text { learning* }\end{array}$ & $\mathrm{NA}$ & 3.130 .65 & $2.96 \quad 0.68$ & 2.510 .84 & 2.86 \\
\hline $\begin{array}{l}\text { The exercises (practice problems) } \\
\text { helped my learning* }\end{array}$ & 3.350 .59 & 3.371 .72 & 3.110 .60 & $2.94 \quad 0.57$ & 3.19 \\
\hline The quizzes helped my learning* & 3.710 .78 & $3.43 \quad 0.98$ & 2.890 .63 & $2.95 \quad 0.51$ & 3.25 \\
\hline
\end{tabular}

"Excludes missing data or "Does not apply" responses

${ }^{b}$ Strongly Disagree $=1$, Disagree $=2$, Agree $=3$, Strongly Agree $=4$

*Item included only in Spring and Summer evaluations, total $\underline{\mathrm{N}}=166$

Table 4. Providing Feedback and Learning Guidance

\begin{tabular}{|c|c|c|c|c|c|c|}
\hline & $\begin{array}{c}\text { BIOS } \\
(n=28)\end{array}$ & $\begin{array}{l}\text { ENVR } \\
(n=47)\end{array}$ & $\underset{(n=65)}{\text { EPD }}$ & $\underset{(n=49)}{\text { HBHE }}$ & $\begin{array}{l}\text { HPAA } \\
(n=25)\end{array}$ & $\begin{array}{l}\text { Average } \\
\text { Item } \\
\text { Score } a, b \\
\end{array}$ \\
\hline & $\underline{\mathrm{MSD}}$ & $\underline{M} \underline{S D}$ & $\underline{M} \underline{\mathrm{SD}}$ & $\underline{\mathrm{M}} \underline{\mathrm{SD}}$ & $\underline{M} \underline{\mathrm{SD}}$ & \\
\hline $\begin{array}{l}\text { I was satisfied with the amount of } \\
\text { interaction I had with the professor. }\end{array}$ & $\begin{array}{lll}2.86 & 0.89\end{array}$ & $3.38 \quad 0.74$ & $\begin{array}{lll}2.76 & 0.77\end{array}$ & $2.60 \quad 0.83$ & 2.390 .95 & 2.80 \\
\hline $\begin{array}{l}\text { I was satisfied with the quality of the } \\
\text { professor's feedback to me on my } \\
\text { work. }\end{array}$ & $2.89 \quad 0.99$ & 3.430 .58 & $3.00 \quad 0.85$ & 2.610 .69 & $2.54 \quad 1.14$ & 2.89 \\
\hline $\begin{array}{l}\text { The professor was available to help } \\
\text { me off-line or outside regular course } \\
\text { activities. }\end{array}$ & $3.09 \quad 1.45$ & $\begin{array}{ll}3.65 & 1.79\end{array}$ & $2.97 \quad 0.81$ & 3.100 .80 & 2.680 .95 & 3.08 \\
\hline $\begin{array}{l}\text { I was satisfied with the amount of } \\
\text { interaction I had with the teaching } \\
\text { assistant. }\end{array}$ & $2.00 \quad 1.15$ & $3.09 \quad 1.03$ & $\begin{array}{lll}3.25 & 0.88\end{array}$ & $2.96 \quad 0.82$ & 2.910 .85 & 2.84 \\
\hline $\begin{array}{l}\text { I was satisfied with the quality of the } \\
\text { TA's feedback to me on my work. }\end{array}$ & $2.22 \quad 1.42$ & $3.11 \quad 1.19$ & $3.28 \quad 0.98$ & $2.88 \quad 0.94$ & $2.65 \quad 0.99$ & 2.83 \\
\hline $\begin{array}{l}\text { Office hours/help sessions/other } \\
\text { contact with professor or teaching } \\
\text { assistant helped my learning* }\end{array}$ & $2.50 \quad 0.65$ & $3.26 \quad 1.68$ & $2.87 \quad 0.94$ & $2.96 \quad 0.56$ & & 2.90 \\
\hline
\end{tabular}

"Excludes missing data or "Does not apply" responses

${ }^{3}$ Strongly Disagree = 1, Disagree = 2, Agree = 3, Strongly Agree $=4$

*Item included only in Spring and Summer evaluations, total $\mathbb{N}=166$ 
Hannon, Umble, Alexander, et al. - Gagne and Laurillard's Models of Instruction Applied to Distance Education: A theoretically driven evaluation of an online curriculum in public health

Table 5. Assessment of Student Learning

\begin{tabular}{|c|c|c|c|c|c|}
\hline & $\begin{array}{l}\text { BIOS } \\
(\mathrm{n}=21)\end{array}$ & $\begin{array}{l}\text { ENVR } \\
(\mathrm{n}=47)\end{array}$ & $\begin{array}{l}\text { EPID } \\
(n=49)\end{array}$ & $\begin{array}{l}\mathrm{HBHE} \\
(\mathrm{n}=49)\end{array}$ & $\begin{array}{l}\text { Average } \\
\text { Item } \\
\text { Score }^{a, b}\end{array}$ \\
\hline & $\underline{\mathrm{M}} \underline{\mathrm{SD}}$ & $\underline{\mathrm{M}} \underline{\mathrm{SD}}$ & $\underline{\mathrm{M}} \underline{\mathrm{SD}}$ & $\underline{\mathrm{M}} \underline{\mathrm{SD}}$ & \\
\hline $\begin{array}{l}\text { The regular examinations helped } \\
\text { my learning* }\end{array}$ & $3.29 \quad 0.72$ & $3.21 \quad 1.62$ & $2.94 \quad 0.67$ & $2.76 \quad 0.68$ & 3.05 \\
\hline $\begin{array}{l}\text { The final examination helped my } \\
\text { learning* }\end{array}$ & $2.82 \quad 0.87$ & $3.21 \quad 1.29$ & $\begin{array}{lll}2.97 & 0.68\end{array}$ & $\begin{array}{lll}2.77 & 0.78\end{array}$ & 2.94 \\
\hline $\begin{array}{l}\text { The grading and methods of } \\
\text { feedback to students helped my } \\
\text { learning* }\end{array}$ & $2.24 \quad 0.89$ & $\begin{array}{lll}3.28 & 0.72\end{array}$ & $2.70 \quad 0.91$ & $\begin{array}{lll}2.66 & 0.79\end{array}$ & 2.72 \\
\hline
\end{tabular}

"Excludes missing data or "Does not apply" responses

${ }^{b}$ Strongly Disagree $=1$, Disagree $=2$, Agree $=3$, Strongly Agree $=4$

*Item included only in Spring and Summer evaluations, total $\underline{\underline{N}}=166$

Table 6. Students' General Satisfaction with the Courses

\begin{tabular}{|c|c|c|c|c|c|c|}
\hline & $\begin{array}{c}\text { BIOS } \\
(n=28)\end{array}$ & $\begin{array}{l}\text { ENVR } \\
(n=47)\end{array}$ & $\underset{(n=65)}{\text { EPD }}$ & $\begin{array}{l}\text { HBHE } \\
(n=49)\end{array}$ & $\begin{array}{l}\text { HPAA } \\
(n=25)\end{array}$ & $\begin{array}{c}\text { Average } \\
\text { Item } \\
\text { Score } \\
\text {, b }\end{array}$ \\
\hline & $\underline{\mathrm{MSD}}$ & $\underline{\mathrm{MD}}$ & $\underline{\mathrm{M}} \underline{\mathrm{SD}}$ & $\underline{\mathrm{MSD}}$ & $\underline{\mathrm{MSD}}$ & \\
\hline I was satisfied with this course. & 3.320 .61 & 3.770 .43 & 3.170 .67 & 3.020 .59 & $2.75 \quad 1.02$ & 3.21 \\
\hline $\begin{array}{l}\text { I would recommend this course to } \\
\text { other students. }\end{array}$ & 3.390 .79 & $3.68 \quad 0.47$ & 3.250 .73 & $2.86 \quad 0.74$ & $2.88 \quad 0.91$ & 3.21 \\
\hline $\begin{array}{l}\text { I would take another Web-based } \\
\text { course at the School of Public Health. }\end{array}$ & $3.50 \quad 0.75$ & 3.550 .58 & 3.380 .63 & 3.170 .75 & $2.80 \quad 0.96$ & 3.28 \\
\hline $\begin{array}{l}\text { Overall, the professor is a good } \\
\text { teacher. }\end{array}$ & $3.44 \quad 0.86$ & 3.740 .44 & $3.30 \quad 0.61$ & $3.20 \quad 0.51$ & 3.140 .65 & 3.36 \\
\hline $\begin{array}{l}\text { This course increased my } \\
\text { understanding of the relationship } \\
\text { between this subject and the general } \\
\text { field of public health. }\end{array}$ & 3.250 .62 & 3.810 .40 & 3.310 .66 & $3.06 \quad 0.56$ & $3.00 \quad 0.82$ & 3.31 \\
\hline $\begin{array}{l}\text { I am satisfied with the technical } \\
\text { instructions I was given before I took } \\
\text { this course. }\end{array}$ & 3.320 .60 & 3.350 .74 & 3.250 .64 & $3.04 \quad 0.59$ & $3.20 \quad 0.71$ & 3.22 \\
\hline $\begin{array}{l}\text { I am satisfied with the technical } \\
\text { assistance I was given during the } \\
\text { course. }\end{array}$ & $\begin{array}{lll}3.16 & 0.77\end{array}$ & $\begin{array}{lll}3.35 & 1.33\end{array}$ & $3.18 \quad 0.52$ & 3.160 .60 & $3.10 \quad 0.72$ & 3.17 \\
\hline
\end{tabular}


Hannon, Umble, Alexander, et al. - Gagne and Laurillard's Models of Instruction Applied to Distance Education: A theoretically driven evaluation of an online curriculum in public health

Figure 1. Five events of Instruction Defined by Gagne, Briggs, and Wager (1992) Compared with Laurillard's (1993) Steps in the Learning Process

\begin{tabular}{|c|c|c|}
\hline Instructional Events & Gagne, Briggs, and Wager (1992) & Laurillard (1993) \\
\hline $\begin{array}{l}\text { 1. Presenting the Stimulus } \\
\text { Material }\end{array}$ & $\begin{array}{l}\text { - The design of learning materials should } \\
\text { be driven by assessment } \\
\text { - Present a variety of examples }\end{array}$ & $\begin{array}{l}\text { - Teacher describes own conception of } \\
\text { material to be leamed }\end{array}$ \\
\hline 2. Providing Learning Guidance & $\begin{array}{l}\text { - Question or prompt students to think in } \\
\text { the correct way about the material to } \\
\text { be learned }\end{array}$ & $\begin{array}{l}\text { - Try to elicit errors and misconceptions } \\
\text { students have about the material } \\
\text { - Provide clarification for these errors }\end{array}$ \\
\hline 3. Eliciting the Performance & $\begin{array}{l}\text { - Give assignments or activities that will } \\
\text { allow students to demonstrate what } \\
\text { they have learned }\end{array}$ & $\begin{array}{l}\text { - Give students the opportunity to describe } \\
\text { their conception of the material }\end{array}$ \\
\hline 4. Providing Feedback & $\begin{array}{l}\text { - Evaluate learning } \\
\text { - Correct mistakes }\end{array}$ & $\begin{array}{l}\text { - Ensure that students view feedback as part } \\
\text { of the learning process }\end{array}$ \\
\hline $\begin{array}{l}\text { 5. Assessing Student } \\
\text { Performance }\end{array}$ & $\begin{array}{l}\text { - Test students with a wide variety of } \\
\text { examples, to ensure that correct } \\
\text { performances are reliable }\end{array}$ & $\begin{array}{l}\text { - Assessment should allow students to } \\
\text { describe their own conceptions of material } \\
\text { and concepts learned }\end{array}$ \\
\hline
\end{tabular}

Nete Laurillard's $(1993,2002)$ model of instruction is represented in one box to reflect that her model is circular rather than sequential and includes constant feedback between teacher and student. However, we attempted to pair components of hes model with the events described by Gagne et al. (1992) that are most similar.

\section{References}

Allen, M., Bourhis, J., Burrell, N., and Mabry, E. (2002). Comparing student satisfaction with distance education to traditional classrooms in higher education: A metaanalysis. The American Journal of Distance Education, 16, 83-97.

Angelo, T. A., and Cross, K. P. (1993). Classroom Assessment Techniques: A handbook for college teachers (2nd ed.). San Francisco: Jossey-Bass.

Beetham, H. (2002). Design of learning programmes (UK). Retrieved August 2, 2002 from: http://www.sh.plym.ac.uk/eds/elt/session5/intro5

Dewhurst, D. G., and Williams, A. D. (1998). An investigation of the potential for a computer-based tutorial program covering the cardiovascular system to replace traditional lectures.

Gagne, R. M., Briggs, L. J., and Wager, W. W. (1992). Principles of instructional design (4th ed.). Fort Worth TX.: Harcourt Brace Jovanovich.

Kulik, C. L. C., and Kulik, J. A. (1986). Effectiveness of computer-based education in colleges. AEDS Journal, 19, 81 - 108.

Laurillard, D. (1993). Rethinking University Teaching: A framework for the effective use of educational technology. London: Routledge.

Laurillard, D. (2002). Rethinking university teaching in a digital age. Retrieved August 2, 2002 from: http://www2.open.ac.uk/ltto/lttoteam/Diana/Digital/rut-digitalage.doc

Russell, T. R. (1999). The no significant difference phenomenon. Montgomery, AL.: International Distance Education Certification Center. 
Hannon, Umble, Alexander, et al. - Gagne and Laurillard's Models of Instruction Applied to Distance Education: A theoretically driven evaluation of an online curriculum in public health

Schulz, K. C., and Dahale, V. (1999). Multimedia modules for enhancing technical laboratory sessions. Campus-Wide Information Systems 16, 81 - 88.

Twigg, C. (2001). Innovations in online learning: Moving beyond no significant difference. Troy, NY: Center for Academic Transformation, Rensselaer Polytechnic Institute. 


\title{
Online Education Systems in Scandinavian and Australian Universities: A comparative study
}

\author{
Morten Flate Paulsen \\ NKI Distance Education \\ Norway
}

\begin{abstract}
This article presents a comparative study of online education systems in Norwegian, Swedish, and Australian universities. The online education systems discussed comprise content creation tools and systems for learning management, student management, and accounting. The author of this article arrives at the conclusion that there seems to be a general lack of integration between theses systems in all three countries. Further, there seems to be little focus on standards specifications such as IMS Global Learning Consortium (IMS) and Sharable Content Object Reference Model (SCORM) in higher education in all three countries. It was found that both Norway and Sweden value the importance of nationally developed learning management systems and student management systems; however, this does not seem to be the case in Australia. There also seems to be much more national coordination and governmental coercion concerning the choice of student management systems used in Sweden and Norway, than is the case in Australia. Finally, with regard to online education, the most striking difference between these three countries is that of economic policy. In Australia, education is considered an important export industry. In Norway and Sweden, however, the export of education does not seem to be an issue for public discussion.
\end{abstract}

Keywords: IMS: SCORM; learning management systems; student management systems; Australia; Norway

\section{Introduction}

This article was conceived during a two-week study tour of eight Australian universities in Queensland and New South Wales. It was later nurtured and developed further through literature studies, in-depth telephone interviews, and email correspondence with representatives from the universities and a number of other contacts. Of particular importance, was the email contact with National Council on Open and Distance Education (NCODE) - Flexible Learning Australasia (http://ncode.mq.edu.au), which helped me collect systems information from all Australian universities.

The Universities visited during the study tour were:

- University of Southern Queensland (USQ), Toowoomba, www.usq.edu.au

- University of Queensland (UQ), www.uq.edu.au

- Central Queensland University (CQU), www.cqu.edu.au/ 
- Griffith University (GU), Logan Campus, www.gu.edu.au/

- Charles Sturt University (CSU), www.csu.edu.au/

- University of Technology, Sydney (UTS), www.uts.edu.au/

- University of Wollongong (UW), www.uow.edu.au/

- James Cook University (JCU), Cairnes Campus, www.jcu.edu.au/

Thirty representatives from Norwegian and thirteen representatives from Swedish universities participated in this traveling seminar, and much time was spent discussing and reflecting upon differences and similarities between Norway's, Sweden's, and Australia's national educational systems. Many participants provided valuable input to this article both during and after the traveling seminar. The seminar was arranged by the University College of Lillehammer, which developed a website with information about the seminar and articles written by participants (australia.hil.no).

This article is also based on the author's research in the European Web-edu project (http://www.nettskolen.com/in_english/web_edu.html), which has conducted a number of regional analyses of European experiences with learning management systems. These analyses are based on more than 100 in-depth interviews with experts from 17 European countries. The regional analyses are being published at the website in Fall 2002. The website also provides definitions and discussions of terms used in this article (Paulsen 2002).

The author has written a book about online education from a Scandinavian perspective (Paulsen, 2001; 2002), and has some previous knowledge of Australian online education gained from his international analysis of online education (Paulsen, 2000) conducted by CISAER, a project supported by the European Leonardo da Vinci program, (www.nettskolen.com/in english/cisaer/index.html). Knowledge about higher education in Australia is also based on the higher education report for the 2001-2003 triennium (DEST 2001).

\section{Online Education Systems}

The online education environment is discussed in this article from a systems perspective that comprises a chain of four systems as listed below and shown in Figure 1.

1. Content Creation Tools (CCT)

2. Learning Management Systems (LMS)

3. Student Management Systems (SMS)

4. Accounting Systems (AS) 
Figure 1. The Chain of Online Education Systems

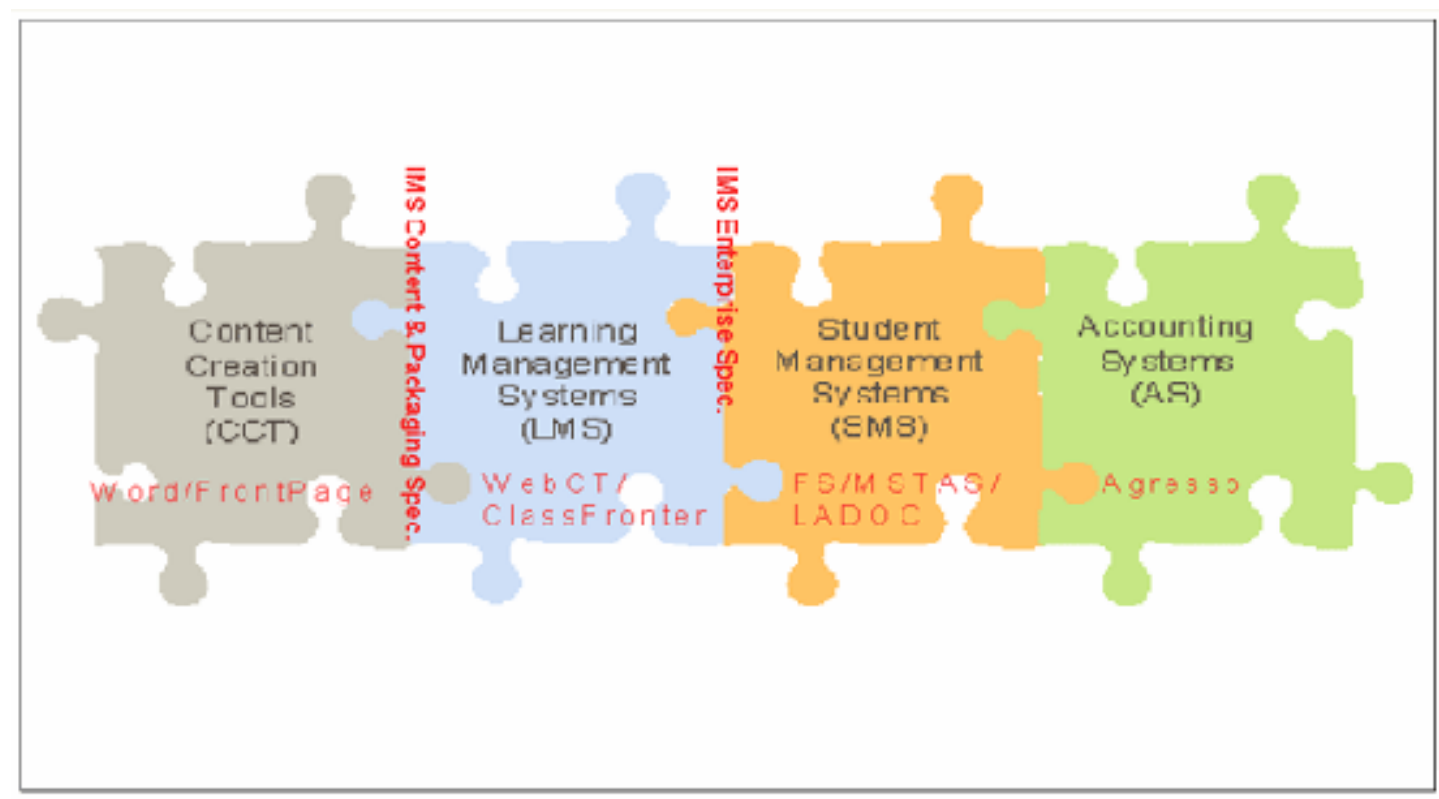

These online education systems are more or less integrated, in that they may overlap, exchange data, or work seamlessly together. So far, in most institutions high levels of integration among systems remains limited. In a discussion of integration between Learning Management Systems (LMS) systems, Student Management Systems (SMS) systems, and Accounting Systems (AS) systems in Norwegian higher education institutions, Runnestø and Ristesund $(2002,159)$ concluded that there is a general lack of integration between LMS systems and SMS systems.

There are several emerging specifications of standards, such as the IMS Global Learning Consortium (IMS) (www.imsproject.org) and Sharable Content Object Reference Model (SCORM) (www.adlnet.org/scorm/downloads.cfm), which may result in improved and easier integration between the four systems. However, the results of this article reveal that there is still little focus on standards in Australian, Norwegian, and Swedish higher education.

A compilation of the online education systems used by universities visited is presented in Figure 1 . The author has not had the capacity at this time, to compile information about which CCT and AS systems the universities are using. 
Table 1. Online education systems used by the Australian institutions visited

\begin{tabular}{|c|c|c|c|}
\hline University & $\begin{array}{l}\text { Learning } \\
\text { Management System }\end{array}$ & $\begin{array}{l}\text { Student Management } \\
\text { Systems and other } \\
\text { systems }\end{array}$ & Standards \\
\hline $\begin{array}{l}\text { University of } \\
\text { Southern } \\
\text { Queensland }\end{array}$ & $\begin{array}{l}\text { Blackboand, } \\
\text { WebCT Vista }\end{array}$ & $\begin{array}{l}\text { Peoplesof } \\
\text { Web-trends, } \\
\text { Rightnow,com } \\
\text { GOOD }\end{array}$ & XML, IMS \\
\hline $\begin{array}{l}\text { University of } \\
\text { Queensland }\end{array}$ & WebCT & Peoplesseft & \\
\hline $\begin{array}{l}\text { Central Queensland } \\
\text { University }\end{array}$ & WeICT & Peoplesof & \\
\hline Grifnth University & Blackboand & $\begin{array}{l}\text { Peoplesoff } \\
\text { Self Developed } \\
\text { (leaming(a)GU) }\end{array}$ & \\
\hline $\begin{array}{l}\text { Charles Sturat } \\
\text { University }\end{array}$ & $\begin{array}{l}\text { In-house, } \\
\text { Blackbaand, } \\
\text { WebcT }\end{array}$ & Banner & \\
\hline $\begin{array}{l}\text { University of } \\
\text { Technology - Sydney }\end{array}$ & Blackboand, Webc $T$ & Strudent One & \\
\hline $\begin{array}{l}\text { University of } \\
\text { Wollongong }\end{array}$ & WebCT & $\begin{array}{l}\text { In-fiouse } \\
\text { LOL }\end{array}$ & IMS \\
\hline $\begin{array}{l}\text { James Cook } \\
\text { University }\end{array}$ & Blackbaand & In-frouse (stutdentsontine) & \\
\hline
\end{tabular}

In the following, each of the four categories of online education systems is discussed with particular focus paid to systems integration and national differences.

\section{Content Creation Tools}

Content creation tools (CCT) are used to develop learning material. Typical examples of such CCT systems are DreamWeaver, Frontpage, Word, PowerPoint, and Director. These are generic CCT systems with few features developed specially for online education. There are probably few national differences with regard to educational use of these CCT systems. Because there are many types of content such as, for example, plain text, slides, graphics, pictures, animations, audio, video etc., it is likely that institutions will need several CCTs. Moreover, it is unlikely that a single LMS system could meet all the needs for content creation.

\section{Integration between CCT and LMS Systems}

Growing focus on standards, such as IMS and SCORM, may provide greater exchangeability of content between LMS systems. For example, The IMS Content and Packaging Specification will make it easier to create reusable content objects useful in a variety of learning systems. However, one should also take note that these are "specifications" rather than "standards." As such, specifications are still developing and have not yet been ratified by any international standards-accrediting agencies. BlackBoard and WebCT, for instance, are partnering with IMS to develop and support such specifications.

It is also worthwhile to note, some LMS systems provide more or less advanced features for content creation. Creation of quizzes, multiple-choice assignments etc., are often handled more efficiently by LMS systems than by generic CCT systems. There are also specific content creation tools for creation of tests, and as such, The IMS Question Test Specification addresses the need to share test items and other assessment tools across different systems. Finally, one should also be aware that LMS systems might require templates and provide publishing features that may support or complicate the integration of CCT and LMS systems. 


\section{Learning Management Systems}

In Australia, WebCT is perhaps the most widespread LMS system, with Blackboard ranking second. An NCODE-FLA (2002) LMS survey (http://ncode.mq.edu.au) of 34 Australian institutions showed 24 instances of WebCT use, 12 instances of BlackBoard use, and six instances of in-house developed LMS systems. This finding is supported by brief on leading learning platforms (The Observatory on Borderless Higher Education, 2002), which shows that Australia holds the highest penetration of BlackBoard and WebCT, with 76 percent of the country's 34 universities licensing such LMS systems.

Among the Australian universities visited, WebCT is used at USQ, UQ, CQU, CSU, UTS, and UW; whereas Blackboard is used by USQ, GU, CSU, UTS, and JCU. The tour indicated that the gross figures would need to be closely examined to determine the level at which each application was used on both a subject and department level, as compared to an enterprise level.

In a personal email, one manager at Charles Stuart University (CSU) Online reported that WebCT is the most commonly LMS in Australia, but that Blackboard is used in the majority of enterprise installations. He further stated there are many stand-alone LMS installations used throughout Australia, and that such systems will never integrate with enterprise systems. These stand-alone systems are consistently counted in raw survey data, but one must question if they should be counted equally.

Charles Stuart University's Online manager also reported using an in-house developed LMS, as well they were just beginning a trial of Blackboard. Having used WebCT in the past for various small projects, CSU recently made the decision to switch from WebCT to BlackBoard after a long, democratic process of discussion.

University of Southern Queensland (USQ) has recently decided to use WebCT Vista, which was released in Australia in March 2002. USQ will use WebCT Vista for local and domestic students, but also continue to use Blackboard for USQOnline in conjunction with their commercial partner, NextEd. Their intention is to manage the transition to both LMS platforms from GOOD via the IMS specification.

Table 2. Number of LMS systems in Australia's 34 universities (NCODE-FLA, 2002)

\begin{tabular}{|c|c|}
\hline LMS & "N" \\
\hline WebCT & 24 \\
\hline BlackBoard & 12 \\
\hline In-house & 6 \\
\hline TopClass & 3 \\
\hline WebMentor & 1 \\
\hline FirstClass & 1 \\
\hline Callista & 1 \\
\hline Lotus Learning Space & 1 \\
\hline
\end{tabular}

The NCODE survey (2002) showed that BlackBoard was the only LMS supported centrally at Edit Cowan University (ECU). However, they have previously used both 
WebCT and a system developed in-house. Further details from ECU are available in a case study (The Observatory on Borderless Higher Education, 2002).

It is interesting to note the dominance of commercial North American systems in Australia. Although there is an overall lack of Australian-developed systems on a commercial level, there are some systems developed in-house. This raises some concerns in Australia, in that the two major LMS players have the market "stitched," meaning that the systems are embedded in the operational culture of Australia's higher education institutions and that uncompetitive pricing structures could evolve.

An analysis of LMS systems in the Nordic countries (Paulsen 2002) states that Nordic institutions tend to prefer LMS systems developed in Nordic countries. Among the 25 different LMS systems identified in the analysis, 16 were of Nordic origin. All other systems were of American, Canadian, or Irish origin. The analysis further indicated that ClassFronter, WebCT, FirstClass, and BlackBoard are the most commonly used LMS systems in the Nordic countries.

In Norwegian higher education, the dominant system in use is the Norwegian developed system ClassFronter (www.fronter.com), while some colleges use standard commercial systems, and others have developed their systems in-house. Of Norway's 54 universities and colleges, 32 offer online education Runnestø and Ristesund (2002, p. 36). As shown in Table 3, several Norwegian universities use more than one system.

Table 3. Number of Learning Management Systems used in 54 Norwegian institutions of higher education (Source: Runnestø and Ristesund, 2002)

\begin{tabular}{|l|c|}
\hline Learning Management System & "N" \\
\hline ClassFronter & 21 \\
\hline Developed In-house & 9 \\
\hline LUVIT & 6 \\
\hline IT's Learning & 4 \\
\hline Finst Class & 3 \\
\hline Kark & 3 \\
\hline WebCT & 3 \\
\hline BlackBoard & 2 \\
\hline TopClass & 1 \\
\hline Lotus Learning Space & 1 \\
\hline TeamWave & 1 \\
\hline Response & 1 \\
\hline
\end{tabular}

Norwegian institutions emphasize the importance of using Norwegian developed systems that are responsive to informational and feedback needs specific to Norwegian institutions.

In Swedish universities and colleges, no one system seems to be dominant, but a number of standard commercial systems are used. According to personal email correspondence with one of Sweden's leading experts on LMS systems, Fredrik Rexhammar (March 18, 2002), Luvit (www.luvit.com), Lecando, Infinity, Grade, Platon, and Web Academy, are the current Swedish-providers of LMS systems. Rexhammar also stated that WebCT and Blackboard are the most common foreign LMS systems currently used in Sweden. In addition, the Swedish-developed system PingPong (www.partitur.se), is also used by some institutions. The following systems are listed in a market overview of LMS systems 
(www.ssv.gov.se/avit/pform2.htm): Luvit, Mentor, Telia Instant Education, Maestro, FirstClass, Comenius Online, Lecando, Librix, Marratech, PingPong, Surfa och lär, and WebCat.

\section{Integration between LMS and SMS Systems}

For historical, legal, and financial reasons, SMS systems tend to be more important than LMS systems. This is because the SMS usually serves as the "master system" from which the LMS accesses and draws necessary data. As a result, integration between SMS and LMS systems tend to vary in sophistication. One may distinguish between the following four levels of integration:

1. Both systems access the same database. However, since few existing systems were originally designed with integration and security in mind, high levels of integration may be difficult to achieve.

2. Both systems have separate databases, but the data are frequently updated and exchanged in a synchronized manner, for example during a daily batch process.

3. Data are frequently transferred one way, from the SMS database to the LMS database, for example during a daily batch process.

4. Data is transferred from the SMS database to the LMS database at the beginning of each semester when students are registered in the SMS. This process may be handled manually.

IMS, SCORM, and other specifications, may facilitate data exchange, thereby making it easier for institutions to substitute one system with another. Hence, these specifications may make institutions less dependent on the system providers. For example, The IMS Enterprise Specification is aimed at administrative applications and services that need to share data about students, courses, and performance across platforms, operating systems, and user interfaces. Similarly, The IMS Learner Profiles Specification describes ways to organize student information, so the systems can be more responsive to the specific needs of each user.

One faculty member at Central Queensland University (CQU) reported in a personal email, that an IMS consultant recently claimed that WebCT, Blackboard and PeopleSoft had agreed on IMS interoperability specifications, presumably for future releases.

Runnestø and Ristesund (2002, p. 159) pointed out that they found a general lack of integration between LMS system and SMS systems in Norwegian colleges and universities. Awareness of this "lack of integration" is, however, increasing in both Australia and Scandinavia. In the NCODE-FLA survey (2002), 11 Australian universities reported varying levels of integration as shown in the quotes below:

- University of Adelaide has achieved full integration with PeopleSoft, employing nightly updates for staff and student details

- Deakin University uses Callista as its student record system and Concept is its human resource system. Both systems are integrated with TopClass, with a fairly administrative-intensive transfer of records between FirstClass and the corporate administrative applications. There is no link with WebCT. 
- Edith Cowan University uses a homegrown records system and enrolment system; however, these systems will be replaced by Callista in the future. The human system currently in use is Concept, and Blackboard is integrated with the existing student and human resources systems.

- Griffiths University uses PeopleSoft, which is fully integrated with its other systems.

- James Cook University has achieved integration with its JCU web, whereas purpose built StudentsOnline and StaffOnline systems work remains ongoing.

- Northern Territory University is currently using ASCOL student administration system and developing Callista TAFE version. When development is completed, Callista will be implemented university wide. Integration with other systems is planned to occur as Callista is implemented.

- The University of Melbourne uses a homegrown student administration system, Merlin, and human resources system Genesys, which are integrated with its LMS, WebRaft. WebRaft is integrated with the Melbourne University's email system.

- The University of New England uses Banner Student and Concept, which are both highly integrated using API with Banner and username and password systems.

- The University of the Sunshine Coast uses PeopleSoft for student administration, finance, human resources, and payroll. In its recent LMS tender, they are looking for integration with its PS systems.

- The University of Tasmania is in the market for a new student system: Concept and HRMS. Both are to be integrated with WebCT.

- The University of Western Sydney is using Concept for staff administration, alongside an in-house student administration system, SRS. These systems are only minimally and variously integrated with current LMS systems in use. Callista is slated to be implemented mid-2002, with the goal of developing gradual interoperability within an integrated system.

\section{Student Management Systems}

There seems to be more national coordination and/or governmental coercion in terms of choice of SMS systems used in Scandinavia, than is the case in Australia. Many SMS systems used in Australia were developed in North America such as: PeopleSoft (CQU, GU), Banner (CSU), and Student One (UTS). However, other universities like University of Wollongong (UW) and James Cook University (JCU), for example, have developed in-house systems, and therefore changing to a commercial system appears to be a major economic obstacle.

The NCODE-FLA survey (2002) provided information about the SMS-systems used by 21 of Australia's 34 universities. This survey indicates that PeopleSoft is the most widely used commercial SMS system in Australia. It also shows that Callista is also widely used and that a number of institutions plan to switch, or are in the process of switching, to Callista. This survey also supports my impression that several universities have chosen to 
develop their systems in-house. It must be noted, that a relatively large range of other systems are also mentioned in the survey.

Table 4. Numbers of SMS systems used in Australia's 34 universities (NCODE-FLA, 2002)

\begin{tabular}{|l|c|}
\hline Student Management Systems & "N" \\
\hline PeopleSoft & $\mathbf{8}$ \\
\hline Callista & 6 \\
\hline In-ltouse developed system & $\mathbf{5}$ \\
\hline
\end{tabular}

In Norway, two student management systems dominate the higher education market: Felles System (http://www.fs.usit.uio.no/) used by most universities, and MSTAS (http://www.enet.no/) used by most colleges. However, it must be emphasized that the two largest private colleges have chosen alternative solutions: The Norwegian School of Management uses Banner and NKI has developed its own in-house system, STAS.

The following short presentation of Felles System was published at www.fs.usit.uio.no/fsenglish.html on February 15, 2002:

Felles System is a computer-based student administrative system developed for universities and colleges in Norway. The following institutions are using Felles System: (The year when they started to use Felles System is in brackets):

- $\quad$ Universities: NTNU (1997), UiB (1996), UiO (1996), UiTø (1996)

- University colleges: AHO (1997), NHH (1997), NLH(1997)

- State colleges: HiA (1999), HiB (1998), HiBu (1999), HiO (1999), HiS (1998), HiST (1999), HiTø (1998), HSH (1999), MF (1998), NMH (2001), KHiB (2001)

Adoption of the Felles System was financed by the Norwegian Ministry of Education and Research, and all publicly financed educational institutions that wish to use Felles System have access to it. Costs of maintenance and further development are shared among user institutions. This system has the following features:

- Persons (applicants, students, faculty members, lecturers, and letter and address solutions)

- Application and admission procedures

- Courses, subjects, programs of study, requirements and regulations

- Eligibility of admission, classes, leave of absence

- $\quad$ Term registration

- $\quad$ Payments (fees for study and exams, reports to financial systems)

- Lectures (planning, publishing, student administration)

- Exams (planning and student administration) 
- Qualifications (awarding of degrees and diplomas)

- $\quad$ Master and PhD (admission and student administration)

- Further and continuing education

- Applications for recognition of foreign or external credentials

- Scholarships (application and awarding)

- Mobility students

- Reports to the Ministry of Education and Research, State Educational Loan Fund, Statistics Norway and others (www.fs.usit.uio.no/fs-english.html)

All Swedish Universities use $L A D O K$ or $L A D O K$ NOVAU, owned by a consortium of 37 Swedish higher education institutions. Information about the $L A D O K$ consortium is available at http://www.ladok.umu.se/. LADOK is a computer-based student admission and documentation system for a university or university college. It focuses on administration of undergraduate and graduate studies. The system is locally deployed and managed by the institutions.

The $L A D O K$ system has a "mutual core," identical to all $L A D O K$ system installations in Sweden. This "mutual core" consists of a structure of database tables and computer programs. Every institution decides which parts of the "mutual core" it wishes to use. It is also possible to use locally developed addendums. In essence, the $L A D O K$ system can be viewed as a large "smorgasbord" from which the institution can pick-and-choose which parts it needs to use.

The $L A D O K$ system consists of two major parts: the admission system, and the documentation system. They are integrated and share data - e.g., name, address, and other facts about applicants and students. A third part, handling documentation of graduate students, has been added to the $L A D O K$ system's "mutual core." Undergraduate studies are handled in terms of single courses and programs of study usually totaling three or four years in length. System files contain information for student identification, general eligibility for university studies, admission to courses and study programs, registration in courses per semester, course data, credit points from courses, degrees awarded, and international studies.

The $L A D O K$ system mainly focuses on student admission and documentation, planning and follow-up. This system was designed for use in all Swedish state financed institutions of higher education. Users of the $L A D O K$ system at an institution can be found at all levels:

- University board and administration Faculty or school heads

- Departments

- Students

Data from $L A D O K$ are exported to the Ministry of Education and other agencies for follow-up purposes. An important objective of $L A D O K$ is to prepare and generate the annual invoice to the government for institutional level undergraduate studies. Although the $L A D O K$ system is owned by a consortium of 37 Swedish higher education 
institutions, maintenance for the $L A D O K$ system "mutual core" is the responsibility of a maintenance group at the University of Umeà. Local system usage is the responsibility of individual institutions, including payment for servers, networking, terminal equipment, and local support.

\section{Integration between LMS, SMS, and AS Systems}

Most institutions have relied on accounting systems for many years. Although AS systems were not developed for integration with LMS systems in mind, they are often part of, or minimally integrated with, a university's SMS systems. So far, the integration between the LMS and AS systems has not attracted much attention. As online education generates more income for institutions, it is likely that increased levels of systems integration will become more important. Some institutions already accept that online enrollment, payment, and student credit account information must become more central.

\section{Accounting Systems}

In contrast to Australia, which enjoys a long history of serving tuition-paying students, Sweden does not accept any tuition fees from its students. In recent years, however, Norwegian universities and colleges have begun charging its students tuition for furtherand continuing education courses. These national differences are significant, in that both countries have developed different incentives for the development of online education and the integration of their AS systems with their SMS and LMS systems.

The accounting systems used in Australian systems are integrated functionally with the SMS or LMS systems. This seems to be the situation for the SMS systems: PeopleSoft and Student One. Similarly, Banner is an integrated accounting system used in the LMS system BlackBoard. In contrast, a separate accounting system named Agresso (www.agresso.com) seems to be dominant in both Norway and Sweden.

\section{Discussion and Conclusions}

In comparing online education systems in Australia, Norway, and Sweden, several important issues become apparent. The most prominent finding facing all three countries is the general lack of integration between content creation tools, learning management systems, student management systems, and accounting systems. To overcome these shortcomings, many institutions have recently initiated efforts to improve overall systems integration. It is hypothesized that those institutions that implement seamlessly integrated systems, will likely improve their chances of becoming successful, large-scale online education providers.

In all three countries, little attention has been paid to adherence to such standard as the IMS and SCORM specifications in higher education. This may stem from institutions' limited knowledge about such specifications, skepticism about the sustainability of specifications, general resistance to standards that seemingly limit individual freedom, and/or a conscious decision that adoption of such specifications are not important enough to justify cost and resource expenditures. Barron (2001) discusses some of these issues in detail.

Norway and Sweden tend to prefer nationally developed LMS and SMS systems. On the other hand, Australian institutions tend to prefer using commercially produced systems. 
This difference may reflect language issues, but it may also stem from pedagogical traditions and other cultural factors.

In terms of choosing of SMS systems, higher levels of national coordination and/or governmental coercion is more evident in Scandinavia than it is in Australia. Many of SMS systems used in Australia were developed in North America. However, two Norwegian systems and one Swedish system completely dominate in the Scandinavian countries, which may possibly result in future collaboration among the Scandinavian universities, over that of Australian universities.

As compared to Norwegian and Swedish universities, Australian universities regard online education as a source of income. This difference may account for greater awareness in Australia of the necessity of integration among AS, LMS, and SMS systems. The most striking difference between the three countries with regard to online education is related to economic policy. In Australia, distance education is viewed as one of the country's most important export industries. The education and training action plan for the information economy from the Commonwealth Government (DEST 2000) clearly states: "Education in Australia is a multi-billion dollar export industry of vital importance to our economy." However, in Scandinavia, export of education does not even seem to be an issue for public discussion.

Australia can benefit by having English as its first language. In contrast, Norwegian and Swedish are home to minority languages, and this fact alone may be one reason that higher education institutions in Norway and Sweden appear to be much less interested in exporting online education to other countries, as compared to their Australian counterparts.

In Scandinavia, education is traditionally perceived as a public service that should be available free of charge. Although there is increasing acceptance for commercialization of education, Swedish universities, are not allowed to charge its students tuition fees. In comparison, Norwegian universities and colleges are now obliged to charge tuition fees for further and continuing education - educational initiatives that in recent years has become the most dynamic and innovative sector of education in Norway. Since Sweden lacks this economic incentive for change, the country will likely face future difficulties when competing with online education in other countries.

On balance, online education appears to be less developed in Sweden than it is in Australia and Norway. This may be partly due to the lack of economic incentives to offer online programs as a source of extra income. It may also be due to the fact that governmental online education initiatives tend to be imposed, and often without local institutional support. One such example is three Swedish distance education consortia, which have received considerable governmental funding since 1993-94 (Hillefors et al, p. 22; Ranebo, 2001). At its peak, these three consortia offered from 40 to 50 courses, to 5,000 to 6,000 students (Hillefors et al., p. 26). After nearly ten years of unimpressive results, funding is to be discontinued. To replace these consortia, the Swedish government has recently established Nätuniversitetet (http://www.netuniversity.se), a new national body to fund and coordinate Sweden's distance education activities. In 2002, Nätuniversitetet will provide financial funding for the equivalent of 2,350 full-time students at 30 Swedish higher institutions.

Norwegian institutions typically charge students 3000 to 4000 euro dollars for online courses, equivalent to one-year full-time study. In contrast, for the year 2002, Swedish universities will receive 12,000 euro dollars in governmental funding from 
Nätuniversitetet for similar online courses of equivalent length. This is about three times more funding than Swedish universities receive for an on-campus student engaged in full time studies. Such lavish funding is probably intended to increase the development of online courses. However, it could also easily set a standard for future costs of online education courses. In the view of this author, the Swedish approach is unwise, as it not cost effective and could set an unhealthy precedent for future overspending.

\section{References}

Barron, T. (2001). Standards: The Vision and the Hype. American Society for Training \& Development (ASTD). Retrieved October 3, 2002 from:

www.learningcircuits.org/nov2000/standards.html

DEST (2000). Learning for the knowledge society. An education and training action plan for the information economy. Retrieved October 3, 2002 from: www.dest.gov.au/schools/Publications/2000/learning.htm

DEST (2001). Higher education report for the 2001-2003 triennium. Retrieved October 3, 2002 from: www.detya.gov.au/highered/he_report/2001_2003/html/1.htm

Hillefors, L., Myringer B., Svanteson B., Rathsman I., and Gisselberg M. (2001). Ett Nätuniversitet för livslàngt lärande och kompetensutveckling. Rapport fràn en utredning utförd pà uppdrag av styrelserna för Distanskonsortiet, Svenska Distanshögskolan ock Västsvenska konsortiet för flexibelt lärande.

NCODE-FLA (2002). Retrieved October 3, 2002 from: http://ncode.mq.edu.au/papers/lmsSurvey.doc

Observatory on Borderless Higher Education, (2002). Leading Learning Platforms: International market presence. Observatory on Borderless Higher Education 2. Retrieved October 3, 2002 from: www.obhe.ac.uk/products/briefings/pdfs/LearningPlatforms.pdf

Observatory on Borderless Higher Education (2002). Concise Case Study: Learning platforms. Observatory on Borderless Higher Education 2. Implementation of a Learning Platform at Edith Cowan University, Australia. Retrieved October 3, 2002 from: www.obhe.ac.uk/products/briefings/pdfs/LearningPlatforms.pdf

Paulsen, M. F. (2002). An Analysis of Online Education and Learning Management Systems in the Nordic Countries. Online Journal of Distance Learning Administration 5(3). Retrieved October 3, 2002 from: http://www.westga.edu/\%7Edistance/ojdla/fall53/paulsen53.html

Paulsen, M. F. 2002. Nettbasert utdanning - erfaringer og visjoner. København: Gyldendal. Retrieved October 3, 2002 from: www.nettskolen.dk/nettskolen/bok

Paulsen, M. F. (2002). Online Education Systems: Discussion and definition of terms. Retrieved October 3, 2002 from: http://www.nettskolen.com/forskning/Definition\%20of\%20Terms.pdf 
Paulsen, M. F. (2001). Nettbasert utdanning - erfaringer og visjoner. Oslo: NKI Forlaget. Retrieved October 3, 2002 from: www.nkiforlaget.no/forlaget/html/utdrag/nettbasert.htm

Paulsen, M. F. (2000). Online Education: An international analysis of Web-based education and strategic recommendations for decision makers. Oslo: NKI Forlaget.

Ranebo, S. (2001). Nordisk kartlägging av nationella initiativ rörande utvecklingen av Virtuella universitet. Nordiska ministerràdets IT-policygrupp. Retrieved October 3, 2002 from: www.yh.aland.fi/dokument/IT_P_VU_rapport_Final.pdf

Runnestø, R., and Ristesund G. (2002). Experiences with Learning Management Systems in Norwegian Universities and Colleges. Retrieved October 3, 2002 from: http://www.nettskolen.com/forskning/Diploma\%20project.pdf

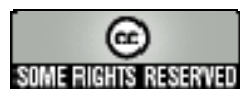


October - 2002

\title{
The Effectiveness of Web-Based Instruction: An initial inquiry
}

\author{
Tatana M. Olson \\ Purdue University \\ Robert A. Wisher \\ U.S. Army Research Institute
}

\begin{abstract}
As the use of Web-based instruction increases in the educational and training domains, many people have recognized the importance of evaluating its effects on student outcomes such as learning, performance, and satisfaction. Often, these results are compared to those of conventional classroom instruction in order to determine which method is "better." However, major differences in technology and presentation rather than instructional content can obscure the true relationship between Web-based instruction and these outcomes. Computer-based instruction (CBI), with more features similar to Web-based instruction, may be a more appropriate benchmark than conventional classroom instruction. Furthermore, there is little consensus as to what variables should be examined or what measures of learning are the most appropriate, making comparisons between studies difficult and inconclusive. In this article, we review the historical findings of CBI as an appropriate benchmark to Web-based instruction. In addition, we review 47 reports of evaluations of Web-based courses in higher education published between 1996 and 2002. A tabulation of the documented findings into eight characteristics is offered, along with our assessments of the experimental designs, effect sizes, and the degree to which the evaluations incorporated features unique to Web-based instruction.
\end{abstract}

Keywords: Web-based courses; benchmarks; CBI

\section{Authors' Note}

We would like to caution readers against drawing inappropriate cause-and-effect conclusions from the results presented in this paper. A goal of this paper is to present data based on existing empirical literature. As demonstrated by our finding of only one study in which random assignment of individuals to conditions occurred, there is a tremendous need for experimental studies of Web-based instruction if we are to draw any definitive conclusions about the effectiveness of Web-based instruction in comparison to other methods. The conclusions that one can draw from the results of a meta-analysis are highly dependent on the research designs of the individual studies examined. For example, if all the studies included are corelational, as were many of the studies reviewed in this paper, associational rather than causal conclusions are more appropriate. In this paper, the terms "effect," "effect sizes," and "effectiveness" are used in accordance with 
the accepted technical language of meta-analysis and are not meant to necessarily imply the existence of causal relationships.

\section{The Effectiveness of Web-Based Instruction: An initial inquiry}

The World Wide Web can be used to provide instruction and instructional support. Webbased instruction offers learners unparalleled access to instructional resources, far surpassing the reach of the traditional classroom. It also makes possible learning experiences that are open, flexible, and distributed, providing opportunities for engaging, interactive, and efficient instruction (Kahn, 2001). Phrases such as "flexible navigation," "richer context," "learner centered," and "social context of learning," are used in the literature to describe Web-based instruction. Furthermore, cognitive-based theories of learning have extended the design and delivery of Web-based instruction, applying the technical nomenclature to instructional practices (Bonk and Dennen, 1999). Indeed, Dills and Romiszowksi (1997) have identified more than 40 instructional paradigms seeking to advance and improve the online learning experience beyond the traditional classroom.

Some researchers have argued, however, that the tried-and-true principles of instructional design, namely interaction and timely feedback, are often absent from Web-based instruction, particularly from individual Websites devised to teach (Eli-Tigi and Branch, 1997). The absence of a sturdy pedagogical underpinning for a Web-based "instructional" program can diminish an otherwise worthy opportunity to improve learning. Welldesigned computer-based instruction developed in the 1970s and 1980s, for example, has been demonstrated to enhance learning outcomes when compared to classroom instruction (Kulik and Kulik, 1991). A central question, then, is just how effective is online instruction? In particular, how does it compare to both the conventional classroom and established forms of stand-alone computer-based instruction (CBI)?

For the purposes of this review, online instruction is considered to be any educational or training program distributed over the Internet or an intranet and conveyed through a browser, such as Internet ExplorerTM or Netscape Navigatorä. Hereafter, it is referred to as Web-based instruction. The use of browsers and the Internet is a relatively new combination in instructional technology. While the effectiveness of traditional CBI has been reviewed thoroughly (Kulik, 1994; Lou, Abrami, and d'Apollonia, 2001), the effectiveness of online instruction has received little analysis. Part of the reason may be that so few cases have been detailed in the literature. This report serves, then, as an initial examination of the empirical evidence for its instructional effectiveness.

\section{Advantages of Distributed Learning}

Many educational institutions and organizations are seeking to take advantage of the benefits offered by distributed learning, such as increased accessibility and improvements in learning. Learning advantages have consistently been found whenever well-designed instruction is delivered through a computer. Fletcher (2001), for example, has established the "Rule of Thirds" based on an extensive review of the empirical findings in educational and training technology. This rule advises that the use of CBI reduces the cost of instruction by about one-third, and additionally, either reduces the time of instruction by about one-third or increases the effectiveness of instruction by one-third. The analyses for this rule were based primarily on stand-alone CBI, not the contemporary use of online technologies. 
Olson \& Wisher - The Effectiveness of Web-Based Instruction: An initial inquiry

Unlike the fixed resources in conventional CBI, Web-based instruction can be conveniently modified and redistributed, readily accessed, and quickly linked to related sources of knowledge, thus establishing a backbone for "anytime, anywhere" learning (Fletcher and Dodds, 2001). Compare these features to, say, a pre-Internet CD-ROM in which instructional messages were encoded in final form, availability was limited to specific computers, and immediate access to a vast array of related materials was not possible. However, many key instructional features, such as learner control and feedback, are shared between Web-based and conventional CBI. A reasonable assumption concerning the effectiveness of Web-based instruction, then, is that it should be at least "as good as" conventional forms of CBI.

Qualities shared by the two delivery media include multimedia formats, self-pacing, tailored feedback, and course management functions. Additionally, the unique features of Web-based instruction, flexible courseware modification, broad accessibility, and online links to related materials, instructors, and fellow students, should make possible improvements in learning outcomes beyond CBI. Learning outcomes from conventional CBI, when compared to conventional classroom instruction, have demonstrated effects significantly above the "no-significant-difference" threshold (Fletcher, 1990; Kulik, 1994). Furthermore, Web-based instruction shares elements of good classroom teaching that are not necessarily available in conventional CBI. Chickering and Ehrmann (1996) outlined seven ways in which technology can leverage practices from the traditional classroom. For example, good practice encourages student contact with faculty, and Webbased environments offer ways to strengthen interactions between faculty and students through email, resource sharing, and collaboration.

\section{Effect Size}

The measurement of effect size is simply a way of quantifying the difference between two groups. For example, if one group has had an "experimental” treatment (Web-based instruction) and the other has not (the conventional classroom), then the effect size is an indicator of the effectiveness of the Web-based treatment compared to that of the classroom. In statistical terms, effect size describes the difference between two group means divided by either the pooled standard deviation or the standard deviation of the treatment group (Glass, McGaw, and Smith, 1991). An advantage of using effect size is that numerous studies can be combined to determine an overall best estimate, or central tendency, of the effect. Generally, values of $0.2,0.5$, and 0.8 are considered to correspond to small, medium, and large effect sizes, respectively (Cohen, 1988).

There is no principled reason to expect Web-based instruction to be any less effective than traditional CBI. Both are capable of interactivity, individual feedback, and multimedia presentation. However, technical limitations with current Web-based configurations may dilute some of these advantages. Inherent limitations such as a small viewing area for video, video with a slow frame speed, or delays in responsiveness as a result of high traffic load on the Internet may restrict its current effectiveness. On the other hand, Web-based instruction offers new advantages to the learner, such as interactivity with instructors and students and quick access to supplementary online resources. As the technology improves, Web-based instruction may have an ultimate advantage. 


\section{Roles of the Web in Instructional Settings}

Web-based instruction offers multiple dimensions of use in education and training environments. As with $\mathrm{CBI}$, it is capable of providing direct instruction to meet individual learning objectives. Due to its networking capability, the Web can play additional roles. These include promoting and facilitating enrollment into courses, availing the syllabus or program of instruction, posting and submitting assignments, interacting with instructors and fellow students, collaboration on assignments, and building learning communities.

The Web has become a powerful tool for learning and teaching at a distance. Its inherent flexibility allows application in a variety of ways within an educational context, ranging from simple course administration and student management to teaching entire courses online. Each of these types of use works towards a different goal. These goals should be recognized when evaluating the use of the Web. For example, an instructor may hold face-to-face lectures in a classroom but post the class syllabus, assignments, and grades on the Web. In this case, it may not be appropriate to evaluate the use of the Web with respect to learning outcomes since the Web was not used in a direct instructional role.

There are a host of factors that contribute to a meaningful learning environment. In an attempt to gain a systematic understanding of these factors, Kahn (1997) developed a framework for Web-based learning, consisting of eight dimensions: 1) pedagogical; 2) technological; 3) interface design; 4) evaluation; 5) management; 6) resource support; 7) ethical; and 8) institutional. Kahn (2001) later offered a framework for placing Webbased instruction along a continuum ranging from "micro" to "macro" uses. The "micro" end of the continuum involves the use of the Web as a way to supplement or enhance conventional classroom instruction (e.g., providing students in a biology course with an interactive map of the brain to help them learn brain functions). Further along the continuum are courses that are partially delivered over the Web, such as elective modules that supplement classroom instruction. Clearly, factors beyond pedagogy such as technical reliability, interface design, and evaluation become increasingly important at this level. Finally, at the "macro" end of the continuum are complete distance learning programs and virtual universities.

Other researchers have also recognized the importance of determining the level of Webuse in a course. For example, Galloway (1998) identified three levels of Web-use. In Level 1, the Web is used to post course material with little or no online instruction. The instructor guides students to the relevant information rather than obliging the students to search for information. In Level 2, the Web is used as the medium of instruction. Course assignments, group projects, and lecture notes are posted on the Web. The teacher becomes the facilitator of knowledge, guiding the student rather than telling them what to do. In addition, there is increased student-student interaction. Courses that are offered completely online fall into Level 3. Teachers and students interact only over the Internet, and know how to use the technology is extremely important at this level.

Web-based instruction is still in an early stage of implementation. Nevertheless, educational institutions, private industry, the government, and the military anticipate immense growth in its use. Obstacles to realizing the Web's full potential for learning clearly remain. These include the appropriateness of pedagogical practices (Fisher, 2000) and the bandwidth bottleneck for certain learner requests (e.g., video on demand) (Saba, 2000). From an evaluation perspective, there has been an inclination to compare the Web-based instruction with conventional classroom instruction (Wisher and Champagne, 2000). However, the historical findings on the effectiveness of conventional CBI may be 
more be a more appropriate basis for a comparison. An assessment of current practices thus may consider whether the capabilities of the Web are being tapped, how interpretable the findings are, and how those findings compare with conventional CBI.

Our assessment is organized as follows: A review of the historical findings of CBI benchmark to Web-based instruction, is presented, followed by a summary of our literature review. Our review encompassed 40 articles selected from a larger set of more than 500 articles published on the topic of Web-based instruction between 1996 and 2002. A tabulation of the documented findings into eight characteristics is offered in Appendix A, along with our assessment of the experimental designs, effect sizes, and the degree to which each evaluation incorporated features unique to Web-based instruction. The selection of characteristics was based on what is generally considered as indicators of overall quality.

\section{Benchmarks for CBI Effectiveness}

CBI has been a significant part of educational technology, beginning with the first reported use of the computer for instructional purposes in 1957 (Saettler, 1990). Its emergence as a true multimedia delivery device occurred in the early 1980s with the coupling of videodisc players with computers. In recent years, the videodisc has been replaced by the CD-ROM. The combination of a computer controlling high quality video and/or audio segments was a compelling advancement in CBI, and the instructional effectiveness of this pairing has been well documented.

Fletcher (1990) conducted a quantitative analysis of the education and training effectiveness of interactive videodisc instruction. Specifically, empirical studies comparing interactive videodisc instruction to conventional instruction were segmented into three groups: higher education, industrial training, and military training. The various learning outcomes investigated include: 1) knowledge outcomes in terms of a student's knowledge of facts or concepts presented in the instructional program; 2) performance outcomes which assessed a student's skill in performing a task or procedure; 3) retention in terms of the durability of learning after an interval of no instruction; and 4) the time to complete the instruction. The effect sizes, or the difference between the mean scores of the treatment and comparison groups divided by the standard deviation of the control group, were computed for each of the 28 studies identified.

The results of the Fletcher (1990) meta-analysis are presented in Table 1, broken down by learning outcome, and in Table 2, broken down by instructional group.

Table 1. Average effect sizes for four types of knowledge outcomes for CBI

\begin{tabular}{|c|c|c|}
\hline Learning Outcome & Effect Size & Percentile \\
\hline Knowledge & .36 & $64^{\mathrm{h}}$ \\
\hline Performance & .33 & $63^{\circ 6}$ \\
Retention & .65 & $74^{\mathrm{h}}$ \\
\hline Time to Complete & 1.19 & $88^{\circ \mathrm{h}}$ \\
\hline
\end{tabular}


Olson \& Wisher - The Effectiveness of Web-Based Instruction: An initial inquiry

Table 2. Average effect sizes for three instructional groups using CBI

\begin{tabular}{|c|c|c|}
\hline Instructional Group & Effect Size & Percentile \\
\hline Higher Education & .66 & $74^{\text {th }}$ \\
\hline Industrial Training & .17 & $6 \bar{f}^{\text {. }}$ \\
\hline Military Training & .39 & $65^{\text {n }}$ \\
\hline
\end{tabular}

Fletcher (1990) concluded on the basis of his analysis, that interactive video instruction was both more effective and less costly than conventional instruction.

In a later analysis of the effectiveness of CBI, Kulik (1994) took into account the conceptual and procedural differences in how the computer was used in the individual studies. In his analysis of 97 studies that compared classes that used CBI to classes that did not, Kulik (1994) computed the overall effect size as well the effect sizes corresponding to five categories of computer use relevant to the present report: 1) tutoring; 2) managing; 3) simulation; 4) enrichment; and 5) programming.

Kulik determined the overall effect size to be .32 , indicating that the average student receiving $\mathrm{CBI}$ performed better than the average student in a conventional class, moving from the 50th percentile to the 61st percentile. However, when categorized by computer use, the effect sizes yielded somewhat discrepant results. Only the effect size for tutoring, at .38, fell into the category, according to Cohen (1988), of being noteworthy, between a small and moderate effect. All other effect sizes were .14 or lower.

The effect size for computer-based programs used for tutoring (.38) is significantly higher than the rest, indicating that students who use computers for these purposes may achieve better outcomes than students who use CBI for management, simulation, enrichment, or programming purposes. In addition, it is clear from the table that basic programming and simulations had minimal effect on student performance. The conclusion of the Kulik (1994) analysis was that researchers must take into account all types of CBI when trying to assess their effects on student learning.

Finally, Liao (1999) conducted a meta-analysis of 46 studies that compared the effects on learning of hypermedia instruction (e.g., networks of related text, graphics, audio, and video) to different types of non-hypermedia instruction (e.g., CBI, text, conventional, videotape). Results indicated that, overall, the use of hypermedia in instruction results in more positive effects on students learning than non-hypermedia instruction with an average effect size equal to 0.41 . However, the effect sizes varied greatly across studies and were influenced by a number of characteristics. Effect sizes were larger for those studies that used a one-group repeated measure design and simulation. In addition, effect sizes were larger for studies that compared hypermedia instruction to videotaped instruction than for studies that compared hypermedia instruction to CBI.

While each of the studies reviewed above provide evidence of the positive effects of CBI on student learning, they also point to the complexity of the issue. Evidence of the relationship between CBI and learning is influenced by many variables including the type of media used, what CBI is being compared to, and the type of research design employed, to name just a few. These issues increase in complexity when applied to Web-based instruction that tends to be less linear and more interactive and dynamic. 


\section{The Effectiveness of Web-based Instruction}

The following review is summative in nature and is limited to studies that evaluated the use of the World Wide Web (WWW) at undergraduate and graduate levels of education. The studies included in the review were examined with reference to four key features: 1) degree of interaction in the course; 2) measurement of learning outcomes; 3) experimental design used in evaluating the course; and 4) extent of Web use throughout the course. Since the purpose of this review is to assess current practices in the use and evaluation of Web-based courses, the criteria that guided the choice of studies for this review were broadly defined. The studies had to involve the use of the Web as an instructional tool either as a supplement to conventional classroom instruction or as the primary medium of instruction. In addition, studies had to include an evaluation of the Web-based components of the course.

The evaluations included in these studies fell into two broad categories. The first category of evaluation consisted of comparisons of Web-based instructional approaches to conventional classroom instruction. These evaluations could involve comparison of a control group with an experimental group derived from the same population of students or a simple comparison between a class taught at one time without the use of the Web and the same class taught at a different time using the Web. The second category of evaluations involved assessment of student performance and reactions relative to a single course.

\section{Methods and Procedure}

The Educational Resources Information Center (ERIC) and Psychological Abstracts databases were searched using the following combinations of key words: "Web-based courses," "Web-based instruction," "Web-based courses and evaluation," "course evaluation and Web," "course evaluation and Internet," "Web and distance education," and "online course and evaluation." Because we were trying to assess current practices in evaluating Web-based instruction, the search was restricted to the years 1996 to 2002. This search identified more than 500 qualifying studies conducted between August 2000 and July 2002. However, most of these studies concerned recommendations for the design of online courses or technology concerns rather than an evaluation of a specific course. Such studies were not included in the review. In addition, we found several relevant studies from the Journal of Asynchronous Learning, Education at a Distance, and the previous four years of the Proceedings of the Distance Teaching and Learning Conference. Researchers in the field of distance education referred us to additional useful references and citations that had not previously been identified by our search of the databases.

Appendix A summarizes the findings reported in the 47 studies derived from the original 40 articles, some of which dealt with more than one study. Although most of the studies involved courses in the physical sciences, the instructional content of the courses concerned a variety of subject matters, including philosophy, nutrition, economics, and sports science.

In our review of the literature on Web-based instruction is organized according to three categories: 1) study characteristics; 2) methodological characteristics; and 3) course characteristics. The analysis of these characteristics provides some insight into what questions people are asking about Web-based instruction and how well they are being answered. Descriptive statistics for these characteristics are presented in Table 3. 
Table 3. Descriptive statistics for studies included in review

\begin{tabular}{|c|c|c|c|c|c|}
\hline Variables & $\mathrm{N}$ & $\%$ & Variables & $\mathrm{N}$ & $\%$ \\
\hline Content Area & & & Course Characteristics & & \\
\hline Math/Engineering/Computers & 11 & 23 & Level of Web Use & & \\
\hline Science/Medicine & 12 & 26 & All.Online & 29 & 62 \\
\hline Distance Education Programs & 7 & 15 & Blend & 17 & 36 \\
\hline Socia1SciencesIEducation & 11 & 23 & Mixed between courses & 1 & 2 \\
\hline Businese & 4 & 9 & & & \\
\hline \multirow[t]{2}{*}{ Langusge } & 2 & 4 & Attrition Data & & \\
\hline & & & Yes & 18 & 38 \\
\hline Educational Level & & & No & 29 & 62 \\
\hline Undergroduate & 3 & 31 & & & \\
\hline Gractate & 8 & 17 & Variables Assessed & & \\
\hline \multirow[t]{2}{*}{ Both } & 1 & 2 & Course design & 21 & 43 \\
\hline & & & Demographics & 22 & 47 \\
\hline Methodological Characteristics & & & Computer Experience & 13 & 28 \\
\hline Sample Size & & & Effectiveness of instructor & 18 & 3 \\
\hline $9-50$ & 13 & 28 & Technicol issues & 12 & 26 \\
\hline $51-100$ & 10 & 21 & Interaction/Participation & 12 & 26 \\
\hline Over 100 & 13 & 28 & Desire to take addational online & 6 & 13 \\
\hline Not Reported & 11 & 23 & $\begin{array}{l}\text { Recommendation of course to } \\
\text { others }\end{array}$ & 3 & 6 \\
\hline \multicolumn{6}{|l|}{ Comparison Group } \\
\hline $\mathrm{Y}_{\mathrm{es}}$ & 29 & 62 & & & \\
\hline No & 18 & 38 & & & \\
\hline
\end{tabular}

\section{Study Characteristics}

\section{Content Areas}

Content areas represented in the studies were wide-ranging. Approximately 23 percent examined the effects of Web-based instruction for teaching math, engineering, and computer courses, whereas 26 percent focused on the teaching of science and medical courses. Another 23 percent focused on the social sciences and education. In addition, about 15 percent of the studies evaluated entire programs of distance learning, which most likely were comprised of many types of courses. The wide variety of content areas discovered in this review demonstrates the flexibility of Web-based instruction to be adapted to the requirements of students and teachers in different subject areas.

\section{Educational Level}

Both undergraduate and graduate students were represented in this review. Of the 47 studies, 81 percent evaluated Web-based instruction for undergraduate students, 17 percent evaluated graduate instruction, and two percent evaluated Web-based instruction for both graduate and undergraduate students. Given the differences in course content and teaching styles between undergraduate and graduate classes, it would have been interesting to assess the differential impact of Web-based instruction on student learning between the two. However, insufficient information was provided by the studies to be able to draw any conclusions on this issue. For example, many studies failed to provide means or standard deviations for learning outcome measures. In addition, many studies involving graduate students did not identify the methods used to assess student learning and performance or either course content or level of Web use. 
Olson \& Wisher - The Effectiveness of Web-Based Instruction: An initial inquiry

\section{Methodological Characteristics}

\section{Sample Size}

The sample size of a study can significantly affect the statistical power of the underlying tests for differences. Of the 47 studies, 36 reported information about the sample sizes of participants. These ranged from 9 to 1,406. Of these 36 studies that provided sample sizes, most (64 percent) had sample sizes of fewer than 100 participants. Effect sizes were available for 10 of these studies, with the mean effect size of approximately 0.09 . For studies in which the sample size exceeded 100, the mean effect size increased to 0.55. In general, the larger the sample size, the stronger the statistical power.

\section{Use of a Comparison Group}

The majority of the studies identified for this review used a comparison group in which students took the same course face-to-face or the same course with no Web-based components. However, 41percent of the studies simply evaluated the Web-based course without any comparison group. A similar pattern was found in evaluations of distance learning technology in training environments in which 55 percent of evaluations did not use a comparison group (Wisher and Champagne, 2000). While a comparison group is not a requirement for course evaluation, the absence of one can threaten the internal validity of the study and restrict data interpretation. Without an equivalent comparison group, it is difficult to draw conclusions about the impact of instruction using the Web on student learning, satisfaction, and other outcomes. Of the 29 studies that had a comparison group, only one (Schutte, 1996) randomly assigned students to conditions. Thus, most of the studies with comparison groups were subject to the influence of many possible confounding variables arising from relationships between Web-based instruction and learning outcomes.

\section{Course Characteristics}

\section{Level of Web Use}

As demonstrated by the results of both Kulik (1994) and Liao (1999), different forms of CBI can differentially affect student outcomes. Thus, it is important to take into account how a particular medium of instruction is applied when evaluating a course. In view of the medium's tremendous ability to distribute seemingly unlimited resources and information to anyone at anytime, this is especially true of Web-based instruction. The flexibility of the Web enables it to be used for a variety of purposes, from course administration and management to complete course delivery; each of these types of use works towards a different goal.

In all of the studies, the Web was used for more than purely management purposes. Of the 47 studies, 17 evaluated "blend courses" or courses that were a mix of both face-toface instruction and Web-based components (e.g., posting of course syllabus and lecture notes, online tutorials and graphics, etc.). While in these "blend courses" the Web was used to fulfill many management functions, students were also required to access the Web regularly in order to be productive members of the class. This access led to different types of Web-use. The remainder of the studies involved courses that where completely online with little or no face-to-face interaction. Of the 30 studies of courses that were offered completely online, 10 evaluated student and teacher interactions, availability of instructor feedback, and technological issues. 
In terms of learning outcomes, effect sizes were available for six of the "blend" courses and nine of the all-online courses. The mean effect size for the "blend" courses was 0.48, while the mean effect size for the all-online courses was 0.08 . While this is not a statistically significant difference (Mann-Whitney U Test, $\mathrm{p}=.14$ ), it does suggest that Web-based instruction may be more beneficial for student learning when used in conjunction with conventional classroom instruction. The direction of the difference is the same as Liaos' (1999) analysis, which showed that the mean effect size for courses that used hypermedia as a supplement to conventional instruction was 0.18 standard units higher than courses that replaced conventional instruction with hypermedia.

\section{Variables Assessed}

Many of the evaluation studies of Web-based instruction, and distance education as a whole, lack a guiding theoretical framework (Saba, 2000; Berge and Mrozowski, 2001). Furthermore, there is no consensus as to what variables are important to examine when evaluating Web-based courses. As online courses incorporate unique elements such as flexibility, a wide range of corresponding resources and tools, and technological considerations among others, determining the evaluation elements becomes more complicated for online courses than for face-to-face instruction. As a result, researchers have assessed a wide range of variables. For studies included in this analysis, variables assessed can be grouped into eight major categories:

Table 4. Variables grouped into eight major categories

\begin{tabular}{|c|c|}
\hline $\begin{array}{l}\text { 1. Demographics (age, gender, } \\
\text { race,) }\end{array}$ & 2. Technical issues \\
\hline $\begin{array}{l}\text { 3. Previous computer } / \text { nternet } \\
\text { experience }\end{array}$ & $\begin{array}{l}\text { 4. Level of } \\
\text { participation/collaboration }\end{array}$ \\
\hline 5. Course design & $\begin{array}{l}\text { 6. Recommendation of course to } \\
\text { others }\end{array}$ \\
\hline 7. Effectiveness of the instructor & $\begin{array}{l}\text { 8. Desire to take additional online } \\
\text { courses }\end{array}$ \\
\hline
\end{tabular}

Although many of the studies assessed the design of the Web-based course and the demographic characteristics of the participants, few evaluated the quality of interaction or collaboration in the course, effectiveness of the instructor, or technology itself.

\section{Attrition}

It has been widely recognized that the attrition of students is a greater problem for online courses than classroom courses (Phipps and Merisotis, 1999; Terry, 2001). In addition, some research has shown that blended courses should be considered separately from completely online courses when assessing student attrition as blended courses have lower attrition rates (Bonk, 2001). However, only 14 (34 percent) of the studies reported information about attrition.

\section{Comparison to CBI Benchmark}

When compared to conventional classroom instruction, the learning outcomes from conventional CBI have demonstrated effect sizes significantly above the "no significant difference" threshold (Fletcher, 1990; Kulik, 1994). The original premise of this article stated that if Web-based instruction were employed effectively, and used to achieve specific learning objectives, it would lead to effect sizes that are at least comparable to 
CBI. Of the 15 studies in this analysis that provided sufficient information to calculate effect sizes, eight (53 percent) of the effect sizes were positive and favored the group that used Web-based instruction, while seven (47 percent), were negative and favored the group that did not use Web-based instruction. The effect sizes ranged from -.40 to 1.60. The grand mean for all 15 effect sizes was 0.24 , and the grand median was 0.095 . The standard deviation of 0.58 indicates wide variability of effect sizes across studies.

Because these data did not meet the assumptions of normality and homoscedasticity, nonparametric tests were performed on the mean effect sizes of the current analysis as well as the analyses conducted by Kulik (1994) and Liao (1999) to compare Web-based instruction to CBI. Results of a Kruskal-Wallis Test indicated that there was no significant difference $(p=.47)$ in mean effect size across the three sets of analyses. The average effect sizes and their corresponding standard deviations for the studies included in this article and the previous analyses conducted by Kulik and Liao are listed in Table 5 .

Table 5. Comparison of effect sizes across analyses

\begin{tabular}{|c|c|c|c|}
\hline & $\begin{array}{c}\text { Web-Based } \\
\text { Instruction }\end{array}$ & $\begin{array}{c}\text { CBI } \\
\text { Kulik (1994) }\end{array}$ & $\begin{array}{c}\text { CBI } \\
\text { Liao (1999) }\end{array}$ \\
\hline Average Effect Size & .24 & .32 & .41 \\
\hline Percentiles & $59^{\text {m }}$ & $63^{\text {r }}$ & $66^{\text {m }}$ \\
\hline Average S.D. of Effect Sizes & .58 & .39 & .87 \\
\hline Number of Studies & 15 & 97 & 46 \\
\hline
\end{tabular}

These results would seem to suggest that Web-based instruction is "as good" as CBI but, as will be discussed in the following section, this may be a premature judgment.

\section{Conclusion}

On the basis of a limited number of empirical studies, Web-based instruction appears to be an improvement over conventional classroom instruction. However, it is debatable whether Web-based instruction compares favorably to CBI. On the surface, the overall effect size is smaller, but not statistically significant. This, of course, cannot be interpreted to say that they are equivalent, but rather that there is no detectable difference. This is partly due to inconsistent and widespread variability in the findings. As the number of studies in the future that report comparative data increase, leading possibly to a more stable central tendency in the effect size, a more reliable assessment of how well Web-based instruction compares to CBI may be possible.

There are numerous reasons why the effectiveness of Web-based instruction may not yet be fully realized. For example, many of the early adopters were faculty from a diversity of fields who were not necessarily trained in instructional design. Their comparisons were, in some cases, a first attempt at Web-based instruction compared to a highly practiced classroom rendition of the course. Another restriction may have stemmed from Internet response delays, which are not uncommon during peak usage periods, in contrast to the immediate responses possible with a stand-alone computer. With packet-based networks, variable delays cause latency problems in the receipt of learning material, particularly with graphic images. Previous research has demonstrated a slight decrement 
in learning due to inherent delays of transmitting complex graphics over the Internet (Wisher and Curnow, 1999).

One objective of this article was to discuss the various roles that the Web plays in educational courses and the importance of taking them into account when evaluating courses. Here, we have limited our analysis to those applications involving direct instruction through the Web. As described earlier, the Web offers many other advantages that the Web offers (e.g., access, flexibility, enrollment, and management) that must be factored in when determining the overall value that the Web offers to a learning enterprise.

How large a learning effect, in terms of an effect size, can we expect from the Web? One possibility comes from research on intelligent tutoring systems. These are knowledgebased tutors that generate customized problems, hints, and aids for the individual learner as opposed to ad hoc, frame oriented instruction. When compared to classroom instruction, evaluations indicate an effect size of 1.0 and higher (Woolf and Regian, 2000). If these individual learning systems are further complemented by collaborative learning tools and online mentoring from regular instructors, effect sizes on the order of two standard deviation units, as suggested by Bloom (1984), may someday be possible. The use of the Web for instruction is at an early stage of development. Until now, there has been a lack of tools for instructional developers to use, but this shortcoming is beginning to change. The potential of Web-based instruction will increase as pedagogical practices improve, advances in standards for structured learning content progress, and improvements in bandwidth are made.

\section{Appendix}

Click here for Appendix A, Characteristics of Studies On Web-Based Instructional Effectiveness.

\section{References}

Angulo, A. J., and Bruce, M. (1999). Student perceptions of supplemental Web-based instruction. Innovative Higher Education, 24, 105 - 125.

Arvan, L., Ory, J. C., Bullock, C. D., Burnaska, K. K., and Hanson, M. (1998). The SCALE Efficiency Projects. Journal of Asynchronous Learning Networks, 2, 33 -60 .

Bee, R. H., and Usip, E. E. (1998). Differing attitudes of economics students about webbased instruction. College Student Journal, 32, 258 - 269.

Berge, Z. L., and Mrozowski, S. (2001). Review of research in distance education, 1990 to 1999. The American Journal of Distance Education, 15, 5 - 19.

Bloom, B. S. (1984). The 2-Sigma problem: The search for methods of group instruction as effective as one-on-one tutoring. Educational Researcher, 13, 4-16.

Bonk, C. J., and Dennen, V. P. (1999). Teaching on the Web: With a little help from my pedagogical friends. Journal of Computing in Higher Education, 11, 3 - 28. 
Bonk, C. J. (2001). Online teaching in an online world. Bloomington, IN: Courseshare.com. Retrieved July 30, 2002 from: http://www.courseshare.com/reports.php

Chickering, A.W., and Ehrmann, S.C. (1996). Implementing the seven principles: Technology as Lever. American Association for Higher Education Bulletin, 3 6.

Cohen, J. (1988). Statistical power analysis for the behavioral sciences (2nd Ed.). Hillsdale, NJ.: Lawrence Erlbaum Associates.

Cooper, L. W. (2001). A comparison of online and traditional computer applications classes. T.H.E. Journal 28, $52-58$.

Davies, R. S., and Mendenhall, R. (1998). Evaluation comparison of online and classroom instruction for HEPE 129 - Fitness and lifestyle management course. Report to Brigham Young University.

Dills, C., and Romiszowski, A. J. (1997). Instructional development paradigms. Englewood Cliffs, NJ.: Educational Technology Publications.

Eli-Tigi, M., and Branch, R. M. (1997). Designing for interaction, learner control, and feedback during Web-based learning. Educational Technology37, 23 - 29.

Fisher, S. G. (2000). Web-based Training: One size does not fit all. In K. Mantyla (Ed.), The 2000/2001 Distance learning yearbook. New York: McGraw-Hill

Fletcher, J. D. (2001). Technology, the Columbus effect, and the third revolution in learning. Institute for Defense Analyses. Paper D-2562.

Fletcher, J. D. (1990). Effectiveness and cost of interactive videodisc instruction in defense training and education. Institute for Defense Analyses Paper P-2372.

Fletcher, J. D., and Dodds, P. (2001). All about ADL. In K. Mantyla and J. A. Woods (Eds.) The 2001/2002 ASTD distance learning yearbook. (p. 229-235). New York: McGraw Hill.

Fredericksen, E., Pickett, A., Shea, P., Pelz, W., and Swan, K. (2000). Student satisfaction and perceived learning with on-line courses: Principles and examples from the SUNY Learning Network. Journal of Asynchronous Learning Networks, 4, 1 - 28. (Includes separate evaluations of two courses)

Gagne, M., and Shepherd, M. (2001). Distance learning in accounting: A comparison between a distance and traditional graduate accounting class. T.H.E. Journal, 28, $58-65$.

Galloway, G. M. (1998). A model of Internet usage for course delivery. Paper presented at the 9th Annual International Conference of the Society for Information Technology and Teacher Education (SITE): Washington DC.

Glass, G. V., McGaw, B, and Smith, M. L. (1981). Meta-analysis in social research. Beverly Hills, CA.: Sage Publications 
Green, R., and Gentemann, K. (2001). Technology in the Curriculum: An assessment of the impact of on-line courses. Retrieved July 30, 2002 from:

http://assessment.gmu.edu/reports/Eng302

Johnson, S. M. (2001). Teaching introductory international relations in an entirely webbased environment. Education at a Distance, 15, 5 - 14.

Johnson, S. D., Aragon, S. R., Shaik, N., and Palma-Rivas, N. (2000). Comparative analysis of online vs. face-to-face instruction. ERIC Document No. ED 448722.

Jones, E. R. (February, 1999). A comparison of an all Web-based class to a traditional class. Paper presented at the 10th Annual International Conference of the Society for Information Technology and Teacher Education, San Antonio, TX.

Kahn, B. H. (1997). A framework for Web-based learning. Paper presented at the Instructional Technology Department, Utah State University, Logan, Utah.

Kahn, B. H. (2001). Web-based training: An introduction. In B.H. Kahn (Ed.) Web-based Training. Englewood Cliffs, NJ.: Educational Technology Publications.

Kulik, C. L., and Kulik, J. A. (1991). Effectiveness of Computer-based Instruction: An updated analysis. Computers in Human Behavior, 7, 75 - 94.

Kulik, J. A. (1994). Meta-analytic studies of findings on computer-based instruction. In E. L. Baker, and H. F. O’Neil (Eds.) Technology assessment in education and training (p. 9-33). Hillsdale, NJ.: Lawrence Erlbaum Associates.

LaRose, R., Gregg, J., and Eastin, M. (July, 1998). Audiographic Telecourses for the Web: An experiment. Paper presented at the International Communication Association, Jerusalem, Israel.

Leasure, A. R., Davis, L., and Thievon, S. L. (2000). Comparison of student outcomes and preferences in a traditional vs. World Wide Web-based baccalaureate nursing research course. Journal of Nursing Education, 39, 149 - 154.

Liao, Y. K. C. (1999). Effects of hypermedia on students' achievement: A meta-analysis. Journal of Educational Multimedia and Hypermedia 8, 255 - 277.

Lou, Y., Abrami, P. C., and d'Apollonia, S. (2001). Small Group Learning and Individual Learning with Technology: A meta-analysis. Review of Educational Research, $71,449-521$.

Magalhaes, M. G. M., and Schiel, D. (1997). A method for evaluation of a course delivered via the World Wide Web in Brazil. In M. G. Moore and G. T. Cozine (Eds.) Web-Based Communications, the Internet, and Distance Education. University Park, PA: The Pennsylvania State University.

Maki, W. S., and Maki, R. H. (2002). Multimedia comprehension skill predicts differential outcomes of web-based and lecture courses. Journal of Experimental Psychology: Applied, 8, 85 - 98. 
Maki, R. H., Maki, W. S., Patterson, M., and Whittaker, P. D. (2000). Evaluation of a web-based introductory psychology course: I. Learning and satisfaction in online versus lecture courses. Behavior Research Methods, Instruments, and Computers 32, $230-239$.

McNulty, J. A., Halama, J., Dauzvardis, M. F., and Espiritu, B. (2000). Evaluation of Web-based computer-aided instruction in a basic science course. Academic Medicine 75(1), 59 - 65.

Murphy, T. H. (2000). An evaluation of a distance education course design for general soils. Journal of Agricultural Education, 41, 103 - 113.

Navarro, P., and Shoemaker, J. (2000). Performance and perceptions of distance learners in cyberspace. In M. G. Moore and G. T. Cozine (Eds.) Web-Based Communications, the Internet, and Distance Education. University Park, PA: The Pennsylvania State University.

Phelps, J., and Reynolds, R. (1999). Formative evaluation of a web-based course in meteorology. Computers and Education, 32, 181 - 193.

Phipps, R., and Merisotis, J. (1999). What's the difference? A review of contemporary research on the effectiveness of distance learning in higher education. Washington DC.: The Institute for Higher Education Policy.

Powers, S. M., Davis, M., and Torrence, E. (1998). Assessing the classroom environment of the virtual classroom. Paper presented at the Annual Meeting of the Mid Western Educational Research Association, Chicago, Illinois.

Ryan, M., Carlton, K. H., and Ali, N. S. (1999). Evaluation of traditional classroom teaching methods versus course delivery via the World Wide Web. Journal of Nursing Education, 38, 272 - 277.

Saba, F. (2000). Research in distance education: A status report. International Review of Research in Open and Distance Learning, 1(1). Retrieved July 30, 2002 from: http://www.irrodl.org/content/v1.1/farhad.html

Saettler, P. (1990). The evolution of American educational technology. Englewood, CO.: Libraries Unlimited.

Sandercock, G. R. H., and Shaw, G. (1999). Learners' performance and evaluation of attitudes towards web course tools in the delivery of an applied sports science module. Asynchronous Learning Networks Magazine, 3, 1-10.

Schlough, S., and Bhuripanyo, S. (1998). The development and evaluation of the Internet delivery of the course "Task Analysis." Paper presented at the 9th International Conference for Information Technology and Teacher Education (SITE), Washington D.C.

Schulman, A. H., and Sims, R. L. (1999). Learning in an online format versus an in-class format: An experimental study. T.H.E. Journal 26, $54-56$. 
Schutte, J. G. (1996). Virtual Teaching in Higher Education: The new intellectual superhighway or just another traffic jam? California State University, Northridge. Retrieved July 30, 2002 from: http://www.csun.edu/sociology/virexp.htm.

Serban, A. M. (2000). Evaluation of Fall 1999 Online Courses. Education at a Distance $14,45-49$.

Shapley, P. (2000). On-line education to develop complex reasoning skills in organic chemistry. Journal of Asynchronous Learning Networks 4(2),

Shaw, G. P., and Pieter, W. (2000). The use of asynchronous learning networks in nutrition education: Student attitude, experiences, and performance. Journal of Asynchronous Learning Networks 4, 40 - 51.

Shuell, T. J. (April, 2000). Teaching and learning in an online environment. Paper presented at the annual meeting of the American Educational Research Association, New Orleans, Louisiana.

Stadtlander, L. M. (1998). Virtual instruction: Teaching an online graduate seminar. Teaching of Psychology 25, 146 - 148.

Summary, R. and Summary, L. (1998). The effectiveness of the World Wide Web as an instructional tool. Paper presented at the 3rd Annual Mid-South Instructional Technology Conference, Murfreesboro, Tennessee.

Taylor, C. D., and Burnkrant, S. R. (1999). Virginia Tech Spring 1999: Online Courses. Assessment Report to the Institute for Distance and Distributed Learning. Virginia Tech University.

Terry, N. (2001). Assessing the enrollment and attrition rates for the online MBA. T.H.E. Journal 28, $64-68$.

Thomson, J. S., and Stringer, S. B. (1998). Evaluating for distance learning: Feedback from students and faculty. Paper presented at the 14th Annual Conference on Distance Teaching and Learning, Madison, WI.

Trier, K. K. (1999). Comparison of the effectiveness of Web-based instruction to campus instruction. Retrieved July 30, 2002 from: http://www.as1.ipfw.edu/99tohe/presentations/trier.htm.

Verbrugge, W. (1997). Distance education via the Internet: Methodology and results. Paper presented at the 30th Annual Summer Conference Proceedings of Small Computer Users in Education. North Myrtle Beach, South Carolina.

Wang, X. C., Kanfer, A., Hinn, D. M., and Arvan, L. (2001). Stretching the Boundaries: Using ALN to reach on-campus students during an off-campus summer session. Journal of Asynchronous Learning Networks 5, 1 - 20.

Waschull, S. B. (2001). The online delivery of psychology courses: Attrition, performance, and evaluation. Teaching of Psychology 28, 143 - 147. 
Wegner, S. B., Holloway, K. C., and Garton, E. M. (1999). The effects of Internet-based instruction on student learning. Journal of Asynchronous Learning Networks 3, $98-106$.

White, S. E. (April, 1999). The Effectiveness of Web-based Instruction: A case study. Paper presented at the Annual Meeting of the Central States Communication Association, St. Louis, MO.

Wisher, R., and Champagne, M. (2000). Distance learning and training: An evaluation perspective. In S. Tobias and J. Fletcher (Eds.) Training and Retraining: A handbook for business, industry, government, and military. New York: Macmillan Reference USA.

Wisher, R., and Curnow, C. (1999). Perceptions and effects of image transmissions during Internet-based training. The American Journal of Distance Education, 13, $37-51$.

Woolf, B. P., and Regian, J. W. (2000). Knowledge-based training systems and the engineering of instruction. In S. Tobias and J. Fletcher (Eds.), Training and Retraining: A handbook for business, industry, government, and the military (p. 339-356). New York: Macmillan Reference USA.

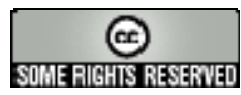


October - 2002

\title{
Redefining the Cost and Complexity of Library Services for Open and Distance Learning
}

\author{
Stephen Parnell \\ University of South Australia
}

\begin{abstract}
Although most universities profess a belief that libraries are a key element in learner support, the full cost and complexity of providing quality library services to support open and distance education tend to be underestimated. It is argued in this article that this underestimation, in part, may reflect a lack of appreciation by faculty and university administrators of the role libraries play in the (distance) learning process. Within libraries and the education sector at large, there is also tends to be a lack of recognition of what portion of the costs of access to libraries and information are borne by other elements within universities, by external organisations, and by individual students. Three fundamental questions addressed are: Why is it necessary to determine the role of libraries in supporting learning? Who meets these costs? How institutionally independent should access to library and information services be? While it is to be expected that the level of costs incurred by different institutions will vary as they meet the library service needs of those who study in different modes, there are pedagogical, ethical, and quality issues that must be considered if the same academic award is to be made.
\end{abstract}

Keywords: learner support; libraries; costing; cost analysis; quality; value judgment

\section{Redefining the Cost and Complexity of Library Services for Open and Distance Learning}

Attention given to identifying the full costs of library services as a component of quality learner support in open and distance education has been limited. While many of the elements covered here appear in the literature, no attempt has yet been identified to bring them together. Although there are studies examining overall higher education costs, particularly in the context of online education, information on costing libraries and their services relative to distance learning remains deficient. This is not entirely surprising given the complexity of the topic and the variation between institutions and how they view and resource library services. Although researchers have examined the costs of library services in a primarily on-campus environment (University of Newcastle, 2000) and direct costs of library service for distance learners (Cavanagh and Tucker, 1993), these and similar studies have not attempted to look beyond the direct costs often faced by an individual university's own library. Therefore, the purpose here is threefold: firstly, to consider libraries as an element in learner support; secondly, to consider less recognised costs associated with providing library and information services; and thirdly, to look at costs faced by individuals outside the physical precincts of universities when they attempt to access information and library services. Underlying themes referred to in 
this article are: the implicit reliance by open and distance education providers concerning the willingness and ability of students to access information through alternative avenues; and the willingness and appropriateness of other libraries supporting distance education students.

\section{The Value of Library Services}

Before looking at the costs faced by different providers and consumers of library services, it is worthwhile considering how these services support learning. This will indicate not just the range of activities that should be costed, but the extent to which libraries other than that of the parent university might meet the needs of distance learners. Services offered by reputable universities include:

- Twenty-four hour, seven days a week access to online library and information resources including library catalogues, citation and other indexes and full-text electronic journals

- Direct access by students to materials contained in general and research collections as well as to resources referred to in reading lists

- Assistance from professional librarians via email, telephone, fax and face-to-face

- Delivery of documents to students, both electronically and via courier or regular postal services

- Training and user education programs and resources via the Web, email, telephone, and face-to-face (including offshore)

- $\quad$ Filtered access to websites via subject and course based virtual libraries

- Facilitated access to the physical collections of other institutions

In short, university and college libraries play an integral role in a given university's total social and learning environment. A fundamental question that needs to be addressed then, is to what extent can these services be regarded as institution independent?

Unwin, Bolton and Stephens (1996) suggest that without ready access to this range of service, students face the risk that their learning experience will be unacceptably bound and controlled. Similarly, significant differences in accessibility of learning resources and experience across study modes should raise serious questions within universities about the appropriateness of offering the same academic award to those students without equivalent access to learning resources.

\section{Why Library Costs are Sometimes Overlooked}

Although library services are considered as an important element in learner support, and despite evidence that library users value the library more highly than many other university-supplied services (Tait 2000; Sell 1980, p. 312), few users assign dollar values to these services that are commensurate with the cost of the service (Kantor, 1995). Similarly, although surveys of guidelines on quality in online education report that students identify access to support services such as libraries as a central concern, some institutions make available to their distance education students only a fraction of the 
Parnell - Redefining the Cost and Complexity of Library Services for Open and Distance Learning

library resources and "other advantages" enjoyed by their on-campus student counterparts. It has been suggested that university administrators are often concerned about who will pay if the full costs of library and other services are made apparent (Bacsich and Ash, 1999). In such instances, it is difficult to avoid the conclusion that as long as the most important library resources are stated as being available online in some form, universities are likely to regard library services (an assumed standard requirement for creditable on-campus teaching), as having been met for the purposes of distance education as well (Garson, 1999).

A number of explanations account for why more realistic costs of quality library services for learners are sometimes overlooked. At the institutional level, where traditional services are also available from a physical library, there is a temptation to view library services to support open and distance education as simply "doing more of the same," with no significant cost implications attached. This simplistic view overlooks the need for additional infrastructure to ensure that distance learners off-campus have access to information and services comparable to that available to on-campus students. As libraries increasingly move from services that are traditional and reactionary, to services integrated creatively and thoughtfully into new technology-reliant curriculum initiatives, they will become more able to play an effective role in learner support (Adams, 1997). They do this by providing timely postal and electronic document delivery services, remote authentication and technology support, devising alternatives to traditional reserve collections, and by offering extended help desk hours that cover different time zones. These key contributions are not easily costed or even separated from other activities.

For many mixed mode institutions the percentage of distance education users is low as compared to the total student population. Furthermore, the evidence to date is that students who learn via distance education usually do not access the services of the home institution at the same rate as local students. At the University of South Australia, for example, less than thirty per cent of distance education students request assistance from the Library's Flexible Delivery Service. Figures from other Australian universities suggest rates of active use seldom approach fifty per cent. Of course this is a simplistic measure of use of library services that takes no account of the use students make of other information sources or libraries. Nor does it take into account anecdotal evidence from faculty that those students taking advantage of distance education library services generally achieve better results in assignments than those who do not. With the dropout rate for undergraduate distance education students generally higher than for those studying on-campus (Thompson, 1997) research is needed to establish whether better library support can help redress this imbalance.

The growth and influence of Internet based information is seen by some, as an alternative to the traditional library. When coupled with confusion stemming from the difference between offering resources and enhancing the learning experience, this adds to the factors that make it possible for institutions to both underestimate the costs of providing library services and accept less than optimal library services for their students studying offcampus. A less flattering explanation is that inadequate library services are an inevitable outcome of the belief that distance education is a way to reduce the costs of academic programs. This view tends to underestimate or ignore the significant infrastructure costs associated with quality library services. It also tends to discount the importance many students ascribe to access to library services and undervalues the role libraries and librarians can play in learning (Dillon, Gunawardena and Parker, 1992; Stephens and Unwin, 1997). It is a reflection that student concerns and behaviour are neither well understood nor regarded as strategic (Bacsich et al., 1999, p. 1). 
Libraries are not without blame either. There is sometimes a tendency to consider only core activities in costing support of distance education. Why is this so? A major factor is undoubtedly the difficulty associated with measuring the usage rates of library resources by students enrolled in open and distance education programs. This is not surprising when even services available on-campus prove difficult to measure. Costs per transaction figures in themselves have proven inadequate to establish annual costs per user, and such studies as exist show cost differences in providing university library services and facilities to external users ranging from two per cent to 125 per cent (Abels, Kantor and Saracevic, 1996; Infomax, 1994). Measuring the value of providing resources and services to meet student needs and the achievement of teaching objectives is even more problematic (Dervin, 1977).

\section{Partner or Parasite?}

The reason that universities are often able to offer their distance education library services "on the cheap," is that many off-campus students either make do with a limited range of resources, manage without a library altogether, or use someone else's library. Public libraries and the libraries of other higher education institutions bear the brunt of this use, an issue recognised in the concept of provider and victim libraries (Dugan, 1997). While many libraries are willing to take on the role of supporting students from other institutions, including those from interstate, inter-provincial, or overseas, costs are seldom apparent to the institution offering the academic program. The Infomax study (1994) concluded that it takes longer to answer reference enquiries from students from other institutions than for "home" users, but was unable to determine the reasons why this is so. It was suggested that this might be because students are less familiar with the host library than with their own, less likely to have participated in information literacy programs, and may ask more complex questions because they have already failed to fulfil their information requirements from information supplied to them as part of their course. This is not to suggest that host libraries are necessarily unwilling to take on a role in supporting distance learning; indeed the opposite is most often the case. Libraries have long recognised that they have much to gain in terms of resource sharing, networking, and collaborating on issues related to the provision of services to what are often mutual clients. Whichever is the case, one outcome at least remains the same: someone rather than the home institution must pay.

The mandate for public libraries to contribute to education is clear:

The public library should provide material in the appropriate media to support formal and informal learning processes. It should also help the user to make use of these learning resources effectively as well as providing facilities, which enable people to study.

(IFLA 2000 Section 1.3.1)

There is considerable representation in the literature examining the role of public libraries in assisting those engaged in open and distance learning. Slade and Kascus (1998) and Nankivell and Dalton (2000) are among those who have identified models of library services that indicate how different types of libraries can work together to meet the information needs of learners. The International Federation of Library Association (IFLA) Public Library Service Guidelines (2001) provides a range of examples of how public libraries in different countries provide resources of value to those studying offcampus. In one well-known project, partners from Sweden, the U.K., Ireland, Spain, and Austria are actively exploring the potential for using the Internet for distance learning in their public libraries. To date, the findings show that most people use the Internet in their 
public library for email and for finding information. They also reveal that those who use the Internet for educational purposes are often ordinary students who need to use computers when away from their own colleges (DERAL, 2000). With new technology coming into public libraries, librarians often see a need to take on additional roles beyond that of simple facilities provider, including the role of educator. Each of these new roles holds with it the potential to reduce demand by students on the libraries of their own institution. While formal agreements and cost sharing may be taken into account in costing programs, the costs of reciprocal services and those available through altruism are unlikely to be considered.

There is considerable potential for further convergence between the role of university and public libraries in distance education. Part of the push in this direction is coming from the public libraries themselves, but there is little doubt that universities also recognise the potential of public libraries. An example is the way in which universities often recommend public libraries to those students who do not enjoy ready access to the Internet. The interesting aspect of public library support arises when publicly funded libraries find that they are supporting the activities of institutions run for profit.

Of course it is not just public libraries that help meet the need of university students for library services. The Association of College and Research (ACRL) provides guidelines for library services to off-site students clearly stating that:

The home library is the primary source of materials; the off-campus librarian is the primary means of access and delivery [and] ... The parent institution is responsible for funding and appropriately meeting the information needs of its extended academic programs in support of their teaching and learning, and, when appropriate, research. This support should provide ready and equitable library service and learning resources to all students regardless of location (ACRL 1998).

Nevertheless, many of those studying through distance education are resident in cities that have a college or university library, and hence, see these as natural avenues to meet their information needs. Host libraries will often allow students of other institutions to use their collections in person and are often adopted by distance students as their information source of first resort (Stephens, 1998, p.139). Indeed, most will not even notice the presence of other students if they allow uncontrolled access to their buildings and have open access stacks. They are less likely to allow them to receive postal and electronic delivery services. As demand on collections grows and the volume of what is usually regarded as non-core work manifests itself, library service providers may be forced to reconsider the nature and extent of their generosity. If visitor use of key resources, such as computers and reserve collections, becomes noticeable, the library's major client groups may also exert pressure to restrict access to these same resources. As libraries increase their reliance on licensed electronic resources, the ability for anyone other than registered staff and students of the "home" university to gain access to subscription databases and electronic journals is likely to be reduced, thereby revealing some of the current hidden costs of library services. This should become especially apparent as disenfranchised students are forced to utilise the resources of their own institution.

Distance education students, compared to their on-campus counterparts, may be less well served in the area of information literacy. Those who believe that the same assistance and resources necessary for students studying on-campus should be provided to students studying off-campus argue that information literacy resources and services must be 
developed to meet the particular needs of those students studying off-campus. If arrangements are made by the host library to enable distance learners to participate in their user education activities, this often hides both the need for such services as well as a potential cost in program development or delivery for the home institution.

The issues facing academic libraries are covered in Parnell (1996). What is of interest here is that "host" libraries may provide assistance to students without an underlying awareness or appreciation of course objectives and requirements. While this reduces the cost of information provision by the distance education provider, it does raise interesting questions as to how far institutional teaching programs and assessment can be quarantined from the external information environment. There is scope for more research to determine as to whether the value of individual library information services is the same if offered by someone else.

This is, of course, a simplistic picture of what libraries can and actually do for students. There are many innovative partnerships between different institutions and libraries of all types that suggest something of the range and complexity of the costing issue. This does not, however, alter the underlying argument presented here, namely such partnerships are seldom considered or costed in distance education programs.

\section{Transferring Costs to Students}

There is a tacit (and sometimes explicit) acceptance by many institutions that students can and should meet some or all costs of the services they use. A number of leading distance providers expect students to contribute towards meeting the cost of postage and photocopying carried out on their behalf by their libraries, even though electronic services are often available without charge. Although fees charged may not necessarily be high, they continue to be identified by students as a barrier to use of library services, confirming the work of Bottomley and Calvert (1993, p. 34) that even those students who acknowledge the value of library services are often unwilling to pay. As more of a given university's teaching and learning goes online and the quality of information freely available via the Internet expands, the wisdom of charging for library services in an environment where institutions compete for students is increasingly questionable. The need to adequately cost such services remains.

McGivney (1993, pp. 17-18) identifies time and cost as the main situational barriers to participation in formal learning. When an institution moves to online education, one of the most common costs borne by students is the transfer that occurs when the student rather than the institution pays to print and post instructional materials. Rumble (1997, p. 117) identified the risk that third generation (electronic access) distance education systems will transfer costs to students, and speculates that they may also change the nature of the cost borne by students from time to money or vice versa. There are two dimensions to the largely over looked issue of the cost in time to students that needs to be devoted to information finding activities. This is the time that students could have been better spent evaluating, analysing, and synthesising information, whether provided to them or self discovered, and time that could have been devoted to some other activity entirely. The issue, however, is not clear-cut, with many educators arguing that the ability to identify and locate relevant information is itself part of the learning process. While libraries extol the virtues of the e-library as an alternative to visiting library buildings, some students accustomed to use of libraries in person already regard lack of browsing and personal assistance from library staff as a barrier to finding information in the online environment. Conversely, some students find that transference of the cost from one of time to direct financial expenditure imposes an unacceptable financial burden. 
Parnell - Redefining the Cost and Complexity of Library Services for Open and Distance Learning

Although many online courses now rely heavily upon readings available electronically from libraries, the survey instrument used as part of the UK networked learning study did not attempt to estimate use of the telephone specifically to access to University resources (Bacsich et al., 1999). Nor did it ask about time or money spent on use of library and other information services. While use of other libraries may be free, this is not always the case, particularly for those enrolled in trans-national undergraduate programs (Back, Cheng and Lam, 1993; Parnell and Stevens, 1999). Institutions similarly often fail to quantify costs that are generally absorbed into larger budgets and therefore cannot be easily attributed to a particular activity. Library staff members running training sessions offshore provide another example. While travel costs are easily identified, the cost of time taken up by travel is less likely to be fully accounted for.

\section{Back Beyond the Digital Library}

While it is not surprising that universities and their libraries currently appear to be focusing on the online environment, it is important not to overlook the value of the substantial print collections held by libraries in learner support. Nor should other library services that value-add to the learning process, such as reference and instructional services, be overlooked. Figures for the year 2000, for library services for the University of South Australia's distance education students, and those of its contracted service for Open Learning Australia, show requests for books continue to match those for articles. This is particularly the case for postgraduate students where much specialised research material is only available in print. This is an issue for those studying offshore as well. Surveys of the same university's students in Hong Kong, Singapore, Taipei and elsewhere confirm both the need for and the difficulties students experience in locating and gaining access to printed resources. Little consideration seems to have been given to comparing costs associated with providing access to information resources to individual students, compared to that of supplying information to them in print, although the importance of access to support material is recognised in work on a business model for the e-University (PricewaterhouseCoopers, 2001).

Despite this role for print, it remains true that for many distance education providers, technology is changing staff and student expectations of what the library should be and should offer. While some academic staff see this as an opportunity to expand and exploit the range of information available to distance education students, others appear to be retreating to reliance upon small discrete packages of selected readings supplemented by a recommendation to "find it on the Internet." It is also apparent that the World Wide Web is altering the current balance between libraries and teaching faculty as information providers, particularly as faculty involved in online education often incorporate direct links to "library" resources within individual courses. While many of these electronic resources are available only as part of an expensive library subscription, developments such as these obscure the value as well as the costs of a comprehensive library service.

Another reason is suggested for institutions failing to identify the full costs of library services. The argument is that if a given university must pay the costs required to provide library services for its off-campus students, it would be at the expense of the on-campus library program (Kascus and Aguilar 1997, p. 33). Even under this model it is debatable whether open and distance learners would receive services equivalent to that of oncampus students as far as immediacy of access and availability of materials is concerned. The disparity in opportunity to learn skills through one-on-one interactions with a librarian during the research process would still remain. It is intriguing to speculate on how many universities could meet the load if all eligible users actually tried to take advantage of existing learner support services. 


\section{Diverse Users and Average Costs: A recipe for confusion}

The costs of distance education are likely to be underestimated unless client groups and services are clearly defined. For dual mode institutions, among the most intractable of these questions of definition in is establishing which activities and students are to be included. They are likely to have students who live many kilometres from the "home" university, but are nonetheless enrolled as "internal students." Conversely, students who live within walking distance might be enrolled entirely in off-campus or fully online programs. Such institutions are a feature of the Australian education environment and are regarded as a successful (Davies and Stacey, 1998, p. 705). It is also increasingly the case that students enrol in diverse courses with multiple institutions. Separating out costs is all but impossible in this context.

Although those who study via distance education do not access the services of the home institution at the same rate as local students, there is evidence that distance learners who use library services require more time from library staff on a per capita basis than those who can visit the library in person. This is particularly the case for those undertaking higher degrees and for those for whom English is a second language. For this latter group of students, particularly overseas residents, western expectations of independent study can be as foreign as the language. To provide effective library services to such students is time consuming, costly, and complex. It is also clear that it is more expensive to service postgraduate students than undergraduates (Cavanagh and Tucker, 1993, p. 67). As institutions increase their off-campus offerings of higher degree programmes, the costs of meeting user needs will rise. This is because, in part, key traditional service strategies, such as library closed reserve collections, do not work well for research level courses.

For institutions with students residing in other countries, there are other factors to consider. Conducting training sessions offshore that parallel on-campus academic teaching programmes represents a considerable investment in time and money on the part of a library; it also provides a clear indication of its commitment to providing a comprehensive range of services to students regardless of mode of study or location. While expensive, training such as that provided by the University of South Australia to its students in Hong Kong, Singapore, and Bangkok has evoked favourable responses from both local agents and students, in part because it is viewed as another measure of equivalence with services available to Australian students (Parnell and Stevens, 1999). Costs include travel, accommodation, renting training facilities, and finding replacement staff for the normal on-campus staff conducting the training.

\section{Library Infrastructure: Overlooked and underestimated?}

Apportioning capital and running costs can be as much of a challenge as determining which avenues students use to find information. Even minor items such as library hours need to be considered. Another consideration of this is how much space of a given building should be attributed to those enrolled as off-campus students. If the opportunity is available, many off-campus students will visit the physical library and indeed this might even be a requirement during residential schools. Traditional costing systems allocate indirect costs to the different resources or user groups on the basis of volume measures such as the number of journals purchased or number of staff employed. The limitation with this approach is that many indirect costs such as research and 
development and marketing are independent of volume measures (Ellis-Newman, 1998, p. 376).

Significant costs may be incurred in determining, facilitating, or shoring up interdependencies between different parts of an institution. An example of such a need in the library context is provided when academic departments either overlook the value to their students of access to libraries, or too readily accept, at face value, assurances that a partner institution will provide library services equivalent to those enjoyed by students able to access their home institution's library. There is no evidence to suggest that universities offering courses offshore and franchising their programs to other organisations for local support undertake any systematic study of the willingness and capacity of other libraries to support their students as standard practice. For the many universities that are increasingly choosing partnership or twinning models to meet student demand for face-to-face contact, this is a significant oversight.

\section{Hidden Costs of Libraries in Distance Education}

Under the original UK Open University course model, the majority of students were assumed not to require a library service from their own university, an assumption based in part on the belief that the strong public library system in that country could meet their needs (Carty and Stark, 1996, p. 305). Although this view is no longer uniformly held, and despite the increasing acceptance and availability of information delivered electronically, the role of the public library network is still viewed as essential to the success of the e-University (SCONUL, 2001).

While it is essential that libraries identify the real costs of their services, they also need to be conscious of the limitations of costing methodologies that concentrate on what is being done rather than what can or should be done. There is also a need to be aware that such institution-centric studies do not take into account costs borne by outside organisations and individuals. There is a danger that in concentrating on the costs of current services in isolation, the relationship between cost and quality and range of service will be overlooked. The risk of determining the "cost of everything and the value of nothing" is real (Bacsich and Ash, 1999). In such an environment, efforts to reduce or contain costs in one sector may simply transfer costs to another part of the delivery or support chain.

Table 1. Commonly costed items

\begin{tabular}{|l|l|}
\hline Equipment and Resources & Staffing Costs \\
\hline Computer system running costs & Find and post book \\
Books in collection & Find, copy and post or scan article \\
Electronic journals and databases & Loan item \\
Printing guides and handouts & Information en quiry \\
Communication & Literature search \\
(fax, post, telecommunication) & Training and user education classes \\
& (on-campus, off-campus, and offshore) \\
& Photocopy service \\
& Re-shelve item \\
& Learning resource development \\
& Administration \\
\hline
\end{tabular}


Broader institutional costs including capital, depreciation, and running costs associated with library buildings are widely recognised, though less likely to be attributed in any estimation of the costs of library services. There are many other elements that could be included. The University of Newcastle study (2000) examining activity based costing provides detailed coverage of these. In distinguishing use of resources within buildings for those who study in mixed or dual modes, there are significant difficulties.

Many activities undertaken by library staff in support of student learning escape notice because they are outside the range of activities normally attributed to librarians. Rumble (1999) concluded that the biggest and least costed element of online learning is learner support. While he interpreted this primarily in terms of the role of tutors within the Open University, the case is also arguable for librarians. One aspect of this overlooked activity for librarians is their role in counselling. A major study in costing activities within Australian higher education institutions (Robertson,1998, p. 40) recognised the importance of counselling as a teaching and learning activity, but considers this only within the context of academic programs, rather than within other sectors of the institution such as the library. Certainly time spent on counselling activities within some university libraries is sufficiently great and differentiated from the normal reference interview to warrant recording separately. A possible explanation for the popularity of this un-marketed service is that library staff are sometimes more immediately accessible than their academic colleagues. While it can be argued that the financial cost of this service will be captured within the item of library staff salaries, this is a poor reflection of either the value of the library service or the costs of providing individual academic programs. The hidden costs of library support for open and distance learning are shown in Table 2.

Table 2. The hidden costs of a distance education library service

\begin{tabular}{|l|l|l|}
\hline Home library costs & Cost to external library & Cost to student \\
\hline $\begin{array}{l}\text { Collaboration with } \\
\text { academic staff - resource } \\
\text { selection and development }\end{array}$ & $\begin{array}{l}\text { Opportunity costs to own } \\
\text { primary clientele }\end{array}$ & Internet connection \\
\hline $\begin{array}{l}\text { Collaboration with } \\
\text { academic staff - response to } \\
\text { student enquiries }\end{array}$ & & Telephone connection \\
\hline $\begin{array}{l}\text { Counselling role for } \\
\text { students }\end{array}$ & $\begin{array}{l}\text { Competition from students of } \\
\text { other institutions }\end{array}$ & Printer Consumables \\
\hline $\begin{array}{l}\text { Collaboration with other } \\
\text { service units }\end{array}$ & & Registration/ service fee \\
\hline $\begin{array}{l}\text { Extended licences for } \\
\text { remote users }\end{array}$ & $\begin{array}{l}\text { Cost of multiple policies and } \\
\text { procedures }\end{array}$ & Computer purchase / hire \\
\hline Authentication work & & Postage \\
\hline $\begin{array}{l}\text { Establishment of separate } \\
\text { services }\end{array}$ & $\begin{array}{l}\text { Establishment of separate } \\
\text { services }\end{array}$ & $\begin{array}{l}\text { Confusion over availability } \\
\text { of services }\end{array}$ \\
\hline
\end{tabular}

The whole issue of costs associated with libraries in distance education is further complicated because many faculty and students tend to view the Internet as either an alternative to the library, or as the same thing. This view can only strengthen as universities seek the economic advantage and pedagogic integrity that appear possible from blurring the boundaries between on-campus, distance, dual-mixed mode and online education into one of flexible delivery. According to one survey, over 80 per cent of new students studying on-campus used the Internet to support their studies (UCLA, 2000, p.11) and students studying offshore through the University of South Australia in 1999 and 2000 identified the Internet as the most frequently used information source (University of South Australia Library, 2001). The changing balance between costs to 
students' use of the Internet, and the effects of student Internet usage on costs of a distance education library service, has yet to be fully explored.

While thus far emphasis has been on the financial costs of library services in distance education, in a climate of greater cost consciousness, we also need to remember to ask whether an increased urgency and capacity to measure "not just how often something is used, but by whom," will aid or divert teaching. At a time of emphasis upon cost effectiveness and cost cutting, there is an understandable temptation for libraries to direct their resources into more frequently used (full-text) services at the expense of less frequently used specialised services. Unless it is an outcome of careful consideration of the underlying educational objectives of the institution, this is to be resisted.

\section{Conclusion: Overlooked and under costed}

There appears, at times, to be a lack of appreciation within the higher education sector of the extent to which the costs of access to library services are borne by other organisational elements, external organisations, and by individual students. The contribution that library services play in students' university learning experience as a whole also tends to be under valued (Stephens and Unwin, 1997; Dority and Garnar, 1999). In an environment in which universities are increasingly looking to outsource services, including aspects of library services, it is important to know what different services cost in order to establish how these relate to total education costs for students as well as for the universities.

There is a strong case for arguing that boundaries must be established that outline the relationship between the complexity of the information environment and where costs actually lie. Although it is argued here that the hidden costs of library services effectively allow institutions to offer distance education programs "on the cheap," this viewpoint should not be taken in a pejorative sense. Nor should it be imagined that it is only the needs of distance education students that are often met outside the provisions of the institution in which they are enrolled. Nonetheless, many academic institutions that offer distance learning take advantage of existing infrastructure and assets without formulating a clear understanding of the role libraries can play in the learning process and in the development of information literate students.

The dearth of relevant studies in the literature suggests that the full costs of providing quality library services to support programs offered by universities through distance education are either overlooked or underestimated by libraries and their parent institutions. There are three inter-related reasons behind this oversight. The first is that in many instances, faculty and university administrators fail to fully understand the complex role library services play in the distance education process. The second reason is an outcome of reliance by learners upon other libraries. While this is well recognised by librarians, this is less likely to be the case by university administrators as a whole. The third and perhaps the most disturbing reason, is the lack of support for the view that if distance education students are to receive the same degree or award as their on-campus counterparts, the same services and resources considered to be an integral part of the education process for on-campus students, must also be made available. While there have been dramatic improvements in the capacity for educational institutions to deliver information and services electronically, services available to those studying through distance education are often not as comprehensive as for those students able to visit a large academic library in person. Research that is currently underway into the costs of 
higher education needs to be extended to include the full costs borne by institutions, their students, and other libraries, in meeting the information needs of distance learners. Given the many institutional variables that need to be considered this will not be an easy task.

\section{References}

Abels, E., Kantor, P., and Saracevic, T. (1996). Studying the cost and value of library and information services: Applying functional cost analysis to the library in transition. Journal of the American Society for Information Science 47(3), 217 27

ACRL (1998). Guidelines for distance learning library services. Association of College and Research Libraries. Retrieved 21 August 2001 from: http://www.ala.org/acrl/guides/distlrng.html

Adams, C. (1997). The Future of Library Services for Distance Education. JLSDE 1(1). Retrieved July 7, 2002 from: http://www.westga.edu/ library/jlsde/vol1/1/CAdams.html

Back, D., Cheng, C., and Lam, M. (1993). Offshore business degree: the economics of student support. In Economics of distance education: 7th Annual Conference of the Asian Association of Open Universities (November, 21 - 25) Open Learning Institute of Hong Kong.

Bacsich, P., and Ash, C. (1999). The hidden costs of networked learning - The impact of a costing framework on educational practice. Paper presented to the 1999 ASCILITE conference, Queensland University of Technology: Brisbane, Australia.

Bacsich, P. (1999). The costs of networked learning. Sheffield Hallam University, UK. Retrieved July 5, 2001 from: http://www.shu.ac.uk/virtual_campus/cnl/

Bottomley, J., and Calvert, J. (1993). Dimensions of Value: Estimating the benefits of higher and distance education programs. In Economics of distance education: 7th Annual Conference, Asian Association of Open Universities (November, 21 - 25) Open Learning Institute of Hong Kong.

Carty, J., and Stark, I. (1996). Towards a Strategy for Supporting Distance-Learning Students through Networked Access to Information: Issues and Challenges in Preparing To Support the Doctorate in Education. Education for Information, 14(4) $305-314$.

Cavanagh, A. K., and Tucker, J. (1993). Costing of Off-Campus Library Services. Proceedings of the sixth off-campus library services conference. Kansas City, KA. (October 6-8), 59 - 72.

Davies, G., and Stacey, E. (1998). Virtual universities: are dual mode universities the solution? In 28th Annual Frontiers in Education Conference. Tempe, AZ. (November 4-7), 705 - 710.

DERAL (2001). Distance Education in Rural Areas via Libraries website. Retrieved May 21, 2002 from: http://www.infc.ulst.ac.uk/ adrian/deral/home.html 
Dervin, B. (1977). Useful Theory for Librarianship: Communication not information. Drexel Library Quarterly 13, 16 - 32.

Dillon, C., Gunawardena, C., and Parker, R. (1992). An evaluation of learner support services in a distance education system, Distance Education 13(1), 29 - 45.

Dority, K., and Garnar, M. (1999). The electronic global library of Jones International University Advances in Library Administration and Organization 17, 93 - 107.

Dugan, R. E., and Hernon, P. (1997). Distance education: Provider and victim libraries. Journal of Academic Librarianship 23(4), 315 - 324.

Ellis-Newman, J., and Robinson, P. (1998). The cost of library services: Activity-based costing in an Australian academic library. Journal of Academic Librarianship 24(5), $373-92$.

Garson, G. D. (1999). The Role of Technology in Quality Education. Retrieved August 21, 2001 from: http://hcl.chass.ncsu.edu/sscore/garson2.htm

Infomax (1994). Unison external use cost survey: a report. Sydney: Macquarie University.

IFLA (2001). The Public Library Service: IFLA / UNESCO guidelines for development. Saur, Munchen. Retrieved August 21, 2001 from: http://www.ifla.org/VII/s8/proj/publ97.pdf

Jones, D. (2000). Emergent development and the virtual university. Retrieved August 21, 2001 from: http://cq-pan.cqu.edu.au/davidjones/Publications/Papers_and_Books/Learning_2000

Kantor, P. B. (1995). Studying the Cost and Value of Library Services: Final report. Technical Report APLAB/94-3/1,2,3,4. ERIC Document ED382206

Kascus, M., and Aguilar, W. (1988). Providing Library Support to Off-campus Programs. College and Research Libraries 49(1), 29 - 37.

McGivney, V. (1993). Participation and non-participation: A review of the literature. In R. Edwards, S. Sieminski and D. Zeldins (Eds.) Adult learners, education and training. London: Routledge.

Nankivell, C., and Dalton, P. (2000). Models for Working Together: Lifelong learners, library cross-use and collaborative solutions. In P. Brophy, S. Fisher, and Z. Clarke (Eds.) Libraries without Walls 3: the delivery of library services to distant users. London: Library Association, pp. 49-59.

Parnell, S. (1996). Literature searches and distance education: Whose problem? Occasional Papers in Open and Distance Learning 20. Open Learning Institute: Charles Sturt University.

Parnell, S., and Stevens, A. (1999). Report on library services for students and staff of the University of South Australia: Singapore and Hong Kong. University of South Australia 
PricewaterhouseCoopers (2000). Business model for the e-University. Retrieved August 21, 2001 from: http://www.hefce.ac.uk/Pubs/HEFCE/2000/00_44.htm

Robertson, S. (1998). Costing methodology for use within Australian higher education institutions. Canberra: Ernst \& Young. Retrieved August 21, 2001 from: http://www.detya.gov.au/archive/highered/otherpub/costme2.pdf

Rumble, G. (1997). The costs and economics of open and distance learning. London: Kogan Page.

Rumble, G. (1999). The Costs of Open Learning: What have we learnt?' In FLISH 99 1999 conference on flexible learning on the information superhighway. Sheffield Hallam University, May. Retrieved August 21, 2001 from: http://www.shu.ac.uk/flish/rumblep.htm

SCONUL - Standing Committee of National and University Libraries (2001). Information support issues for the e-University: a discussion paper: Appendix. Retrieved September 26, 2002 from: http://www.sconul.ac.uk/discppr.doc

Sell, B. (1980). An evaluative, holistic and user-oriented approach to assessing and monitoring effectiveness of the academic library in its setting. In N. K. Kaske (Ed.) Library Effectiveness: a state of the art. Washington: American Library Association, 296 - 336.

Slade, A., and Kascus, M. (1998). An international comparison of library services for distance learning. In P. S. Thomas and M. Jones (Comps.) The Eighth OffCampus Library Services Conference Proceedings. Providence, RI. (April 22-24) Mount Pleasant, MI: Central Michigan University Press. 280 - 281.

Stephens, K., and Unwin, L. (1997). The Heart of the Matter: Libraries, Distance Education and Independent Thinking. JSLDE, 1(1). Retrieved August 22, 2001 from: http://www.westga.edu/ library/jlsde/jlsde1.1.html

Stephens, K. (1998). Library experiences of postgraduate distance learning students, In P. Brophy, S. Fisher, and Z. Clarke (Eds.) Libraries Without Walls 2: the delivery of library services to distant users. London: Library Association. 122 - 142.

Tait, A (2000). Planning student support for open and distance learning. Open learning, 15(3) $287-299$.

Thompson, E. (1997). Distance education dropout: What can we do? In R. Pospisil and R. Willcoxson. Learning through teaching: Proceedings of the 6th Annual Teaching Learning Forum, Murdoch University. Retrieved August 30, 2001 from: http://cleo.murdoch.edu.au/asu/pubs/tlf/tlf97/thom324.html

UCLA Centre for Communication Policy (2000). The UCLA Internet report: Surveying the digital future. Retrieved August 22, 2001 from: http://ccp.ucla.edu/uclainternet.pdf

University of Newcastle (2000). Activity Based Costing: A Study to develop a costing methodology for Library and Information Technology Activities for the Australian Higher Education Sector. Canberra: Department of Education, 
Training and Youth Affairs. Retrieved September 30, 2002 from: http://www.dest.gov.au/highered/otherpub/libraries/libraries.pdf

Unwin, L., Bolton, N., and Stephens, K. (1997). The Role of the Library in Distance Learning, Final Report. London: British Library.

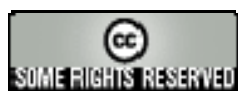




\title{
Student Dropout at the Hellenic Open University - Evaluation of the graduate program: Studies in Education
}

\author{
Dimitris Vergidis and Chris Panagiotakopoulos \\ Hellenic Open University \\ Greece
}

\begin{abstract}
This study traces the root causes of dropout rates in one post-graduate course "Studies in Education," offered by the Hellenic Open University (HOU). From our research findings, it was found that the main cause of dropping out stem from a combination of adult learners' obligations, specifically balancing their academic workload with their employment commitments and family obligations (mainly for female students). The second reason for dropout rates among adult distance education learners include students' miscalculation of the available time for studying and their underestimation of the extra effort required for effective learning. These reasons can be compared to the educational material, which, in general, was not considered overly difficult and did not appear to compel students to abandon their studies.
\end{abstract}

Keywords: dropout; distance education; adult education

\section{Introduction}

The establishment of open universities around the world aims to address the educational and re-educational needs of workforce labor needs by providing quality, high level studies (Evans and Lockwood, 1994; Evans and Nation, 1996). Open Universities develop educational activities based on an educational philosophy that is different from the conventional educational systems. The main aspect of this open learning philosophy is to promote life long education and to provide adults with "a second educational chance” (Keegan, 1993).

The method used known as distance learning studies addresses the educational needs of citizens and increases the educational benefits within the geographical dominion of a country or even outside its borders, thereby by-passing geographic, social, economic and time obstacles. With this method educational policies that promote educational equality are supported. Open universities can provide university level education to citizens who, owing to prohibitive reasons - such as not being able to physically be present at a specific place - would otherwise prevent them from studying (Garrison, 1993; Davies, 1997). In other words, access to open learning offers sensitive population groups (e.g., unemployed, handicapped, mothers, emigrants, immigrants, etc.) the opportunity to further themselves through attaining a quality education. 
Vergidis \& Panagiotakopoulos - Student Dropout at the Hellenic Open University

Taking the above into consideration, this article focuses on the establishment of the Hellenic Open University (HOU), the origins of which can be traced back to 1992. In 1995, an administrative committee was established to help determine and manage the orientation of this nascent institution. In 1997, its founding law was passed. Looking at the records of the administrative committee of for 1995-1997, a period of time in which the overall characteristics of the institution were defined and formed, it was evident that the British model significantly influenced the subsequent formation and operation of the Hellenic Open University. Furthermore, after an interdisciplinary agreement was ratified allowing the Hellenic Open University to use such learning materials, many materials developed for distance learning in English universities (i.e., Manchester and the Open University), were translated into Greek.

During the period 1997-1999, a sizable portion of the Hellenic Open University's educational material was developed and the first members of its staff were trained in this new educational methodology. From 1999 to 2000, the Hellenic Open University began to function fully, with 4,537 students enrolled in undergraduate and graduate courses. Today, student demand for distance learning studies surpasses the Hellenic Open University's current course offerings. For 4,537 places, the Hellenic Open University received 23,941 applications (13,500 for undergraduate studies and 10,441 for post graduate studies). To admit students, a draw is usually held. Also it must be underlined that although tertiary studies in Greece are offered to students free of cost, at the Hellenic Open University charges students tuition to cover its operating costs.

\section{Studies in the Hellenic Open University}

The Hellenic Open University adopted the modular system, with modules of one academic year as its basic functioning unit. Educational material used primarily consists of printed material, supplemented with audio-visual material. Each tutor-advisor oversees the learning progress of about 30 students. To earn an undergraduate degree, students must successfully complete 12 modules in not less than four academic years. Note, that the term module for the Hellenic Open University means an entire course lasting one academic year. To earn a postgraduate degree, students must successfully complete four modules (not earlier than two academic years). At the post graduate level, simple modules of one academic year are provided to interested students. To complete a module, students must complete four essays totaling 30 percent of the final grade and sit for a final exam, accounting for 70 percent of the final grade. Students have the option of attending four group-counseling meetings that take place at home or at a convenient location nearby.

\section{Research Questions}

We conducted a survey to examine the root causes of student dropout occurring within the modules intended for teachers or teachers-to-be: Open and Distance Learning Education (SED01), Adult Education (SED02), The Child's Development in the Social Environment (SED03), Administration of Educational Units (SED04) and Educational Research in Action (SED05). Together, these modules constitute the postgraduate course called "Studies in Education."

Student dropout occurs at all levels of education. A rich literature concerning primary and secondary education dropout and educational underachievement reveals an area of great interest for researchers spanning many years. Research focusing specifically on the reasons of student dropout at universities can be found in Tinto, (1975) Bajtelsmit, (1988), and Giles (1999). The reasons behind the causes of this phenomenon at the Hellenic Open University is of particular importance, especially taking into consideration 
that distance learning is aimed to reduce educational inequality. Because these students have all enrolled in the module of their choice and paid part of their fee, it is assumed from the outset that these adult learners have selected and programmed their course of studies in accordance with their personal interests, capabilities, personal responsibilities and obligations. The study of the causes of student dropout at the Hellenic Open University can substantially contribute to the evaluation of the institution as a whole, especially for the University's postgraduate program: "Studies in Education."

In this study we examined the extent to which certain characteristics of postgraduate learners were related to gender. We studied the demographic and occupational characteristics of those students who chose to discontinue their studies and the reasons they gave for their decisions. It is clarified at this point, that we examined the root causes of study interruption during the module and before the final examinations.

To complete the picture of overall student participation in this particular postgraduate program, we examined the number of students who completed the four compulsory essays and the number of group-counseling sessions they attended. In particular, the research questions that we sought to answer included the following:

- To what extent is dropout due to factors concerning students themselves, and to what extent is it due to the difficulty of study and educational material

- What was the degree of student participation of those who chose to abandon the educational process of the Hellenic Open University

- To what degree did the educational material influence students' decisions to discontinue their studies

\section{Method and Techniques}

As tutors and course developers of the educational materials for the graduate course "Studies in Education," we were concerned about of the causes of our students dropping out. In the 1999-2000 academic year, of f 1,220 graduate students enrolled in the program "Studies in Education," 173 students dropped out (see Table 1). Of the 173 students who abandoned their studies, 108 (62.4 percent) participated in a structured interview. The remaining students could either not be located or refused to participate in the research survey. Our observations had led us to believe that the main reasons students cited as leading them to abandon their studies were:

- Unexpected situations that did not allow for the continuation of their study

- Difficulties related to study and/or lack of sufficient studying time 
Table 1. Dropout rates of students enrolled in the graduate gourse "Studies in Education" ( $m=$ male, $f=$ female)

\begin{tabular}{|c|c|c|c|c|c|c|c|}
\hline & & \multicolumn{2}{|c|}{ Enrolled } & \multicolumn{2}{|c|}{ Dropouts } & \multicolumn{2}{|c|}{ Samuple } \\
\hline & & $\mathrm{II}$ & $\%$ & $\mathrm{II}$ & $\%$ & II & $\%$ \\
\hline \multirow{3}{*}{ SED01 } & M & 370 & 48,8 & 49 & 13,2 & 30 & 51,2 \\
\hline & $F$ & $3 \& 8$ & 51,2 & 52 & 13,4 & 32 & 61,5 \\
\hline & Total & 758 & 100 & 101 & 13,3 & 62 & 61,4 \\
\hline \multirow{3}{*}{ SED02 } & $\mathrm{M}$ & 35 & 33,3 & 16 & 45,7 & 8 & 50 \\
\hline & $F$ & 70 & 66,7 & 8 & 11,4 & 5 & 62,5 \\
\hline & Total & 105 & 100 & 24 & 22,9 & 13 & 54,2 \\
\hline \multirow{3}{*}{ SED03 } & $\mathrm{M}$ & 82 & 41,8 & 11 & 13,4 & 7 & 63,6 \\
\hline & F & 111 & 58,2 & 22 & 19,3 & 14 & 63,5 \\
\hline & Total & 196 & 100 & 33 & 169 & 21 & 63,6 \\
\hline \multirow{3}{*}{ SEDU4 } & $\mathbf{M}$ & 71 & 62,8 & 3 & 4,2 & 2 & 66,7 \\
\hline & F & 42 & 37,2 & 5 & 11,9 & 5 & 100 \\
\hline & Total & 113 & 100 & 8 & 7,1 & 7 & 87,5 \\
\hline \multirow{3}{*}{ SED05 } & M & 19 & 39.6 & 7 & 36,8 & 5 & 71,4 \\
\hline & F & 29 & 60,4 & 0 & 0 & 0 & 0 \\
\hline & Total & 48 & 100 & 7 & 14,6 & 5 & 71,4 \\
\hline \multirow{3}{*}{ TOTAL } & $\mathrm{M}$ & 577 & 47,3 & 86 & 49,7 & 52 & 48,1 \\
\hline & $F$ & 643 & 52,7 & 87 & 50,3 & 56 & 51,9 \\
\hline & Tolal & $122 \pi$ & 100 & 173 & 100 & 108 & 100 \\
\hline
\end{tabular}

As we can see in Table 1, the sample included male and female students who dropped all five modules, with females to comprising the 52.7 percent of the total sample and the 50.3 percent of the total dropout rate for all students. Fifty percent of those students who dropped out from all the modules agreed to participate in a structured interview in the first semester of 2001. Student dropout rates were tabulated using the following criteria:

1. The number of essays completed before students made their decision to discontinue their studies

]

2. The number of group counseling sessions attended before students made their decision to discontinue their studies

In this manner, we were able to segment out and cross check the reasons why students chose to drop out, the levels of difficulty of educational materials used, and students' actual course participation rate (as expected by the Hellenic Open University).

\section{Characteristics of Students that Dropped Out}

According to the existing legal framework in Greece, students aged 23-45 have priority for enrollment. As we can see in Table 2, students who encountered the highest dropout rates belong to the 35-39 age group (30 percent), followed by the 30-34 age group (27 percent). Fifty-seven percent of those students who chose to dropout were between the age of 30 and 39 years old. 
Table 2. Student dropout rates by Age Group and by Study Module

\begin{tabular}{|c|c|c|c|c|c|c|c|c|c|c|c|c|}
\hline & \multicolumn{2}{|c|}{ SEDO1 } & \multicolumn{2}{|c|}{ SEDO2 } & \multicolumn{2}{|c|}{ SEDDI3 } & \multicolumn{2}{|c|}{ SEDOA } & \multicolumn{2}{|c|}{ SED05 } & \multicolumn{2}{|c|}{ Tudul } \\
\hline & $\mathrm{n}$ & $\%$ & $\mathbf{n}$ & $\%$ & $\mathrm{n}$ & $\%$ & $\mathrm{n}$ & $\%$ & $\mathbf{n}$ & $\%$ & $\mathrm{n}$ & $\%$ \\
\hline $20-24$ & 1 & 2 & 0 & 0 & 0 & 0 & 0 & 0 & 0 & 0 & 1 & 1 \\
\hline $25-29$ & 12 & 19 & 4 & 31 & 4 & 19 & 0 & 0 & 0 & 0 & 20 & 19 \\
\hline $30-34$ & 13 & 21 & 2 & 15 & 9 & 13 & 2 & 29 & 3 & 60 & 29 & 27 \\
\hline $35-39$ & 17 & 27 & 4 & 31 & 6 & 28 & 4 & 57 & 2 & 40 & 33 & 30 \\
\hline $10-\mathrm{At}$ & 15 & 24 & 3 & 23 & 2 & 10 & 1 & 14 & (1] & 0 & 21 & 19 \\
\hline $45-49$ & 3 & 5 & 0 & 0 & 0 & 0 & 0 & 0 & 0 & 0 & 3 & 3 \\
\hline $50-54$ & 1 & 2 & 0 & 0 & 0 & 0 & 0 & 0 & 0 & 0 & 1 & 1 \\
\hline Talad & 62 & 100 & 13 & 100 & 21 & 100 & 7 & 100 & 3 & 100 & 108 & 100 \\
\hline
\end{tabular}

As Table 3 makes evident, all students who dropped out (with the exception of one) were employed. Only one student enrolled in module SED01 (Open and Distance Learning Education) was unemployed.

Table 3. Employment status of students who dropped out ( $m=$ male, $f=$ female)

\begin{tabular}{|c|c|c|c|c|}
\hline & & Employed & Dnemployed & Total \\
\hline \multirow{3}{*}{ SED01 } & $\mathrm{M}$ & 30 & 0 & - \\
\hline & $\mathrm{F}$ & 31 & 1 & - \\
\hline & Total & 61 & 1 & 62 \\
\hline \multirow{3}{*}{ SFDO2 } & $\mathrm{M}$ & 8 & 0 & - \\
\hline & $\mathrm{F}$ & 5 & 0 & - \\
\hline & Total & 13 & 0 & 13 \\
\hline \multirow{3}{*}{ SED03 } & $\mathrm{M}$ & 7 & 0 & - \\
\hline & $\mathrm{F}$ & 14 & 0 & - \\
\hline & Tulal & 21 & 0 & 21 \\
\hline \multirow{3}{*}{ SED04 } & $\mathrm{M}$ & 2 & 0 & - \\
\hline & $F$ & 5 & 0 & - \\
\hline & Total & 7 & 0 & 7 \\
\hline \multirow{3}{*}{ SED05 } & $\mathrm{M}$ & 5 & $\overline{0}$ & - \\
\hline & $\mathrm{F}$ & 0 & 0 & - \\
\hline & Total & 5 & 0 & 5 \\
\hline \multirow{3}{*}{ Tuisl } & $\mathrm{M}$ & 52 & 0 & - \\
\hline & $\mathrm{F}$ & 55 & 1 & - \\
\hline & Tolal & $107(99 \%)$ & $1(10 ;)$ & $108(100 \%)$ \\
\hline
\end{tabular}

The majority of students who dropped out belonged to the 30-39 age groups, and were employed as school-teachers (see Table 4). 
Vergidis \& Panagiotakopoulos - Student Dropout at the Hellenic Open University

Table 4. Teacher and non-teacher dropout rates ( $m=$ male, $f=$ female)

\begin{tabular}{|c|c|c|c|c|}
\hline & & Teachers & Yon Teachers & Total \\
\hline \multirow{3}{*}{ SED01 } & $\mathbf{M}$ & 2.5 & 5 & 30 \\
\hline & $\mathbf{F}$ & 24 & 8 & 32 \\
\hline & Total & $49 \quad(79 \%)$ & $13 \quad(21 \%)$ & $(100 \%)$ \\
\hline \multirow{3}{*}{ SEDU2 } & $\mathbf{M}$ & 5 & 3 & 8 \\
\hline & $\mathbf{F}$ & 2 & 3 & 5 \\
\hline & Total & $7 \quad(53 \%)$ & $6(47 \%)$ & $13 \quad(100 \%)$ \\
\hline \multirow{3}{*}{ SFDOH } & $\mathbf{M}$ & 6 & 1 & 7 \\
\hline & $\mathbf{F}$ & 11 & 3 & 14 \\
\hline & Totul & $17 \quad(80,90 \%)$ & $4 \quad(19,1 \%)$ & $21(100 \%)$ \\
\hline \multirow{3}{*}{ SED04 } & $\mathrm{M}$ & 2 & 0 & 2 \\
\hline & $F$ & 5 & 0 & 5 \\
\hline & Total & $7(100 \%)$ & $0(0 \%)$ & $7(100 \%)$ \\
\hline \multirow{3}{*}{ SED05 } & $\mathbf{M}$ & 3 & 2 & 5 \\
\hline & $\mathbf{F}$ & 0 & 0 & 0 \\
\hline & Total & $3 \quad(60 \%)$ & $2(40 \%)$ & $5 \quad(100 \%)$ \\
\hline \multirow{3}{*}{ Tot.al } & $\mathrm{M}$ & 11 & 11 & 52 \\
\hline & $\mathbf{F}$ & 42 & 14 & 56 \\
\hline & Total & $83(77 \%)$ & $25(23 \%)$ & $108 \quad(100 \%)$ \\
\hline
\end{tabular}

As expected, many graduate students enrolled in 'Studies in Education' were employed as teachers, the occupational group that manifested a higher dropout rate in all modules than non-teachers. However, our research shows that in modules SED02 (Adult Education) and SED05 (Educational Research in Action), many students who opted to dropout were not teachers.

In the SED02 module (Adult Education), which experienced high rates of student dropout (22.8 percent as compared to a mean of 14.2 percent), roughly half were not teachers. In contrast, in the SED04 module (Administration of Educational Units), in which every graduate student enrolled was employed as a teacher (see Table 4), but held the smallest percentage of student dropout (7.1 percent compared to the mean of 14.2 percent).

In terms of student characteristics, we can conclude that the majority of students who dropped from studies were between the ages 30 to 39, and almost all were employed. In terms of work history, a lower percentage of teachers dropped out of their studies than other working students. As compared to other working students, it is possible that teachers are either more familiar with studying and essay writing, or that they often have larger blocks of free time, or are more familiar with the concepts being taught.

\section{Causes and Reasons for Student Dropout Rates}

Individuals wishing to register at the Hellenic Open University are not required to take entry exams, but instead simply complete an application form. If demand for a course is high, a draw takes place to determine who will gain entry. However, unlike conventional Greek universities, Hellenic Open University courses are cost recoverable, thus every student enrolled must pay tuition fees, a portion of which is paid in advance to secure a spot in the program of their choice. Therefore, we can safely say that the students have self-selected and programmed their studies before submitting their application and have, indeed, chosen the subject of their preference. 
The most frequently reported cause students for dropping out of studies stemmed from various unexpected and emergency situations. The second most frequently reported cause for dropping out, as already mentioned, was the students' overall underestimation of the time and effort necessary for effective studies and learning.

As we can see in Table 5, with respect to the reported reasons for student dropout, roughly half of the students (47 percent) pointed to their occupational obligations and/or workload. Dropout rates related to work commitments were reported mainly in the subjects SED02 (Adult Education) and SED01 (Open and Distance Learning Education). In terms of gender, 54 percent of male students cited workload and occupational obligations as their primary reason for dropping out, as did 46 percent of the female students.

Table 5. Reasons cited by students for dropping out

\begin{tabular}{|c|c|c|c|c|c|c|c|}
\hline & $\begin{array}{c}\text { SED0I } \\
\text { n } \\
\% \\
\end{array}$ & $\begin{array}{c}\text { SED02 } \\
n \\
\% \\
\end{array}$ & $\begin{array}{c}\text { SED03 } \\
n \\
\% \\
\end{array}$ & $\begin{array}{c}\text { SED04 } \\
n \\
\% \\
\end{array}$ & $\begin{array}{c}\text { SED } \% 5 \\
n \\
\% \\
\end{array}$ & $\begin{array}{c}\text { TOTAL } \\
n \\
\% \\
\end{array}$ & $\begin{array}{c}\text { Women } \\
\%\end{array}$ \\
\hline $\begin{array}{l}\text { Workioad, } \\
\text { increase in } \\
\text { occupational } \\
\text { responsibilities }\end{array}$ & $\begin{array}{l}30 \\
48\end{array}$ & $\begin{array}{l}9 \\
69\end{array}$ & $\begin{array}{l}8 \\
38\end{array}$ & $\begin{array}{l}2 \\
29\end{array}$ & $\begin{array}{c}1 \\
20\end{array}$ & $\begin{array}{l}50 \\
47 \%\end{array}$ & 46,0 \\
\hline $\begin{array}{l}\text { Family } \\
\text { reasons: } \\
\text { marriage, } \\
\text { pregnancy, } \\
\text { traveling } \\
\text { socio-economic } \\
\text { problems, etc. }\end{array}$ & $\begin{array}{l}19 \\
30\end{array}$ & $\begin{array}{l}1 \\
8\end{array}$ & $\begin{array}{c}7 \\
33\end{array}$ & $\begin{array}{c}2 \\
29\end{array}$ & $\begin{array}{l}0 \\
0\end{array}$ & $\begin{array}{c}29 \\
27 \%\end{array}$ & 72,5 \\
\hline $\begin{array}{l}\text { Health } \\
\text { problems, } \\
\text { surgery, etc. }\end{array}$ & $\begin{array}{c}6 \\
10 \\
\end{array}$ & $\begin{array}{l}2 \\
15\end{array}$ & $\begin{array}{l}2 \\
10\end{array}$ & $\begin{array}{c}2 \\
29\end{array}$ & $\begin{array}{l}0 \\
0\end{array}$ & $\begin{array}{l}12 \\
11\end{array}$ & 67,0 \\
\hline $\begin{array}{l}\text { Wrong choice } \\
\text { of program - } \\
\text { no interest } \\
\text { concerning the } \\
\text { professional } \\
\text { progress }\end{array}$ & $\begin{array}{c}6 \\
10\end{array}$ & $\begin{array}{l}0 \\
0\end{array}$ & $\begin{array}{l}0 \\
0\end{array}$ & $\begin{array}{c}1 \\
13\end{array}$ & $\begin{array}{c}1 \\
20\end{array}$ & $\begin{array}{l}8 \\
7\end{array}$ & 37,5 \\
\hline $\begin{array}{l}\text { Improper } \\
\text { material - } \\
\text { Improper } \\
\text { teaching } \\
\text { method }\end{array}$ & $\begin{array}{l}0 \\
0\end{array}$ & $\begin{array}{l}1 \\
8\end{array}$ & $\begin{array}{l}3 \\
14\end{array}$ & $\begin{array}{l}0 \\
0\end{array}$ & $\begin{array}{l}3 \\
60\end{array}$ & $\begin{array}{l}7 \\
6\end{array}$ & 17,0 \\
\hline $\begin{array}{l}\text { Unable to } \\
\text { understand the } \\
\text { material }\end{array}$ & $\begin{array}{l}1 \\
2\end{array}$ & 0 & 1 & 0 & 0 & 2 & 0,0 \\
\hline Total & $\begin{array}{c}62 \\
100 \%\end{array}$ & $\begin{array}{c}13 \\
100 \%\end{array}$ & $\begin{array}{c}21 \\
100 \%\end{array}$ & $\begin{array}{c}7 \\
100 \%\end{array}$ & $\begin{array}{c}5 \\
100 \%\end{array}$ & $\begin{array}{c}108 \\
100 \%\end{array}$ & \\
\hline
\end{tabular}

It is clear from our research that, as expected, the students' workload and occupational demands tend to relate to students' choosing to dropping out of their studies, and therefore do not constitute urgent attention. It is also clear that students tend to hold unrealistic views of the time necessary for effective studying and learning. Students studying at the Hellenic Open University were required to work hard work and allocate plenty of time for studying, demands that many students failed to recognize prior to enrolling. 
Vergidis \& Panagiotakopoulos - Student Dropout at the Hellenic Open University

Unexpected factors cited by students who dropped out were grouped in two categories. The first category included various "family" reasons such as marriage, divorce, and other unexpected socio-economic problems. The second group of reasons encompassed "other" unexpected factors that tend to occur in the lives of adults, which have immediate consequences in their every day routine, and thus upset their educational plans. Such reasons included death, loss of wages, or loss of employment.

Of the 27 percent of the sample who cited "family reasons" for dropping out, 27.5 percent were male and 72.5 percent female. Our finding show that students who incorrectly estimated either the amount of time that must be made available for effective studying and leaning, and/or the extent of their family obligations, also tended not to anticipate the various abrupt changes that often occur in the lives of working adults, changes that adversely affect their ability to complete their studies.

Of students enrolled in SED01 (Open and Distance Learning Education) and SED03 (The Child's Development in the Social Environment), female students were three times more likely to drop out due to "family" reasons than male students.

Because we consider "health problems" to be independent of reasons related to "family" obligations, as well as "other" factors, we included a third category called "unexpected" events that lead students to abandon their studies. Eleven percent of the students cited poor health for abandoning their studies. In this instance, we have "unexpected events" independent from the students' programming and their studies at the Hellenic Open University.

Of the three root causes directly connected to their studies, seven percent of students who engaged in our research mentioned erroneous course choices which proved to be of no personal or professional interest and thus led to their decision to discontinue their studies.

While six percent cited the distance method of study as their reason for dropping out, two percent of students reported that the educational material in SED03, The Child's Development in the Social Environment, and SED05, Educational Research in Action was difficult to understand.

Table 6 indicates the stages of the courses in which students tended to give up. Some 52 percent of the students sampled failed to write any write any essays and 28 percent only completed one. In sum, occupational duties and family reasons prevented 80 percent of the students sampled from continuing their studies; they dropped out at the beginning of their course(s)before completing any essays or only one essay. This finding is in accordance with results from previous research by Holmberg (1995). Nonetheless, 16 percent of the sample chose to abandon their studies after completing two essays, while some discontinued just before the final exams, even though they had completed three or four essays. 
Vergidis \& Panagiotakopoulos - Student Dropout at the Hellenic Open University

Table 6. Number of written essays completed prior to dropping out

\begin{tabular}{|c|c|c|c|c|c|c|c|c|c|c|c|}
\hline \multirow[t]{2}{*}{$\begin{array}{l}\text { Vumber of } \\
\text { elaborated } \\
\text { written essays }\end{array}$} & SED01 & \multicolumn{2}{|c|}{ SED02 } & \multicolumn{2}{|c|}{ SED03 } & \multicolumn{2}{|c|}{ SED04 } & \multicolumn{2}{|c|}{ SLD05 } & \multicolumn{2}{|c|}{ Total } \\
\hline & n $\%$ & $\mathrm{n}$ & $\%$ & $\mathrm{n}$ & $\%$ & $\mathrm{n}$ & $\%$ & $\mathrm{n}$ & $\%$ & $\mathrm{~N}$ & $\%$ \\
\hline 0 & $30 \quad 48$ & 7 & 54 & 12 & 57 & 5 & 71 & 2 & 40 & 56 & 52 \\
\hline 1 & $19 \quad 31$ & 4 & 31 & 4 & 19 & 2 & 29 & 1 & 20 & 30 & 28 \\
\hline 2 & $13 \quad 21$ & 2 & 15 & 2 & 10 & 0 & 0 & 1 & 20 & 18 & 16 \\
\hline 3 & 0 & 0 & 0 & 2 & 10 & 0 & 0 & 1 & 20 & 3 & 3 \\
\hline 4 & $\begin{array}{ll}0 & 0\end{array}$ & 0 & 0 & 1 & 4 & 0 & 0 & 0 & 0 & 1 & 1 \\
\hline Total & 62100 & 13 & 100 & 21 & 100 & $\overline{7}$ & 100 & 5 & 100 & 108 & 100 \\
\hline
\end{tabular}

It is interesting to note that although their participation in the optional group counseling sessions for this group was higher than that of other students, 80 percent of the students sampled abandoned their studies without submitting any of the four required essays. Twenty-five percent of the students in the sample did not participate in any group counseling sessions, and 28 percent attended only one group counseling session and 53 percent of the sample attended one or no group counseling sessions, as compared to 80 percent who completed one or no essay. Thirty-one percent of the students in our sample attended two group counseling sessions, and 10 percent attended all four optional meetings, although they still ultimately decided to dropout.

Table 7. Number of Group Counseling Sessions (GCS) attended by students who dropped out by subject

\begin{tabular}{|c|c|c|c|c|c|c|c|c|c|c|c|c|}
\hline $\begin{array}{l}\text { Number of } \\
\text { GCS } \\
\text { participated }\end{array}$ & \multicolumn{2}{|c|}{ SED01 } & \multicolumn{2}{|c|}{ SED02 } & \multicolumn{2}{|c|}{ SED03 } & \multicolumn{2}{|c|}{ SED04 } & \multicolumn{2}{|c|}{ SEDOS } & \multicolumn{2}{|c|}{ Total } \\
\hline & $\mathrm{nt}$ & $\%$ & & $\%$ & & 95 & & $\%$ & & $\%$ & $\mathrm{n}$ & $\%$ \\
\hline 0 & 19 & 31 & 1 & 8 & 4 & 19 & 1 & 14 & 2 & 40 & 27 & 25 \\
\hline 1 & 17 & 27 & 6 & 46 & 5 & 24 & 2 & 29 & 0 & 0 & 30 & 28 \\
\hline 2 & 18 & 29 & 4 & 30 & 7 & 33 & 3 & 43 & 1 & 20 & 33 & 31 \\
\hline 3 & 6 & 10 & I & 8 & 0 & 0 & 0 & 0 & 0 & 0 & 7 & 6 \\
\hline 4 & 2 & 3 & 1 & 8 & 5 & 24 & 1 & 14 & 2 & 40 & 11 & 10 \\
\hline Total & 62 & 100 & 13 & 100 & 21 & 100 & 7 & 100 & 5 & 100 & 108 & 100 \\
\hline
\end{tabular}

Student dropout was higher in subjects SED03 (The Child's Development in the Social Environment) and SED05 (Educational Research in Action). It appears that essay writing is harder for some students, so much so it compels them to abandon their studies even though they appear keen and demonstrate active interest by participating in the optional group counseling sessions.

\section{The Educational Material}

Students' evaluations of the educational material, which is the central method of distance learning used by the Hellenic Open University, are of great interest. The opinions held by students who dropped out of educational materials are of high importance to the Hellenic Open University, in that they represent those that did not successfully complete their studies due to factors unrelated to "personal" reasons. Twenty percent of the sample found the educational material difficult or extremely difficult. 
Vergidis \& Panagiotakopoulos - Student Dropout at the Hellenic Open University

Table 8. Opinions of students who dropped out of the educational material by subject

\begin{tabular}{|c|c|c|c|c|c|c|c|c|c|c|c|c|}
\hline & \multicolumn{2}{|c|}{ SED01 } & \multicolumn{2}{|c|}{ SED02 } & \multicolumn{2}{|c|}{ SED03 } & \multicolumn{2}{|c|}{ SED04 } & \multicolumn{2}{|c|}{ SED05 } & \multicolumn{2}{|c|}{ Total } \\
\hline & $\mathrm{n}$ & $v_{n}$ & $\mathrm{n}$ & $\%$ & n & $\%$ & $\mathrm{n}$ & $w_{n}$ & n & $w_{h}$ & $n$ & $u_{n}$ \\
\hline $\begin{array}{l}\text { Vory } \\
\text { dtffecult }\end{array}$ & 0 & 0 & 0 & 0 & 2 & 10 & 0 & 0 & 1 & 20 & 3 & 3 \\
\hline Difficudt & 2 & 3 & 1 & 8 & 10 & 48 & 0 & 0 & 4 & 80 & 17 & 16 \\
\hline Demanting & 0 & 0 & 3 & 23 & 5 & 24 & 0 & 0 & 0 & 0 & 8 & 7 \\
\hline Easy & 14 & 23 & 3 & 23 & 1 & 4 & 5 & 71 & 0 & 0 & 23 & 21 \\
\hline $\begin{array}{l}\text { Could do it } \\
\text { on hishor } \\
\text { own }\end{array}$ & 46 & 74 & 6 & 46 & 3 & 14 & 2 & 29 & 0 & 0 & 57 & 53 \\
\hline Total & 62 & 100 & 13 & 100 & 21 & 100 & 7 & 100 & 5 & 100 & 108 & 100 \\
\hline
\end{tabular}

Fifty-three percent of the students sampled stated that they could study the educational material on their own, and 21 percent found it easy to understand. It is clear from our finding that the educational material did not deter the majority of enrolled students from completing their studies. It should be noted here that only two students from the sample cited the educational material as the main reason they abandoned their studies.

However, in terms of the educational material used, our research revealed areas of difficulty were concentrated almost entirely in two subjects: SED03 (The Child's Development in the Social Environment) and SED05 (Educational Research in Action). In both subjects, the material used was not written by the Hellenic Open University faculty, but instead was an adaptation of an equivalent course offered by the Open University UK. In n terms of the number of essays completed as shown in Table 9, we can draw conclusions concerning the opinions of the sample about the educational material. 
Table 9. Opinions of students who dropped out regarding the educational material by number of essays completed

\begin{tabular}{|c|c|c|c|c|c|c|}
\hline \multirow{3}{*}{$\begin{array}{l}\text { Opinions of } \\
\text { the } \\
\text { educational } \\
\text { material }\end{array}$} & \multirow[b]{2}{*}{ T'otal } & \multicolumn{5}{|c|}{ Essays } \\
\hline & & 0 & 1 & 2 & 3 & 4 \\
\hline & n & n $\quad y_{6}$ & n $\%$ & n $\%$ & $\mathrm{~N} \quad \mathrm{~V}_{0}$ & n \\
\hline $\begin{array}{l}\text { Very } \\
\text { Diffoudt }\end{array}$ & 3 & 3 & 1 & 0 & 0 & 0 \\
\hline Diffeut & $17 \quad 16$ & 59 & $4 \quad 13$ & $\begin{array}{ll}4 & 22\end{array}$ & 3100 & 1100 \\
\hline Demanding & 87 & 59 & 310 & $0 \quad 0$ & 00 & 00 \\
\hline$E \propto y y$ & $23 \quad 21$ & $15 \quad 27$ & $\begin{array}{ll}5 & 17\end{array}$ & $3 \quad 17$ & 00 & 00 \\
\hline $\begin{array}{l}\text { Coutd do it on } \\
\text { hisher ow }\end{array}$ & $57 \quad 53$ & $29 \quad 52$ & $17 \quad 57$ & 1161 & 00 & $\begin{array}{ll}0 & 0\end{array}$ \\
\hline Total & 108100 & $56 \quad 100$ & $30 \quad 100$ & $18 \quad 100$ & 3100 & 1100 \\
\hline
\end{tabular}

The majority of students who completed one or two essays tended to find the educational material easy to use and comprehend. This finding can be compared to the view of those students who failed to complete any essays and reveals that the complexity and difficulty of the educational materials was not a barrier to the majority of the students and thus not a factor leading them to abandon their studies.

However, a small minority of students who dropped out, and who did complete three or four essays, still found the educational material difficult. This finding reveals that there was a minority of students enrolled in subjects SED03 (The Child's Development in the Social Environment) and SED05 (Educational Research in Action), who found the educational material difficult to grasp, subsequently compelling them to abandon their studies after having completed two, three, or even four essays, although they tried hard not to do so.

When analyzing the numbers in Table 10, we drew a similar conclusion. 
Table 10. Student dropout opinion of the educational material in terms of the group counseling sessions in which they participated

\begin{tabular}{|c|c|c|c|c|c|c|}
\hline \multirow{3}{*}{$\begin{array}{l}\text { Opinion of the } \\
\text { erluc:atia nal } \\
\text { material }\end{array}$} & \multirow[b]{2}{*}{ Total } & \multicolumn{5}{|c|}{ Group Coutuselting Sessions (GCS) } \\
\hline & & $\theta$ & $\boldsymbol{T}$ & 2 & 3 & 4 \\
\hline & $11 \%$ & II $\quad \%$ & II \% & $11 \%$ & II \% & II $\quad q_{0}^{\prime}$ \\
\hline $\begin{array}{l}\text { Vary } \\
\text { difinculit }\end{array}$ & 3 & 4 & 0 & 6 & 0 & 0 \\
\hline Difjicuit & $17 \quad 16$ & $3 \quad 11$ & 26 & $4 \quad 12$ & $\begin{array}{ll}1 & 14\end{array}$ & 764 \\
\hline Demanding & 7 & 4 & $\begin{array}{ll}5 & 17\end{array}$ & 1 & 14 & 0 \\
\hline $\bar{E} \alpha y$ & $23 \quad 21$ & 933 & $\begin{array}{ll}5 & 17\end{array}$ & $7 \quad 21$ & $\begin{array}{ll}1 & 14\end{array}$ & 1 \\
\hline $\begin{array}{l}\text { Cowli do it on } \\
\text { his/her own }\end{array}$ & 5753 & 1348 & 1860 & 1958 & 58 & 327 \\
\hline Total & $108 \quad 100$ & 27100 & 30100 & 33100 & 7100 & $11 \quad 100$ \\
\hline
\end{tabular}

The majority of students sampled who attended one, two, or three group counseling sessions characterized the educational material used as easy to comprehend. There was, however, a small minority of students who attended every group counseling session, who still characterized the educational material as difficult to understand. It was revealed that some students who were enrolled in the subjects SED03 (Child Development in the Social Setting) and SED05 (Social Research in Action) chose to abandon their studies because they had difficulty understanding the educational material despite their participation in the expected procedures.

For the students sampled, "interest" in studies at the Hellenic Open University appears to be differentiated in relation to their intention to re-enroll in the same subject as well. Forty-nine percent of the sample intends to re-enroll in the same subject, while 34 percent answered this same question negatively; 17 percent were undecided. Note, that for reenrollment the students must again pay tuition fees. 
Table 11. Intentions of students who dropped out to re-enroll in the same subject ( $m=$ male, $f=$ female)

\begin{tabular}{|c|c|c|c|c|c|}
\hline & & Yes & No & Don't. know & Tetal \\
\hline \multirow{3}{*}{ SED01 } & $\mathrm{M}$ & 1.5 & 6 & 9 & 30 \\
\hline & $\mathrm{F}$ & 16 & 9 & 7 & 32 \\
\hline & Total & 31 & 15 & 16 & 62 \\
\hline \multirow{3}{*}{ SEDO2 } & $\mathrm{M}$ & 5 & 2 & 1 & 8 \\
\hline & $F$ & 3 & 2 & 0 & 5 \\
\hline & Total & 8 & 4 & 1 & 13 \\
\hline \multirow{3}{*}{ SED03 } & M & 1 & 6 & 0 & 7 \\
\hline & $F$ & 9 & 4 & 1 & 14 \\
\hline & Total & 10 & 10 & 1 & 21 \\
\hline \multirow{3}{*}{ SEIDI4 } & $\mathrm{M}$ & 1 & 1 & 0 & 2 \\
\hline & $F$ & 3 & 2 & 0 & 5 \\
\hline & Total & 4 & 3 & 0 & 7 \\
\hline \multirow{3}{*}{ SED05 } & $\mathrm{M}$ & 6 & 5 & 0 & 5 \\
\hline & $\mathrm{F}$ & 0 & 0 & 0 & 0 \\
\hline & Total & 0 & 5 & 0 & 5 \\
\hline \multirow{3}{*}{ Total } & $\mathrm{M}$ & $22(42,3 \%)$ & $20(38,5 \%)$ & $10(19,2 \%)$ & $52(100 \%)$ \\
\hline & F & $31(55,4 \%)$ & $17(30,4 \%)$ & $8(14,2 \%)$ & $56(100 \%)$ \\
\hline & Tolal & $53(49,0 \%)$ & $37(34,0 \%)$ & $18(17,0 \%)$ & $108(100 \%)$ \\
\hline
\end{tabular}

It is interesting to note that although no student from the survey sample intended to reenroll in subject SED05 (Educational Research in Action), nearly every female student intended to re-enroll in subject SED03 (The Child's Development in the Social Environment) as compared to almost every male student refusal to do so. From our research, it appears that gender does play a role in urging students to base their final decision as to whether or not to re-enroll in these subjects. Our research also shows that women tend to be more positive than men in terms of re-enrollment in the same subject.

\section{Conclusions}

The above survey leads us to the conclusion that the majority of students enrolled in the graduate course of the Hellenic Open University "Studies in Education" are between 3039 years of age, and are presently employed as school-teachers. According to the student respondents to our survey, the main cause of dropping out stems from working adults' obligations, specifically:

- Workload and work commitments (for both male and female)

- Family obligations (mainly for women)

Moreover, our research reveals differences based on gender. In terms of citing family obligations leading to dropping out, female students dominate this category. The second reason cited for dropping out stems from students' overall miscalculation of the time required for study. Fluctuations in the time available for study affected by changes in work and family environments, coupled with an underestimation of the actual effort and time necessary for studies at the Hellenic Open University, lead many students to abandon their studies. Students who opted to drop out generally failed to recognize the intensity of the subjects taught, and thus failed to devote the time necessary for study.

Slightly more than 10 percent of the students dropped out due to unpredictable factors. Difficulties associated with essay writing that contributed to dropout were mainly concentrated in two subjects (SED03, SED05). However, it is worth noting that in these 
same two subjects, students who discontinued their studies showed a high rate of participation in optional group counseling sessions. Only a few students reported that the educational materials were so difficult as to lead them to abandon their studies. It is important that 74 percent of the sample found the educational material easy or stated that they could manage it. A problem with the educational material appeared in those subjects SED03, SED05, which was an adaptation of an equivalent course taught at the Open University UK. Finally, despite having once again to pay required tuition fees, half of the sample expressed the intention to re-enroll at the Hellenic Open University (in the same subject).

Taking the above into consideration, we conclude that it is necessary for the Hellenic Open University to move towards the improvement of its educational material in those subjects based on translations (SED03 and SED05) and more specifically towards the writing of appropriate educational content that reflects current Greek reality. We also make it clear that a more systematic evaluation of the educational material is required. Generally, the quality of the educational material is still an important factor leading to student drop out (Wood, 1996; Galusha, 1997). Regarding informative material for prospective student candidates (e.g., the students' handbook) it should be clearly stated that:

The decision to study at the Hellenic Open University (as is the case for any other high educational institution) assumes students engage in a systematic course of study. Studying at the Hellenic Open University requires students to allocate enough time (something adults often lack) and to keep up with the assigned schedule, both of which are vital for the continuation of studies at the Hellenic Open University.

\section{References}

Bajtelsmit, J. W. (1988). Predicting Distance Learning Drop-outs: Testing a conceptual model of attrition in distance study. Bryn Mawr: The American College.

Davies, C. (1977). Open Learning Systems for mature students. Dorset: Council for Educational Technology.

Evans, T., and Lockwood, F. (1994). Understanding Learners in Open and Distance Education. London: Kogan Page.

Evans, T., and Nation, D. (1996). Opening Education: Policies and Practices from Open and Distance Learning. London: Routledge.

Frase, M. (1989). Dropout Rates in the United States: 1988. Washington, DC.: National Center for Educational Statistics.

Galusha J. M. (1997). Barriers to Learning in Distance Education. University of Southern Mississippi, USA. Retrieved March 28, 2002 from: http://www.infrastruction.com/barriers.htm

Garrison, D. R. (1993). Quality and access in distance education: theoretical considerations. In Keegan, D. (Ed.) Theoretical Principles of Distance Education, London: Routledge.

Giles, I. M. (1999). An Examination of Persistence and Dropout in the Online ComputerConferenced Classroom. Doctoral Dissertation. Virginia Polytechnic Institute and State University, Northern Virginia Center. 
Holmberg, B. (1995). Theory and Practice of Distance Education. New York: Routledge.

Keegan, D. (1993). Theoretical Principles of Distance Education, London, Routledge.

Tinto, V. (1975). Drop-Out from Higher Education: A theoretical synthesis of recent research. Review of Educational Research 45(1) 89 - 125.

Wood, H. (1996). Designing Study Materials for Distance Students. Charles Sturt University, Australia. Retrieved March, 28, 2002 from: http://www.csu.edu.au/division/OLI/oli-rd/occpap17/design.htm

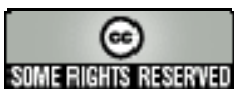




\title{
Simulating the Computer Science Closed Laboratory in an Asynchronous Learning Network
}

\section{Timothy Margush}

The University of Akron

USA

\begin{abstract}
The quiz tool that is part of the WebCT package is used to provide an asynchronous simulation of a (synchronous) closed laboratory experience to beginner computer science students. The technique suggested in this paper and which may be applied to other disciplines, offers students a guided path through an exploratory, discovery based learning experience.
\end{abstract}

Keywords: WebCT; programmed learning; computer science; programming; teaching programming; closed laboratory

\section{Introduction}

In the 1991 Report of the Association for Computing Machinery and the Institute for Electrical and Electronics Engineers-Computer Science (ACM/IEEE-CS) Joint Curriculum Task Force (Tucker, 1991), closed laboratory experiences are recommended as an essential part of the undergraduate computer science program. In that report the closed laboratory model is defined as:

. . . a scheduled, structured, and supervised assignment that involves the use of computing hardware, software, or instrumentation for its completion. Students complete a closed lab by attending a scheduled session, usually 2-3 hours long, at a specific facility. Supervision is provided by the instructor or a qualified assistant who is familiar with the details of the assignment. The specialized equipment, software, and supervision offered by closed laboratories makes them more desirable than open laboratories in certain situations. Closed laboratories are particularly important in situations where the assignment relies on instructor-student interaction or a team effort among students to complete the work.

The most recent report from the ACM/IEEE-CS Joint Curriculum Task Force stipulates: "Most courses in a computer science program must include a laboratory component that requires students to develop their technical skills and acquire an understanding of 
effective professional practice” (Chang, 2001). This report reinforces the importance of including laboratory experiences to the learning process.

Closed laboratory experiences were first introduced to the computer science curriculum in the mid to late 1980s. This mode of instruction offered a controlled and supervised setting where students could design and test small programs, or use prewritten programs to support experimental inquiries into various issues related to the course material. By definition, the closed laboratory environment requires the presence of instructors or assistants knowledgeable enough to help students through difficult parts of the assignment. Closed laboratory assignments are typically designed to be completed within a two or three hour time frame.

As more universities try to meet the needs of an increasingly diverse and mobile student population, faculty have been encouraged to develop class offerings in distance learning formats or at least to provide online support for traditional classes. These online components are offered in both synchronous and asynchronous modes.

Synchronous distance learning implies person-to-person communication in real time. The communication medium can be as simple as the telephone or may involve Internet based technologies such as chat rooms, whiteboard, text messages, audio/video presentations, or virtual classroom simulations. The important theme is that students and instructor communicate in real-time. Because this format combines particular demands on both student and instructor schedules, this mode may be impractical for students who may live in widely different time zones.

Asynchronous distance learning means that students and instructors may access course information at different times. Support for the asynchronous model is generally through CD-ROM, or online accessible content, message boards, and email. One disadvantage of the asynchronous model is the delay between questions and answers. Instructors may compose elaborate email responses to student questions, only to learn that students either answered questions for themselves shortly after submitting their questions or have lost interest due to the lack of any immediate response. Delays in obtaining answers to questions may prevent students from completing assignments in a timely manner.

Because all students gather at an appointed time and place to work together on a prepared assignment, the closed laboratory model is, by definition, synchronous. Thus the need to provide this important mode of instruction in an online environment brings special challenges. A synchronous online environment can meet the requirements outlined in the Task Force's definition of closed laboratory if a "specific facility" is interpreted to mean a common chat room, and if supervision can be accomplished in an online format. Team efforts and instructor-led experiments can be facilitated through the use of whiteboard, chat, and even voice and video tools.

At the time the ACM 1991 guidelines were written, the specialized software mentioned in the definition was either expensive or required machine resources were not commonly available to many students in their homes. As system and software prices have dropped, and as home computers have become more powerful and ubiquitous, it is now probable that more students will have the required resources in their homes to support all of the activities typically performed in closed lab settings. In fact, for the introductory programming classes, it is possible to provide free, yet sophisticated, integrated development environments to support programming activities.

Closed laboratory components have been a standard part of introductory courses in many undergraduate computer science programs. Advances in technology and the readily 
available hardware and software needed to decentralize the computer laboratory make it feasible to explore distance learning implementations of the closed laboratory model.

Using interactive voice or text messaging, remote desktop viewing or control, and possibly chat or whiteboard tools, synchronous techniques are ideal in that they allow immediate feedback to questions. Students are able to progress through assignments without unnecessary delays, obtaining help when needed. However, due to conflicts between student and instructor schedules, this mode of instruction may sometimes be impractical.

As asynchronous implementation increase flexibility in scheduling, students around the world are able to work at their own convenience. However, such techniques deviate from some of the strict wording of the definition of a closed laboratory experience. However, by relaxing some of the constraints in the definition, many of the benefits afforded by the closed laboratory setting can be retained even in an asynchronous learning network.

This paper documents the use of the WebCT quiz tool to provide a programmed learning style of presentation that combines tutorial, hands-on practice, and assessment to simulate the closed laboratory experience. This approach is a compromise between the closed laboratory setting and an open laboratory style (where students are provided little or no help in completing an assignment) that can easily be implemented in an asynchronous learning network. The use of the WebCT quiz tool as a programmed learning guide allows students to work through an assignment in a step-by-step fashion, at their own time and pace, without the frustration of being unable to complete a critical step that would prevent them from finishing the assignment.

\section{Background}

Programmed learning techniques were popularized in the 1960s, based largely on the work of B. F. Skinner. In this approach to education, a cognitive domain is divided into small presentation units, sometimes called frames. The frames are sequenced so knowledge units required for subsequent frames are mastered before they are needed. Two modes of programmed learning are generally identified, linear and branching. Both Personalized System of Instruction (PSI) and Computer Aided Instruction (CAI) have made use of both of these techniques for many years (Pettijohn, 1998).

The WebCT platform's quiz tool provides a simple and effective tool to implement the linear model of programmed learning. The WebCT quiz can be configured to present one question at a time, allowing small portions of a learning unit to be presented. This fulfills the first requirement of the programmed learning technique. Each question may contain a description of a concept, or simply present a task to be completed. Each frame of the presentation ends with some type of assessment. This could be a simple yes/no, multiple choice, short answer, or even paragraph style question that would allow a complete program or code fragment to be pasted into the answer area.

Once a question has been answered, a typical CAI system calls for analysis of the answer and perhaps employing branching techniques to provide custom feedback to students. In the linear model, the system simply moves on to the next question. Since the WebCT quiz module does not analyze the responses to individual questions until the entire quiz is completed and submitted for grading, immediate feedback can only be general in nature and must be supplied as part of the next question to be presented. This supplies reinforcement when correct answers are given, and offers an opportunity to present essential information to facilitate progress through subsequent frames. 
Margush - Simulating the Computer Science Closed Laboratory in an Asynchronous Learning Network

\section{Simulating the Closed Laboratory using Programmed Learning Techniques in WebCT}

Closed laboratory exercises designed to supplement introductory programming classes typically involve the following activities: detection and correction of basic programming errors (syntax), locating and correcting errors in logic (semantics), synthesis and modification of code (program design and maintenance). Successful completion of these tasks often requires a multiple step solution. To ensure students can progress through each step, instructors are present in the closed laboratory setting to provide assistance when required. The major barrier to converting a traditional closed laboratory assignment to an asynchronous format is the absence of this immediate help. Without the availability of an instructor, students may be unable to complete a critical task and thus to progress through subsequent stages of the assignment.

One possible solution is to employ programmed learning techniques with feedback and reinforcement. Using this approach, the individual steps of a task are presented in sequential learning frames. Each frame includes the presentation of some new idea or a task to be performed. Each frame ends with a question that must be answered before proceeding to the next. By anticipating the critical points in an assignment, solutions needed to progress through the multi step task can be included at the beginning of the next frame, thus providing immediate encouragement for those students who successfully complete each step. More importantly, it allows a student who has answered a question incorrectly (or not at all) to view a correct response and make the appropriate adjustments to their program, allowing them to continue with the next step. Although a branching model of programmed learning would provide more individualized feedback, the linear model is sufficient in most cases to replace the role of the instructor in the closed laboratory setting.

Although designed to administer quizzes via the World Wide Web, the WebCT quiz tool can be used to implement a closed laboratory assignment in a linear style programmed learning module. It also enables quizzes to be presented in two basic modes: one question may be presented at a time, or all questions may be viewed as a single webpage. To use this tool to create a programmed learning module, the questions must be viewed one at a time. It is also desirable to control the order in which the frames are viewed. The quiz tool can be configured to prevent students from revisiting a question once it has been skipped or answered. This feature also allows the module to be used as an evaluation tool.

The one shortcoming of the WebCT quiz tool as a platform for the presentation of a programmed learning module, is its inability to immediately evaluate each response and provide customized feedback. Quizzes administrated via the WebCT quiz tool are not graded until all questions are answered and the student submits the quiz for grading. This means that feedback must be of a general nature and must be included at the start of the next frame.

The WebCT quiz module provides automated grading facilities for many of the question types. This makes grading lab assignments an easy task. For one thing, all of the assignments are submitted in the same format; and since submissions are electronic, all responses are clearly legible, thus the often time consuming process of grading lab assignments is reduced.

The quiz tool provides several mechanisms for providing students with comprehensive feedback after the assignment is graded. WebCT quizzes allow the grader to supply a written comment after each response. Automatic feedback can also be built into the 
questions themselves and can be made available to student after the completed assignment has been submitted. Provision is made for general feedback for each question, as well as custom feedback for each possible response (for some question types). The quiz can also be configured to display different levels of feedback.

Although it would be possible to overcome many of these shortcomings through the use of external or custom software, integration of such a product within the WebCT environment is difficult. WebCT-Vista advertises the inclusion of: "a development toolkit for integration with either custom or commercial learning software, giving institutions the ability to seamlessly incorporate external e-learning applications" (WebCT, 2002). This facility may allow integration with the WebCT internal email and grade book, making the development of a custom programmed learning and assessment tool feasible.

The basic ideas elaborated above may be applied to create programmed learning modules in a variety of disciplines. The rest of this paper examines some of the techniques I have used in developing an asynchronous learning network version of a typical closed laboratory assignment for an introductory programming course. In this case, sample questions from a laboratory exercise covering basic repetition structures are used to illustrate the concepts. In this lab assignment, students needed to predict the behavior of existing loops, modify the behavior of loops, and design their own loops.

Most laboratory assignments are accompanied with some pre-written source code files. In our course, all students use the same compiler (provided with the textbook), so required assignment files are provided in a format used by that compiler. This zipped collection of files is made available for download. Prior to beginning the assignment, the zip archive must be retrieved and expanded on the students' local disks. For some students, the process of downloading and unzipping an archive is new, and appropriate instructions and software are provided.

Lab exercises begin with a list of objectives. Traditionally, I include some background material presented in small informational blocks. Each block ends with a question that can usually be answered by reading the material. In general, 10 to 20 percent of the assignment comprises questions such as Sample Question 1, which is an example of a pre-lab style question:

Sample Question 1: This Hands On assignment focuses on repetition structures. The objectives are: (1) to write a simple counter-controlled loop using the for structure; (2) to become more familiar with the different repetition structures provided in C; (3) to understand the importance of proper initialization of variables; and (4) to learn that more than one solution can be produced for a given problem. The $\mathrm{C}++$ programming language supports three distinct repetition structures: while, for, and do/while. Each of these structures is generally used for specific situations, but the programmer should recognize that the common usage does not mean another structure will not work. By exploring the use of an alternative structure in a given situation, the programmer should be able to recognize similarities and differences in the structures.

Name the three looping structures supported by the $\mathrm{C}++$ language:

Once the background material has been introduced, the student is instructed to open the project for the first task. One of the important skills programmers need to develop is the ability to read and understand programs written by others. Most lab exercises include activities that develop this skill. Sample Question 2, provided below, is an example of a question that encourages learners to develop program reading skills: 
Sample Question 2: You will need to open the workspace for part A of the assignment. Look at the source code and read the documentation. The program is supposed to compute the sum of a sequence of integers based on user input. If the user enters 3 and 5 , what should the program display (according to the program specifications) as the sum?

A) 3 B) 5 C) 12 D) some large negative value E) none of the above

If students simply run the program, they will probably give the wrong answer to this question, as the provided program (by design) does not meet the stated specifications. Other similar questions might ask students to examine segments of code and predict the results, or execute the program with particular test data and report the results.

So far, students can work through the lab without facing critical programming tasks that might cause frustration and possibly prevent them from completing the assignment. When changes to the program are required, subsequent tasks often depend on students making correct modifications. After asking students to make a change to the program, the subsequent question should include a correct solution. If students are unable to complete the prior step, they may easily copy and paste the suggested solution into their program and proceed to the next question. Sample Question 3 illustrates how a possible answer might be included at the beginning of a question:

Sample Question 3: Hopefully you moved the cout statement to the location shown below. This will allow the original value of the variable start to be printed before it is changed by the body of the loop. Be sure your program resembles the one below before going on with this question.

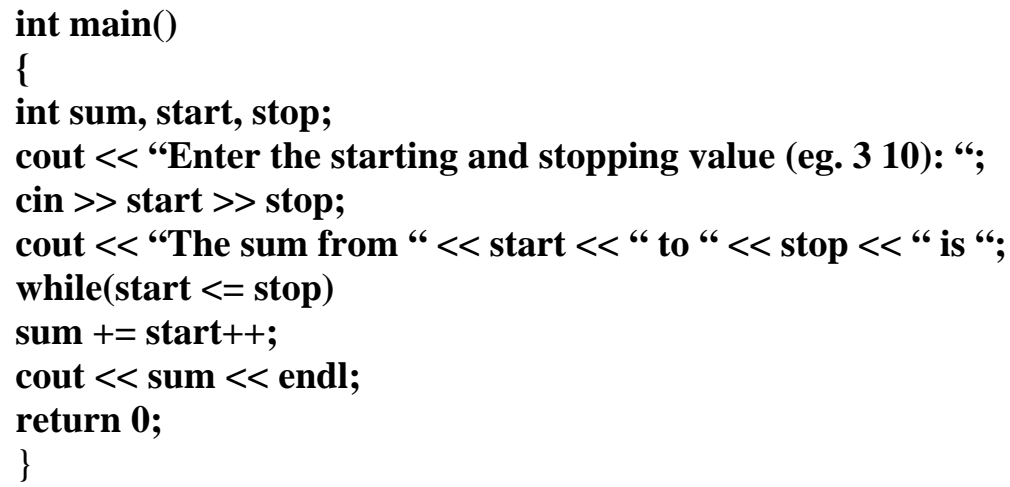

This change has not corrected all of the problems. You should still be concerned about the incorrect sum being displayed. What is the cause of the problem?

When students encounter Sample Question 3, they would have just completed the previous frame in which they were asked to correct an observed error related to the value of the variable start. The solution displayed in the question shows the correct modification required by the previous task. If students' answers are incorrect, they have the opportunity to correct them before going on. Having correct solutions at this point is essential to continuing. At the end of each frame, students are asked to identify the cause of the remaining logical error. In the next question, they will be asked to correct the error. If they made an inappropriate change to answer the preceding question, or if they incorrectly identify the error at this stage, they will not have much chance at supplying the appropriate correction at the next stage of the assignment; therefore, the correct answer to this question will again be supplied in the next.

Sample Question 4 includes a brief analysis of the problem the student was asked to identify in Sample Question 3 and suggests a solution. This will usually be sufficient to 
get a student back on track if they did not see this problem and tried to make some other change.

Sample Question 4: As you probably determined, the problem with the loop is that the variable sum is not initialized. Add a statement to set sum to zero before the start of the loop. Verify that the program gives the correct output for several input cases.

There is one final change that you need to make to complete this portion of the lab. Modify the looping structure completely, using a for loop in place of the while loop. You can change the body of the loop, but do not change any of the surrounding code. Specifically, replace the two lines (starting with the keyword while) with a for loop that correctly computes the sum.

Test, and when satisfied, paste a copy of the modified main function here:

Successful completion of this task again requires modification of the existing code. The solution is then pasted into a paragraph style answer box in the WebCT quiz. Since this is the last task to be performed on this part of the assignment, no solution needs to be provided in the next frame. However, students will benefit from eventually seeing a correct solution, so it is important to provide feedback once the assignment has been graded. I generally use the feedback option in WebCT to provide feedback for each question, especially if the correct answer is not given in the next question. When grading assignments, there is a place to add comments to each response, so this makes it easy to customize feedback.

\section{Conclusions}

Introductory programming courses are typically taken by students who have little or no programming experience. Prior to taking our introductory computer programming course in an online, asynchronous format, many students expressed concern about the lack of inperson help. Indeed, knowing from experience that students often needed help at several stages of the assignment in order to complete it successfully, I also initially had doubts about the effectiveness of using the closed lab assignments as a component of the asynchronous course. The programmed learning style of presentation seems to have successfully addressed these difficulties. Student evaluations have provided positive feedback about the HandsOn assignments (my terminology for the closed laboratory assignments). Three students wrote:

"In regards to the HandsOn experience, these exercises are one of the most helpful tools to learn programming."

"I am most impressed with the hands-on assignments in particular. If you recall, I was in this course back in Fall 2000 and the hands-on assignments are very similar to the in-class labs we had then. They are very interactive and they illustrate some fundamental concepts in the course."

"Firstly, I am very happy with the hands on assignments because I took this course at another university last semester and needless to say I am retaking it because I did not have enough practice."

When building an asynchronous version of a course that traditionally includes a closed lab experience, it is well worth the time to develop a programmed style interactive quiz that simulates the closed laboratory session. I generally give students an entire day to complete a HandsOn assignment. This allows students adequate time to think about 
problems they encounter, and perhaps get help through the discussion board, email, or chat (if available) from the instructor or other students. Most students have little difficulty completing the assignments within this time frame.

As long as specialized equipment is not required, the application of programmed learning techniques to the problem of implementing closed laboratory experiences in an asynchronous learning network may be extended to other traditional laboratory settings. The ready availability of computers and software required for introductory computer science laboratories makes the distance learning format possible at this time. For medical or scientific labs, this may not be the case. Even in the field of computer science, access to special input devices such as virtual reality equipment or digitizing tablets may not be feasible at remote locations. Such laboratories would still likely require on-site facilities or a simulation of the equipment.

\section{References}

Chang, C. (2001). Computing Curricula 2001 Computer Science: The Joint Task Force on Computing Curricula, IEEE Computer Society and Association for Computing Machinery. Retrieved June 15, 2002 from: http://www.acm.org/sigcse/cc2001/cc2001.pdf

Pettijohn, T. F. (1998). Psychology: A ConnecText, Fourth Edition. Hightstown, NJ.: Dushkin-McGraw Hill.

Tucker, A. B. (1991). Computing Curricula 1991: Report of the ACM/IEEE-CS Joint Curriculum Task Force. New York: ACM Press.

WebCT (n.d.) Vista Extensible, Enterprise-Class Architecture. Retrieved October 1, 2002 from:

http://www.WebCT.com/products/viewpage?name=products vista architecture.

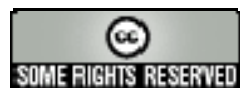


Research Notes - Vol. 3, No. 2

\title{
The Effect of Self-selection on Student Satisfaction and Performance in Online Classes
}

\author{
Pan G. Yatrakis, Ph.D. \\ Nova Southeastern University \\ Helen K. Simon, CFP, MBA \\ Nova Southeastern University
}

\begin{abstract}
This paper examines student performance, satisfaction, and retention of information in online classes as a function of student choice as to the format of instruction. Student outcomes are studied for two groups enrolled in online classes: those who were allowed to choose between an online and a ground-based format and who chose the online format voluntarily; and those who were obliged to take classes in the online format without being afforded the opportunity to choose.
\end{abstract}

Keywords: attitudes; business schools; comparative studies; distance learning; education evaluation; Internet; online instruction; student satisfaction

\section{Introduction}

The market for courses provided over the Internet has experienced the fastest growth among all segments of the education industry. It has been estimated that college revenues from Internet and Intranet courses will reach US \$15 billion in 2002, up from only US \$4 billion four years ago (Jones, 2000), and that Web-based instruction will account for 46 percent of the education and training market by 2003 (Mottl, 2000). Nevertheless, many colleges and universities that provide courses over the Internet continue to offer the same courses in the traditional, ground-based format, as well. This practice permits students to select between the two formats according to their perception of the advantages or drawbacks that each provides in their own particular situation. For example, a student who is a "self starter" and who values flexibility and convenience may choose to take a course in the online format, while students who are less "selfdirected" and value guidance and the supportive environment of a traditional classroom, may select the ground-based format.

On the other hand, some institutions offering online courses do not afford students the opportunity to choose. Several, such as Jones International University and Cardean University, offer all their courses in the online format only. Others, such as the University of Phoenix enroll students in separate ground-based and online tracks and compel them to take all their courses in the specific track, which they have chosen. Still others, such as the authors' school, the Wayne Huizenga Graduate School of Business and Entrepreneurship at Nova Southeastern University, provide most courses in both formats, but also offer others only online. 
Yatrakis \& Simon - The Effect of Self-selection on Student Satisfaction and Performance in Online Classes

The purpose of the authors' research was to determine whether there exists a significant difference in online students' learning outcomes, depending on whether they enrolled in online courses by choice, or because no other alternative was available. In this article the term "online class" refers to classes in which students never physically enter a traditional classroom, with all interaction being via an online medium. The term "ground-based course" refers traditional courses where interaction between students and instructors occurs predominantly face-to-face in classrooms.

\section{Previous Research}

There is a wealth of literature on student outcomes in online courses, but the main theme is comparisons between online and ground-based formats. Most researchers have found no significant difference in outcomes between the two formats (Dominguez and Ridley 1999; Ryan, 2000; Gagne and Shepherd, 2001; Cooper 2001; Shea et. al., 2001). Some, however, have cited student concerns about instructional quality in online courses (Bloom, 1998; Terry, 2000), while others consider virtual courses an "inferior technology" particularly in the teaching of complex material (Farrington, 1999; Brown and Liedholm, 2002).

Other researchers have focused on approaches and methods, which may improve outcomes in the online environment. For example, Haythornthwaite et al. (2000), found that a ground-based "boot camp" preceding online courses can help build a sense of community among distance learning students and enhance their satisfaction and learning outcomes. Doran (2001) found that small group collaborative activity improved outcomes in online courses. A similar finding was made by one of the authors of the present study, who compared the grades and course evaluations of two student groups that had taken an online MBA-level Managerial Economics class at two different times. He found that the second group, who were given assignments on which they had to collaborate (via chat rooms, bulletin boards, conference calls, etc.) showed significantly higher levels of satisfaction and information retention than the first group, that was allowed to work individually (Yatrakis, 2001).

To date, however, there have been no studies of the consequences of allowing students to choose between taking courses online or in the traditional, ground based format, despite numerous indications that such consequences may, in fact, exist. For example, it is widely recognized that online courses appeal to students who value flexibility (Cooper, 2001), but that they also require much more work and discipline than is expected in ground-based courses (Brown and Liedholm, 2002). The learning styles of online MBA students and their preferred methods of course delivery have also been identified (Barnes, Preziosi and Gooden, 2002). It would stand to reason that, ceteris paribus, students who feel most comfortable with online course delivery would be the most likely to enroll in courses taught in the online format. This process of self-selection may indeed contribute to the findings of no significant difference in outcomes between students taking courses in either format. What happens, however, when students are not given that choice, but are compelled to take courses in the online format whether or not they fit the profile of potentially successful online students? Students themselves seem to recognize that the availability of alternatives can be advantageous. In Cooper's (2001) study, 131 students (94 from traditional and 37 from online classes) were asked whether a computer applications class should be offered only online, only on the ground, or in both formats; 100 percent responded that it should be offered in both formats. It is the purpose of the present study to examine this issue in the context of the authors' own institution, and specifically in its Master of Business Administration (MBA) program, where some courses are offered only in an online format, while others are conducted both online and in traditional, ground-based classrooms. 


\section{The Huizenga School MBA Program}

The Huizenga Graduate School of Business and Entrepreneurship is part of Nova Southeastern University, the 12th largest private university in the United States, with campuses in Ft. Lauderdale, Florida and programs in 22 states and eight countries outside the US. Enrollment at the Huizenga School totals about 2,500 students, of whom approximately 1,600 are MBA candidates, with the rest enrolled in other Master's degree programs and a Doctoral program. The MBA program offers 46courses, including prerequisites, core courses, specialty courses, and a capstone course. Of these, all five prerequisite courses are only available online, as is the information technology course mentioned previously. All other courses are taught in both groundbased and online formats, except for the capstone course, which is ground-based only. Registration for the online classes is capped at 15students, which is about two-thirds the size of ground-based MBA classes. The online classes make use of the usual support facilities, including bulletin boards, chat rooms, assignment managers, grade managers and the like. At the instructor's discretion, streaming video and/or voice chat sessions may be used. Information technology personnel are available on weekdays from 8:30 a.m. to 10 p.m., on Saturdays from 8:30 a.m. to 8 p.m. and on Sundays from noon to 6 p.m. to solve problems and provide real-time assistance to instructors and students.

At the conclusion of the course, students were required to complete a uniform evaluation in which they were asked to rate the course, the instructor, and the school's infrastructure and support facilities. Students were asked to assign a value of one through five in answer to statements in the evaluation, according to the following scale: 1 - strongly disagree, 2 - disagree, 3 - neutral, 4 agree, and 5 - strongly agree.

Two of these statements were particularly relevant to the issues examined in the present study: (1) "I was very satisfied with the amount of time spent interacting with my classmates"; and (2) "The course work and discussions resulted in high retention of information."

Although the first statement does not rate overall satisfaction with the online course, it is the only statement in the evaluation that measures student satisfaction of any kind; hence, it was used as a proxy for overall student satisfaction. It should also be noted that the second question measured student "perceptions" of information retention. However, as Ryan (2000) observed, comparisons of student perceptions constitute good indicators of the relative effectiveness of different delivery formats. They may also be useful in comparing the effects of student choice or lack thereof. In any event, the present study also uses a third metric, the actual grades achieved by students enrolled in online classes for which there was no ground-based alternative, as well as those achieved by students in classes where ground-based alternatives were available.

\section{Methodology}

Student responses to the two course evaluation statements cited above were collected and tabulated from a sample of 397 students who chose to enroll in courses that were available in either online or ground-based formats (the "choice" group); as well as a sample of 433 students who were enrolled in courses that were available only online (the "no choice" group). Not all students answered both questions: the response rate to the first question (satisfaction) was 409 out of a possible 433 (94.5 percent) for the "No Choice" group, and 305 out of 397 (76.8 percent) for the "Choice" group.

On the second question (retention of information), 429 of the "No Choice" students responded (99.1 percent), compared to 315 (79.3 percent) of the "Choice” group. 
Student grades for these courses were also tabulated for the two student groups. "Two-Factor Analysis of Variance (ANOVA) without Replication" was used to determine whether the two groups differed significantly in their responses to the two questions, and in their course grades.

\section{Results}

Tables 1, 2 and 3 present the results of the ANOVAs. Figures 1 through 3 are graphic representations of the student grade and evaluation data.

Figure 1. Academic performance of "Choice" and "No Choice" groups

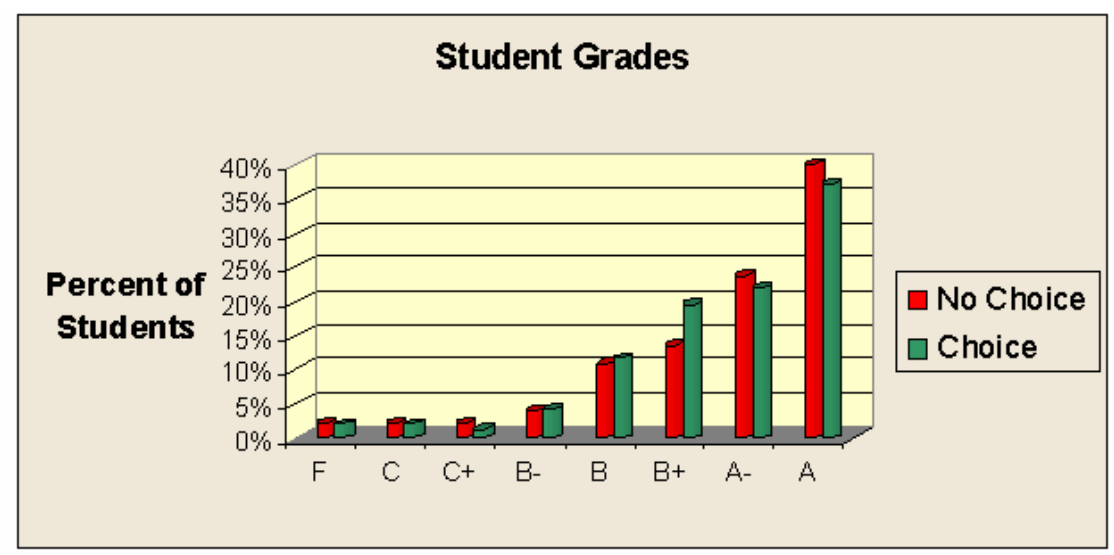

Table 1. Academic performance of "Choice" and "No Choice" groups

\begin{tabular}{|c|c|c|c|c|c|c|}
\hline $\begin{array}{l}\text { ANOVA: Two-Factor without } \\
\text { Replication }\end{array}$ & & & & & & \\
\hline SUMMARY & Count & Sum & Average & Variance & & \\
\hline No Choice & 8 & 1 & 0.125 & $\begin{array}{l}0.01888 \\
6\end{array}$ & & \\
\hline Choice & 8 & 1 & $\begin{array}{l}0.12501 \\
3\end{array}$ & $\begin{array}{l}0.01668 \\
7\end{array}$ & & \\
\hline \multicolumn{7}{|l|}{ ANOVA } \\
\hline Source of Variation & SS & $d f$ & $M S$ & $F$ & $P$-value & F crit \\
\hline Rows & $\begin{array}{l}6.25 \mathrm{E}- \\
10\end{array}$ & 1 & $\begin{array}{l}6.25 \mathrm{E}- \\
10\end{array}$ & $1.6 \mathrm{E}-06$ & $\begin{array}{l}0.99902 \\
6\end{array}$ & 5.59146 \\
\hline Error & $\begin{array}{l}0.00273 \\
3\end{array}$ & 7 & 0.00039 & & & \\
\hline
\end{tabular}


Figure 2. Student Satisfaction* of "Choice" and "No Choice" Groups

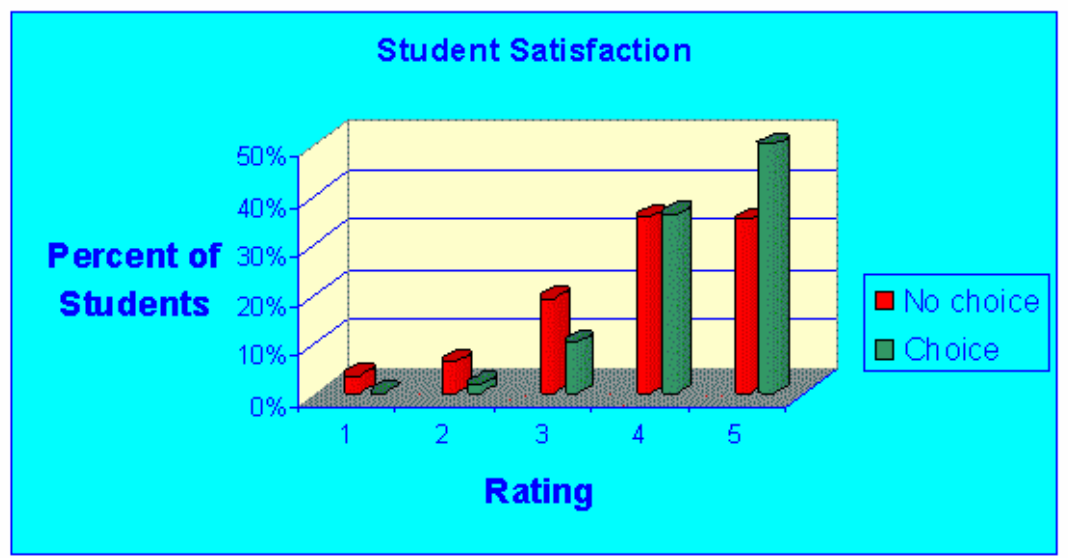

${ }^{*}$ Ratings were as follows: 1 - strongly disagree, 2 - disagree, 3 - neutral, 4 - agree, and 5 - strongly agree

Table 2. Student satisfaction of "Choice" and "No Choice" groups

\begin{tabular}{|c|c|c|c|c|c|c|}
\hline $\begin{array}{l}\text { ANOVA: Two-Factor without } \\
\text { Replication }\end{array}$ & & & & & & \\
\hline SUMMARY & Count & Sum & Average & Variance & & \\
\hline No Choice & 5 & 408 & 81.6 & 3830.8 & & \\
\hline Choice & 5 & 305 & 61 & 4723 & & \\
\hline \multicolumn{7}{|l|}{ ANOVA } \\
\hline Source of Variation & SS & $d f$ & $M S$ & $F$ & P-value & F crit \\
\hline Rows & 1060.9 & 1 & 1060.9 & $\begin{array}{l}4.08588 \\
5\end{array}$ & $\begin{array}{l}0.11332 \\
2\end{array}$ & 7.70865 \\
\hline Error & 1038.6 & 4 & 259.65 & & & \\
\hline
\end{tabular}

Figure 3. Student retention* of "Choice" and "No Choice" groups

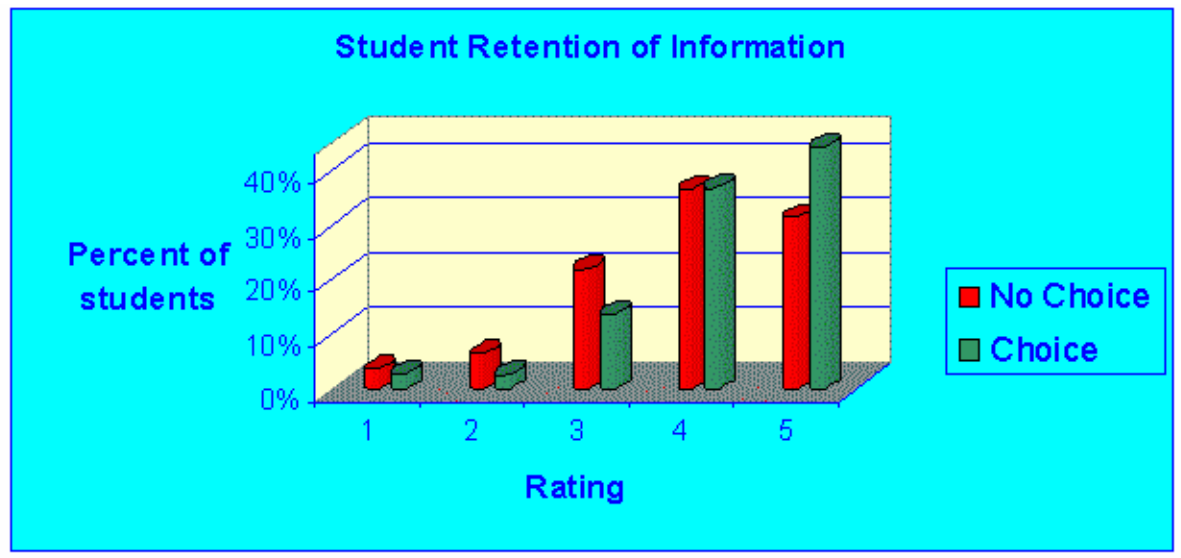

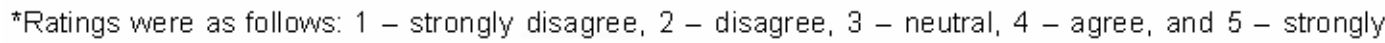
agree 
Table 3. Student retention of "Choice" and "No Choice" groups

\begin{tabular}{|c|c|c|c|c|c|c|}
\hline \multicolumn{7}{|c|}{$\begin{array}{l}\text { ANOVA: Two-Factor without } \\
\text { Replication }\end{array}$} \\
\hline SUMMARY & Count & Sum & Average & Variance & & \\
\hline No Choice & 5 & 429 & 85.8 & 3977.7 & & \\
\hline Choice & 5 & 315 & 63 & 3731.5 & & \\
\hline \multicolumn{7}{|l|}{ ANOVA } \\
\hline Source of Variation & SS & $d f$ & $M S$ & $F$ & P-value & F crit \\
\hline Rows & 1299.6 & 1 & 1299.6 & \multicolumn{3}{|c|}{4.8701520 .0919497 .70865} \\
\hline Error & 1067.4 & 4 & 266.85 & & & \\
\hline
\end{tabular}

As may be seen from the data contained in tables and figures 1 through 3, students who enrolled in online courses after being given a choice between the online and ground-based formats (the "Choice" group) rated their courses higher on satisfaction and retention of information that did students in the "No Choice" group. The P-values for the two ANOVAs indicate that the null hypothesis of no difference in responses between the two groups is rejected at the nine percent confidence level for perceived retention of information, and at the 11 percent confidence level for satisfaction. Though significant at levels somewhat higher than the conventional five percent, the results nevertheless suggest that considerable differences exist between the two student groups in their responses to these two questions.

However, the ANOVA of student grades conclusively supports the null hypothesis of no difference between the two groups. Indeed, the median grades for both groups are the same (A- or 3.7), as is their mean grade average (3.3). The only discernible difference appears to be at both tails of the grade distribution, which are fatter for the "No Choice" group.

\section{Conclusions}

The results of this study suggest that students who choose to enroll in courses in an online format achieve higher rates of satisfaction and perceived retention of information than do students who enroll in online courses when no such choice is provided. This finding is consistent with those of earlier studies that reported different types of learning styles and characteristics of successful online learners, and suggests that students enrolled in such courses by choice probably possess the attributes likely to make online learning a satisfactory and constructive experience. The results seem to indicate that voluntary online courses apparently attract a higher percentage of such students than do the mandatory ones, and therefore produce higher levels of satisfaction and perceived information retention as measured by the students' course evaluations.

The findings of this study with respect to student grades do not seem to correlate with students' perceptions. It might reasonably be assumed that students reporting higher levels of satisfaction and perceived retention of information should also perform better as measured by course grades. In fact, our research shows that this was not the case. These seemingly conflicting results suggest that students feel a greater degree of satisfaction when allowed to self-select for online courses, and that this "self selection" may carry over into their perception of retained information. But in terms of actual learning, to the degree that this is measured by grades, being afforded a choice appears to make little difference in outcomes.

The results with respect to grades do suggest that the two groups of students are similar in their learning abilities, and that the instructors' grading is reasonably uniform and consistent across the online courses of the Huizenga School's MBA program. Moreover, this appears to be true 
regardless of whether or not students are afforded the opportunity to select the format of course delivery.

The implications of this study's findings for college administrators are two-pronged. On the one hand, student choice increases student satisfaction and perception of information retention. On the other hand, choice apparently makes no difference to grade outcomes. Accordingly, the results can be used to support choice as satisfying the preferences of the learning institutions' customers, or to deflect requests to implement such choice on the grounds that it makes no difference in learning outcomes. In practical terms, the provision of choice may come down to financial considerations, and tradeoffs between these and student satisfaction. It may be more costly to provide courses on both the online and ground-based tracks, but the additional costs should be weighed against the generally positive learning experience which choice provides.

It should be noted that this study is far from definitive, and that further work is needed to corroborate these findings in a broader context. There is surely some random noise in the data: by definition, the courses taken by the two student groups are not the same; the instructors are not the same; and it is possible that the characteristics of the students themselves may vary across the two groups. These potential differences are mitigated by the application of uniform admission standards, but they may not be entirely absent. For example, it is possible that students enrolling voluntarily in online courses may have higher GMAT scores or may be more motivated or more committed than their peers. Still, any substantial difference between the two student groups could be expected to show up in their relative performance, and no such difference is apparent with respect to their grades.

A related area which should be investigated is the performance of students in conventional ground-based classes when allowed to self-select and when afforded no such choice: a study, in other words, analogous to the present analysis except in its focus on ground-based rather than online students. Such research could corroborate, and would certainly complement, the findings of the present study with respect to student choice.

Finally, the aforementioned differences between the two groups in the "tails" of the grade distribution are curious and warrant further investigation. A comparison indicates that the "Choice" group displays a tighter distribution of grades about the mean, while the "No Choice" group shows comparatively fatter tails at both extremes. The proportion of "No Choice" students receiving high grades (A and A-) exceeds that of "Choice" students, as does the proportion receiving low grades $(\mathrm{C}+, \mathrm{C}$ and $\mathrm{F})$. Conversely, the proportion of "Choice" students with grades of B-, B and B+ is higher than that of the "No Choice" students, while median and mean grades for the two groups are basically the same. Further research on these issues might expand the analysis to other institutions of higher education, utilize broader measures of student learning, and perhaps focus on specific characteristics of the two groups, which might contribute to the observed differences in their behavior.

\section{References}

Barnes, F. B., Preziosi, R. C., and Gooden, D. (2001). An Examination of the Learning Styles of Online MBA Students and Their Preferred Delivery Methods. Paper presented at The Institute of Behavior and Applied Management, San Diego, CA.

Bloom, D. F. (1998). Digital Diploma Mills, Part III. The Bloom Is Off the Rose, Monograph. Retrieved May 15, 2002 from: http://www.vpaa.uillinois.edu/tid/resources/noble.html

Brown, B. W., and Liedholm, C. (2002). Can Web Courses Replicate the Classroom in Principles of Microeconomics? American Economic Review 92(2), 444 - 448. 
Cooper, L. W. (2001). A Comparison of Online and Traditional Computer Applications Classes. THE 28(8), $52-58$

Dominguez, P. S., and Ridley R. (1999). Reassessing the Assessment of Distance Education Courses. THE Journal Technological Horizons in Education 27(2). Retrieved May 15 2002 from: http://www.thejournal.com/magazine/vault/A2223.cfm

Doran, C. L. (2001). The Effective Use of Learning Groups in Online Education. New Horizons in Adult Education 15(2). Retrieved May 13, 2002 from: www.salzburgseminar.org/reports/ASC28bib.pdf

Farrington, G. C. (1999). The New Technologies and the Future of Residential Undergraduate Education 34(4), 38 - 44.

Gagne, M., and Shepherd, M. (2001). Distance Learning in Accounting. THE 28(9). Retrieved June 17, 2002 from: http://www.thejournal.com/magazine/vault/A3433.cfm

Haythornthwaite, C., Kazmer, M. M., and Robins, J. (2000). Community Development Among Distance Learners: Temporal and Technological Dimensions. Journal of ComputerMediated Communication 6(1). http://jcmc.indiana.edu/vol6/issue1/haythornthwaite.html

Jones, D. (2000). Will Business Schools Go Out of Business? E-Learning, Corporate Academies Change the Rules. USA Today, May 23.

Mottl, J. N. (2000). Learn At A Distance. Information Week, p.767.

Ryan, R. C., (2000). Student Assessment Comparison of Lecture and Online Construction Equipment and Methods Classes. THE Journal, 27(5). Retrieved May 13, 2002 from: http://www.thejournal.com/magazine/vault/A2596.cfm

Shea, P., Fredericksen, E., Pickett, A., Pelz, W., and Swan, K. (2001). Measures of Learning Effectiveness in the SUNY Learning Network. In J. Bourne, and J. C. Moore (Eds.) Online Education, Volume 2, Learning Effectiveness, Faculty Satisfaction, and Cost Effectiveness. SLOAN-C Series 2001.

Terry, N. (2000). MBA Student Perceptions About the Effectiveness of Internet Instruction. Business Education Forum 54(4), 42 - 44.

Yatrakis, P. G. (2001). The Effect of Self-Selection on Student Performance in Online Courses. Paper presented at International Council for Open and Distance Education (ICDE) Conference. Dusseldorf, Germany, April.

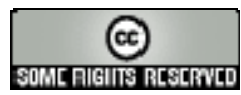




\title{
Role of Delivery, Course Design and Teacher- Student Interaction: Observations of adult distance education and Traditional on-campus education
}

\author{
Om Kumar Harsh \\ University of South Australia \\ Sadiq Sohail, $M$. \\ King Fahd University of Petroleum and Minerals, \\ Saudi Arabia
}

\begin{abstract}
This paper provides readers with an observation of an adult distance education programme, which took place in Malaysia. These observations are presented in terms of: study mode, course design, and interaction between three distinct student groups, and their teachers. Other factors that influence adult distance learning melded with traditional classroom settings were also observed. These factors included the demographics of distance learning students, type and nature of studentto-student and teacher-to-student interaction, students' employment, prior employment, and the subject studied. Our observation suggest that appropriate distance education design, coupled with hybrid opportunities for interaction among students engaged in distance and traditional oncampus modalities, optimise the learning experience of students engaged in both types of learning. Our observations also indicate that factors such as Web-based course design, students' previous technical competencies and employment history, must also be taken into consideration, when designing and delivering distance education programmes of study. The authors conclude from their observations that further research is needed in terms of proper distance education course design that address environmental factors such as students' employment history, previous educational experiences, and comfort levels using information and communications technology.
\end{abstract}

Keywords: adult distance education; distance learning; Web; Web communication; Web course design; teacher-student interaction

\section{Introduction}

Distance education, a pedagogical process that involves imparting knowledge beyond the traditional borders of students' physical attendance in a classroom, has been in existence for centuries. Recent advancements in Internet and communication technology have fuelled the growth of flexible course design and online delivery, giving new impetus to advance distance learning pedagogy. Because of rapid expansions in the global marketplace and the emergence of knowledge based economies, educational institutions around the world are striving to satisfy ever-increasing demand for higher education. However, many publicly funded institutions are 
Harsh \& Sohail - Role of Delivery, Course Design and Teacher-Student Interaction: Observations of adult distance education and Traditional on-campus education

facing severe budget cuts from governments. Faced with funding shortfalls, many educational institutions are looking to new markets and adopting a more market-orientated approach to offset their operational costs. As a result, many institutions are exploring new markets in distant locations to complement their traditional local "markets."

Higher education has now become an arena where universities from around the world compete with each other for "customers." One such means to expand markets is through the provision of distance learning via the use of new information and Internet technologies (Altbach, 1998). A growing number of studies in this area of distance education have researched issues such as the transfer of education and knowledge via distance education modalities from one country to another; and increasingly on how distance education as a concept is being merged with elements of open learning, and multi media delivery (Cookson, Donaldson, and Allan, 1990; Edwards, R., 1997; Jones, O’Shea, and Scanlon,1987).

While distance learning itself is not a new pedagogical concept, in recent years there has been an explosion in the mechanisms and tools available for its implementation and support. Distance learning providers are faced with the often tough choices of sending their staff to the learner, shipping increasing quantities of study and research materials, and investing heavily in audio and video broadcast technologies to support students learning at a distance. In spite of tremendous upfront capital expenditures, broadcast capabilities have now revolutionized the scope and capability of distance learning programmes, creating favourable conditions that ease or remove time and space barriers previously faced by students. For some educational institutions, distance learning has become successfully integrated into their everyday learning environment, using new information technologies supported by the World Wide Web and telecommunication infrastructures.

Recent advancements in computer networking technologies have extend distance learning's scope and capabilities. Computer-based instruction programmes are continuously being upgraded, reused, and revised, allowing students more freedom to learn at a distance at a time and pace that are often convenient to them. With tremendous advancements in network access worldwide and progress in communication and information technologies generally, distance-learning programmes are becoming a viable means of offering educational opportunities to students. To support distance education students, more instructor-to-student and student-to-student interaction - similar to that found in traditional classroom instruction - is being incorporated into online programme materials (Sukumar et al., 2001).

A wider availability of protocols, such as the hypertext environment of the World Wide Web and the network capabilities of video and audio-conferencing, has also increased the application and pedagogical effectiveness of distance-based learning. Combined with lower costs and increasing penetration of personal computers in such everyday life venues as public kiosks, places of work, and the home, distance learning is now poised for explosive growth worldwide.

In the past, adult learning was traditionally restricted to ad-hoc training or education confined to reaching a pre-determined learning outcome, such acquiring a specific skill or competency related to employment. In spite of the growth of technologies that offers increased support for effective distance learning, ad hoc training and education remains the most common application in many countries such as China, where the number of adult distance education learners is estimated to be between two and four million people (Zhang, 2001). Other such examples include the Open University in UK, and extensive programmes in countries such as Norway to South Africa (Wilkes and Burnham, 1991). However, because the majority of adult education initiatives were traditionally designed to teach specific skills and competencies related to work, students and faculty still tend to perceive distance education as "partial training," - and a poor cousin of "oncampus” education. 
Harsh \& Sohail - Role of Delivery, Course Design and Teacher-Student Interaction:

Observations of adult distance education and Traditional on-campus education

Adult education is a substantial field of pedagogical study that spans basic skills upgrading, to vocational training that targets specific adult populations and age groups. Moreover, adult education caters to students who often work full- or part-time and have family obligations. Liveright and Haygood (1969) defined adult education as: "a process whereby persons who no longer attend school on a regular full-time basis . . undertake sequential and organized activities with the conscious intention of bringing about changes in information, knowledge, understanding, or skill, appreciation and attitudes; or for the purpose of identifying or solving personal or community problems." It is our experience, that adults with diverse interests and differentiated backgrounds such as programme developers, teachers, advisors, administrators, educational administrators, frequently undertake educational upgrading using the distance mode. Similarly, business, industry, community agencies, health care organizations, continuing and professional education, often look to adult education modalities to train and upgrade their workforce.

\section{Tools Available for Distance Education}

The 1990s witnessed an explosion in communication and information technology development, followed by waves of information dissemination. Microwave and satellite technologies have significantly allowed the increase the number of television sets around the world, with broadcast signals reaching farther and to more locations, and delivering content at ever decreasing costs. New educational markets previously either non-existent or severely constrained by time and space, are now emerging. As a result, in the past 20 years there has been a significant increase in television-based learning initiatives that "should be more than a passive transmission of academic information” (Cartwright, 1994).

The emergence of two-way communication between learners and their instructors has been a large factor driving the growth of distance education. Video conferencing and two-way video communication technology enables instructors and students to see each other while engaging in classroom studies, a mode considered by many distance educators that greatly enhances adults' distance learning experience. This type of "full presence" learning system is becoming the minimum standard required for distance education programmes (Fuge, 1995). Successful distance education programmes tend to incorporate synchronous and asynchronous interaction among the students, creating conditions that help many intellectual leaps to occur (Sherry, 1996). Videoconferencing technology allows interaction not simply between the learner and the instructor, but also among the learners themselves. In the near future, fibre optic cable networks that increase bandwidth will greatly enhance the overall quality and "richness" of communication and information received by students, helping them to learn more effectively in the distance education mode.

Economic barriers previously associated with higher education both in terms of tuition paid and travel costs have been lowered to such an extent that many students who were previously denied access to education, now have access. For example, students often share the cost of video and Internet connections used, lowering costs related to distance education even further (Zhang, 2001).

Virtual reality is the next breakthrough expected in distance education. Increases in bandwidth allow for greater quantities of digital information to flow across fibre-optic cable and satellite networks, enabling "virtual reality" to evolve into a tool used in mainstream distance learning. Combining virtual reality technology with artificial intelligence will, in turn, enable the creation of a "virtual classroom lecture," further enhancing the experience of students engaged in distance learning.

Fulton, (1992) cites five fundamentals necessary for an effective distance education programme: 
Harsh \& Sohail - Role of Delivery, Course Design and Teacher-Student Interaction: Observations of adult distance education and Traditional on-campus education

1. Contact between the student and the instructor

2. Active learning through writing out answers

3. Timely feedback to the instructor on students' comprehension”

4. Timely feedback to students on work done

5. Opportunity for students to make revisions and learn from their mistakes

However, we believe much has changed since Fulton's 1992 study. Taking into consideration our current perspective of distance education in Malaysia, we would like to add a few more points Fulton's model:

1. Merging interaction between younger distance education students and older adult distance education students

2. Weekly instructor/student meetings

3. Facilitation of interaction between on-campus students and adult distance education students, when and where it makes sense

\section{Some Concerns Surrounding Adult Learning}

\section{Memory}

- Memory in adult students fades when faced with meaningless learning, learning that involves reassessment of old knowledge and rote memorization (Merriam et al., 1991). With age and increased levels of responsibility, adult learners' memories often become fragmented.

- Adult's short-term memory capacity is limited to about five to nine bits of new information at one time (Cruikshank et al., 1995). New information stored in short-term memory erodes with the passage of time. However, when the memory is overloaded, "chunking” information together that into categories enables adult learners to increase their short-term memory capacity (Dixon et al., 1994).

- Young and middle-aged learners, as a general rule, are more self-confident and tend to be goal oriented. Research shows that young and middle-aged learners are often able to memorize facts more easily than older adults. Adults in the middle years (age 35 to 45) have been found to be more responsible, a finding that is in accordance with our present experiment. As older adult students tend to be passive and less flexible (Cross, 1981), reintegration into educational settings must be emphasized. To maximize strengths and minimize weaknesses for the entire group, earning groups will ideally be composed of students of various ages.

In light of previous research, we have developed a course called "Designing Websites" that contain small manageable learning modules. We will discuss in this article how this course design for adults works, and how it facilitates "memorizing" and "learning" for a specific group during student/student or teacher/student(s) interactions. 
Harsh \& Sohail - Role of Delivery, Course Design and Teacher-Student Interaction: Observations of adult distance education and Traditional on-campus education

\section{Motivation}

Houle (1961) separated the motivations of learners into three general typologies:

1. Goal-oriented learners who use education as a means to an ends

2. Activity-oriented learners who participate for the sake of the social interaction

3. Learning-oriented learners who seek knowledge for knowledge’s sake

Continuing education delivered at a distance via new and emerging information and communication technologies, is no longer a novelty but a necessity for working adults. Motivation, therefore, must not only stem from students' necessity to learn, but also from "within." This means conditions must be created whereby students become more eager to learn. Mental eagerness and imagination are directly related to the outcomes of the learning process itself. While learning processes can be created, actual learning outcomes cannot. Thus, student motivation plays a central role in achieving any given educational outcome. With student motivation in mind, we developed a course in which the organization of weekly meetings with students and instructors was fully explored. Our question in designing this course was: How do we motivate our students engaged in distance activities to learn how to learn?

\section{Website Nomenclature}

When designing websites, it is important that students understand website nomenclature. As well, understanding how Internet websites integrate and work together as a "web" is also an important issue (Pool et al., 1997). In designing our course on "Website Design," we were aware that "navigational integration" could possibly create confusion for our adult education students learning at a distance. We thus designed our course with a particular focus on website navigational integration. Recognizing that many students may not be comfortable with such an intensive level of navigational integration, we offered students basic instruction on how to "visit" a corresponding site, if and when the need arose.

\section{Objective of the Study}

Students in Malaysia come from different ethnic, cultural, and educational backgrounds. Students engaged in our course ranged in age from their early twenties to late forties. . Each student also brought to the course their own previous skill levels and expectations. For instance, we found that mature students' expectations varied greatly from those of their younger counterparts, in that they desired and expected to derive immediate benefit from their education. We also observed that mature students tend to prefer to study in areas related to their work, profession, or existing skills. Similarly, the older students' worldview tends to be more practical and hence, they expect to utilize their time for more focused, pre-defined, goal oriented work. Given this scenario, we designed a distance education course that encouraged them to learn. We hope sharing our experiences will create strategies for future research that will help advance adult distance education programming.

\section{Our Experiences}

For our course design, we randomly selected fifteen students. The first group of five students were traditional classroom students; the second group of five students were distance education students, age 20-22 years; the third group of five students were adult distance education students, aged 35 to 45 years. Our aim was to identify positive and negative factors that influenced 
Harsh \& Sohail - Role of Delivery, Course Design and Teacher-Student Interaction: Observations of adult distance education and Traditional on-campus education

learning-outcomes among a diverse range of students engaged in distance and traditional oncampus studies. All three groups were assigned the same project named, "Designing Websites." This topic was chosen because it was thought to be popular and of general interest to all students. Our only entrance requirement for this course was that students in all three groups attend a faceto-face introductory class.

Because this course was the first exposure for some of the students to the technology used and adult learning in general, we felt it necessary to organise a face-to-face introductory class in which all three groups were briefed on housekeeping issues such as the course syllabus, textbook used, teacher's consulting hours and procedures. We also discussed the first project in length and distributed to each student group a handout containing relevant course information such as project completion dates, procedures, minimum technical requirements, and an overview of course study units, etc. Students were also given a handout containing step-by-step instructions on how to surf the web, set-up and access their email account, submit assignments via email, and download software. Lastly, students were also provided a list of resource websites, many of which contained lists of frequently asked questions related to the course. Students from all three groups were then assigned user names and passwords to access the course website where the course materials were made available. Throughout this face-to-face class, students were repeatedly encouraged to contact a member of the teaching team or visit a study lab in the event that they encountered any real or perceived problems. We determined that our introduction session was of sufficient complexity balanced with simplicity, that most students could readily understand what was required of them without too much problem.

To start the project and to facilitate interaction students and their instructors, we created email lists for the separate groups. This tactic also ensured that all members within a group share information with other members of their group.

All course materials required for this project (i.e., lectures, tutorials, programming tools, etc.) were posted on the course website, which were housed on a local server. Students accessed the class website via user names and password assigned during the introductory class. Given the limited scope of our course material, we determined that students needed to hyperlink several corresponding websites to fully understand the concepts behind taught in the course. Late version Hyper Text Markup Language (HTML) and Visual Basic script version software required for completion of this project was also posted on the class website for students to download and use. A complete set of project guidelines, procedures guide, and minimum guidelines for the final website project, was also posted.

During the first two weeks of the course, students from the three groups were taught the basics of HTML and Visual Basic scripts in two traditional face-to-face classes taught on-campus. However, distance education students (group 2, and group 3) engaged only in face-to-face instruction once per week, for a total of two full days of face-to-face instruction for the duration of the course. In sum, distance learners attended two face-to-face classes, as compared to traditional students who attended classes every day for the duration of the three-month course. During the two days spent with students (group 2, and group 3) who would complete the rest of their studies in the distance mode, several more handouts were given outlining the basics of HTML and Visual Basic scripts, etc. Open class discussion also occurred in these two face-toface sessions, where students were encouraged to form bonds and share their concerns and ideas.

\section{Observations}

We observed that students from all three groups submitted their projects on time. Moreover, all three groups completed their projects to a minimally acceptable standard. But when delving into a more detailed comparison, there were marked differences between the three student groups. 
Harsh \& Sohail - Role of Delivery, Course Design and Teacher-Student Interaction:

Observations of adult distance education and Traditional on-campus education

While the traditional classroom students (group 1) performed extremely well on all projects, group two (distance education, aged 20-22) average grades were15 percent lower than group one; and group three students' (distance education, aged 35-45) performance was 18 per cent lower than the first group.

When comparing the three groups using group 1(on-campus) as the benchmark, we observed that many distance education students said they felt less confident because they lacked access to a physical classroom. Another interesting observation was that the older distance education students in group 3 (aged 35 to 45), tended to feel more confident about their studies than the younger distance learners in group 2, (age 20 to 22). We also observed that both student groups, 2 and 3, studying online tended to display more responsible behaviour toward their distance education peers.

Not surprisingly, initiative also appears to play a role in achieving online learning success. In one instance, one student (group 2) did not own computer at home; however this student managed to complete their project by working with another student. Moreover, this same student produced the best work and was awarded the highest grade.

\section{Student-Student Interaction through Communication}

Based on our observations, we believe that a combination of face-to-face and online communication with the students was important for learner success. In our experience, a combination of in-class and online modalities tended to enhance students' confidence and overall learning experience. Student-student interaction not only enhanced confidence levels, it also facilitated the exchange of ideas among students, which is a necessary process of learning. Because individual students had dissimilar perspectives and approached problems from different angles, as a whole, they learned in a more broad and comprehensive manner.

\section{Instructor-Student Communication}

In distance education, communication by instructors was primarily conducted through email and on occasion, by telephone. In our course, when a student posed a question, our response to that question was sent to all three groups. All student-to-student questions were also made available to instructors, so we could share relevant questions with other groups when and where we felt it was appropriate. Our objective in doing such, was to build a learning environment that was, in many respects, similar to that of a physical classroom.

\section{Completion and Outcome of Project}

After the projects were completed and graded, we invited feedback from all three student groups. Our objective was to explore the consequences of our integrated study approach, which we hoped would leverage their learning. We observed the following:

1. Most students tended to like project work, which could be segmented, so that they could fit it more with personal schedules and not loose marks. Distance education students in group 2 (age 20-22), tended to prefer small, more structured learning modules, whereas distance learners in group 3 (age 35 to 45) tended to prefer even smaller learning modules.

2. Many students, including those studying in the distance mode, preferred to tape record in-class lectures on audiocassettes, believing that this would help them to follow instructions more closely. 
Harsh \& Sohail - Role of Delivery, Course Design and Teacher-Student Interaction: Observations of adult distance education and Traditional on-campus education

3. Distance education students previously exposed to information technology (i.e., working with computer at their places of work) were more confident in the use of technology than their peers studying in the distance mode.

\section{Distance Versus On-Campus Education: Our experience}

There were some similarities worth noting between distance students age 20 to 22 years (group 2 ), and adult distance education students age 35 to 45 years (group 3). For students in both groups who were employed in job scenarios related to the course taken, the main concern was how to organize time efficiently and effectively. For students in both groups who were not employed in a job related to the course, concerns focused on "lack of confidence issues," particularly during at the beginning of the course when "everything was so new." Both distance education groups reported that their confidence levels rose as they began participating in the student-to-student and tutor-to-student email consultative processes.

Another point of similarity between both distance groups was that they generally felt confident enough about what they learned, and displayed high levels of confidence when speaking knowledgably about the subject in course presentations.

Although students were encouraged to interact with peers within their group, we discovered that one adult distance education student (group 3), was in constant touch with a traditional oncampus student (group 1). Both students benefited greatly from this cross-modality exchange, as they were able to help each other "learn how to learn." When questioned the adult distance education student (group 3) said she gained more confidence in that the concepts taught became more tangible, whereas the classroom student (group 1) felt that the small, segmented distance learning modules designed were easier to understand.

We observed that distance education students more readily linked their daily job and other activities to their education. This may stem from their tendency to adopt a more practical approach to learning, but we feel it also may be evidence of factors stemming from limited time and memory. This observation can be compared to in-class students, a group that generally more closely adhered to the concepts taught by the teacher.

\section{Adult Distance Education and Wearable Computing}

While it is important for many working adults to update their skills and knowledge via distance education, despite its flexibility, this mode still restricts students' movement as they are often tied to their desk at home or at work. In this context, the age of "wearable computers" such as coming generations of even smaller laptops, web/cellular telephones, etc., are worth discussing. Using such highly portable micro-technology will release people from their desks, and increase their mobility and flexibility in terms of accessing and using of online learning resources whenever and wherever. Students will have total control concerning the time and place that learning will take place. Increased bandwidth, advances in satellite technology, and the use of artificial intelligence will one day greatly enhance the anywhere, anytime learning experience of distance learners.

\section{Conclusion}

To examine the possibility of designing appropriate learning environments that facilitate interaction between distance education students and students engaged in traditional classroom studies, we conclude from our observations that more research is necessary. Two-way interactions between distance and classroom students can greatly enhance the anywhere, anytime learning experience of distance learners. 
Harsh \& Sohail - Role of Delivery, Course Design and Teacher-Student Interaction:

Observations of adult distance education and Traditional on-campus education

From our perspective, the most important outcome of this experience is that we now know how to use our resources more effectively and efficiently - i.e., design of future online training, development of Web-related material, and methods and tactics to facilitate the flow and exchange of appropriate views between and among students and the instructors engaged in different modes of study. Based on our experience in Malaysia, we recommend building bridges between distance and traditional classroom education and conducting weekly meetings to help distance adult education students to learn how to learn.

\section{References}

Altbach, P. (1998). Comparative Higher Education Knowledge: The university and development. London: Ablex Publishing Corporation.

Cartwright, G. P. (1994). Distance learning: A different time, a different place. Change 26(4) 30 -32 .

Cookson, P., Donaldson, J., and Allan, B. (1990). Our education services go to market. Australia Now 14(1) $25-27$.

Cross, P. (1981). Adults as Learners. San Francisco: Jossey-Bass.

Cruikshank, D. R., Bainer, D. L., and Metcalf, K. K. (1995). The Act of Teaching. New York: McGraw-Hill, Inc.

Dixon, N. M. (1994). The Organizational Learning Cycle: How we can learn collectively. London: McGraw-Hill.

Edwards, R. (1997). Changing Places: Flexibility, lifelong learning, and a learning society. New York: Routledge.

Fuge, J. A. (1995). State Distance-learning Networks: More than meets the eye - The Iowa Communications Network: A bad deal for everyone. Rural Telecommunications 14(1) 13 -16 .

Fulton, J. R. (1992). Microcomputers in distance education: applications for extension. Journal of Extension 30(2). Retrieved August 21, 2002 from:

http://www.joe.org/joe/1992summer/a6.html

Houle, C. O. (1961). The Inquiring Mind. Madison, WI.: University of Wisconsin Press.

Jones, A., O'Shea, T., and Scanlon, E. (1987). The Computer Revolution in Education: New technologies in distance education teaching. New York: St. Martins Press.

Liveright, A. A and Haygood, N. (1969). The Exeter Paper. University of Chicago: Center for the study of liberal education for adults.

Merriam, S. B., and Caffarella, R. S. (1991). Learning in Adulthood. San Francisco: Jossey-Bass.

Pool, J. M., Scanlon T., Schroeder W., Snyder C, and DeAngelo T., (1997). Web Site Usability. North Andover, MA.: User Interface Engineering. 
Sherry, L. (1996). Issues in Distance Learning. International Journal of Educational Telecommunications 1(4) 337 - 365.

Sukumar, Parasuraman, S., and Sohail, Sadiq, M, (2001), Impact of Multimedia on Training, Distance and Continuing Education.' International Conference on Millennium Dawn in Training and Continuing Education. 24-26 April 2001. University of Bahrain Conference Proceedings, $207-213$.

Wilkes, C. W., and Burnham, B. R. (1991). Adult Learner Motivations and Electronics Distance Education. The American Journal of Distance Education 5(1), 43 - 50.

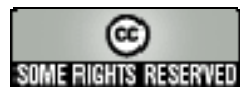




\title{
Research Notes - Vol. 3, No. 2
}

\section{Leadership and Distance Education in Higher Education: A US perspective}

\author{
Sonja A. Irlbeck \\ University of Minnesota
}

\begin{abstract}
The premise of this article is that while in the US understanding is growing about the technologies and strategies needed for effective distance education in an online environment, leadership efforts remain weak. The article describes leadership for distance education, historical perspectives of leading distance education, and how the Internet has directly changed distance education efforts in US higher education institutions. The article concludes with an appraisal of how the approach of higher education leaders must change in order for distance education efforts to be successful.
\end{abstract}

Keywords: change; distance education; higher education; Internet; leaders; leadership; technology; policy

\section{Introduction}

The worlds of work and education are changing, and leaders in today's educational institutions need to determine how to effectively lead in the acquisition, development, and dissemination of information to tomorrow's workers. Leadership is necessary to bring cohesion to the distance education arena within higher education. Drucker (1998) maintained that in the latter part of the last century, technology resulted in a transformation of the social structure. We saw the "rise and fall of the blue-collar worker" (p. 539), the rise of the industrial worker who gave way to the rise of the knowledge worker, a term unknown prior to 1959 (p. 542). These societal and cultural changes meant leaders were challenged to rethink how they encouraged management, workers, and organizations. If as Drucker (1998, p. 551) claimed, "Knowledge has become the key resource," ways need to be found to develop and share knowledge. This is the challenge for higher education transformational leaders.

A transformation is taking place in higher education regarding technology, the Internet and education. This paper investigates some of the leadership aspects of that transformation.

\section{Technology's Influence on Higher Education}

A number of US based commissions, committees and agencies have investigated distance education for twenty-first century learning, including the Council for Higher Education Accreditation (2000) and the Web-Based Education Commission to the President and the Congress (2000). Nearly all studies have addressed technology, policy development, changes to higher education, and learners. Although recent resources are beginning to fill that gap (Bates, 
2000; Hanna, 2000; Lucas, 2000; Shoemaker, 1998), few commissions and agencies have addressed the leadership needed to make this shift possible. "With the increased capabilities of newer generations of distance education technology, postsecondary institutions are being forced to revisit, if not altogether redefine, their missions” (Lewis, Snow, and Farris, 1999, p. 5) and to rethink the leadership needed to make the transition. One report on US distance education policy (Ace Offices of Government Relations, 2000) asserts that technology and distance education are influencing higher education in a way that may not be controlled by previous structures, providers of services, or traditional policies. Different reports refer to the rate of growth in Internet based distance learning (Institute for Higher Education Policy, 2000, p. vii) or the idea that classrooms have been transformed (Web-based Education Commission, 2000, p. 1). These sources acknowledged that the present and future are going to be different from traditional classroom-based education: “... the Internet and WWW profoundly influence society in general and colleges and universities in particular. Not since the 15th century printing press has an 'invention' generated such potential to dramatically change...” (The Institute for Higher Education Policy, 2000, p. 5). Technology-based education is the most recent event to trigger dramatic demographic, economic, and social changes, which is clearly altering teaching and learning relationships in the US. This change is perhaps more significant than those that followed the Morrill Act of 1862, which created land grant colleges, and the G.I. Bill in 1944, that allowed for a large influx of students into higher education (Duning, Van Kekerix, and Zaborowski, 1993, p. 266).

Several studies have investigated the results of distance education by comparing distance education with traditional education (Boling and Robinson, 1999; Kasworm, 1997; Lewis, et al., 1999; Main and Riise, 1995; National Center for Educational Statistics, 1999). However, limited attention was given to administrative aspects of distance learning programs (Chang; 1998; Irlbeck, 2001; Lape and Hart, 1997). Whether distance education is more or less effective than traditional education is no longer a question requiring investigation. The Web-Based Education Commission to the President and the Congress (2000) is one of the most recent panels of experts to issue a call to action regarding distance education in the US. This panel listed the following action points related to effective leadership:

- Make powerful new Internet resources, especially broadband access, widely and equitably available and affordable for all learners

- Provide continuous and relevant training and support for educators and administrators at all levels

- Build a new research framework of how people learn in the Internet age

- Develop high quality online educational content that meets the highest standards of educational excellence

- Revise outdated regulations that impede innovation and replace them with approaches that embrace anytime, anywhere, any place learning

- Protect online learners and ensure their privacy

- Sustain funding - via traditional and new sources - that is adequate to the challenge at hand. Technology is expensive, and web-based learning is no exception. (Web-based Education Commission, 2000, p. iii-iv).

Institutional leadership needs to be exercised in new ways in order to accomplish such action points described above. Hanna (2000) maintains: "There is a critical need for bold leaders who can help shape the changes that are transforming our colleges and universities. . . the task and challenge of leadership and of developing new paths for the future of both traditional and new universities would be daunting” (p. 12 -13). Hanna insists that research is still needed to study characteristics required for distance education programs to grow and be successful in colleges and universities.

Recent statistics show that Internet-based distance education programs are growing exponentially in the US, primarily because of the availability of the Internet (National Center 
for Education Statistics, 1999). The postsecondary online market is currently estimated at US $\$ 1.2$ billion and is expected to grow to US $\$ 7$ billion by 2003. Nearly 710,000 students were enrolled in distributed learning courses in 1998, with an expected 2.2 million students enrolling in 2002. Despite rising enrollments, only 16 percent of students fit the profile of traditional students, those aged 18 to 22 year old, who attend full-time and live on campus (Web-based Education Commission, 2000). Examples of collaboration and implementation of distance education offerings in higher education include expanding partnerships with research universities to form online directories of courses, two- and four-year colleges in various states creating distance-learning consortiums, and grants for course redesigns (Council for Higher Education Accreditation, 2000). These opportunities and changes in the way higher education is implemented require thoughtful and effective leadership. Yet for some, distance education represents a new area of activity. As a result, bold new ways of thinking are being asked of higher education administrators, a group that has generally not previously been asked to respond to innovation.

The US can learn lessons about leadership and distance education from successful international distance education institutions such as the British Open University, Athabasca University Canada's Open University, and Australia's Deakin University. With discussions in American colleges and universities relating to guideline and policy revisions, the trend to form new leadership patterns are becoming apparent. For example, the American Council on Education created a task force on distance learning in 1995-96, whose goal was to create guiding principles that apply to learners, providers of learning, and others who oversee learning quality and effectiveness in formal education programs. This task force identified five categories: 1) learning design; 2) learner support; 3) organizational commitment; 4) learning outcomes; and 5) technology. The Council's call for effective visionary leadership is captured in its principles for organizational commitment: "Distance learning initiatives must be backed by an organizational commitment to quality and effectiveness in all aspects of the learning environment" (American Council on Education, 1996, p. 15).

If US higher education is to maintain its leadership position regarding innovation in education, the time has come for US based leaders in higher education to incorporate viable distance education modalities into its mainstream. This requires leadership. Shoemaker (1998) poses the question: "What kind of person is needed to lead . . . ? There is little education for the management of this field, which brings a peculiar need for the understanding of academic culture and mores, together with a need for excellent modern management skills that encourage creativity, and marketing knowledge and skills. These elements comprise a framework to support pursuit of these challenges, and are needed in order to keep pace with a fast changing market . . ." (p. 2). These are some of the challenges in providing useful higher education opportunities for young students, returning students, mid-career students, and life-long learners.

\section{Leadership in Higher Education}

It will take visionary leaders and brave policy makers, coupled with dedicated instructors and savvy administrators to create new, viable, and acceptable higher education opportunities for all styles and ages of future learners. Leaders in higher education are dealing with ever increasing types of and more rapid change. This section reviews how higher education is shifting from a "convocational model” to a "convergence model," heralding a significant paradigm shift. Green makes the case that driven by new and emerging societal needs for lifelong learning coupled with advances in information technology, more learners are converging to create this paradigm shift. Distance education is integrally intertwined with this paradigm shift toward convergence. Hall (1995) describes this change as a technological revolution that is changing all learning. "Through applications of technology, the traditional university of convocation is about to become the university of convergence" (p. 12). Extending d this thought, Green (March/ April 
1999, p. 15) stated that along with research universities, residential colleges, and commuter institutions, distance education should be viewed as a fourth sector of higher education.

As higher education moves from a convocational model to one of convergence, there will most likely be corresponding changes in leadership in higher education. This transformation of leadership structures both in the US and internationally requires an understanding of the present higher education setting of convocation, issues associated with significant change, and an understanding of how to lead that change.

In the mid 1980s, Bass, who refined transformational leadership theory to its present perspective, observed that modern universities tend to "represent organizations in which transformational leadership is less likely to be seen” (1985, p. 159). However, a model of transformational leadership is needed in the area of distance education within higher education. Bass's view from 1985 has radically changed in recent years. Johnstone, from the Western Interstate Commission on Higher Education, commented that with more attention being given to distance education in colleges and universities, the issue is beginning to reach critical mass in the US (Irlbeck, 2000).

Lucas (2000) focused on the importance of changes that need to occur in US higher education, conceding that while higher education often reacts slowly to change, it has contributed to significant social change in the past as exemplified by the Morrill Act of 1862, and the implementation of the G.I. Bill in 1944. Much has been written about higher education changing from a "faculty-and-teaching model to a student-and learning-centered model" (p. 78) and that "new technologies are leading to major structural changes in the management and organization of teaching..." (p. 216). For people to remain knowledgeable and employable, learning is evolving from a discrete (i.e., four-year) activity to a continual (i.e., lifelong learning) activity. Drucker (1998) described the knowledge worker as the replacement for the blue-collar worker in the US. Knowledge workers need to be more highly educated, interact with a wide variety of people and situations, and require educational updating on a regular basis (p. 10). These requirements challenge traditional degree-granting institutions to think in new ways, and transform their current teaching/learning processes in order to meet the needs and demands of new types of learners.

Rowley, Lujan, and Dolence (1998) claimed that higher education is facing a shift in leadership. Whereas in the past, higher education institutions tended to lead societal development, and serve as centers for study and development, this role is being changed by technology and the information age (p. 16). Higher education needs to rethink issues of student access and the learning environment. These authors argue that institutions are now experiencing a radical shift, converting from institutions that provide strictly a "timeout for learning" model, to a model premised on "perpetual learning" (p. 92). In the future, higher education will be challenged to offer both models of convocation and convergence.

Several authors (American Council on Education, 1996; Bates, 2000; Kovel-Jarboe, 1997; Lape and Hart, 1997) point to categories of needs to be considered by today's higher education leaders. These categories call for higher education leaders to frame policies regarding infrastructures that support technological innovation and distance education. Table 1 summarizes these needs as viewed by four authors. 
Irlbeck- Leadership and Distance Education in Higher Education: A US perspective

Table 1. Comparison of Categories and Authors' Descriptions: Examples of categories cited in literature

\begin{tabular}{|c|c|c|c|c|}
\hline $\begin{array}{l}\text { Leadership } \\
\text { Categories }\end{array}$ & $\begin{array}{l}\text { American } \\
\text { Council on } \\
\text { Education }\end{array}$ & Bates & KovelJarboe & Lape and Hart \\
\hline Planning & $\begin{array}{l}\text { Policies } \\
\text { incorporate } \\
\text { needs of } \\
\text { distance } \\
\text { education }\end{array}$ & $\begin{array}{l}\text { - Leadership, } \\
\text { vision and } \\
\text { planning (New } \\
\text { technology is } \\
\text { accompanied by } \\
\text { major change. } \\
\text { - Management } \\
\text { (Administrative } \\
\text { and academic } \\
\text { policies). }\end{array}$ & $\begin{array}{l}\text { - Quality } \\
\text { Assurance } \\
\text { - Human } \\
\text { Resources }\end{array}$ & $\begin{array}{l}\text { - } \quad \text { Planning } \\
\text { - } \text { to actors leading } \\
\text { distance education } \\
\text { \& technologies; } \\
\text { identify barriers } \\
\text { - Organizational } \\
\text { and instructional } \\
\text { changes }\end{array}$ \\
\hline Implementation & $\begin{array}{l}\text { Overall mission } \\
\text { compatible with } \\
\text { provider }\end{array}$ & $\begin{array}{l}\text { Curriculum (Use of } \\
\text { technology } \\
\text { embedded with } \\
\text { wider strategy for } \\
\text { teaching/ learning) }\end{array}$ & $\begin{array}{l}\text { Governance, } \\
\text { mission, and } \\
\text { programs }\end{array}$ & $\begin{array}{l}\text { - Mission and } \\
\text { policies } \\
\text { - Curriculum } \\
\text { issues; changes in } \\
\text { teaching/learning } \\
\text { strategies }\end{array}$ \\
\hline Resources & $\begin{array}{l}\text { Financial and } \\
\text { administrative } \\
\text { commitment }\end{array}$ & $\begin{array}{l}\text { - Funding } \\
\text { - Technology } \\
\text { Infrastructure } \\
\text { - Faculty support }\end{array}$ & $\begin{array}{l}\text { - Financial } \\
\text { - Infrastructure }\end{array}$ & Costs \\
\hline Support & $\begin{array}{l}\text { Administrative } \\
\text { and support } \\
\text { systems } \\
\text { compatible with } \\
\text { delivery systems }\end{array}$ & & Student Support & \\
\hline
\end{tabular}

As presented by Bates and others, the new visions and educational challenges that will emerge in coming years will change the way we think about and participate in higher education.

\section{A Paradigm Shift in Higher Education}

Bates (2000) referred to Daryl Le Grew, an international distance education advocate from Deakin University, Australia, who described "a paradigm shift" that is currently taking place in higher education. Examples included the transition from an industrial society to an information society, from a once only education to lifelong education. Green (1999) further summarized the issue: “. . .we are witnessing a significant evolutionary event in American higher education. This event is the emergence of distance education and distributed learning . . .” (p. 13). Informed, visionary leadership is necessary to match this change.

An example of such visionary leadership is Western Governors University (WGU), a virtual university that was envisioned and brought to fruition in the mid-1990s as a joint effort of thirteen western US states and the US territory of Guam. Several western states collaborated on this experiment, making it possible for WGU to reach an operational stage in just over three years. WGU enables individuals to remain in their existing work, family, and community roles as they broaden their options for work roles. A concern from state leaders that reinforced this effort was the ongoing loss of young adult workers when they left their home state to gain work-related skills. Rather than duplicating existing opportunities WGU proposed to serve, instead and from its inception in late 1995, WGU envisioned itself more as a conduit to existing distance education opportunities.

The idea that blossomed into Western Governors University began to take shape when a planning document describing vision, goals, and a design plan was presented and accepted. The 
first three degree and certificate programs became available to students in 1998. By offering competency-based degrees, Western Governors University created a niche for itself that enhanced the role of community colleges in the western states and Guam, and provided both leadership and incentives for thinking about new approaches to higher education.

How was this bold initiative accomplished? WGU was a true blending of talents with underlying goal of creating a "global learning community." New educational options and opportunities became potentially available to every community in the western states and territory of the United States. Rapid implementation of this goal was made possible by the dedication, commitment, and leadership by a team of people, coupled with strong and continued support from business, education, and political leaders in the states.

\section{Conclusion}

As technology-enhanced distance education gains greater acceptance, it will gain stature as a distinct entity that represents high quality education, providing opportunities to students no matter where they are located. Tichy (1986, p. 4) wrote: “Transforming an organization also requires a new vision, new frames for thinking about strategy, structure, and people. While some ... can start with a clean slate, transformational leaders must begin with what is already in place.” As they transition from the old leadership paradigm toward a new vision, incorporating newer technologies and creating the structures, policies and other supports for viable distance education programs, this is the role that transformational leaders must play in today's colleges and universities.

The higher education world is changing, and opportunities created by technology coupled with the possibilities of distance education are exciting and intimidating at the same time. These changes call for program directors, department leaders, deans, and faculty to demonstrate transformational leadership. Working together to exercise leadership in discussing, planning and implementing the required changes while, at the same time, focusing on the central importance of students and content delivery, will provide the best that education has to offer.

\section{References}

Ace Offices of Government Relations, P. A., and General Counsel, (2000). Developing a Distance Education Policy for 21st Century Learning. Division of Government and Public Affairs. Retrieved July 5, 2001 from: http://www.acenet.edu/washington/distance_ed/2000/03march/distance_ed.html

American Council on Education. (1996). Guiding Principles for Distance Learning in a Learning Society. Washington, D.C.: American Council on Education, Center for Adult Learning and Educational Credentials.

Bass, B. M. (1985). Leadership and Performance Beyond Expectations. New York: The Free Press.

Bates, A. W. (2000). Managing Technological Change: Strategies for college and university leaders. San Francisco: Jossey-Bass Publishers.

Boling, N. C., and Robinson, D. H. (1999). Individual Study, Interactive Multimedia, or Cooperative Learning: Which Activity Best Supplements Lecture-based Distanceeducation? Journal of Educational Psychology 91(1). 169 - 174. 
Irlbeck-Leadership and Distance Education in Higher Education: A US perspective

Chang, V. (1998). Policy Development for Distance Education (ECO-JC-98-13). Los Angeles, CA: ERIC.

Council for Higher Education Accreditation. (2000). Distance Learning in Higher Education: CHEA Update Number 3. Council for Higher Education Accreditation.

Drucker, P. F. (1998). The Age of Social Transformation. In G. R. Hickman (Ed.) Leading Organizations: Perspectives for a New Era (p. 538-556). Thousand Oaks, CA.: SAGE Publications.

Duning, B. S., Van Kekerix, M. J., and Zaborowski, L. M. (1993). Reaching Learners Through Telecommunications. San Francisco: Jossey-Bass.

Green, K. C. (1999). When Wishes Come True: Colleges and the Convergence of Access, Lifelong Learning, and Technology. Change March/April. 11 - 15.

Hall, J. (1995). The Revolution in Electronic Technology and the Modern University: The Convergence of Means. In Y. Evans and D. Nation (Eds.) Opening Education: Policies and Practices from Open and Distance Education. New York: Routledge.

Hanna, D. E. (2000). Higher Education in an Era of digital Competition: Choices and Challenges. Madison, WI.: Atwood Publishing.

Irlbeck, S. (2000). Interview with Johnson for paper, Dimensions of Leadership in Higher Education Distance Education. St. Paul: unpublished.

Irlbeck, S. A. (2001). Leadership and Distance Education. Educational Doctoral dissertation, University of Minnesota, Minneapolis, MN. unpublished.

Kasworm, C. E. (1997). The Agony and the Ecstasy of Adult Learning: Faculty Learning Computing Technology: What Lessons can we Learn from these Experiences? Paper presented at the Annual Meeting of the American Association for Adult and Continuing Education. ED-416-402: ERIC.

Kovel-Jarboe, P. (1997). From the margin to the mainstream: State-level policy and planning for distance education. New Directions for Community Colleges 99. 23 - 32: JosseyBass Publishers.

Lape, D. H., and Hart, P. K. (1997). Changing the Way we Teach by Changing the College: Leading the way together. New Directions for Community Colleges 99, 15 - 22.

Lewis, L., Snow, K., and Farris, E. (1999). Distance Education at Postsecondary Education Institutions: 1997-98 National Center for Education Statistics (NCES). Washington, D. C.: U. S. Department of Education, Office of Educational Research and Improvement.

Lucas, A. F. (2000). Leading Academic Change: Essential roles for department chairs. San Francisco: Lucas and Associates.

Main, R. G., and Riise, E. (1995). A Study of Interaction in Distance Learning (interim Technical Report AL/HR-TP-1994-0037). Chico, CA.: California State University. 
National Center for Education Statistics (1999). Distance Education at Postsecondary Education Institutions: 1997-98. Washington D. C.: U. S. Department of Education, Office of Educational Research and Improvement.

Rowley, D. J., Lujan, H. D., and Dolence, M. G. (1998). Strategic Choices for the Academy: How demand for lifelong learning will re-create higher education. San Francisco, CA: Jossey-Bass.

Shoemaker, J. C. C. (1998). Leadership in Continuing and Distance Education in Higher Education. Boston, MA.: Allyn and Bacon.

The Institute for Higher Education Policy (1999). What's the Difference? A Review of Contemporary Research on the Effectiveness of Distance Learning in Higher Education. The Institute for Higher Education Policy. Retrieved August 10, 2002 from: http://www.educause.edu/asp/doclib/abstract.asp?ID=CSD1488

Tichy, N. M., and Devanna, M. A. (1986). The Transformational Leader. New York: John Wiley and Sons.

Web-based Education Commission. (2000). The Power of the Internet for Learning: Moving from Promise to Practice. Washington, D. C.: Education Publications Center, U. S. Department of Education.

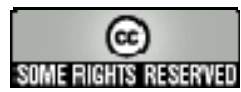


October - 2002

\section{Book Notes - Vol. 3, No. 2}

\section{Educación a Distancia: de la teoría a la práctica}

Author: Aretio, Lorenzo García (2000). Educación a Distancia: de la teoría a la práctica. 329 pages. Barcelona: Ariel. 329 ISBN: 8434426374

Reviewed by: Alejandro Pisanty, Universidad Nacional Autónoma de México

Professor Lorenzo García Aretio's book is a pleasure to read in Spanish. Lorenzo is, among other things, the UNESCO Chair for Distance Education and a superb conversationalist. The joy of hearing his voice is certainly evident when reading this book. His merry, bubbly chat is converted to formal and precise writing, in which paragraphs containing highly condensed theoretical reasoning, or a distillation from years of practice, remains eminently readable.

Lorenzo's book also shows another valuable trace from his conversations. Lorenzo's is permanently engaged in many simultaneous dialogues with distance educators in Spain and Latin America, as well as elsewhere. These conversations accelerate his train of thought, provide him with multiple layers of experience, and are processed into an evolving framework which encompasses the evolution of Spain's Universidad Nacional de Educación a Distancia (UNED) and many of its sister institutions, as well as emerging paradigms such as isolated rural schools or established face-to-face institutions entering the field of distance education.

Arguably the strongest point of the book is found on page 113. After guiding the reader through the conceptual foundations of the field - namely its history, potentials, and theory - Lorenzo concentrates on the mediated dialogue, and provides a detailed list of elements from previously established theories (proposed by Peters, Wedemeyer, Moore, Holmberg, Garrison, Henri, Slavin, and Simonson) from which he builds his own theoretical framework that subsequently serves as pragmatic and usable framework for practice. From Peters' theory of industrialization, Lorenzo points to the need for careful planning in distance education. From Wedemeyer's theory of independence, he explains the value of self-guided student action (not excluding collaborative learning, computer mediated communication [CMC], and institutional control). From Moore's transactional distance theory, he elucidates the importance of dialogue, central to Lorenzo's theoretical proposal and his view of the structure of learning materials. Then he applies Holmberg's views of guided didactic conversation, to discuss synchronous and asynchronous communications. From Garrison he takes the concept of control to illuminate a need for evaluation, assessment, and control itself. From Henri and Slavin and others, he focuses on the value of collaborative learning through CMC. From Simonson he draws on the concept of equivalence of results between distance and other forms of education. Lorenzo then describes the forms of simulated asynchronous dialogue, and real synchronous and asynchronous dialogue, to consider the role of advanced technologies in distance education.

For this reviewer, Lorenzo downplays somewhat the transcendental changes that interactivity and multidirectional dialogues have brought into distance education in the recent years. Since he is personally beyond this transition, it is perhaps not so serious that he does not explicitly recognize an earlier generation of distance educators that have yet to integrate interactivity and peer-to-peer 
communications, typical of the Internet and of videoconferencing, into their text and broadcast approaches prevalent in many areas of the field.

Lorenzo's chapter on tutoring merits special mention because it grows from an organic tradition of tutoring in open education then adapts it gracefully to IT-supported environments. Quoting Sherry, he distinguishes several roles of tutors and focuses on the role of the learning guide. He underscores the need for cordiality, acceptance, honesty, and empathy, and then adds capacity for listening and reading. Quoting Spruce, Lorenzo gives a valuable reminder for tutors: In order to allow students to reflect instead of tutors filling the voids in conversation, "listen to silence."

In discussing tutoring in distance education, Lorenzo emphasizes that even in distance-taught courses, face-to-face tutoring has a specific and important role to play. This may be less so in many countries and educational systems, but all important in institutions like Lorenzo's own, Spain's UNED, which has successfully established a large number of centers across the country where students may go for tutoring and examinations.

One might wish for a more extensive treatment of tutoring through email and Web-based forums. Our experiences in Mexico, for instance, have shown how successful this can be (e.g., our course Estrategia y toma de decisiones en educación a distancia, taught over the Internet in 2001 within the RIFET project of IOHE/COLAM, coordinated by Jorge Martínez-Peniche), as well as the importance of participating tutors to have explicit guidance.

Also, our experience and that of others in many schools demonstrate the value for tutoring and learning of the proper functioning of virtual communities. Although these are subjects in themselves and their construction in educational projects present many challenges, they still merit treatment in a book on distance education. Lorenzo's own forum, CUED-L , shows both the challenges and merits of a virtual-community approach.

For this reviewer, the chapter on tutors, coupled with the chapter "Internet in distance education," provides a sufficient starting point for many individuals who might be considering the creation or expansion of distance education programs. Still it falls short for those who might be seeking more concrete guidance for progress in their projects.

The strength of this book lies in its chapters on learning materials. Emphasis on quality teaching materials will never be enough and Lorenzo provides strong reminders of the need for quality and relevance, and explains the difficulties of costing and planning the development of materials. He also provides readers with a useful and well-reasoned classification of teaching materials.

Those who look to this book to learn how to build online learning projects, or online support for educational projects, will likely need additional guidance. But they will have been provided with a solid basis of understanding regarding the scope and boundaries of their projects.

Another point this reviewer finds weak is the section on selecting the appropriate media for distance education materials. Perhaps this is due to Lorenzo's personal preference or personal history in distance education projects, but for this reviewer this section on selection of appropriate media fell short of my expectations and perhaps of many readers' needs. Although Lorenzo quotes more than 15 authors in the pages dedicated to this subject, he does not quote any of Tony Bates' excellent work on the topic. Thus, the reader is left without contact, in this section, with Bates' ACTIONS model, which in our experience provides extremely useful guidance for putting together distance education projects. We also would have started by emphasizing the "no-silverbullet" approach - i.e., the thesis that the only appropriate technology or medium for distance education is an appropriate combination of technologies and media tailored for each project according to such variables as educational objectives, target audiences, etc. This shortcoming is less pertinent to teachers or tutors in basic functions of distance education, and more so to 
decision makers. However, even the most "rank and file" academics in distance education are often "schools unto themselves," and therefore as project leaders and decision makers they often fulfill whatever execution or operational roles are necessary to write materials, design instructional approaches, program simulations or interfaces, assess learning, etc. Therefore teachers and tutors also need to integrate information and media.

It will be timely now to discuss a few discrepancies, which may be more of approach than of deeper substance. Given our experience in communicating about distance education to non-expert decision makers, whether in government, private enterprise, and even within the educational systems, it is the view of this reviewer that it would have been useful to have a more explicit discussion on the distinctions between open and distance education. "Open" and "distance" are orthogonal coordinates. "Open" is basically a referent for the organization of schools and courses for the contract or compact made between student and school. "Distance" is a referent for the physical relationship of learner and provider (school, teacher, laboratory, library, etc.)

Open courses may have essentially no significant distance component. An example is the Universidad Nacional Autónoma de México’s Sistema Universitaria Abierta, the Open University System, which until recently required that students attend libraries, tutoring sessions, examinations, etc. Another common example lies in videoconference-based courses, which retain such traditional characteristics of schools as syllabi, scheduling, prerequisite courses, etc. Lorenzo's book would be more useful in many contexts if it expanded on these distinctions.

Another point of (lesser) disagreement, is his treatment of videoconferencing. In particular, Lorenzo mentions it mostly in the context of the Internet, where lack of effective bandwidth and processor power still limit its growth. Thanks to the availability of standardized H.323 videoconferencing over IP, properly interfaced to H.320, the emergence of high-bandwidth networks are still very much a work-in-progress, especially for courses or activities where the last mile leads to a desktop. On the other hand, in many countries and regions, H.320 videoconferencing using video classrooms and dedicated or ISDN-switched data links, provides a significant amount of actual distance education content. Such technology also enables skeptical traditional teachers to make the transition to distance education thanks to the small and quite natural step it takes to move from lecturing in a classroom and extending that classroom through videoconferencing.

For teachers who seek to conduct online communication with students and provide study materials over the Internet, this step becomes a natural. In this fashion, teachers are faced with the challenges and opportunities of putting together the contents, materials, media, and practices of sound distance education. This perspective is slighted by Lorenzo, and this reviewer gladly admits that he may be right in doing so.

However, to this reviewer it appears that Lorenzo has embraced the "mediated dialogue" thesis a bit too unconditionally. Although the theory chapters are directed to general practitioners of distance education, readers with a theoretical bent may seek a more in-depth discussion of alternatives. From a different perspective, a reader with a technological bent may approach this book wishing for a more thorough following of the thread of digital convergence. Personally, I believe convergence will probably happen sooner than Lorenzo assumes. Even in developing economies there are platforms already supporting lightweight cyber-café oriented Web pages, together with more heavyweight digital video adaptations of TV-oriented video production. Furthermore, faced with growing pressure from younger students seeking to have hi-tech media at their disposal, we are discovering ways to deal with limitations of low-bandwidth, and scarce and expensive connections to the Internet, even in isolated population centers that have poor communication infrastructure. 
Some readers may also miss a more thorough discussion of digital libraries, learning objects, and other significant supports for distance education. However, there is clearly a limit of what any single book can contain, particularly in a world where even the nature of documents is being discussed in detail and changed continuously. But little more than a hint provided on these subjects was possible. Watching the evolution of these subjects from the platform provided by Lorenzo's book will doubtless be of interest to many.

All in all this is an excellent book. In my view it delivers on the promise made in its subtitle: "From theory to practice." Lorenzo starts by describing theories of distance teaching and learning, listing and ranking them, choosing the strong points of each, and making them bear on practice in a Catholic way.

His approach is no mish-mash. He sticks to the theory of the guided didactic conversation as a leading thread, and progresses to the practicalities of distance education with strong guidance of theoretical principles. And as a stickler of the idea that there's hardly anything of more practical value than a good theory, or, to take a principle from a wildly different time, place, and field, "Ohne Theorie keine Revolution," this reviewer is particularly satisfied with the well rounded, balanced way in which Lorenzo achieves his purpose.

An additional merit to underline is the depth of thought that permeates Lorenzo's book - the grace of its expression and the way all of this is brought together to be of practical value for readers. An excellent choice of literature, quoted in precise and opportune way, complements the values already mentioned. Hopefully a new edition, or maybe an online support provided by volunteers and vetted by Lorenzo, will provide an index, the lack of which is a painful shortcoming in so many Spanish-language publications.

In sum, this book is a reason for distance educators to learn Spanish soon, or to press their favorite publisher to get it translated it into their language. 


\section{Sustaining Distance Education: Integrating learning technologies into the fabric of the enterprise}

Editor: Berge, Zane L.(2001). Sustaining Distance Education: Integrating learning technologies into the fabric of the enterprise. 413 pages, San Francisco, CA: Jossey-Bass. ISBN 0787953318

Reviewed by: David Passmore, The Pennsylvania State University

I am an eager reader of the published works of Zane L. Berge. As director of training systems for the Instructional Systems Development Program at the University of Maryland at Baltimore County, Berge brings a strong intellectual perspective to any discussion of distance education. He has a wide and practical vision of practices in distance education through his extensive consulting experience. Moreover, much of his research and writing does not focus on the desiccated, hair splitting academic disputations in which distance education "theorists" engage frequently. His research and writing in the field of computer-mediated communication gets "down and dirty" with the difficult and often unexamined processes by which technology users collaborate and build community. It is no surprise to me, then, that Berge's work is often so well received by his peers. He is the co-editor (with Deborah Schreiber) of Distance training: How innovative organizations are using technology to maximize learning and meet business objectives, a 1998 Jossey-Bass volume that won The Charles A. Wedemeyer Award.

At least two attributes that are scarce among writers about distance education and training, stand out across the body of work produced by Zane Berge. First, his writing displays an analytical flair manifest in his partiality for organization and classification. Readers of Berge's work usually come away with a wonderfully digestible, boiled down gumbo of kernel phenomena, trends, and practices in distance education and training. In a nascent field of practice such as distance education and training, such taxonomic fervor helps to promote learning and research on unifying and meta-analytic themes. Second, Berge's published works show a talent for application of somewhat stiff, formal, “ from on high" concepts in distance education and training, to the resource-constrained, technologically imperfect world of mere mortals saddled with action plans, PERT charts, and budgets requiring them. Provided are valuable information and insights that are most arguably needed right now, not later when we learn more to design, develop, and deliver distance education and training for our organizations. Berge's writings offer readers as much to improve practice as they provide to advance theoretical structures and understanding. For the most part, Berge's current work, Sustaining Distance Training, embodies these worthy attributes.

Berge's aim in Sustaining Distance Training is "to explore in a more systematic way the question: How do organizations sustain efforts in distance training when their goals call for more than conducting isolated or sporadic distance training events?" (p. xii, emphasis in original). His approach is to offer case studies drawn from for profit enterprises, non-profit organizations, and government agencies. In two introductory chapters, Berge provides an overview of contexts for distance education and training (prevalence, definitions, and training, education, and workplace trends) along with frameworks that, according to Berge: "suggest that there are stages or levels of 
Book Review - Sustaining Distance Education: Integrating learning technologies into the fabric of the enterprise

technological and other capabilities within and organization with regard to technology-enhanced learning and distance education” (p. 13). The 17 chapters that follow contain case studies clustered around three major themes: meeting the challenge of uncommon organizational change; setting competitive standards; and achieving organizational goals. Lastly, Berge follows these case studies with a chapter, "Tools for Change," that provides readers with a roadmap for better integration of distance education and training with the variegated perspectives and cultures exhibited across organizations. For the task-driven reader, Berge's final chapter offers a checklist of ways that instructional designs can link to organizational perspectives.

An appendix to this book, the content of which might not entirely satiate research experts, describes the case study methodology that generated much of the information presented and conclusions proffered in this book. A glossary of distance education, training, and technology terms rounds out the book, along with a detailed and useful index (a feature scarce in many recently published books, but which is maintained so well in most works published by JosseyBass). Personally, I believe that the glossary probably has little use for readers, because my preference as a reader is to have definitions of terms integrated into the text and, in that way, available to me just in time. I do not like to guess whether a term for which I demand clarification might have a definition in a many-page distant glossary. Oh, well, I suppose this is not a serious distraction for many readers. De gustibus non est disputandum.

The first major section of six case studies grouped around the theme "Meeting the Challenge of Uncommon Organizational Change," reveals the tensions created in some organizations to "do something, do anything" to scramble on the bandwagon of distance education and training at the expense of properly managing change so that it does not disrupt orderly progress toward organizational goals. Case studies from such diverse organizational settings as the US military, regional and worldwide telecommunications firms, a company attempting to assist clients to work virtually, and a US government tax collection agency, illustrate how difficult it is to focus distance education and training to serve organizational aims. These case studies also demonstrate solutions to this difficulty, which are as varied as the organizations studies as they are effective.

The second major section of six case studies exemplifies responses generated in the auto, financial service, telecommunications, consulting, and computer manufacturing industries to the task of "Setting Competitive Standards." The case studies in this section help readers reflect on a number of significant planning decisions. For instance, what functions can distance education and training efforts fulfill for organizations? How should organizations plan, organize, and control these efforts? What level and mix of resources are required? What are the attributes and features of quality distance education and training? Are there any benchmarks? And how do answers to such questions about inputs, processes, and products of distance education and training interact with knowledge about the cultures of organizations, the realities of their resource and product markets, indigenous human capital and technological sophistication of organizations, the locations in the organizational life cycle of primary products and services, and preferences and economic bases for sourcing decisions about design, development, and delivery of education and training?

The theme of the third, and final, major section of case studies in Berge's book concerns “Achieving Organizational Goals Using Sustained Distance Training.” The five chapters in this section present cases studies from such diverse sectors as public education, mail and package delivery, online education, and disaster prevention and relief. These cases deal primarily with implementation practices and issues. These case reports will stimulate the reader with interests in how distance education and training contribute to organizational performance, in specifying components of benefits as well as costs of distance education and training for purposes of compiling ROI, and in viewing the roles of distance education and training within CQI and process improvement principles and aims. Taken together, these cases speak clearly to the wisdom of discarding current conceptions of the status of distance education and training efforts in organizations. In fact, so often aspects of the design, development, and delivery of education 
and training in organizations are viewed as though they form projects, not as though they are components of organizational strategy. Berge defines a project, using the Project Management Institute definition, as a "temporary endeavor undertaken to create a unique product or service" (p. 17). One lesson I derive from reading the case reports in this section of the book is that the fruits of investments in distance in education and training might never produce yields without full reconciliation and integration of these investments with the performance goals of organizations.

The reader will learn much from this volume of case studies, as most of the case studies are informative. Moreover, most are accessible in the sense that readers are provided with enough information about the organization studied and about the distinctive factors facing these organizations in the adoption, implementation, and integration of distance education and training. A few of the case studies seem to resemble cautious public relations pieces written in bland prose in which descriptions out weights or analysis. However, the bottom line for Berge's edited volume is that readers will be rewarded with the opportunity to inspect and contemplate actual distance education and training efforts, which occur in diverse organization settings and respond to a wide variety of organizational needs.

In my estimation, however, the crown jewel of this book is the two introductory chapters written by Zane Berge. These two chapters are a "must reads" for managers seeking a quick synopsis of what to expect from distance education and training. These chapters are also ideal for some managers who require a persuasive briefing about the differences between the somewhat older, comfortable view of education and training as simple information transmission and the emerging view of education and training with adult learners as transformative, learner centered, holistic experiences. Many managers can chant mantras about the centrality of education and training for the health of their organizations, but they never might have seen the business case made so well and simply as Berge does in these introductory chapters. Berge wraps all of this up for readers in a package of straightforward, lucid prose. I believe this book is a great investment. It makes me want to hear more from Zane Berge about distance education and training.

Berge believes the audience for his book includes "organizational managers, performance consulting professionals, and practitioners charged with training functions in corporations, nonprofit organizations, and government agencies” (p. xiv). I agree. Berge's introductory chapters provide just the right information necessary to help especially new managers, consultants, and trainers understand the business case for distance education and training. Also, the case studies allow this audience to examine how a variety of organizations have implemented distance education and training, in spite of barriers and difficulties. Another audience identified by Berge are: "students and professionals trying to enter the distance training field... [with applicability to] courses in business management, government training, and college classes...[in fields such as] education” (pp. xiv-xv). However, I feel that this book, as excellent as the case studies are, would more likely end up on a reading list, but not as a primary textbook.

One little sidebar: if you still like readings printed works, and are not yet firm about requiring all of your text to appear on a monitor, you will like the work Jossey-Bass has done with the design of this over 400-page book. The book is large enough to rest comfortably on one's lap. Its pages feature wide margins, readable fonts and point sizes, and enough leading between lines of text to invite easy scanning. Taken as a whole, the book design seems open and inviting. With the advent of all sorts of design layouts emerging from vanity press offerings and self-publishing efforts, I still can recognize a Jossey-Bass book from a distance!
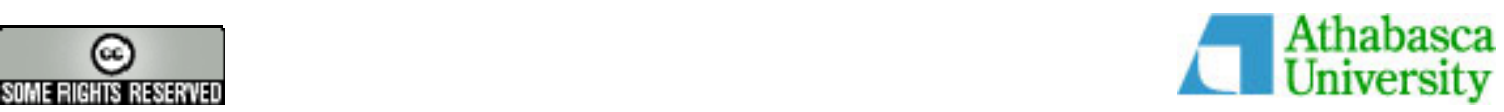
October - 2002

\section{Book Notes - Vol. 3, No. 2}

\section{The Third Shift: Women learning online}

Author: Kramarae, C. (2001). The Third Shift: Women learning online. Washington, DC.: American Association of University Women Educational Foundation. 86 pages, paperback. ISBN: 1879922290

Reviewed by: Barbara Spronk, Senior Consultant, International Extension College, UK

According to numbers cited in the introduction to this fascinating and useful study, in the United States in 2002 more than two million students are expected to enrol in distance learning courses (read 'online courses' - the terms are conflated in this study). Of these millions, the average student is 34 years old, employed part-time, has previous college credit-and is female. Cheris Kramarae calls this "a social phenomenon," and has led the research on which this publication is based in order to document these women's assessments of their experiences and concerns. The hope is that awareness of women's problems and actions required to help overcome them will increase the women's success in online programs.

The term "third shift" is a metaphor that builds on sociologist Arlie Russell Hochschild's use of "second shift" to describe the domestic, family and community work that women come home to when they finish their time at the office or factory. Education, Kramarae explains, is a third shift for many of these women. In this report, women students describe how they grapple individually, often in isolation, with time constraints that hinder them in fitting distance learning into their already packed work and family lives. These women also talk about why they pursue this third shift, how they manage the balance amongst competing demands, and what would make distance learning easier for them.

The report is divided into five parts. Part One is an introduction in which terms are defined, rationales and context for the research are provided, and the methodology is briefly described. In Part Two we learn from study participants why they have taken up online learning, and about their preferences, experiences, and learning styles. These learners reflect on the extent to which online learning is a last resort, and the type of student to whom it is best suited. Part Three deals with the barriers these learners encounter. These barriers - costs, age, time demands, family factors, and accreditation-will come as no surprise to experienced distance educators; nonetheless it is valuable to have them documented once again, this time in the context of online learning. Part Four takes up the issue of whether computer-mediated communication really is the great equalizer that its proponents have claimed. The answer provided by the participants in this study is that clearly no. In their experience, no gender differences in communication patterns, styles and dynamics persist in virtual environments. This section alone, documenting these differences, makes the book worth purchasing. The report closes with a set of conclusions and recommendations. These are useful, but again, they will come as no surprise to experienced distance educators.

The methodology of the research on which the report is based is both its strength and weakness. This is a qualitative rather than quantitative study. I found the reasons the author provides for this approach convincing, but those who hunger for numbers are likely to remain unsatisfied. We 
benefit from hearing the study participants' voices; the report contains a wealth of quotations from their responses to the online questionnaires (carefully designed and tested) that comprised the main research tool. In addition, the researchers wisely included some men in their study population. Unfortunately, the report does not clearly distinguish between comments made by women, and those by men. I assume, rightly or wrongly, that because the study's focus is women, it is the women's voices we are hearing/reading, but I am not certain. Nor is any continuing comparison made of women's and men's experiences. This would have served to highlight the distinctive features of each gender's assessments of their online experience, and made the results more compelling.

The audience for this book is clearly U.S. online educators. The experience documented here and the lessons learned will be of interest and use to online educators elsewhere as well, at least to provoke comparisons with their and their learners' own experience of online learning. This book will have provided a great service if it prompts others to follow the author's lead and conduct, document and publish their own experience.

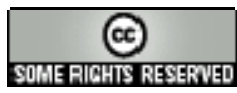


October - 2002

Book Notes - Vol. 3, No. 2

\section{Educuase Leadership Strategy No 1: Preparing your campus for a networked future}

Editor: Luker, Mark A. (2000). Preparing your Campus for a Networked Future: Educuase Leadership Strategy No 1. San Francisco, California: Jossey-Bass Publishers 109 pages, softcover. ISBN 0787947342

Reviewed by: Erin Keough, Open Learning \& Information Network (OLIN), Canada.

This book is part of a series on leadership strategies "designed to help university and college presidents and other top leaders in higher education understand and prepare for the impact of advanced networking on the institutions" (p.xv). It is interesting to review following what some have termed the "nuclear winter" in telecommunications industry, a book related to the networked future that was written, or at least conceived, in 1999, when enthusiasm for how electronic networks would change the world was at its peak. Although these authors, like many of us, might wish to temper the predictions made about the speed at which advanced networking would "break the access, performance and cost barriers that have in the past presented an insurmountable obstacle to the new vision of education"(p.1), much of the information and policy advice in the book has withstood the test of a short but turbulent time.

The book is true to its stated intent in that it takes a high-level, simplified and concise look at a number of issues relating to deploying advanced networks on, and between, university and college campuses. It avoids "techno-speak" and provides simple definitions of terms that senior administrators will be unable to avoid if they are going to make informed decisions in this area. An undauntingly sized book, it is clearly written and may be read in a reasonable period of time.

A group of nine authors with an impressive set of credentials as senior administrators in higher education institutions and advanced networks collaborated on this book. Its eight chapters deal with the history of the development of the educational advanced network in the US, its role in education, some specifics about online libraries, two explanatory case studies, and advice on how administrators can work both within their own institutions and with other agencies to facilitate the growth of networks on and between their campuses.

Chapter 1 provides clear definitions of a number of terms and descriptions of the tools that are commonly used in relation to online learning, including new collaborative applications such as learning management systems and shared learning object repositories. It goes on to describe the enhanced applications and opportunities that an advanced network can facilitate, compared to those accessed by the Internet that we know today. It further highlights social, economic, political, and policy implications that must be addressed if institutions are to fully participate in the networked future.

Chapter 2 selects one of the many aspects of higher education that will be affected by advanced networking, the library, and provides a balanced explanation of the challenges encountered in establishing a "virtual library." It describes the current state of development, or lack thereof, of 
Book Review - Educuase Leadership Strategy No 1: Preparing your campus for a networked future

digital libraries, the issues of converting legacy content to online format, and compares some costs of traditional and online collections and access. It outlines the many policy areas, such as copyright and intellectual property, that influence the development of such libraries, and closes with a brief discussion of the new role of libraries and librarians in a networked environment.

Chapter 3 presents a brief history of the development of the Internet in the US from its beginning 30 years ago as a Department of Defense project, through its stage as the National Science Foundation Network (NSFNet), to its commercial Internet status of today. It goes on to describe development and capability of today's US advanced research and education network - Internet 2. It discusses the issues related to deploying this advanced network among US higher education institutions with significant research mandates, its potential expansion to teaching institutions, links to sister networks globally, and the new layers of interoperable software and networking protocols that will have to be implemented to achieve this internetworking.

Chapter 4 provides a high level view of how to design an advanced network that is suitable for an institution's needs so that it can "maintain its currency and gracefully accommodate future advances” (p. 42). It talks frankly about design challenges and associated costs. It emphasizes the need to use standard building blocks and to plan continuously to assure a snug fit with institutional needs, finance and culture. It also highlights some ongoing, and often overlooked costs of running quality networks including provision of end-user support, retention of highly skilled but highly mobile technical staff, and assurance of network security.

Chapter 5 steps outside the individual campus to describe the roles of regional, national and international networks, pointing out the benefits which occur to campuses that collaborate in deploying and using such networks. The benefits of participation in a national and international network are demonstrated through descriptions of the outputs of prestigious communities of researchers who have utilized advanced networks to collaborate globally and obtain outcomes that would have been otherwise impossible to achieve in a single institution. The chapter argues that economies of scale almost dictate that institutions band together to provide the critical mass required to make networks affordable at a per unit basis, and concludes with a description of a potential role for regional networks in providing access to the broader learning community.

Chapter 6 provides a historical account of the role that the US government played in the development of the commercial Internet through its support of the original research networks. It emphasizes the importance of expanding Internet 2 beyond the some 50 research institutions and universities it currently connects to a much broader group of teaching universities, colleges and schools. It presents a rationale for state and national governments on the importance of a larger participation rate in the US, and an approach to achieve it through a combination of institutional, state and federal government initiatives.

Chapter 7 provides readers with two case studies of how two small baccalaureate-degree granting institutions were able to implement and deploy technology-enriched instructional environments by, among other things, providing all faculty and students with notebook computers and supplying nearly all classrooms with power and network connections at every seat. It discusses the prioritizing of institutional objectives to meet the financial realities of this decision, the change in institutional culture required, and the benefits and challenges both on and off campus of such a dramatic move. The chapter also contains a section on lessons learned by the administrators of these two institutions as they implemented these significant changes.

Chapter 8 offers a short review of primary information and arguments made by the authors in the previous chapters. Also discussed are initiatives that campus leaders can undertake in their institutions and in the broader educational community to encourage the growth of advanced networks in a manner that maximizes the benefits for all learners. 
Drawing upon the extensive experience of the authors rather than literature, rather than an academic book, this is a practitioner's book. It is not a book for network managers, or librarians who already have significant portions of their services online. It is a book for senior educational administrators who were not so long ago professors of philosophy, chemistry, or English. It is a concise and easily read book, that addresses a number of the major policy issues that administrators will most likely face when they move their campuses to a more networked environment.

A reader might also be interested in how other aspects of institutional life might be influenced by advanced networks, e.g., the registrar's office, intellectual property and contractual agreements with faculty, and financial and administration areas, to name but a few. A quick review of the titles of the subsequent volumes in the series indicates that some of these topics might be introduced there.

When reading this book, administrators should realize that it is written from a US perspective. The examples and case studies are exclusively American, as is the discussion about the development, deployment and acceptable use policies of the current advanced network which all relate to Internet 2. Although many countries can trace the roots of the Internet to the US Department of Defense network, the evolutionary path of the growth of advanced research and education differ from country to country. How the sister networks of Internet 2, such as Ca*net 4 in Canada and GEANT in Europe have developed, which types of institutions might participate, and their acceptable use guide lines vary significantly from the US model. In Canada, for instance, a much broader set of institutions may join Ca*net 4. In general, an institution gains access to the advanced network through an ORAN that operates the giga POP. However, administrators in other countries who read this book should bear in mind that although laws, policies, and details of implementation differ from country to country, the underlying principles, policy areas and challenges presented in the book have relevance in many countries.

In conclusion, this book is a reasonable introductory primer to an area into which many are reluctant to tread.

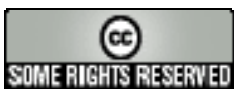


Book Notes - Vol. 3, No. 2

\section{Socio-Economics of Virtual Universities: Experiences from open and distance higher education in Europe}

Editors: Nickolmann, Friedhelm and Ortner, Gerhard E., (1999). Socio-Economics of Virtual Universities: Experiences from open and distance higher education in Europe. Beltz Deutscher Studien Verlag: Weinheim. ISBN 3892718954

Reviewed by: Paul Kirschner, Open University Netherlands

While vacationing in Spain in the summer of 2002, the reading of a book about virtual universities that has a publishing date of 1999 and whose literature almost completely predates 1996 gnaws on my sanity. What am I to write? How am I to judge this book's content?

If I begin on the "topicality" of the content, I can stop immediately. But that will not yield the promised review, so let's do it a different way. I'll begin with the content and with the title itself: Virtual Universities. How do they think up such titles? Isn't virtual reality, a reality that does not exist? Instead, isn't it a combination of interaction between the digital zeroes and ones of my computer (often networked with other computers) and the perceptions of my sensory organs and how they are processed by my brain. The feelings, people, and things that inhabit such virtual worlds don't really exist, except in my own mind. But now a "virtual university?" As I understand from this book, virtual universities really do exist, real people work there (and are paid real money), real students study there, and real diplomas are awarded. Nothing virtual about this! Or is "virtual universities" just a sexy new buzzword to set apart what used to be called correspondence or distance universities from traditional, contiguous universities? If this is the case and the "campus of a VU is globally open, electronically accessible . . . free of real time constrictions ..." (p. 10) then I am again back to my first problem, namely that topicality renders the term "virtual" virtually useless? Most universities are already partially virtual or are rapidly becoming so. So what's a poor vacationer to do?

Room and the demands of the editors of this journal do not permit an in-depth discussion of each of the contributions to this book. Because there are 11 contributions, even a summary review of each would yield too long a review, so I will suffice with a general discussion. Reader, decide for yourself.

The major strength of this book is that each of the individual contributions is generally of outstanding quality in itself. Each chapter warrants - and merits - close reading. At the same time, I do have a major problem with this thorough and well-documented work, namely that each chapter is an essay in itself, and each are not well related to the other chapters. The book is a collection of gems, but together they do not form a piece of jewellery. Two examples can demonstrate this. 
Curran and Föllmer, for example, both present excellent essays on the economic underpinnings of distance education, handling costs, benefits, supply, demand, et cetera. The problem is that while they both profess to be based upon data form 1997, the reader is presented with data that differ sometimes as much as 50-100 percent between the two chapters. And in two other chapters, Medina and Ortner both refer to cost effectiveness and efficiency issues, yet the reader is hard pressed after reading the essays to "find the similarities" in terminology and viewpoint. This disconnect between similarities is compounded by the fact that although Medina begins with a macro and micro-economic discussion of open distance learning, he turns it into an encyclopaedic discussion of costs at all levels and ends with a discussion of quality control.

A second major problem is a grave lack of consistency in terminology among the chapters. I have already discussed a few of these inconsistencies, but the major inconsistency is that open higher education, open distance learning, distance education, virtual higher education, and virtual university are used intermittently and interchangeably as if they are one and the same. A virtual university - if I understand it correctly - is an information and communication technologymediated university. But the fact that a university is ICT-mediated does not necessarily make it "open." And this openness may vary with respect to time and place of study, those who may study there (e.g., students with no prior credentials versus those who have met all specified entrance requirements), and the goals and means of achieving academic program credentials. Which type of "open" these "virtual" institutes of higher education are, is not made clear in this book (and let's not forget that not all higher education is university education!)

One contribution can be singled out, namely Elen, Lowyck and Van den Berg's chapter titled "Virtual University: Will Learning Benefit?” By avoiding the pitfall of defining causal relations between the two, the authors offer a rare and clear discussion of technology and learning. They are rightfully critical and their chapter should be seen as required reading for the current crop of educational managers and their educational snake oil selling guru counterparts in industry and consulting.

Now that my vacation is over and I have finished reading the book and writing this review, I must unfortunately conclude that I still don't know what “virtual universities” are and I still have no clear view of their socio-economics.

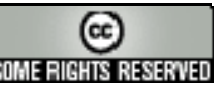




\section{Book Notes - Vol. 3, No. 2}

\section{Delivering Digitally: Managing the transition to the knowledge media}

Editor: Inglis, Alistair , Peter Ling and Vera Joosten (2002). Delivering Digitally: Managing the transition to the knowledge media, 2nd Edition. London: Kogan Page. ISBN: 0749434716

Reviewed by: Terry Anderson, Canada Research Chair in Distance Education, Athabasca University

We know that significant organizational change must have roots both at the top of an organization and "in the trenches" amongst those who must implement the change. In the middle lies a critical group of middle managers, directors and unit coordinators who are charged with defining and implementing both the broad plans and the minute details that create and sustain any change. It is to this later group that the second edition of Delivering Digitally is targeted.

In general, this book succeeds because it adroitly mixes the administrative detail necessary for anyone whose job depends on getting things done and producing results, with a deeper understanding of the culture, tradition and values that uniquely define public university education systems. This second edition of the text adds two features to the 1999 edition. Short cases studies are added to most chapters, which provide a useful, practical context and exemplar of the content covered. The second feature is a list of Web links that seem to add little value - first because the list itself is not organized in any logical fashion, and second because a Web address is not provided, by which I can spare myself the agony of typing in long www addresses.

The book has four sections. The first section overviews the context of digital delivery covering the origins of the Net, the forces driving educational change, and a general introduction to theory and practice of learning in a digital age. Each of these chapters is broad yet detailed enough to provide a good background to the "big picture." I was surprised to see no reference to some of the latest buzzwords such as "learning objects," the "educational semantic Web," and "mobile computing" in the technology chapter, but maybe this is too much currency to ask of a print text!

The second section gets down to business with two great chapters on that topic of most interest to managers - money! These are followed by chapters on the necessary technological infrastructure, staff training and workload issues, and courseware production and learner support services. This infrastructure section concludes with a discussion of ways and means to evaluate innovations using knowledge media. This chapter is informative and covers a great deal of ground, but seems to too quickly focus in on detailed work of formal evaluators and their theoretical perspectives and frameworks, while missing the sense that stakeholders and their unique interests are usually the best (or at least the most important) criteria upon which to base a practical evaluation. The final, rather short chapter, in this section overviews project and change management, providing a nice overview of the critical management issues that can so easily decide the fate of educational innovations. 
Of particular interest is the author's acknowledgement of the two current paradigms that dominate distance education and often confuse students, administrators, and researchers. First are systems that develop independent study packages that maximize student control of time and space. Second are those distance education systems that focus on interactive communications (in either synchronous or asynchronous modalities) between and among teachers and students. The authors note that likely some mix of these two paradigms will be adopted by most institutions, but they skirt the issue of just which type of context is more likely to result in most successful distance education systems. To be fair, they note that: "the approach that is most important in each situation will depend upon an range of factors such as the nature of the subject, the backgrounds of the learners, the outcomes being sought and the context in which the program is being offered” (p. 44). These are nice generalities, but not much of a guideline for busy managers trying to make the single best decision.

The third section contains a single chapter on "quality management." This is a most useful chapter, especially for North Americans who are often far behind Australian and European administrators in detailing the process by which quality is measured, best practices defined, and systematic improvements are made to higher education. The final section - a single chapter very briefly introduces some of the newer technologies of the Web - including three paragraphs on the learning objects I noted missing earlier! Don't buy this book for a look into the crystal ball of emerging technology - but do read it if you want to learn how to better look at, understand and consequently improve your own education system.

All of which to say, this is a useful text that will find a home on the shelf (and reasons for regular retrieval to the desk) of many education managers. For those forced to "do something and do it right” in regard to e-learning, there are few books that offer content that is more thorough, practical and still highly readable.
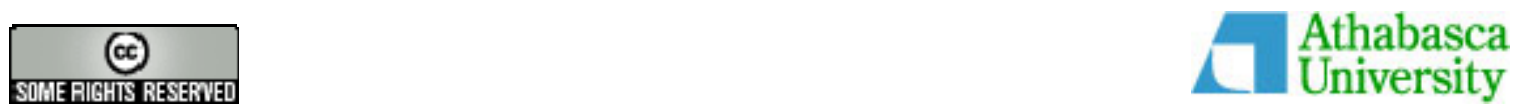
October - 2002

\title{
Technical Evaluation Report
}

\section{International E-learning Specifications}

\author{
Norm Friesen \\ Campus Alberta Repository of Educational Objects (CAREO) \\ Rory McGreal \\ Athabasca University
}

\begin{abstract}
A previous report in this series discussed the classification of online course delivery systems according to the Advanced Distributed Learning Partnerships (ADL), and the international standards accepted by the ADL. The standardisation of courseware in this manner is necessary for the development of inter-institutional course sharing and quality control. The present report gives further definitions of the criteria applied by international standards organisations, and lists the principal specifications/ standards bodies now in operation.
\end{abstract}

\section{Definitions}

The following definitions have been adapted from Webopedia (http://webopedia.internet.com).

Specifications are less evolved than standards and attempt to capture a rough consensus in the user or implementer community. Specifications enable people to get on with the job of system and content development. It can take a long time before specifications are finally approved as standards.

Standards are definitions or formats that have been approved by a recognised standards organisation, or are accepted as de facto standards by the industry. Standards serve a regulatory function and have been created for programming languages, operating systems, data formats, communications protocols, and electrical interfaces.

Application Profile is a simplified and interpreted version of a standard or specification that is created to serve the needs of a particular community of users or implementers. Application profiles can combine elements from more than one specification or standard into a single profile, but should not modify these in such a way that would impact interoperability negatively.

Metadata is data "about data." Like a card or record in a library catalogue, metadata describes a resource (e.g., a book, document, video clip, application), but unlike a library record, metadata can either be embedded in the resource it describes, or be located separately from it. Metadata can be generated either manually or automatically, but is most often structured according to semantically understood elements - access points such as author, title and location. 
Interoperability is the ability of systems or components to work together, without unnecessary human intervention. In the case of metadata, interoperability refers specifically to the ability to exchange information and to process information that has been exchanged. True interoperability would allow users to search and otherwise make use of systems in a seamless manner - despite their location, origin, or internal operation.

$X M L$ is the acronym for Extensible Markup Language, a specification defining syntax for tagging that often looks similar to HTML. But unlike HTML, XML allows developers to create their own custom tags. This makes it possible to label the purpose of particular elements in a document - instead of simply specifying the way these elements might appear in a Web browser, as is the case with HTML. A set of tags or elements created in XML that specify the kind and format of permitted data is known as a DTD (Document Type Definition) or Schema. $\mathrm{XML}$ documents that actually contain this data are known as XML records.

\section{Specifications}

Dublin Core (http://purl.oclc.org/dc/) is named for Dublin, Ohio, not Dublin, Ireland, and has been described as the most broadly based metadata specification. It coexists comfortably with the other metadata sets and is intended to facilitate interoperability between the semantics of metadata specifications. Dublin Core metadata is syntax-independent, and can be encoded in a number of ways - in metatags in the header of an HTML document, in XML documents or in RDF/XML markup. Dublin Core consists of only fifteen optional elements such as Title, Description, Creator, Subject, etc.

IMS (http://imsproject.com), the acronym for Instructional Management Systems, was established by EduCom (now EduCause) in 1994. The mandate of IMS is to serve as a catalyst for the development of instructional software, the creation of an online management infrastructure for learning, the facilitation of collaborative learning activities and certification. Its members include Apple, Cisco, IBM, Industry Canada, Microsoft, Oracle, Sun, and the US Defence Department. The IMS has been developing a number of specifications for the community of e-learning developers: i.e., content packaging, digital repository interoperability, and learning design. Included with these is a metadata specification that both incorporates and extends the Dublin Core. Bindings or encodings are available for IMS metadata in both XML and RDF/XML. Although the IMS metadata schema represents an important activity, the IMS is not just a metadata schema. The IMS is involved in the development of other learning application specifications.

ARIADNE (http://ariadne.unil.ch/), the acronym for The Alliance of Remote Instructional Authoring and Distribution Networks for Europe, has fostered the sharing and reuse of electronic pedagogical material by universities and corporations. It attempted to create a European-wide repository for pedagogical documents called the Knowledge Pool System. It has also acted as a co-author of the IMS metadata structure.

ADL SCORM (http://www.adlnet.org/Scorm/) is the Advanced Distributed Learning Network Sharable Courseware Object Reference Model, supported by the US Department of Defence and the US government. It combines and interprets a number of interrelated technical specifications built upon the work of the AICC, IMS and IEEE to create a unified content model. This model specifies the behaviour and aggregation of modular, interactive learning components, and makes extensive use of XML. Like IMS, SCORM is not simply concerned with metadata, but combines metadata with a number of other specifications that deal with a variety of aspects of learning content and management. 


\section{Standards}

IEEE LTSC LOM (http://ltsc.ieee.org) is the acronym for The Institute for Electrical and Electronics Engineers Learning Technologies Standards Committee, which creates and supports standards and best practices related to the technical aspects of e-learning. The IEEE LTSC is releasing the Learning Object Metadata, referred to as IEEE LTSC LOM P1484.12, as an approved standard. This standard is almost identical to the IMS metadata specification, and is compatible with Dublin Core metadata.

ISO (http://jtc1sc36.org/\#terms_of_reference) is the acronym for the International Standards Organization, a network of the national standards institutes of some 130 countries responsible for coordinating the development of international standards of all sorts. The Information Technology for Learning, Education, and Training Committee of the ISO supports the standardisation of information and communications technologies for learning. This sub-group liases closely with the IEEE LTSC. The standard number being used for educational metadata is IECJTC1 SC36.

\section{Application Profile}

There are other organizations working on metadata that conforms to international metadata specifications. Because the purpose of metadata is to enable interoperability between systems, organisations involved want to conform to emerging metadata standards. For example, the Canadian Core Metadata Application Profile, or CanCore, is an attempt to interpret and simplify the elements of the IMS model.

CanCore (http://www.cancore.ca) is the acronym for The Canadian Core Learning Resource Metadata Application Profile, and is primarily concerned with the vocabularies and semantics associated with IMS metadata elements. Users of the CanCore protocol know that their data will conform to the emerging international standard for educational metadata based on and fully compatible with the IMS Learning Resource Metadata Information Model. CanCore has defined a sub-set of data elements from this IMS model for the purposes of the efficient and uniform description of digital educational resources. It is intended to facilitate the interchange of records describing educational resources and the discovery of these resources. CanCore is at the leading edge in providing both semantic and syntactic guidance to the implementation of the IMS and IEEE Learning Object Metadata specifications.

\section{Related Organisations}

AICC (http://aicc.org/). The Aviation Industry Computer-Based Training Committee created early guidelines and recommendations for online learning systems. It provides guidelines for interoperability using metadata and protocols.

ALIC (http://www.alic.gr.jp/). The Advanced Learning Infrastructure Committee, Japan, works with other international standards bodies for metadata. It facilitates interoperability within Japan and outside.

CEN/ ISSS (http://www.cenorm.be/isss/). The European Committee for Standardization Information Society Standardization System provides for both formal and informal standardisation. This includes guides to best practice as well as full standards. It works by consensus among industry and consumer groups. It covers a broad constituency and is flexible in its methods. 
CSystems RLO/ RIO (http://www.cisco.com/). Re-usable Learning Objects/ Re-usable Information Objects are based on chunked reusable objects that form a complete lesson. The objects incorporate metadata that conforms to the IMS/SCORM specifications.

CLEO (http://www.cleolab.org/) is the acronym for Customized Learning Experiences Online, and is a one year long research collaboration between corporations including Cisco Systems, Click2Learn, IBM Mindspan Solutions, Microsoft, and NETg. Using the ADL SCORM specification, $C L E O$ focuses on applied research on technical and pedagogical issues.

MARBI (http://www.ala.org/alcts/organization/div/marbi/marbi.html), the acronym for The Machine-Readable Bibliographic Information Committee, is the body within the American Library Association responsible for developing official $A L A$ positions on standards for the representation in machine-readable form of bibliographic information. MARBI focuses its attention on the development of the MARC format.

MARC 21 (http://lcweb.loc.gov/marc/). The Machine-Readable Cataloguing record is a library standard for the representation and communication of bibliographic and related information in a machine-readable form. It is comprised three elements: (1) record structure, (2) content designation, and (3) data content of the record. Supported by the Library of Congress Network Development and MARC Standards Office, MARC consists of dozens of metadata elements, yet is generally not considered flexible enough for the cataloguing of Internet resources. Dublin Core is perceived by many as a substitute for MARC in this area of distributed digital resources.

Microsoft LRN (http://www.microsoft.com/elearn/support.asp). The Microsoft Learning Resource Interchange is a specific implementation of the IMS content packaging specification, . 1.0. Microsoft $L R N$ incorporates the IMS metadata and provides a toolkit.

OAI (http://www.openarchives.org/) is the acronym for the Open Archives Initiative, which advances interoperability standards that facilitate the propagation of content, and increases accessibility to intellectual content. Among the most important of the $O A I$ initiatives is the metadata harvesting protocol, a means of systematically sharing metadata records across distributed databases or repositories. The $O A I$ is supported by the Digital Library Federation and the Coalition for Networked Information.

Warwick Framework (http://www.dlib.org/dlib/july96/lagoze/07lagoze.html) has not been widely accepted, but remains significant for metadata generally. Warwick Framework provides a higher-level context for Dublin Core, nesting components or packages of information in containers, thus facilitating interoperability. It allows for the selective manipulation of data.

Z39.50 (http://www.loc.gov/z3950/agency/). The International Standards Maintenance Agency and the Library of Congress Network Development and MARC Standards Office support this information retrieval protocol that facilitates communication among different information systems. Z39.50 allows users to search multiple, heterogeneous databases from a single interface or point of access in real time. It is widely used in libraries and it supports MARC records and other types of metadata.

\section{Learning Object Repositories}

The metadata employed by these repositories may not conform fully to the international standards. They are given here as working examples of learning object repositories.

CAREO (http://www.careo.org) is the acronym for the Campus Alberta Repository of Educational Objects, and has as its primary goal the creation of a searchable Web-based collection of multidisciplinary teaching materials for educators across Alberta and beyond. 
CAREO is a project undertaken jointly by the University of Alberta and the University of Calgary in cooperation with Broadband Enabled Lifelong Learning Environment (BELLE), Canadian Network for the Advancement of Research in Industry and Education (CANARIE), and the University of Calgary Health Education Cluster project.

GEM (http://www.thegateway.org/). The Gateway to Educational Materials is learning object repository housing un-catalogued educational materials. It is supported by a consortium of more than 200 organizations and individuals under the aegis of the US Department of Education and ERIC.

JA-SIG (http://www.mis2.udel.edu/ja-sig/) is the acronym for the Java in Administration Special Interest Group, a collection of interactive online learning materials written in the Java computer language. It was created before the emergence of international specifications in the area of educational metadata.

MERLOT (http://www.merlot.org) is the acronym for the Multimedia Educational Resource for Learning and Online Teaching, a project of the California state university system under the Distributed Learning and Teaching, and Multimedia Repository initiatives. MERLOT houses a collection of high quality interactive online learning materials, many of which have been evaluated by professionals.

TeleCampus Online Course Directory (http://telecampus.edu). The TeleCampus metadata repository has a data structure that conforms to international specifications. It consists of Web links to more than 55,000 courses, modules, and lessons in over 30 countries. Note that it houses only the metadata and not the actual lessons, modules, and courses. It links to the institutions that own them.

Edutella (http://edutella.jxta.org/servlets/ProjectHome) is a peer-to-peer exchange network for metadata. Edutella is based on the well-known GNUtella open source application, and its development is supported by the Wallenberg Global Learning Network, a partnership of organisations in Sweden and Germany.

EML (http://eml.ou.nl/introduction/) is the acronym for the Educational Modelling Language, a system for codifying pedagogical experiences created by the Open University of the Netherlands in partnership with CISCO. It defines a document type in XML that allows for the modelling of units of study in terms of roles, relations, interactions, and activities.

PALO (http://sensei.lsi.uned.es/palo/) is a Spanish initiative similar to EML. It is expressed in $\mathrm{XML}$ and has different levels for content, activities, structure, sequencing and management.

This series of software evaluation reports will continue with reviews of other online collaborative tools.

N.B. Owing to the speed with which Web addresses are changed, the online references cited in this report may be outdated. They can be checked at the Athabasca University software evaluation site: http://cde.athabascau.ca/softeval/. Italicised product names in this report are assumed to be registered trademarks.

JPB. Technical Notes, Series Editor 
October - 2002

\title{
Technical Evaluation Report
}

\section{Online Polling Services}

Jon Baggaley, Tom Kane, and Bill Wade

Masters in Distance Education Programme

Athabasca University - Canada's Open University

\begin{abstract}
Real-time collection of student opinions and their instant feedback can be useful in guiding the design and implementation of online educational sessions. Students can gain insights into each others' attitudes and opinions, often anonymously and confidentially; and teachers can adapt to the feedback in directing the progress of a session based on, in effect, a series of "if then" contingency measures. Online tabular and diagrammatic features can provide useful visual summaries of polling results, indicating whether or not the session's learning outcomes are being achieved. Online polling services available differ greatly in the extent to which they provide these useful educational features. To guide distance educators in their selection and implementation of online polling and quizzing procedures, an evaluation study was conducted featuring a selection of the poll creation systems that were available at the time of study.
\end{abstract}

All questionnaire, quizzing, survey, and assessment products/ services are referred to generically in the report as "polling systems."

\section{Evaluation Criteria}

In the interests of open distance education access, the study was restricted to those websites and services that are free of charge, or have no payment versions. Inevitably, the use of cost-free services is accompanied by certain non-financial costs (e.g., exposure to advertising, and access to the stored data), each of which represents an important criterion in an educational product evaluation. Most services examined in this study do not allow the user to download the data at all, or only make such data available for a short period of time. These are important factors for online educators to consider in the selection of a polling methodology, since ready and continual access to polling data is essential to the right of teachers and students to own the data they generate.

With these issues in mind, the evaluation team developed a 20-point set of product rating criteria for the evaluation of polling systems and services. They include:

- Cost: including tolerance of advertising, and need to supply user data for registration

- $\quad$ Ease of use: complexity of installation, help, and usage functions, etc.

- Designer control: Does the poll creator have wording and formatting control?

- Question range: e.g., multiple-choice, open-ended, and repeated questioning options 
- Delivery of Results: e.g., instantaneity of feedback, and amount of statistical detail

- Data storage: where are questions and responses stored, and who owns them?

The full list of criteria is presented at the evaluation Web site accompanying these reports.

\section{Trials of Free Online Services}

1) AdvancedSurvey fulfils most of the educational user's online polling needs. It generates multiple-choice, multiple-response, and textual responses to questions. The poll designer can decide whether to permit or forbid multiple attempts to answer the survey, and whether or not the respondent will receive feedback of results. The service's step-by-step procedures are well described, although the definition of question type might be more conveniently presented as a primary design function rather than as a follow-up to the definition of response types. The service site allows the poll designer to download results, albeit without a great deal of analysis. The user has no control over the formats of polling results. Occasional problems in accessing the AdvancedSurvey online server were noted.

2) CGISpy. This site is a storehouse of server-side polling scripts and HTML form-creation kits. To those with the necessary technical and programming skills, these are useful poll creation tools. A significant drawback of CGISpy is that the one polling format available at the time of our study involves a single multiple-choice question only.

3) Dream Tools provides sleek presentation formats, though has the same drawback as CGISpy i.e., the ability to generate only one multiple choice question per study, which is a major drawback for educational users of polling techniques.

4) Freedback is also a polling form-creation procedure for use by those with Web programming skills. The Freedback Web site takes the poll creator through a series of clearly defined steps using the form builder tool. This generates HTML code that users can paste into their own Web page source code. Freedback supports the use of radio buttons, response check boxes, dropdown menus, text formats, and open-ended comments. As a result, the user is able to design a wide range of polls, with the responses sent immediately to the creator by email. Pedagogically, Freedback increases opportunities for asynchronous, one-way interaction (student to instructor), although the individual email feedback procedure prevents participants in an educational session from reacting instantly to collated poll results.

5) Misterpoll is an easy to use and reliable online application that allows a poll's creator to decide whether it should be public (i.e., listed in the service's main polls directory) or private (i.e., the designer provides participants with an exclusive link to the poll). Misterpoll provides the option of immediate or delayed feedback, permits multiple questions of several different types, and allows voters to comment on the poll itself. An instructor can create a series of individual or multi-question polls for integration into an online synchronous or asynchronous conference. Questions must be created in advance, and cannot be re-worded or re-sequenced thereafter. This makes it difficult for users to present questions spontaneously.

6) QuizCenter originated at the University of Hawaii's Community College at Maui, and is now operated by Discovery.com. QuizCenter's primary goal is to help teachers with student assessments, to which end it sends the data collected to the teacher, while retaining the questions on the QuizCenter server. The service permits a wide variety of question types (e.g., multiplechoice, multiple-answer, text/ essay, short-answer). QuizCenter is easy to use, though provides limited feedback regarding performance percentages rather than more precise feedback of polling results. 
7) Quiz Master is a well designed question design tool intended to generate print based exams from a database of questions using the Question Bank Editor. Its useful features include multiple question types, random question selection, answer shuffling, and an Export as HTML feature facilitating distribution of the exam online. An additional Export as Text feature would be useful, permitting the instructor to receive a copy of the exam by email. Use of the software involves a moderate learning curve, though novice users can master the question development and exam generation processes by using the help menu. The software provides support for graphic, video, and audio files (including wav and midi formats), though does not permit the printing of embedded graphics, a function often useful in poll development.

8) Zoomerang is a student assessment tool for use by teachers. It has free and limited versions, as well as a commercial one priced at the time of study at \$599 US. Zoomerang is easy to use and provides a wide range of question types. It provides polling feedback involving basic calculations (number of respondents, total of answers, percentages, etc.). The poll designer can place a link to Zoomerang poll results on a course website, or can use the Zpro emailer tool. A limitation to the service's educational use is the availability of question and response data in online formats only. The Zoomerang Web site states that the poll designer (member) owns the polling questions and answers. However, these data are stored exclusively on the service site for ten days only, and cannot be downloaded. The service also offers access to user mailing lists, which may cause some concern to users wishing to protect their privacy.

\section{Conclusions}

Efficient use of online polling methods can help distance educators and their students to monitor and improve their online interactions. Polling methods engage participants actively during an online discussion, increasing their active learning and improving student-teacher interaction. Most online poll creation services provide clear, step-by-step guidance during poll creation. However, the selection of an appropriate service for educational use must be made with care. A major consideration is the privacy and ownership of the question and response data. With the exception of CGISpy, which provides polling scripts rather than generating actual polling data, all of the Web sites examined in this study store the data at an external service site, and some prevent them from being downloaded. It is recommended that prospective users of an online polling service should read its User Agreement with care, and should only select it if the data ownership conditions are clearly described. There is a clear need for the development of educational polling services that address the specific design needs and rights of educational users.

The next report in this series will compare online video-conferencing products.

N.B. Owing to the speed with which Web addresses are changed, the online references cited in this report may be outdated. They can be checked at the Athabasca University software evaluation site: http://cde.athabascau.ca/softeval/. Italicised product names in this report are assumed to be registered trademarks.

JPB. Technical Notes, Series Editor

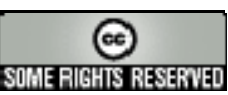


October - 2002

\title{
Technical Evaluation Report
}

\section{Online Videoconferencing Products}

\author{
Pam Craven, Brian Keppy, and Jon Baggaley \\ Masters of Distance Education Programme \\ Athabasca University
}

\begin{abstract}
This is the first in Athabasca University's series of evaluation reports to feature online webcam and videoconferencing products. While webcam software generates a simple visual presentation from a live online camera, videoconferencing products contain a wider range of interactive features serving multi-point interactions between participants. In many online situations, the addition of video images to a live presentation can add substantially to its educational effectiveness. Ten products/ online services are reviewed, supporting a wide range of video-based activities.
\end{abstract}

\section{Evaluation Criteria}

Video-based communication routines are rarely provided in isolation of other online collaborative methods, and most conferencing products reviewed in this study are, in fact, integrated products containing other features. For example, all are audio products that also feature video components. They have been chosen for this cross product comparison, not having been featured in earlier integrated product reviews in the current series. The quality of interactions provided by these products and the different configurations they allow, were evaluated in two user interactions each lasting a minimum of one continuous hour.

The evaluation criteria applied in the study were based on those developed for the comparison of audio-conferencing packages earlier in this report series, with the addition of definitions relating to the products' video components. The new criteria were:

- Clarity: based on pixelation, using a 5 point scale: 1 = barely visible, 3 = standard, and 5 $=$ digital video quality.

- Synchronisation: similar to audio delay, but based on video as well as audio, using a 5point scale: 1 = major delay in video ( $2+$ seconds), 3 = acceptable minor delay, and $5=$ TV quality.

- Screen Size Scalable: refers to the ability to increase or decrease the screen size, and on the effects of this adjustment on performance and clarity.

The full list of criteria is presented at the evaluation website accompanying these reports. 


\section{Trials of Software Products}

1) ClicktoMeet is a server-based conferencing product, which is the outcome of a recent merger between CuseeMe Networks and First Virtual Communications. Though primarily aimed at corporate users, ClicktoMeet contains numerous educationally useful features, including highquality multi-point audio/ videoconferencing with customisable displays, file and whiteboardsharing, and co-browsing (the ability for participants to lead one another on Web tours). At present the product's use is restricted to the Internet Explorer browser, and does not support Macintosh platforms.

2) CometCam is a free software product that is easy to install and learn. It provides high-quality two-way audio and videoconferencing, and private chat rooms with video and text. The names of online contact are indicated, and communication may take place with more than one contact simultaneously. Problems were experienced in our tests with the hands free audio transmission mode, and with audio lag times.

3) Dwyco is advanced software for Windows platforms. It allows users to send and receive real time video, audio, and text. The software is flexible and works equally well as a video chat tool and a video broadcast server. It provides private rooms, each with password protection. Inconsistencies were experienced in the current tests regarding the quality of audio and the speed of text message delivery. Technical support for the product is limited.

4) Eyeball Chat is a free, integrated software package permitting live video chat, sharing of video messages, and transfer of graphic and audio files. Eyeball Chat provides reliable video quality, integrated chat rooms with privacy settings, and is compatible with the AIM, MSN and Yahoo Messenger tools. It provides an easy method for contacting others, and indicates whether or not contacts are online. In our tests, the audio was occasionally fuzzy, and lag periods of several seconds were experienced.

5) FocusFocus is a free, browser based, video-telephone software, providing multi-point video/ audio connectivity and chat services. Private chat rooms are available for use by up to 25 people. FocusFocus includes a simple procedure for the resolution of audio and video problems, though these did not prevent audio delays and interference noises from occurring during the evaluation.

\section{Trials of Online Services}

6) ChatTown is a free website service providing email, webpage hosting, text, and video chat rooms. ChatTown appears to support an active online community, providing users with links to current news, weather, and special interest topics. ChatTown has a marked commercial image.

7) EarthCamTV is a free website that allows users to broadcast and receive live video images. Registered users receive a unique channel within the EarthCamTV system, which permits one-onone chats.

8) Video Connection is a free website similar to the previous two websites. Video Connection provides real time text and video chats with screen shots and fast video refresh rates.

9) WebCam is an online resource for webcam users. WebCam's hosting services use a proprietary proxy server, allowing the user to present live, reality type content on their webpages: e.g., video of traffic conditions, day care facilities, and transmissions from content providers such as radio and television stations and corporations. Fees are payable per channel, on a per minute or month basis. 
10) WebCamNow is an interactive video network supporting live Webcam presentations, video chat, and the ability to link to a webpage. A maximum video rate of six frames per minute is provided, with a refresh rate of 60 frames per minute. WebCamNow is more appropriate for oneon-one communication than for multi-point conferencing. It has limited integration with other educationally useful tools (e.g., file-sharing).

\section{Conclusions}

Currently, high quality online Webcam and videoconferencing products come at a price. Problems in video and audio transmissions reliability were encountered with all of the free products tested in this study. Even more costly server-based software such as ClicktoMeet can yield problems such as audio lag when used on low speed dial-up connections. As many distance education students around the world do not have access to high speed Internet connections, distance educators should apply online videoconferencing methods cautiously in their teaching at this stage, pending the availability of products that cater to all types of student connection equally. For general educational conferencing purposes, teachers should examine whether a video component is really necessary. In many of our tests, it proved more convenient to turn the video component off to increase the efficiency of the audio interaction (some students prefer to do this anyway in order to protect their privacy). In conferencing sessions where video demonstrations are essential, it is important to note that online products can give adequate quality without the need to invest in expensive telephone-based video systems.

The next report in this series will compare synchronous chat and instant-messaging tools.

N.B. Owing to the speed with which Web addresses are changed, the online references cited in this report may be outdated. They can be checked at the Athabasca University software evaluation site: http://cde.athabascau.ca/softeval/. Italicised product names in this report are assumed to be registered trademarks.

JPB. Technical Notes, Series Editor

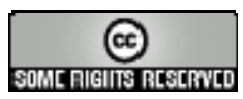




\title{
Technical Evaluation Report
}

\section{Chat and Instant Messaging Systems (synchronous): Report 2/ 3}

\author{
Ellen Kinsel, Merv Roy, Hartley Waldman, \\ Donna (M. M.) Woloschuk, and Patrick J. Fahy \\ Masters of Distance Education Programme \\ Athabasca University - Canada's Open University
}

\begin{abstract}
This study extends the earlier review of online chat systems (Report 6), by reviewing a further seven products that provide text-based instant messaging (IM). The functionality of these products in distance education contexts is stressed in relation to their comparative costs, complexity, control, clarity, technical framework, and other functional options.
\end{abstract}

\section{Evaluation Criteria}

Instant messaging (IM) is a method of synchronous communication that is rapidly developing from being a means of entertainment for computer users and romance seekers to a legitimate method of remote communication in business and distance education (DE). Because bandwidth and the costs of appropriate hardware for voice and video communication still represent barriers for many DE users, text messaging remains a useful method of computer based synchronous communication. As IM gains in popularity as a DE tool, it is important to establish evaluation criteria for the variety of available IM applications. The criteria applied in this study were divided into two groups:

1) Basic features useful in DE, including:

- Ease of installation and availability of product support

- Speed of download on a high speed connection

- Technical competence required to use the product

- Administrative options (e.g., ability to screen users and ignore unwanted invitations; create a private chat room; locate other users; archive instant messaging conversations)

- Status indicators regarding personal and other users' availability

- Overall chat window readability

2) Useful features not essential in DE, including:

- Participants' ability to update their personal profiles; accept chat from contacts not on a personal address list; send and receive files

- Support for webcam co-browsing, and online audio activities

- Availability of audio and other alerting signals

- Interoperability with other multiple IM services 


\section{Trials of Free Products}

1) AOL Messenger (AOL-IM) is the latest version of this popular product, which provides a full set of IM features useful to the DE student and teacher. Its interface has a simple but professional look that provides a variety of personal customisation features such as audio and text alerts, virus checking on file transfer, privacy options, status indicator, mail notification, formatting and visual display options. Drawbacks are that the product is proprietary and lacks interoperability, thus preventing users from receiving messages from contacts who use other popular IM tools. This shortcoming obliges users to persuade their contacts to adopt the $A O L-I M$ product also.

2) Jabber has a similar look and feel to AOL-IM. Jabber is available in a light Web-based version which does not require the program to be installed on users' computer; and offers a range of personal customisation features and interoperability with other IM applications including MSN Messenger and ICQ. Jabber lacks some of the formatting features provided by AOL-IM (e.g., emoticons, icon tools for links, images and email support).

3) MSN Messenger is an IM program that provides notification when contacts are online. In the latest version, messages can be sent and chat initiated with up to four contacts simultaneously. The product provides adequate text messaging and file-transfer options. It features large, easily recognised icons and menus that simplify tasks such as the addition of contacts to address lists. As with AOL-IM, buddies can be organised into groups, and moved or copied from one group to another by a simple drag-and-drop method. Because contact lists are stored on the MSN servers, they are accessible from any Messenger-equipped computer. Unfortunately, the full contact list is permanently displayed and this can be annoying if the list is lengthy. Users cannot make themselves invisible or limit file-transfer capabilities to specific contacts. However, they can block all contacts from seeing that they are online. They can also provide a list of others who have added them to their contact lists, and can require others to obtain permission before doing so. The product requires more memory than other products tested in this study, and lacks interoperability with other IM products.

4) Odigo includes basic chat and IM features without the simple look and feel ideal for DE users. Participants interact through a 3-D interface with features including personalised icons (avatars) representing simultaneous contacts. The application's useful features include message-filtering options aimed at locating chat partners with similar interests, and co-browsing (Web tours), which enable users to chat and browse on the Web without having to move between separate browser windows.

5) Trillian is a "one fits many" package that allows users to connect with a range of messaging clients, including IRC, AIM, ICQ, MSN, and Yahoo, through a single interface display. Trillian eliminates the need to run multiple IM clients in order to stay in touch with the users of different IM services. Trillian provides access to features available in those other services, and it reduces the amount of hard-disk space required to run multiple IM applications. Contact lists from the different services are dynamically updated. Set-up wizards guide the user through the creation of user names and passwords for the different services available. The look-and-feel of the Trillian interface can be customised by the use of downloadable formats (skins). The package permits multiple user profiles, so that users who share a single computer can each establish an individual IM account via the same client software. Multi-party chat is only available among MSN Messenger users, and there are no audio/ video enhancements or free chat-room features. Trillian runs satisfactorily over low bandwidth, and supports the Windows environment only. Frequent updates are required, though an auto-update feature eases the downloading and installation of the latest software patches. 


\section{Trials of Priced, Integrated Products}

6) Elluminate (vClass). Formerly called TutorsEdge, this is a well-integrated product providing synchronous text messaging, audio, polling, and whiteboard features via multi-point connections. Elluminate (vClass) is not cost free, though it is easy to install and use. Classroom meetings have to be organised in advance and passwords issued to participants for access. This makes Elluminate (vClass) better suited to instructor controlled presentations and discussions than to student initiated interactions. Instructors assign rights to the participants in each meeting, and can allow others to take over an instructor capacity once online. Slide presentations can be loaded for use in a session, and participants can be permitted to browse through the slides independently or at the instructor's pace. In one of our test sessions, involving six websites and over 20 participants, slides were delivered relatively quickly to users with low-bandwidth connections. Elluminate (vClass) permits public and private text messaging, but participants should note that users with chat room administrative privileges (e.g., the instructor) have access to both types of message. The product runs satisfactorily on slow dial-up connections using client processors with speeds from $250 \mathrm{MHz}$ upwards. Download and installation of the large software file is time consuming, lasting approximately 20 minutes on a local area network (LAN) connection via a $56 \mathrm{~K}$ router connection.

7) PictureTalk provides, at a financial cost, a Web-based technology for live, desktop screen casts across the Internet and corporate networks to an unlimited number of session participants. Synchronous text messaging is just one component of the package, which also includes synchronous text chatting, file and application sharing, audio, a whiteboard, live screen capture, transfer of desktop control, and the ability to conduct spontaneous meetings without an organiser (i.e., instructor). Participants can send text messages to the presenter and other participants, either privately or in the group at large. The complexity of PictureTalk is both an asset and a liability. It has a relatively steep learning curve, which is worth considering if application sharing between a number of participants is a priority. The product supports a seamless cross-platform environment (PC, Macintosh and Unix); and its services can be hosted externally or through licensed server software. A performance optimiser allows presenters to choose between display quality and speed, thereby allowing all participants to benefit regardless of their bandwidth or platform.

\section{Conclusions}

Of the seven products reviewed, the most unique features are provided by Trillian. This product provides efficient no frills, synchronous text messaging, as well as integration with other IM tools. Trillian is also available at no cost. Users can install Trillian more speedily than many of the other products compared in the current study. All of the products tested have advantages and disadvantages, and the prospective user should examine these before selecting a product for particular educational purposes. Most products use variations of the standard IM interface, and are intuitive and visually uncluttered. Odigo, on the other hand, places a greater emphasis on graphic appeal than on text messaging efficiency, and its relative visual clutter causes it to be less intuitive than the other products, and more appropriate for online gaming than for educational uses.

$A O L-I M$ has a convenient chat screen, though Jabber has higher interoperability on different user platforms. As IM technologies mature, interoperability will prove essential to the emergence of common cross platform standards. If audio communication is required as well as text messaging, MSN Messenger offers efficient two-way voice conferencing via a simple interface. It also provides instant text messaging between up to four individuals, though requires all participants to use the MSN application. PictureTalk can be used with a greater number of participants at relatively low cost, with a wide range of features. Elluminate is easy to learn and requires lower bandwidth, though is relatively costly and designed for teacher controlled communication. These factors reduce its usefulness as a spontaneous, collaborative tool for student use. If the use of no 
cost tools is a priority, a combination of MSN Messenger and Trillian is recommended, providing optimal functionality for DE students as well as teachers.

The next report in this series will examine a further set of synchronous chat and instantmessaging tools.

N.B. Owing to the speed with which Web addresses are changed, the online references cited in this report may be outdated. They can be checked at the Athabasca University software evaluation site: http://cde.athabascau.ca/softeval/. Italicised product names in this report are assumed to be registered trademarks.

JPB. Technical Notes, Series Editor

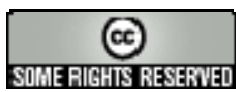




\title{
Technical Evaluation Report
}

\section{Chat and Instant Messaging Systems (synchronous): Report 3/ 3}

\author{
Brian Ludwig, Krista Poscente, \\ Jon Baggaley, and Patrick J. Fahy \\ Masters of Distance Education Programme \\ Athabasca University - Canada's Open University
}

\begin{abstract}
[Previous reviews of chat and IM systems are presented in $\underline{\text { Report } 6}$ and $\underline{\text { Report } 14}$ in this series.]

A further set of four text-based instant messaging (IM) products was evaluated: AT\&T Anywhere, Parachat, Sonork, and Yahoo Messenger, all available at no cost. Yahoo Messenger was judged to be the most effective of the three products for use by distance education (DE) teachers and students, being compatible with most common operating systems and accommodating up to 50 chat room participants. Yahoo Messenger also possesses integrated audio and video capabilities. AT\&T Anywhere is an efficient product, which supports Windows-based operating systems only. Parachat (Basic version) is a basic, browser accessed chat board without instant messaging (IM) capabilities.
\end{abstract}

\section{Evaluation Procedure}

The three synchronous text-based products tested in this study offer the typical assortment of educationally useful tools, including: text-based chat communications; direct text messaging; private messaging; the ability to create chat rooms for multi-way conferencing; identification of participants; status indicators; alerts upon receiving new messages; an option to include or block users; automatic acknowledgement when users log on/ off; and cut and paste text methods. AT\&T Anywhere, Sonork, and Yahoo Messenger each require a software download, and are installed as client software. The three products were each tested in repeated communications between two or more participants, running continuously on their computers for a period of five days. Parachat operates through a webpage, and one was designed specifically for this test, linking to a dedicated room on the product's public server. Evaluation criteria were consistent with those used in comparable evaluations earlier in this series. Every adjustable, synchronous text related feature of each of the three products was evaluated. The added audio and video features of Yahoo Messenger were not examined, and their availability was not allowed to influence the team's overall ratings of the three products' general IM capabilities.

\section{Trials of Products and Services}

1) AT\&T Anywhere (version 3.0.0.0512) is an efficient synchronous text-based product. Download, installation, and configuration are user friendly, and clear Web-based tutorial and help guides are available. AT\&T Anywhere loads in a small unobtrusive display window, and yields no 
unwanted icons or pop-up displays. It organises and keeps track of contacts who use other textbased programs such as Yahoo Messenger and ICQ - a feature which, though useful, can create problems in the attempt to use both programs simultaneously, because $A T \& T$ prevents this. AT\&T will not remain open for extended periods, and the user needs to log in again if the program has been idle for several hours. The product works on Windows platforms only.

2) Parachat (Basic version) is a no cost, Web-based text chat service for website designers. The software generates a single line of HTML code for embedding into a webpage, allowing users to launch a pop-up chat room either by a webpage link or an embedded java applet. The chat rooms are hosted on ParaChat's own servers. Each room permits public and private text-based chatting, plus the ability to ignore a user, and modify fonts. Parachat lacks many educationally useful features found in the other two products (e.g., start-up options; status indicators; user profiles; the option to accept/ ignore messages from users not on the user's contact list; and the monitoring of other chat rooms). The chat administrator's options for customising the chat area are primarily limited to modifying its colour schemes. The basic version's key benefit is the ease with which Web developers can add one or more basic chat rooms to their sites at no cost.

Commercial versions of ParaChat contain features additional to those of the basic version. The first level of commercial upgrade, ParaChat AC (\$10 US per month), provides increased administrative and security features including Web tours (i.e., shared browsing), password protection, and the option to expel participants. The second upgrade level, ParaChat Pro (starting at \$75 US per month), provides a comprehensive package of administrative and customisation features including language translation, database integration, and chat room transcription. ParaChat Server is the final level of upgrade, with a one-time purchase price of \$600 US and optional maintenance contracts. This version provides the features of ParaChat Pro plus the ability to control and customise server installation and delivery procedures. No version of ParaChat provides instant messenger (IM) services.

3) Sonork is a messaging product that is evolving rapidly, for which reason it is one of the first in this series of evaluation studies to be reviewed a second time. Sonork is designed for IM communication within workgroups in private and secure Intranet networks, as well as across the Internet. Sonork contains valuable tools for website developers and network administrators, and was the most effective product encountered in a comprehensive search by one of the evaluation team (JB) for an IM system capable of operating between workstations in one location as well as across the Internet. The product provides varied chat features: login status options; the ability to track the use of multiple chat rooms; permanent hosting of chat rooms by the network or individual users; also a calendar and task reminders. Sonork's installation requires a firm grasp of network design and configurations, and is assisted by a useful installation application.

4) Yahoo Messenger is also a popular product that has been reviewed previously in this series. Yahoo Messenger is a good, synchronous text-based package, with user friendly download, installation and configuration procedures, and customisable privacy features including chat room password protection. Two types of private chat rooms are available: one accommodating up to 50 users, and a conference room for up to 10 invited guests. Yahoo also provides audio and video conferencing, and works on multiple operating systems including Windows, Macintosh, Linux, Palm, and Unix. Though powerful, Yahoo Messenger is a relatively obtrusive program designed for entertainment purposes rather than educational use. It places multiple icons on the user's screen, including a Yahoo toolbar in the Internet Explorer browser. In our tests, the "Filter offensive words" feature did not work.

[Note: The Audio section of the evaluation website accompanying these reviews refers to other messaging products, including MediaRing and VoiceNet.] 


\section{Conclusions}

AT\&T Anywhere and Yahoo Messenger, both available at no charge, are efficient synchronous text-based products providing both chat and IM services. The evaluation team considers Yahoo Messenger to be the most effective product of the three for use in DE conferencing, owing to its interoperability and advanced conferencing features. Yahoo has the added benefits of audio and video conferencing, though these features were not allowed to influence the evaluation team's ratings of the product's text based efficiency. Primary advantages of AT\&T Anywhere are: 1) it is less obtrusive than Yahoo Messenger, which opens distracting pop up advertising windows during its use; and 2) the ease with which $A T \& T$ provides access to users' accounts with other major chat services, including Yahoo. Parachat (Basic) provides Web designers with basic chat room facilities containing limited features. It lacks the wide range of educationally useful features available in the other two products (though many of these are available in its commercial versions). Sonork offers further chat and IM tools for the network developer. Educators may wish to bear these comparisons in mind when selecting from the growing range of chat and IM systems currently available for specific purposes.

The next report in this series will examine a set of integrated collaborative tools.

N.B. Owing to the speed with which Web addresses are changed, the online references cited in this report may be outdated. They can be checked at the Athabasca University software evaluation site: http://cde.athabascau.ca/softeval/. Italicised product names in this report are assumed to be registered trademarks.

JPB. Technical Notes, Series Editor

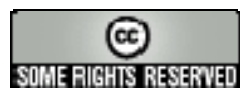


October - 2002

\title{
Technical Evaluation Report
}

\section{Integrated Collaborative Tools}

\author{
Lynn Fujino, Neil Martindale, Sharon Mulder, \\ Clare Woodward, and Patrick J. Fahy \\ Masters of Distance Education Programme \\ Athabasca University - Canada's Open University
}

\begin{abstract}
Previous reports in this series have featured examples of integrated products that combine into a single software package, techniques offered individually by other products. Increasing acceptance of online collaboration is generating interest in such tools on the part of product developers and users. The distance education (DE) market is now awash with integrated products involving methods ranging from the relatively standard text-based conferencing to synchronous and asynchronous audio and video conferencing techniques. Integrated products typically add a range of ancillary tools to these main features (e.g., whiteboards, polling methods, file sharing and email capability). When choosing an appropriate product for DE usage it is important to discern which of the multitude of features are essential in different situations. The current study examines five contrasting integrated products from the DE user's perspective.
\end{abstract}

\section{Evaluation Criteria}

Initially, the evaluation team attempted to identify a set of freeware conferencing methods that had not been evaluated in the series previously. However, integrated collaboration packages are typically targeted at the private sector, causing many manufacturers to place hefty price tags on them. So five no cost or low cost products/ services were examined in terms of their ease of access, intuitiveness, and functionality, and in relation to the evaluation criteria used in earlier reports in the series:

- Common Technical Framework: issues such as minimum system requirements, interoperability, scalability, and file sharing

- Clarity: ease of presentation, noise, clutter, etc.

- Control: design of the Web-human interface and access to content

- Complexity: user processes such as registration, log in, and inter website navigation

- Costs: fixed and variable monetary and maintenance time costs

Each of these criteria contains sub-divisions that apply to one or more of the product's synchronous and asynchronous components.

As indicated in previous reports, manufacturers use the term integrated in a number of ways: course/ learning management systems; learning environments; total learning solutions, etc. There is little standardisation in the use of these terms, however, and the current study does not claim to represent any particular integrated product classification. 


\section{Trials of Integrated Products}

1) CommunityZero is a set of three differently priced products (Core, Advantage, \& Server), offering interactive tools for asynchronous discussion and content sharing within a single Webbased package. The evaluation team selected the least expensive option, Core, for review. Core contains a comprehensive set of asynchronous collaboration tools, including bulletin board, calendar and note board, file sharing via separate directories for text and graphic files, and a single-question polling feature. It lacks the useful instructional tools of synchronous audio and whiteboard, and the ability to sort text messages into threaded groups. In a typical DE course, the volume of folders and postings can become disorientating. Five levels of access are available (founder, administrator, moderator, member, and guest), and members may be granted individualized access. The membership sign up process is somewhat confusing, and new members must register with CommunityZero before using an invitation key to join a community. The Core capacity is five megabytes of file storage, unlimited text storage, and 10,000 page views (PV) per month. More file storage and PV are available at a price. Core seems to have a high degree of market stability, being part of an ongoing strategy to develop customised Webhosting packages. The evaluation team encountered lengthy download times, probably due to intense traffic on the CommunityZero servers.

2) Delphi Forums is an integrated text-based package available both as freeware and in an enhanced fee-based version. The freeware includes private forums, chat, file transfer, and polling tools. When users log in, a list of the most recently viewed forums appears and users have the straightforward option of adding a forum to their "Favourites" file. Delphi Forums is appropriate for educational users, with no intrusive pop up advertising. There is no limit to the size of conference messages, though the lack of audio conferencing, whiteboard, and archiving facilities limits the product's utility in DE. A major advantage is the product's cross-platform interoperability (PC, Macintosh, etc.).

3) WebClassroom's main interface is a synchronous whiteboard where users can add, view, and collaborate on text and image files, post Web links and conduct polls. The creation of optional headings and graphic boxes assists in the organisation of files on the whiteboard. The moderator has limited options for controlling users' access to the tools, giving them either no privileges or complete access. A Hand-Raising feature allows moderators to address questions and comments in sequence. The Image Whiteboard, but not the main whiteboard, can be archived for later use. The efficient group use of WebClassroom requires practice and the development of user protocols. Uploaded files can be jointly edited and saved to users' hard drives. To avoid confusion, it would be wise to restrict the participants who can post updated files. The whiteboard display can extend beyond the viewing window, with scrolling access to the whole display. This feature could lead users to overlook the files beyond the immediate display. WebClassroom does not have an asynchronous chat feature, though its Post-a-Note and Question \& Answer features provide unthreaded, asynchronous messaging.

4) Wimba combines text-based conferencing with asynchronous audio features, including voice boards and streaming audio that can be added to websites, also email and language learning tools, all hosted on the vendor's servers. Wimba is straightforward to use and is a cross platform application (PC and Macintosh) that runs on both Netscape and Explorer browsers. The product does not have synchronous text or audio conferencing, whiteboard, or file sharing features. There is no apparent size limit to the audio files that can be used, and the evaluation team encountered no audio streaming problems. Wimba has particular potential in language education, although one of the team experienced difficulty in the attempt to access the product through her PC in Japan, using a non-English (Japanese) operating system. Wimba offers a time limited, cost free trial period with a limit of five simultaneous users to each message board. The product's license agreement requires the user to forfeit copyright to any material posted on the Wimba server, 
which is a major concern for producers of educational materials and educators responsible for their students' rights of ownership over the messages they create in educational situations.

5) Yahoo Groups is an online service that can be used as a simple listserv, and for sending members postings by email without their need to access the website directly. It can also be used as an asynchronous platform on which users can post messages and files, access Web links, engage in synchronous text chat and polls, and study database files created by the moderator. Files can be posted directly on the website in the Files, Photos, and Database sections, though can be attached to specific postings by email only, rather than on the website itself. The administrator (owner) of the group can pre-approve postings, set the members' levels of access to different features, and grant administrative privileges to a moderator. Yahoo Groups features a searchable archive of messages, and the group calendar can be used to schedule meetings, post assignment deadlines, and send reminder notes to members by email. The service's pop up advertisements can be a nuisance in an educational situation. The chat client indicates it has a voice feature, although at the time of testing this feature did not work. [Yahoo Support indicated that this feature was not available.] If synchronous audio is necessary, Yahoo Groups could be used in conjunction with Yahoo Messenger (see earlier reports).

[Note: The audio section of the evaluation website accompanying these reviews refers to other integrated products, including CentraNow, Conversa, and TeamSpace.]

\section{Conclusions}

Current lack of clear standards for integrated collaborative products allows vendors to provide a wide range of tools, some useful in DE, other less so. CommunityZero, Delphi Forums, and Yahoo Groups all permit adequate text/ image based collaboration at no cost, although would be more useful for DE users if they also incorporated some audio features. Wimba provides asynchronous audio and Web development features with particular utility in language education, though at this stage lacks the synchronous tools that could complement this function. The most unusual of the five products is WebClassroom, which provides a range of tools in a whiteboard setting which is original but at times confusing. All five products are non-platform specific, and users can access the collaborative spaces from each of the major types of computers and browsers. They are also all Web hosted products, which remove the need to download and install extensive software. This may be regarded as an advantage for DE users, though the added proprietary requirements of Wimba reduce its applicability in educational contexts. Despite the fact that each product offers useful features, they also have distinct shortcomings for DE usage, and these should be carefully examined in the selection of products for specific educational purposes.

N.B. Owing to the speed with which Web addresses are changed, the online references cited in this report may be outdated. They can be checked at the Athabasca University software evaluation site: http://cde.athabascau.ca/softeval/. Italicised product names in this report are assumed to be registered trademarks.

JPB. Technical Notes, Series Editor

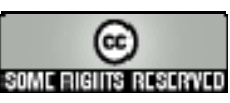

